Prepared for the U.S. Department of Energy under Contract DE-AC05-76RL01830

\title{
Characterization of Filtration Scale-Up Performance
}

\author{
RC Daniel KJ Cantrell RW Shimskey \\ JM Billing RA Peterson LK Jagoda \\ ML Luna ML Bonebrake
}

March 2009 
WTP-RPT-168, Rev 0

\title{
DISCLAIMER
}

This report was prepared as an account of work sponsored by an agency of the United States Government. Neither the United States Government nor any agency thereof, nor Battelle Memorial Institute, nor any of their employees, makes any warranty, express or implied, or assumes any legal liability or responsibility for the accuracy, completeness, or usefulness of any information, apparatus, product, or process disclosed, or represents that its use would not infringe privately owned rights. Reference herein to any specific commercial product, process, or service by trade name, trademark, manufacturer, or otherwise does not necessarily constitute or imply its endorsement, recommendation, or favoring by the United States Government or any agency thereof, or Battelle Memorial Institute. The views and opinions of authors expressed herein do not necessarily state or reflect those of the United States Government or any agency thereof.

\author{
PACIFIC NORTHWEST NATIONAL LABORATORY \\ operated by \\ BATTELLE \\ for the \\ UNITED STATES DEPARTMENT OF ENERGY \\ under Contract DE-AC05-76RL01830
}

Printed in the United States of America
Available to DOE and DOE contractors from the
Office of Scientific and Technical Information,
P.O. Box 62, Oak Ridge, TN 37831-0062;
ph: (865) 576-8401
fax: (865) 5765728
email: reports@adonis.osti.gov

\author{
Available to the public from the National Technical Information Service, \\ U.S. Department of Commerce, 5285 Port Royal Rd., Springfield, VA 22161 \\ ph: (800) 553-6847 \\ fax: (703) 605-6900 \\ email: orders@nits.fedworld.gov \\ online ordering: http://www.ntis.gov/ordering.htm
}


PNNL-18117

WTP-RPT-168, Rev 0

\title{
Characterization of Filtration Scale-Up Performance
}

\author{
RC Daniel KJ Cantrell RW Shimskey \\ JM Billing RA Peterson LK Jagoda \\ ML Luna ML Bonebrake
}

March 2009

Test specification: 24590-WTP-TSP-RT-07-004, Rev. 0

Work Authorization: 019

Test plan: TP-RPP-WTP-509, Rev. 0

Test exceptions: 24590-WTP-TEF-RT-07-00016, Rev. 0

24590-WTP-TEF-RT-08-00013, Rev. 0

24590-WTP-TEF-RT-08-00014, Rev. 0

24590-WTP-TEF-RT-08-00015, Rev. 0

R\&T focus area: Pretreatment

Test Scoping Statement: None

Prepared for the U.S. Department of Energy

Under Contract DE-AC05-76RL01830

Pacific Northwest National Laboratory

Richland, Washington 99352 


\section{Completeness of Testing}

This report describes the results of work and testing specified by Test Specification 24590-WTP-TSP-RT-07-004, Rev. 0 and Test Plan TP-RPP-WTP-509, Rev. 0. The work and any associated testing followed the quality assurance requirements outlined in the Test Specification/Plan. The descriptions provided in this test report are an accurate account of both the conduct of the work and the data collected. Test plan results are reported. Also reported are any unusual or anomalous occurrences that are different from expected results. The test results and this report have been reviewed and verified.

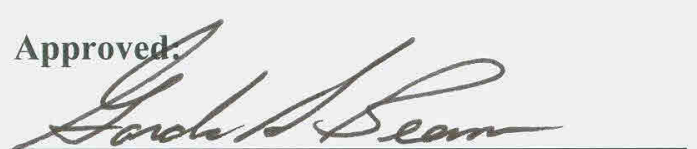

Gordon H. Beeman, Manager WTP R\&T Support Project

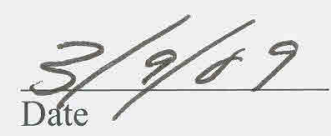




\section{Contents}

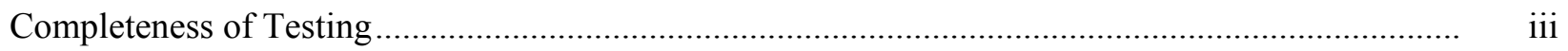

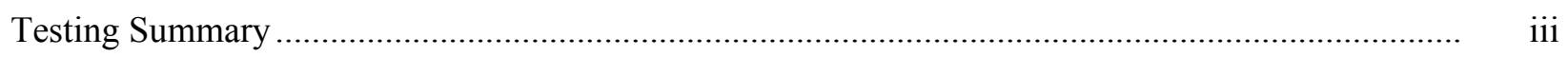

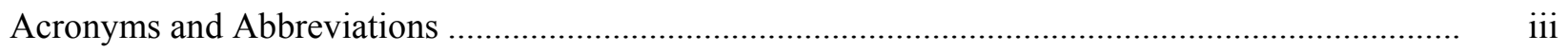

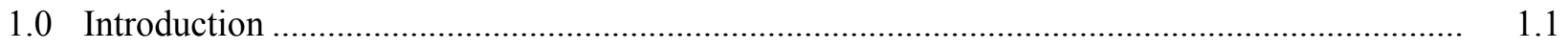

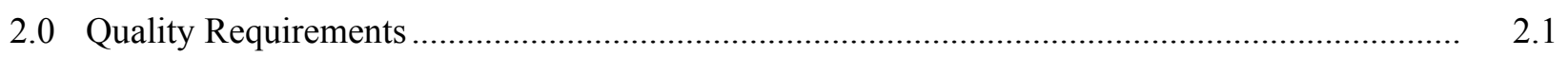

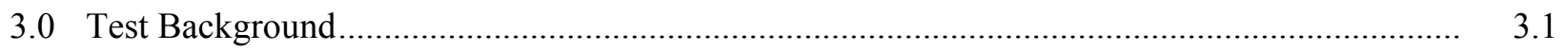

3.1 Test Objectives and Scope of Work …..................................................................... 3.2

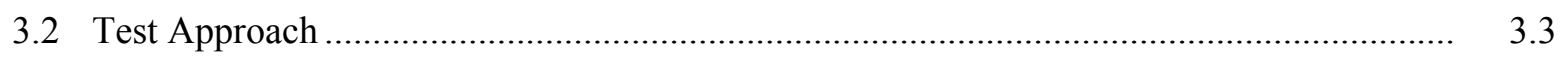

3.2.1 Scale-Up AV/TMP Matrix Tests................................................................... 3.3

3.2.2 Scale-Up Temperature Tests ............................................................................ 3.4

4.0 Experimental Methods and Analyses ............................................................................

4.1 Filtration/Leaching Apparatus................................................................................ 4.1

4.1.1 Cells Unit Filter ....................................................................................... 4.1

4.1.2 Crossflow Ultrafiltration Testing System.......................................................... 4.2

4.1.3 Instrumentation and Data Acquisition System.................................................... 4.6

4.1.4 Operations of CUF and Sampling .................................................................. 4.7

4.2 Measurement of Permeate Viscosity ..................................................................... 4.8

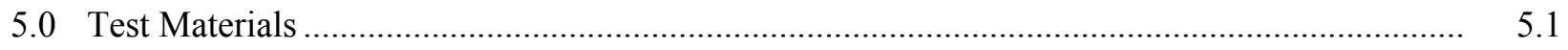

5.1 Simulant Sludge Solids Slurry …...................................................................... 5.1

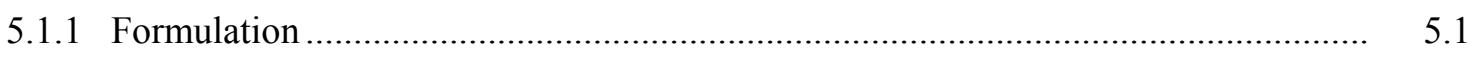

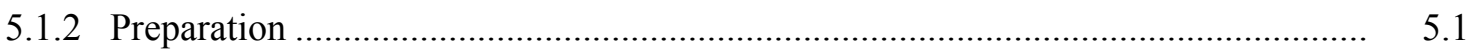

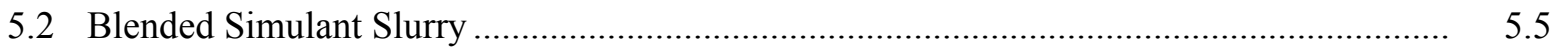

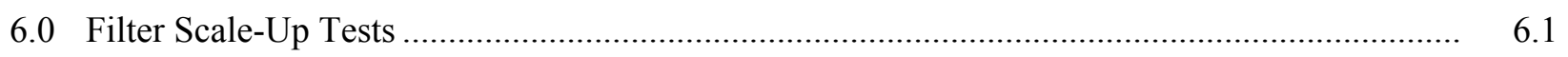

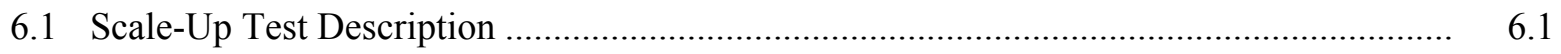

6.2 Analysis of AV/TMP Scale-Up Test Filtration Data .................................................... 6.5

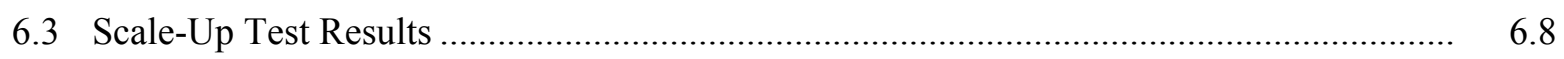

6.3.1 Simulant Sludge Solids Scale-Up Test Results .................................................. 6.8

6.3.2 Blended Simulant Scale-Up Test Results......................................................... 6.15

6.4 Summary and Conclusions of Scale-Up Tests ........................................................... 6.21

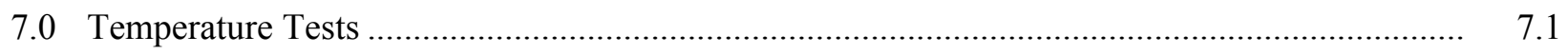

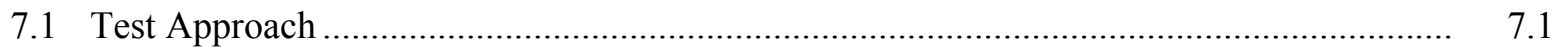

7.1.1 Preleach Temperature Tests in Detail ............................................................... 7.2

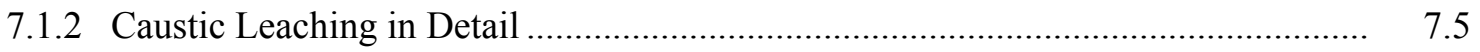

7.1.3 Post-Leach Temperature Tests in Detail ............................................................ 7.7

7.2 Analysis of Temperature Test Flux Data ................................................................ 7.10

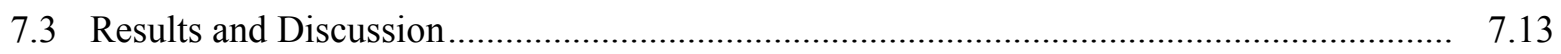


7.3.1 Temperature Dependence of Permeate Viscosity................................................. 7.13

7.3.2 Temperature Dependence of Filter Flux ............................................................ 7.16

7.3.3 Comparison of Temperature Correlations ....................................................... 7.25

7.3.4 The Effect of Permeate Viscosity and Its Implications ......................................... 7.26

7.3.5 Precipitation of Solids the Post-Leach Permeate.................................................... 7.29

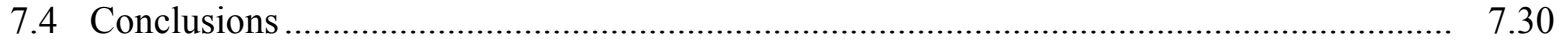

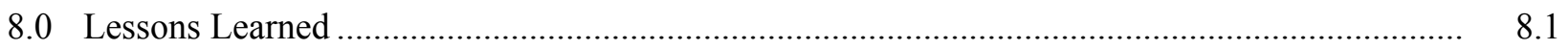

8.1 Inability to Achieve Target AV Conditions ................................................................. 8.1

8.2 Differences in Fouling Behavior of the 2-ft and 8-ft Elements........................................ 8.1

8.3 Differences in Measured and Expected UDS concentrations............................................ 8.2

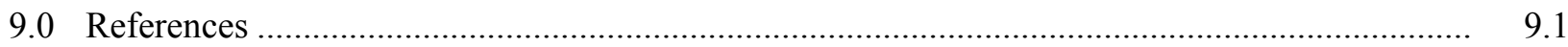

Appendix A: Effect of Temperature on Permeate Flux versus Time on 8-Ft Ultrafilter Used for Scale-Up Testing .

Appendix B: Sample Analyses of Permeate Flux versus Temperature for 8-Ft Ultrafilter Used for Scale-Up Testing .....

B.1

Appendix C: Temperature Test Caustic-Leaching Conditions and Justifications .

C. 1 


\section{Figures}

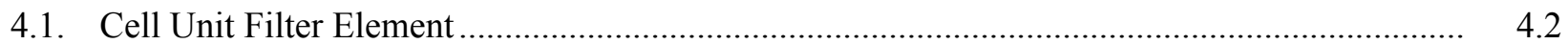

4.2. Cell Unit Filter Assembly Sketch (not to scale) .....................................................................

4.3. The Cell Unit Filter Assembly ............................................................................................ 4.2

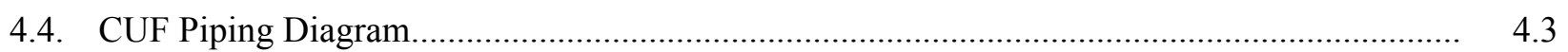

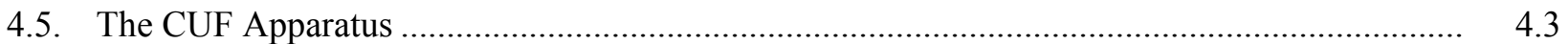

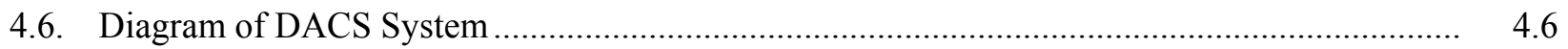

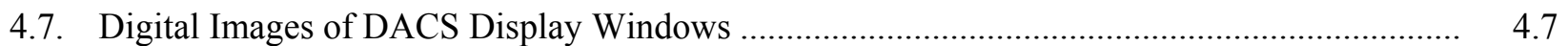

6.1. Graphical Results for the Low-Solids Text Matrix Simulant Sludge Solids Slurry Scaling Test.

6.2. Filtration Results for the Low-Solids Matrix Simulant Sludge Solids Scaling Test Showing the Flux Dependence on A) AV and B) TMP

6.3. Dewatering Curve for Simulant Sludge Solids Slurry on 2-ft and 8-ft CUF Filter Elements Based on an Assumed $5 \mathrm{wt} \%$ Initial Slurry UDS Concentration

6.4. Graphical Results for the High-Solids Text Matrix Simulant Sludge Solids Slurry Scaling Test.

6.5. Filtration Results for the High-Solids Matrix Simulant Sludge Solids Scaling Test Showing the Flux Dependence on A) AV and B) TMP

6.6. Graphical Results for the Low-Solids Text Matrix Blended Simulant Slurry Scaling Test........

6.7. Filtration Results for the low-Solids Matrix Blended Simulant Scaling Test Showing The Flux Dependence on A) AV and B) TMP.

6.8. Dewatering Curve for a Blended Simulant Slurry on 2-ft and 8-ft CUF Filter Elements

6.19

6.9. Graphical Results for the High-Solids Test Matrix Blended Simulant Slurry Scaling Test .......

6.10. Filtration Results for the High-Solids Matrix Blended simulant Scaling Test Showing the Flux Dependence on A) AV and B) TMP.

7.1. Plot of Initial Permeate Viscosity in Accordance with Temperature Relationship Given by Equation 7.10

7.2. Plot of Leached and Washed Permeate Viscosity in Accordance with Temperature Relationship Given by Equation 7.10

7.3. Filter Flux Data Collected During the Initial (Preleach) Blended Simulant Temperature Tests

7.4. Filter Flux Data Plotted in Accordance with Equation 7.8

7.5. Time Evolution of the $\mathrm{J}_{0,298}$ Temperature Correlation Parameter During the Preleach Blended Simulant Slurry Temperature Tests

7.6. Time Evolution of the $\beta$ Temperature Correlation Parameter During the Preleach Blended Simulant Slurry Temperature Tests.

7.7. Time Evolution of the $J_{o, 298}$ Temperature Correlation Parameter During the Leached and Washed Blended Simulant Slurry Temperature Tests

7.8. Time Evolution of the $\beta$ Temperature Correlation Parameter During the Leached and Washed Blended Simulant Slurry Temperature Tests 
7.9. Time Evolution of Filter Flux for a Blended Simulant Slurry (with $\mathrm{ZrO}_{2}$ fines) During Heat-Up and Backpulsing Tests. Data taken from WTP-RPT-183.

7.10. Time Evolution of Filter Flux for a Blended Simulant Slurry (with $\mathrm{ZrO}_{2}$ fines) During Heat-Up and Backpulsing Tests. Uncorrected data taken from WTP-RPT-183.

\section{Tables}

S.1. Test Objectives .

S.2. Test Exceptions.............................................................................................................

S.3. Results and Performance Against Success Criteria .............................................................. xiii

S.4. R\&T Test Conditions............................................................................................................ xvi

S.5. Test Discrepancies Listed and Described ….......................................................................... xviii

5.1. Composition of the Original PNNL and Optima Formulations for the Iron-Rich Sludge Solids Component Used in Scale-up Testing ........................................................................ 5.2

5.2. Composition of the Precipitated Solids Washing Solution ..................................................... 5.3

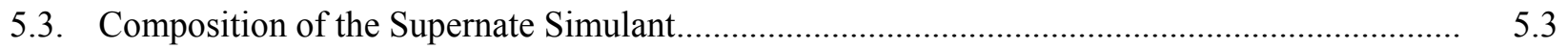

5.4. Composition of the Starting Metal Nitrate Solution for Metal Hydroxide Precipitation ............ $\quad 5.4$

5.5. Trim Chemicals Added to Precipitated Metal Hydroxide Solution ......................................... 5.5

6.1. Filtration Test Matrix Conditions...................................................................................... 6.2

6.2. List of AV/TMP Achieved During 8-ft Scale-Up Matrix Tests.............................................. 6.3

6.3. Solids Concentrations Tested During Simulant Sludge Solids 8-ft Scale Tests ....................... 6.4

6.4. Solids Concentrations Tested During Blended Simulant 8-ft Scale Tests ................................ 6.4

6.5. UDS concentrations Examined by the Reference 2-ft Scale Tests .......................................... 6.5

6.6. Comparison of Calculated Concentrations Achieved in 2-ft and 8-ft Tests............................ 6.5

6.7. Filtration test Measurement Parameters Provided by the CUF DACS ................................... 6.6

6.8. Tabular Results for the Low-Solids Test Matrix Simulant Sludge Solids Slurry Scaling Test.

6.9. Tabular Results for the High-Solids Text Matrix Simulant Sludge Solids Slurry Scaling Test.

6.10. Tabular Results for the Low-Solids Text Matrix Blended Simulant Slurry Scaling Test.......... $\quad 6.16$

6.11. Tabular Results for the High-Solids Text Matrix Blended Simulant Slurry Scaling Test ......... $\quad 6.20$

7.1. Summary of Samples Collected in Association with Preleach Temperature Testing ................ 7.3

7.2. Simple Mass Balance for the Preleach Temperature Tests ...................................................

7.3. Achievable Conditions for Preleach Temperature Testing ..................................................... 7.4

7.4. Axial Pressure Drop for Preleach Temperature Testing …................................................. 7.5

7.5. Summary of Samples Collected in Association with Temperature Test Leaching Operations... $\quad 7.6$

7.6. Simple Mass Balance for the Temperature Test Leaching Operations ................................... 7.7 
7.7. Measured Dissolved Solids of Slurry Supernates at Various Steps in the Caustic Leaching and Washing Processes.

7.8. Summary of Samples Collected in Association with Post-Leach Temperature Testing............ 7.8

7.9. Simple Mass Balance for the Post-Leach Temperature Tests ................................................... 7.9

7.10. Achievable Conditions for Post-Leach Temperature Testing ................................................ 7.9

7.11. Axial Pressure Drop for Post-Leach Temperature Testing ....................................................

7.12. Filtration Test Measurement Parameters Provided by the CUF DACS .................................. 7.10

7.13. Initial (Preleach) Blended Simulant Permeate Viscosity as a Function of Temperature ........... 7.14

7.14. Initial (preleach) Blended Simulant Permeate Viscosity as a Function of Temperature............ 7.15

7.15. Leached and Washed Blended Simulant Permeate Viscosity as a Function of Temperature ..... 7.15

7.16. Leached and Washed Blended Simulant Permeate Viscosity as a Function of Temperature ..... 7.15

7.17. Temperature Constants $J_{o, 298}$ and $\beta$ for the $5.0 \mathrm{wt} \%$ UDS Preleach Blended Simulant Slurry as a Function of Filtration Time.

7.18. Temperature Constant $J_{o, 298}$ at select UDS Concentrations for the Preleach Blended Simulant Slurry.

7.19. Temperature Constant $\beta$ at Select UDS Concentrations for the Preleach Blended Simulant Slurry.

7.20. Temperature Constant $J_{0,298}$ at select UDS Concentrations for the Leached and Washed Blended Simulant Slurry.

7.21. Temperature Constant $\beta$ at Select UDS Concentrations for the Leached and Washed Blended Simulant Slurry.

7.22. Comparison of $\beta$ and $\lambda$ Values Regressed for Both As-prepared and Leached/Washed Blended Simulant Slurries. 



\section{Acronyms and Abbreviations}

$\begin{array}{ll}\text { APD } & \text { Axial Pressure Drop } \\ \text { APEL } & \text { Applied Process Engineering Laboratory } \\ \text { ASO } & \text { Analytical Service Operations } \\ \text { AV } & \text { axial velocity } \\ \text { BNI } & \text { Bechtel National, Inc. } \\ { }^{\circ} \text { C } & \text { degree centigrade } \\ \text { CBM3 } & \text { CUF Blended Matrix Test 3 } \\ \text { CFR } & \text { Code of Federal Regulations } \\ \text { CUF } & \text { crossflow ultrafiltration testing system } \\ \text { DACS } & \text { data-acquisition collection system } \\ \text { DI } & \text { deionized (water) } \\ \text { DOE } & \text { U.S. Department of Energy } \\ \text { EFRT } & \text { External Flowsheet Review Team } \\ \text { fps } & \text { foot per second } \\ \text { ft/s } & \text { foot per second } \\ \text { g/mL } & \text { gram per milliliter } \\ \text { GPM } & \text { gallon per minute } \\ \text { HLW } & \text { high-level waste } \\ \text { HP } & \text { horse power } \\ \text { HX } & \text { heat exchanger } \\ \text { IRP } & \text { Issue Response Plan } \\ \text { ITF } & \text { Integrated Test Facility } \\ \text { LAW } & \text { low-activity waste } \\ \text { mL/min } & \text { milliliter per minute } \\ \text { M\&TE } & \text { measuring and test equipment } \\ \text { PEP } & \text { Pretreatment Engineering Platform } \\ \text { PRV } & \text { pressure relief valve } \\ \text { psid } & \text { pound per square inch differential } \\ \text { psig } & \text { pound per square inch gauge } \\ \text { PNNL } & \text { Pacific Northwest National Laboratory } \\ \text { PTF } & \text { Pretreatment Facility } \\ \text { QAM } & \text { Quality Assurance Manual } \\ \text { QAP } & \text { Quality Assurance Plan } \\ \text { RARD } & \text { Quality Assurance Requirements and Description } \\ & \text { Radiochemical Processing Laboratory } \\ & \end{array}$


RPP-WTP River Protection Project-Waste Treatment Plant Support Program

RTD resistance temperature detector

R\&T Research and Technology

SBMS Standards Based Management System

TMP transmembrane pressure

UDS undissolved solids

UFP ultrafiltration process

WTP Hanford Tank Waste Treatment and Immobilization Plant 
WTP-RPT-168, Rev 0

\section{Testing Summary}

The scale-up performance of sintered stainless steel crossflow filter elements planned for use at the Pretreatment Engineering Platform (PEP) and at the Waste Treatment and Immobilization Plant (WTP) were characterized in partial fulfillment (see Table S.1) of the requirements of Test Plan TP-RPP-WTP-509. ${ }^{\text {(a) }}$ This test report details the results of experimental activities related only to filter scale-up characterization. These tests were performed under the Simulant Testing Program supporting Phase 1 of the demonstration of the pretreatment leaching processes at PEP. Pacific Northwest National Laboratory (PNNL) conducted the tests discussed herein for Bechtel National, Inc. (BNI) to address the data needs of Test Specification 24590-WTP-TSP-RT-07-004. ${ }^{(b)}$ Scale-up characterization tests employ high-level waste (HLW) simulants developed under the Test Plan TP-RPP-WTP-469. ${ }^{\text {(c) }}$ The experimental activities outlined in TP-RPP-WTP-509 examined specific processes from two broad areas of simulant behavior: 1) leaching performance of the boehmite simulant as a function of suspending phase chemistry and 2) filtration performance of the blended simulant with respect to filter scale-up and fouling. Benchscale experiments supporting scale-up testing employed both 2-foot and 8-foot filters composed of a single 0.5-inch inner diameter stainless steel filter tube. WTP operations will employ bundles of either 8 -foot or 10-foot filter elements, and each bundle will be composed of ten 0.5 -inch inner diameter filter tubes.

With regard to leaching behavior, the effect of anions on the kinetics of boehmite leaching was examined. Two experiments were conducted: 1) one examined the effect of the aluminate anion on the rate of boehmite dissolution and 2) another determined the effect of secondary anions typical of Hanford tank wastes on the rate of boehmite dissolution. Both experiments provide insight into how compositional variations in the suspending phase impact the effectiveness of the leaching processes. In addition, the aluminate anion studies provide information on the consequences of gibbsite in waste. The latter derives from the expected fast dissolution of gibbsite relative to boehmite.

This test report is concerned with the results of the filtration performance with respect to scale-up. Test results for boehmite dissolution kinetics and filter fouling are reported elsewhere (see Table S.1). The primary goal of scale-up testing was to examine how filter length influenced permeate flux rates. To accomplish this, the existing cells unit filter system, which employs a 2-ft-long, 0.5-in. (inner) diameter sintered stainless steel filter element, was redesigned to accommodate an 8 -ft. sintered stainless steel filter element of the same diameter. Testing was then performed to evaluate the filtration performance of waste simulant slurries. Scale-up testing consisted of two separate series of filtration tests: 1) scale-up axial velocity (AV)/transmembrane pressure (TMP) matrix tests and 2) scale-up temperature tests. The AV/TMP matrix tests examined filtration performance of two different waste simulant slurries in the 8-ft. cells unit filter system. Waste simulant slurry formulations for the 8-ft. scale-up test was selected to

(a) RC Daniel, and RW Shimskey. 2007. Test Plan for Simulant Testing in Support of Phase I Demonstration of the Ultrafiltration and Leaching Processes in the Integrated Test Facility. 24590-101-TSA-W000-0004-7200019 Rev 00A (TP-RPP-WTP-509, Rev. 0). Pacific Northwest National Laboratory, Richland, Washington.

(b) PS Sundar. 2007. Simulant Testing in Support of Phase I Demonstration of the Ultrafiltration and Leaching Processes in the Integrated Test Facility. 24590-WTP-TSP-RT-07-004, Rev. 0, Bechtel National, Inc., Richland, Washington.

(c) RL Russell, and HD Smith. 2007. Test Plan for the Development and Demonstration of Leaching and Ultrafiltration Simulants. 24590-101-TSA-W000-0004-182-00001 Rev 00A (TP-RPP-WTP-469, Rev. 0), Pacific Northwest National Laboratory, Richland, Washington. 
match simulant slurries for which filtration performance had been characterized on the 2-ft crossflow ultrafiltration (CUF) system. For the scale-up temperature tests, the filtration performance at three test temperatures (i.e., $25^{\circ} \mathrm{C}, 35^{\circ} \mathrm{C}$, and $45^{\circ} \mathrm{C}$ ) was determined to evaluate if filter flux versus temperature correlations developed using the 2 -ft filters were also valid for the 8 -ft filters.

\section{$\underline{\text { AV/TMP Scaling Tests }}$}

AV/TMP matrix tests were conducted to determine the effect of filter length on CUF system performance using the approach outlined in Sections 6.2.1 and 6.2.2 in Test Plan TP-RPP-WTP-509. Testing employed an 8-ft-long filter element. Two simulant trials were performed using 1) a simulant sludge solids slurry (i.e., the iron-rich sludge or filtration simulant) and 2) a blended simulant slurry. The compositions of both simulant slurries are described in Section 5 of this report and are based on formulations developed under the simulant development test plan, TP-RPP-WTP-469. The 8-ft scaling tests with the simulant sludge solids and blended simulant slurries attempted to repeat identical tests performed as part of the simulant development task with the 2-ft filter element.

Scaling tests examined filtration performance over a matrix of set AV/TMP set-points in which axial velocities from 9 to $17 \mathrm{ft} / \mathrm{sec}$ and transmembrane pressures from 20 to 60 psid were targeted. Because of limited pump capacity, not all targeted AV/TMP conditions planned for testing could be achieved (see Table 6.10 and Table 6.11). Additionally, these scaling tests were conducted at two slurry test concentrations: a lowsolids concentration and a high-solids concentration. For the slurry scaling tests on the simulant sludge solids, the slurry concentrations tested were $5.4 \mathrm{wt} \%$ and $20.2 \mathrm{wt} \%$ undissolved solids (UDS). ${ }^{\text {(a) }}$ For the blended simulant slurry scaling tests, the tested concentrations were $5.4 \mathrm{wt} \%$ and $15.9 \mathrm{wt} \%$. The results of these tests were compared to existing 2-foot filtration performance data for blended simulant and simulant sludge solids slurries. All scaling tests were performed at $25^{\circ} \mathrm{C}$. Additional details regarding the AV/TMP scaling tests, including both test setup and experimental results and discussion, are provided in Section 6.0 of this report.

Results of the scaling tests conducted with a simulant sludge solids slurry (Section 6.3.1) indicate that the 2-ft and 8-ft filters exhibit comparable performance. Initial permeate flow flux rates appear to be independent of filter length (Table 6.8 and Figure 6.1). Filtration mechanisms for both 2-ft and 8-ft filter elements appear to be similar, as the flux shows comparable AV and TMP dependences (Figure 6.2). One noticeable difference between the 2-ft and 8-ft tests is the absence of transient filter flux decrease in the 8$\mathrm{ft}$ test (Table 6.8). Such a decrease is indicative of filter fouling, as was observed in the 2-ft filter test. This suggests that fouling mechanisms may differ in the 2-ft and 8-ft tests; however, the 8-ft test used the same volume of slurry as the 2 - $\mathrm{ft}$ test. Because of this, it is possible that the fines that caused the longterm decrease in filter flux in the 2 -ft filter were simply depleted before fully fouling the 8 -ft filter.

Analysis of filter scaling effects for a blended simulant slurry (Section 6.3.2) were complicated by the inability to achieve all AV and TMP conditions and by a relative insensitivity of the filtrate flux for this slurry with respect to UDS concentration (Figure 6.8). Comparison of the 2-ft and 8-ft scale blended simulant filter fluxes at low-solids concentration (Table 6.10 and Figure 6.6) suggests decreases from $10 \%$ to $20 \%$ as filter length is increased from 2 to $8 \mathrm{ft}$. The significance of this decrease is questionable

(a) Unless otherwise stated, slurry (undissolved) solids concentrations presented in discussion and summary sections in this report are based on mass balance calculations rather than measurements of slurry undissolved solids. 
given likely differences in filter cleanliness and slight difference in starting solids concentration. The behavior of low-solids filter flux with changes in AV and TMP appear similar for the 2- and 8-ft scales, and as such, it can be tentatively concluded that scaling effects for dilute blended simulants are minor with respect to AV/TMP functionality.

Meaningful evaluation of scaling effects for a blended simulant slurry at high-solids concentration could not be achieved because of disparate test concentrations between the 2- and 8- $\mathrm{ft}$ scale tests (see Table 6.6). Specifically, the test concentration achieved in the 2 -ft scale (30.4 wt\%) could not be achieved in the 8-ft scale tests without pump cavitation. The highest concentration for the 8-ft scale test under which stable pump conditions could be achieved was $15.9-\mathrm{wt} \%$. Comparison of the 2-ft-high solids (30.4-wt\%) data to the 8-ft-high solids (15.9-wt\%) data finds similar filter flux at all test conditions (Table 6.11 and Figure 6.9). Similarity between the 2-ft and 8-ft-high-solids flux, despite their disparate test concentrations, is indicative of the insensitivity of the blended simulant filter flux to solids concentrations rather than any scaling effects. As with the low-solids blended simulant data, the behavior of high-solids blended simulant filter flux with changes in AV and TMP are similar for the 2- and 8-ft scales.

\section{Temperature Scaling Tests}

The scale-up temperature tests were conducted according to Test Plan TP-RPP-WTP-509. Testing employed the crossflow filtration system described in Section 3 of this report. Full details of the temperature scaling tests, including test setup, experimental results, and discussion, are provided in Section 7.0 of this report. A brief outline is given in the following paragraphs.

Approximately $20 \mathrm{~L}$ of a dilute $(\sim 5-\mathrm{wt} \%)$ "as-prepared" blended simulant slurry was loaded into the CUF system. Next, the slurry was subjected to continuous recycle filtration (such that all permeate collected was recycled back into the slurry reservoir) for 4 hours at $25^{\circ} \mathrm{C}, 35^{\circ} \mathrm{C}$, and $45^{\circ} \mathrm{C}$. At the end of the $45^{\circ} \mathrm{C}$ measurement, the slurry was cooled to $25^{\circ} \mathrm{C}$, and the 4-hour recycle filtration test was repeated. All filtration steps employed a target AV of $13 \mathrm{ft} / \mathrm{s}$ and a target transmembrane pressure of $40 \mathrm{psid}$. During filtration, the CUF operational parameters such as TMP, AV, permeate flow rate, and slurry temperature were continuously monitored using the CUF data acquisition system.

The temperature series outlined above was performed for both an initial (i.e., "as-prepared") and leached (i.e., a caustic-leached and washed) blended simulant slurry. Temperature tests were run initially on the as-prepared blended simulant slurry. Once this first set of tests was complete, the slurry was caustic-leached at $100^{\circ} \mathrm{C}$ for 12 hours in a concentrated sodium hydroxide solution. After leaching, the slurry was diluted and the temperature test series repeated. Comparison of pre- and post-leach data allows for evaluation of the effects of chemical processing and slurry chemistry on the temperature correlations.

Both initial and leached/washed slurries were tested at six separate UDS concentrations. Solids concentrations were controlled by dewatering the slurry after each temperature series. Dewatering operations typically targeted removal of approximately one-third of the slurry supernate volume. However, this target could not always be satisfied because of minimum operating volumes for the CUF slurry reservoir and pumping systems. Comparison of temperature correlations at different solids concentrations allows evaluation of concentration effects. For the as-prepared (i.e., preleach) blended 
simulant slurry, the test concentrations spanned $5.0 \mathrm{wt} \%$ to $28.3 \mathrm{wt} \%$ UDS. For the caustic-leached and washed blended simulant slurry, the test concentrations ranged from $4.8 \mathrm{wt} \%$ to $21.7 \mathrm{wt} \%$ UDS.

The filtration performance of blended simulant slurries was evaluated on a CUF system with an 8-ft filter element installed at $25^{\circ} \mathrm{C}, 35^{\circ} \mathrm{C}$, and $45^{\circ} \mathrm{C}$. From these tests, correlations allowing the correction of flux for temperature were derived for both an as-prepared and a caustic-leached and washed slurry. In both cases, the correction correlation is of the form:

$$
J_{25^{\circ} \mathrm{C}}=J_{T} \exp \left[\beta\left(\frac{1}{T}-\frac{1}{298}\right)\right]
$$

In this equation, $J_{T}$ is the flux measured at the temperature $T$ (in $\mathrm{K}$ ), and $J_{25^{\circ} \mathrm{C}}$ is the flux adjusted (or reduced) to $25^{\circ} \mathrm{C}$ or $298 \mathrm{~K}$. The correction correlation is based on an existing equation reported in WTP-RPT-043. ${ }^{\text {(a) }}$ It is:

$$
J_{25^{\circ} \mathrm{C}}=J_{T} \exp \left[2500\left(\frac{1}{T}-\frac{1}{298}\right)\right]
$$

An analysis of the filter flux at different temperatures indicates $\beta$ values of $3000 \pm 200 \mathrm{~K}$ for asprepared/preleach slurries (Section 7.3.2.1) and $2300 \pm 200 \mathrm{~K}$ for caustic-leached/washed slurries (Section 7.3.2.2). The range of flux correction applicability for these two $\beta$ values is 25 to $45^{\circ} \mathrm{C}$.

These temperature correlations differ only in the value of $\beta$ used. The temperature-correction equations for the preleach simulant slurry show a significantly higher value of $3000 \pm 200 \mathrm{~K}$ relative to that of the existing correlation (i.e., $2500 \mathrm{~K}$ ). This difference may derive from a number of factors including flux transience, filter length, slurry concentration, and permeate physical and chemical properties. On the other hand, the $\beta$ value for the caustic-leached/washed blended simulant $(2300 \pm 200 \mathrm{~K})$ agrees with the existing coefficient of 2500 to within the range of variation observed in the measurement.

The temperature tests also provided information on the mechanisms underlying the changes in filter flux with temperature. Improvement in permeate flux at increased slurry temperature is typically attributed to reduced permeate viscosity. However, for both the as-prepared and caustic-leached/washed simulant slurries, the measured increase in filter flux with increasing temperature during 8 - $\mathrm{ft}$ scale tests was greater than expected from the lowering of permeate viscosity alone (Section 7.3.1). In addition, the improvement in filter flux with increased slurry temperature became greater at higher slurry concentrations (Figure 7.6 and Figure 7.8). For all 8-ft scaling temperature tests, the increase in temperature was accompanied by filter backpulsing. As such, it appears that changes in filter flux are governed by a combination of changes in the permeate viscosity and in the overall filter resistance. Possible factors effecting filter resistance include 1) the slurry filter cake structure or thickness, 2) changes in the degree of depth fouling, or 3) changes in the filter medium properties such as porosity and pore size.

(a) JGH Geeting, RT Hallen, LK Jagoda, AP Poloski, RD Scheele, and DR Weier. 2003. Filtration, Washing, and Caustic Leaching of Hanford Tank AZ-101 Sludge. WTP-RPT-043, Rev. 1, Pacific Northwest National Laboratory, Richland, Washington. 
Given that slurry concentration appears to affect the degree of flux improvement with temperature, changes in the filter cake structure or thickness likely govern a significant part of the filtration performance at increased temperature. These changes can occur as a dynamic process during filtration, whereby existing cake is sheared away and replaced by new solids or they can occur during backpulsing, when the filter cake is fully disturbed and forced off the filter surface. Although the data generated from temperature testing do not allow assessment of which mechanism functions herein, data measured in previous tests suggest that these changes do not occur dynamically at higher temperatures and that they are primarily driven by filter backpulsing (see Section 7.3.4). The latter has important implications for how filtration data are corrected for temperature because it indicates that filter cake disruption must be considered when applying temperature correction formulas.

Analysis of filter fouling data reported in Section 5 of WTP-RPT- $183^{(\mathrm{a})}$ suggests that temperature variations that occur during continuous filtration without any backpulsing are best corrected by considering variation of permeate viscosity alone (Section 7.3.4). As such, the temperature correction formula becomes:

$$
J_{25^{\circ} \mathrm{C}}=J_{T} \exp \left[\lambda\left(\frac{1}{T}-\frac{1}{298 \mathrm{~K}}\right)\right]
$$

where $\lambda$ describes how permeate viscosity changes with temperature and is $1950 \mathrm{~K}$ and $1680 \mathrm{~K}$ for preleach and leached/washed blended simulant slurries, respectively. On the other hand, changes in temperature accompanied by backpulsing and/or complete disruption of the filter cake need to be treated using the full temperature correlation (i.e., that with $\beta=3000 \pm 200 \mathrm{~K}$ for preleach materials or $\beta=2300 \pm 200 \mathrm{~K}$ for leached and washed material).

\section{Objectives}

The test objectives are summarized in Table S.1 along with a discussion of how the objectives were met. Several objectives (shaded in light gray) did not specifically apply to the scope provided in this report; they will be/are already reported in companion reports. The test plan called for issuing a single report; however, based on the scope of work, the tests involving boehmite and gibbsite dissolution were reported with similar scope authorized by test plan TP-RPP-WTP-460 Rev. 0.

(a) RL Russell, HD Smith, JM Billing, RA Peterson, and DE Rinehart. 2008. Development and Demonstration of Ultrafiltration Simulants. WTP-RPT-183, Pacific Northwest National Laboratory, Richland, Washington. 
WTP-RPT-168, Rev 0

Table S.1. Test Objectives

\begin{tabular}{|c|c|c|c|}
\hline & Test Objective & $\begin{array}{c}\text { Objective } \\
\text { Met? }(\mathrm{Y} / \mathrm{N})\end{array}$ & Discussion \\
\hline 1) & $\begin{array}{l}\text { Determine the effect of initial } \\
\text { aluminate ion concentration on the } \\
\text { rate of boehmite leaching in caustic } \\
\text { solutions and in the presence of } \\
\text { soluble anions in a waste. The anions } \\
\text { to be considered are those that are } \\
\text { typically present in the Hanford Tank } \\
\text { Farm wastes in significant amounts. } \\
\text { This includes carbonate, free- } \\
\text { hydroxide, nitrate, nitrite, oxalate, } \\
\text { phosphate, and sulfate. }\end{array}$ & NA & 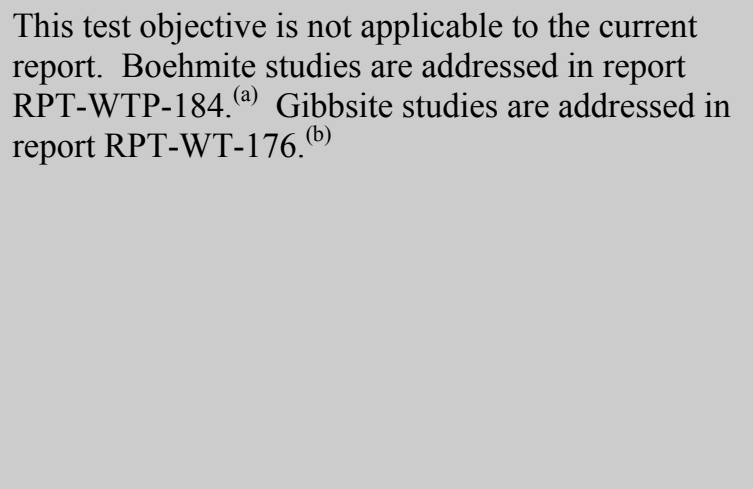 \\
\hline 2) & $\begin{array}{l}\text { Determine the sensitivity of the rate } \\
\text { of dissolution of boehmite to soluble } \\
\text { anions through a limited number of } \\
\text { laboratory tests. The anions to be } \\
\text { considered are those that are typically } \\
\text { present in the Hanford Tank Farm } \\
\text { wastes in significant amounts. This } \\
\text { includes carbonate, free-hydroxide, } \\
\text { nitrate, nitrite, oxalate, phosphate, } \\
\text { and sulfate. }\end{array}$ & NA & $\begin{array}{l}\text { As of March 20, 2008, PNNL has been released from } \\
\text { this objective by Test Exception, 24590-WTP-TEF- } \\
\text { RT-07-00016. }\end{array}$ \\
\hline 3) & $\begin{array}{l}\text { Determine the effect of scaling the } \\
\text { length of the ultrafilter element from } \\
2 \mathrm{ft} \text { to } 8 \mathrm{ft} \text { on the filtrate flux over the } \\
\text { expected operating range of the } \\
\text { ultrafilter using the CUF. }\end{array}$ & $\mathrm{Y}$ & $\begin{array}{l}\text { As described in Section } 6.0 \text { of this report, CUF } \\
\text { testing was performed on a simulant sludge solids } \\
\text { slurry and a blended simulant solids slurry using an } \\
8 \text {-ft filter element. A predetermined matrix of six } \\
\text { tests was conducted in which axial velocities from } 9 \\
\text { to } 17 \mathrm{ft} / \mathrm{sec} \text { and transmembrane pressures from } 20 \text { to } \\
60 \mathrm{psid} \text { were targeted. Because of limited pump } \\
\text { capacity, the actual range of AVs achieved was only } \\
9 \text { to } 14.2 \mathrm{ft} / \mathrm{s} \text {. This matrix was conducted on both the } \\
\text { initial low-solids concentration and a dewatered } \\
\text { high-solids concentration for both simulant slurries. } \\
\text { The effect of scaling was determined by comparing } \\
\text { these results with analogous simulant trials } \\
\text { conducted previously with a 2-ft filter element. }\end{array}$ \\
\hline
\end{tabular}

(a) RL Russell, RA Peterson, HD Smith, DE Rinehart, PM Aker, and EC Buck. 2008. Development and Characterization of Boehmite Component Simulant. WTP-RPT-184, Pacific Northwest National Laboratory, Richland, Washington.

(b) RL Russell, HD Smith, RA Peterson, and DE Rinehart. 2008. Development and Characterization of Gibbsite Component Simulant. WTP-RPT-176, Pacific Northwest National Laboratory, Richland, Washington. 
Table S.1. (contd)

Objective

Test Objective

4) Use an 8-ft-long filter element in the CUF unit to determine the effect of temperature on the filtration of a waste simulant over the range of temperature conditions for the leaching processes.
Met? (Y/N)

Discussion

As described in Section 7.0 of this report, CUF testing was performed on a blended simulant solids slurry using a cold 8 -ft filter element. Testing was done using an axial velocity of $13 \pm 2 \mathrm{ft} / \mathrm{sec}$ and a transmembrane pressure of $40 \pm 10$ psid. Tests were conducted at $25^{\circ} \mathrm{C}, 35^{\circ} \mathrm{C}, 45^{\circ} \mathrm{C}$, and a final replicate at $25^{\circ} \mathrm{C}$ for six different UDS concentrations ranging from 5.0 to $28.3 \mathrm{wt} \%$. After the initial series of testing was completed, the slurry was caustic leached and the entire matrix of temperatures and solids concentrations was repeated. For post-leach testing, six different UDS concentrations ranging from 4.8 to $21.7 \mathrm{wt} \%$ were tested.

5) Use a 2-ft-long filter element in the

NA This test objective is not applicable to the current report. It is addressed in report WTP-RPT- 183. CUF unit to evaluate the effect of the fine particle fraction in the ultrafiltration simulant on fouling of the filter element over the range of concentrations of operating solids. The fine particle fraction is defined as those particles with diameters smaller than the 10th percentile (i.e., the dp10) of the particle-size number distribution.

6) Perform various simulant aging tests to understand the changes that may occur to the simulant in storage and to ensure the adequacy of the simulant for use in the PEP.

7) Perform Cr-simulant leaching tests to establish that the $\mathrm{Cr}$-simulant from the larger batch exhibits similar or better leaching behavior than the initial trial batch during caustic and oxidative leaching operations.

8) Perform leaching tests to determine the mass loss, and aluminum and chromium dissolution rates during caustic leaching under varying temperature processing conditions without aeration in both UFP-1A/B and UFP-2A/B vessels as well as to measure the effect of aeration on chromium leaching in UFP-2A/B.

NA Test objective 6 was added by Test Exception 24590WTP-TEF-RT-08-00013, Rev. 0. This test objective is not applicable to the current report. It will be addressed in a future report (document number to be determined).

NA Test objective 7 was added by Test Exception 24590WTP-TEF-RT-08-00013, Rev. 0. This test objective is not applicable to the current report. It will be addressed in a future report (document number to be determined).

NA Test objective 8 was added by Test Exception 24590WTP-TEF-RT-08-00014, Rev. 0. This test objective is not applicable to the current report. It will be addressed in a future report (document number to be determined). 
Table S.1. (contd)

\begin{tabular}{|c|c|c|c|}
\hline & Test Objective & $\begin{array}{c}\text { Objective } \\
\text { Met? }(\mathrm{Y} / \mathrm{N})\end{array}$ & Discussion \\
\hline 9) & $\begin{array}{l}\text { Perform leaching tests to develop an } \\
\text { accurate model for the dissolution of } \\
\text { boehmite. }\end{array}$ & NA & $\begin{array}{l}\text { Test objective } 9 \text { was added by Test Exception } 24590 \text { - } \\
\text { WTP-TEF-RT-08-00015, Rev. } 0 \text {. This test objective } \\
\text { is not applicable to the current report. It will be } \\
\text { addressed in a future report (document number to be } \\
\text { determined). }\end{array}$ \\
\hline 10) & $\begin{array}{l}\text { Perform leaching tests to verify the } \\
\text { effect of aluminate ions on the } \\
\text { performance of the boehmite } \\
\text { component B3 during caustic leach at } \\
\text { temperatures lower than } 100^{\circ} \mathrm{C} \text { and to } \\
\text { determine the effect of temperature } \\
\text { on the dissolution rate of boehmite } \\
\text { component B7. }\end{array}$ & NA & $\begin{array}{l}\text { Test objective } 9 \text { was added by Test Exception } 24590 \text { - } \\
\text { WTP-TEF-RT-08-00015, Rev. } 0 \text {. This test objective } \\
\text { is not applicable to the current report. It will be } \\
\text { addressed in a future report (document number to be } \\
\text { determined). }\end{array}$ \\
\hline 11) & $\begin{array}{l}\text { Perform leaching tests to determine } \\
\text { the extent of boehmite conversion one } \\
\text { would expect under leaching } \\
\text { conditions during the planned testing } \\
\text { in PEP. }\end{array}$ & NA & $\begin{array}{l}\text { Test objective } 9 \text { was added by Test Exception } 24590 \text { - } \\
\text { WTP-TEF-RT-08-00015, Rev. } 0 \text {. This test objective } \\
\text { is not applicable to the current report. It will be } \\
\text { addressed in a future report (document number to be } \\
\text { determined). }\end{array}$ \\
\hline
\end{tabular}

\section{Test Exceptions}

Four test exceptions were issued for Test Plan TP-RPP-WTP-509, These test exceptions are summarized in Table S.2 along with a brief description of how each exception impacted existing objectives and test plan scope. 
Table S.2. Test Exceptions

\begin{tabular}{|c|c|}
\hline List Test Exceptions & Describe Test Exceptions \\
\hline $\begin{array}{l}\text { - 24590-WTP-TEF-RT-07-00016, } \\
\text { Rev. } 0\end{array}$ & $\begin{array}{l}\text { This test exception released Pacific Northwest National Laboratory from } \\
\text { test objective } 2 \text { (see Table S.1). }\end{array}$ \\
\hline $\begin{array}{l}\text { - 24590-WTP-TEF-RT-08-00013, } \\
\text { Rev. } 0\end{array}$ & $\begin{array}{l}\text { This test exception did not affect any existing test plan objectives. It } \\
\text { added test objectives concerned with 1) aging of the PEP simulants } \\
\text { during storage and 2) leaching of the chromium simulant. These are } \\
\text { objectives } 6 \text { and } 7 \text { in Table S.1. }\end{array}$ \\
\hline $\begin{array}{l}\text { - 24590-WTP-TEF-RT-08-00014, } \\
\text { Rev. } 0\end{array}$ & $\begin{array}{l}\text { This test exception both affected existing test objectives and added new } \\
\text { test objectives. Tests associated with objective } 4 \text { were modified slightly } \\
\text { in response to this test exception. Specifically, the temperatures to } \\
\text { study the filter performance were changed from } 25^{\circ} \mathrm{C}, 45^{\circ} \mathrm{C} \text {, and } 65^{\circ} \mathrm{C} \\
\text { to } 25^{\circ} \mathrm{C}, 35^{\circ} \mathrm{C} \text {, and } 45^{\circ} \mathrm{C} \text {. In addition, a new objective concerned with } \\
\text { the influence of temperature and aeration on caustic leaching processes } \\
\text { was added to TP-RPP-WTP-509. These are summarized in objective } 8 \\
\text { in Table S.1. }\end{array}$ \\
\hline $\begin{array}{l}\text { - 24590-WTP-TEF-RT-08-00015, } \\
\text { Rev. } 0\end{array}$ & $\begin{array}{l}\text { This test exception did not affect any existing objectives in TP-RPP- } \\
\text { WTP-509. It added three new test objectives concerned with 1) in-depth } \\
\text { assessment of the boehmite leaching kinetics in the presence of } \\
\text { dissolved aluminate in significant concentration and 2) the extent of } \\
\text { leaching under planned PEP operating conditions. These are } \\
\text { summarized in objectives } 9,10 \text {, and } 11 \text { in Table S.1. }\end{array}$ \\
\hline
\end{tabular}

\section{Results and Performance Against Success Criteria}

Test plan TP-RPP-WTP-509 delineated several success criteria, which are listed in Table S.3. Selected criteria were relevant to the test scope included in this report; the other criteria that are outside of the reported scope are shaded.

Table S.3. Results and Performance Against Success Criteria

List Success Criteria

1) Development of empirical information that allows determination of the effect of initial aluminate ion concentration on the kinetics of boehmite leaching in a waste simulant.

2) Determination of the sensitivity of boehmite leaching to carbonate, free-hydroxide, nitrate, nitrite, oxalate, phosphate, and sulfate anions in a waste-simulant solution.

3) Determination of the effect of scaling the length of the ultrafilter element from 2 - $\mathrm{ft}$ to 8 - $\mathrm{ft}$ on the performance of the filter over the expected process operating range of transmembrane pressure, axial velocity, and ultrafiltration temperature.
Explain How the Tests Did or Did Not Meet the Success Criteria

This criterion is not applicable to the current report. Boehmite studies are addressed in report RPT-WTP184. Gibbsite studies are addressed in report RPT-WT176.

This criterion is no longer applicable. As of March 20, 2008, PNNL has been released from this objective by Test Exception, 24590-WTP-TEF-RT-07-00016.

All testing as defined in the test plan was completed. 

Meet the Success Criteria

4) Determination of the effect of temperature on the filtration flux for the waste simulant over the range of solid concentrations and temperature conditions for the leaching processes.

5) Determination of the effect of fine-particle concentration on the propensity of the waste simulant to foul the ultrafilter element over the range of concentrations of operating solids in the waste simulant.
All testing as defined in the test plan was completed.

This criterion is not applicable to the current report. It is addressed in RPT-WTP-183.

\section{Quality Requirements}

PNNL is operated by Battelle for the U.S. Department of Energy (DOE). PNNL implements a Quality Assurance Program that is based upon the requirements as defined in the DOE Order 414.1C, "Quality Assurance" and 10 CFR 830, "Energy/Nuclear Safety Management," Subpart A-Quality Assurance Requirements. PNNL has chosen to implement the requirements of DOE Order 414.1C and 10 CFR 830, Subpart A by integrating them into the laboratory's management systems and daily operating processes. The procedures necessary to implement the requirements are documented through the laboratory's Standards-Based Management System (SBMS).

PNNL implemented the RPP-WTP quality requirements by performing work in accordance with the River Protection Project - Waste Treatment Plant Support Program (RPP-WTP) Quality Assurance Plan (RPP-WTP-QA-001, QAP). Work was performed to the quality requirements of NQA-1-1989 Part I, Basic and Supplementary Requirements, NQA-2a-1990, Part 2.7, and DOE/RW-0333P, Rev 13, Quality Assurance Requirements and Description (QARD). These quality requirements were implemented through the River Protection Project - Waste Treatment Plant Support Program (RPP-WTP) Quality Assurance Manual (RPP-WTP-QA-003, QAM). The analytical requirements were implemented through the River Protection Project-Waste Treatment Plant Support Program's (RPP-WTP)'s Statement of Work (RPP-WTP-QA-005) with the Radiochemical Processing Laboratory (RPL) Analytical Service Operations (ASO).

A matrix that cross-references the NQA-1, NQA-2a, and QARD requirements with the procedures for RPP-WTP work was provided in the test plan TP-RPP-WTP-509. It included justification for those requirements not implemented.

Experiments that were not method-specific were performed in accordance with RPP-WTP's procedures QA-RPP-WTP-1101 "Scientific Investigations" and QA-RPP-WTP-1201 "Calibration and Control of Measuring and Testing Equipment" so that sufficient data were taken with properly calibrated measuring and test equipment to obtain quality results.

The RPP-WTP addressed internal verification and validation activities by conducting an independent technical review of the final data report in accordance with RPP-WTP's procedure QA-RPP-WTP-604. This review verified that the reported results were traceable, that inferences and conclusions were soundly 
based, and the reported work satisfied the Test Plan objectives. This review procedure is part of PNNL's RPP-WTP Quality Assurance Manual.

\section{R\&T Test Conditions}

The research and technology (R\&T) test conditions, as defined in the BNI Test Specification 24590WTP-TSP-RT-07-004 ${ }^{(\mathrm{a})}$ and in the test exceptions listed in Table S.2 associated with the test plan TPRPP-WTP-509 Rev 0, are summarized in Table S.4. The R\&T conditions are listed in accordance with the specific testing category they address. These categories include:

- Boehmite dissolution tests - associated with test objectives 1, 2, 9, and 10 in Table S.1

- Filtration tests - associated with test objectives 3, 4, and 5 in Table S.1

- Aging tests - associated with test objective 6 in Table S.1

- Chromium simulant leaching tests - associated with test objective 7 in Table S.1

- PEP leaching support tests - associated with test objectives 8 and 11 in Table S.1.

Not all R\&T test conditions were applicable to the tests and results presented in this report.

Conditions that do not apply are shaded in grey in Table S.4 and direct the reader to the report where the information is (or shall be) reported.

(a) WTP Doc. No. 24590-WTP-TSP-RT-07-004, Rev 0, Simulant Testing in Support of Phase I Demonstration of the Ultrafiltration and Leaching Processes in the Integrated Test Facility, P.S. Sundar, April 13, 2007. 
WTP-RPT-168, Rev 0

Table S.4. R\&T Test Conditions

\begin{abstract}
List R\&T Test Conditions
Boehmite Dissolution Tests - examine the impact of aluminate, hydroxide, and other anions on boehmite dissolution kinetics.

Boehmite Dissolution Tests - verify the effect of temperature on the dissolution of boehmite component B7 and verify the effect of aluminate ion on the performance of the boehmite component B3 during caustic leach at temperatures lower than $100^{\circ} \mathrm{C}$.

Boehmite Dissolution Tests - provide greater discrimination on anion impact by performing tests under a greater range of anion concentrations.
\end{abstract}

Filtration Tests - test a base simulant under identical process conditions with 2 -ft and 8 -ft filter elements.

Filtration Tests - increase the fines loading in filtration test base simulant to evaluate the impact of fouling on filtration performance.

Filtration Tests - use an 8-ft filter element to measure the filtration rate as a function of temperature up to $45^{\circ} \mathrm{C}$ for the base filtration simulant.
Aging Tests - will be performed in the 250-gal tote, a 1-gal container in the laboratory, a container in a heat-cycled oven, and a baffled 1-gal container that is mixed in the laboratory. Samples will be taken throughout the tests and characterized by particle size distribution, settling, rheology, and centrifuged solids content to evaluate the effect of aging on the behavior of the simulant.
Were Test Conditions Followed?

Not applicable to this report. Results discussed in WTP-RPT-176 and WTP-RPT-184.

Not applicable to this report.

Not applicable to current testing. PNNL was released from this requirement by Test Exception, 24590-WTP-TEF-RT-07-00016, Rev 0.

Filtration tests with an 8-ft filter element were performed with 1) a simulant sludge solids slurry and 2) a blended simulant slurry were performed. The results were compared to existing $2-\mathrm{ft}$ filter data to determine if any filter length scale-up effects impact filtration performance. The 8-ft filtration studies employed a AV/TMP matrix used in previous 2-ft filter studies. In most cases, the AV/TMP set-points from the 2-ft studies could be matched on the 8-ft CUF. However, for high AV and/or TMP, the pump did not provide sufficient power to achieve the targeted AV/TMP (see Table S.5)

Not applicable to this report. Results discussed in WTP-RPT-183.

Filtration tests using an 8-ft filter and a blended simulant slurry were performed at three temperatures: $25^{\circ} \mathrm{C}, 35^{\circ} \mathrm{C}$, and $45^{\circ} \mathrm{C}$. Tests were originally planned to examine temperatures up to $65^{\circ} \mathrm{C}$, but test exception 24590 -WTP-TEF-RT-0800014 limited the upper temperature range to $45^{\circ} \mathrm{C}$. For these tests, axial velocity and transmembrane set points of $13 \mathrm{ft} / \mathrm{s}$ and 40 psid were specified. However, these set points could not be achieved during certain test because of limited pump power (see Table S.5). Tests allowed evaluation of the impact of temperature on the filtration performance of an 8-ft filter element.

Not applicable to this report. 
Table S.4. (contd)

\begin{tabular}{|c|c|}
\hline List R\&T Test Conditions & Were Test Conditions Followed? \\
\hline $\begin{array}{l}\text { Chromium Simulant Leaching Tests - will be } \\
\text { performed with both a caustic leach and an } \\
\text { oxidative leach to evaluate the leaching } \\
\text { performance of the various vendor batches of } \mathrm{Cr} \text { - } \\
\text { simulant. }\end{array}$ & Not applicable to this report. \\
\hline $\begin{array}{l}\text { PEP Leaching Support Tests - are to be carried } \\
\text { out with the vendor-produced } 250 \text {-gal batch of the } \\
\text { PEP simulant and the vendor-produced } \mathrm{CrOOH} \\
\text { Test Batch } 1 \text { simulant slurry. The tests are directed } \\
\text { to determine the mass loss and aluminum and } \\
\text { chromium dissolution rates during caustic leaching } \\
\text { under varying temperature processing conditions } \\
\text { without aeration in both UFP-1A/B and UFP-2A/B } \\
\text { vessels as well as to measure the effect of aeration } \\
\text { on chromium leaching in UFP-2A/B. }\end{array}$ & Not applicable to this report. \\
\hline $\begin{array}{l}\text { PEP Leaching Support Tests - will be performed } \\
\text { using a vendor-produced } 250 \text {-gal batch of the PEP } \\
\text { simulant. The tests are directed to measure the } \\
\text { extent of boehmite conversion expected under } \\
\text { leaching conditions during the planned testing in the } \\
\text { PEP. }\end{array}$ & Not applicable to this report. \\
\hline
\end{tabular}

\section{Simulant Use}

Use of actual Hanford tank waste in the PEP is not possible because of safety, cost, and volume concerns. To address the need for demonstration of separation and leaching processes at PEP, PNNL developed a waste simulant that mimics the chemical, leaching, and ultrafiltration behaviors of actual tank waste under Test Plan TP-RPP-WTP-469. A simulant formulation developed under TP-RPP-WTP-469 was used for simulant tests described in the controlling test plan, TP-RPP-WTP-509, which includes the scale-up and temperature test described in this report. A detailed description of the rationale, approach, and testing of the simulants used in the execution of TP-RPP-WTP-509 may be found in WTP-RPT-183. 


\section{Discrepancies and Follow-on Tests}

The testing reported here includes two test discrepancies, which are described in Table S.5.

Table S.5. Test Discrepancies Listed and Described

\begin{tabular}{|c|c|c|}
\hline & Test Discrepancies & Description \\
\hline 1) & $\begin{array}{l}\text { During execution of temperature tests associated with } \\
\text { test objective } 3 \text { (Section } 6.2 .1 \text { of TP-RPP-WTP-509), } \\
\text { the pump did not deliver sufficient power to achieve } \\
\text { some target AV and TMP combinations. }\end{array}$ & $\begin{array}{l}\text { Filter scale-up testing (described in Section } 6 \text { of this } \\
\text { report) targeted a matrix of AV and TMP. Because of } \\
\text { significant pressure drop across the } 8 \text { - } \mathrm{ft} \text { filter, the } \\
\text { pump used to circulate the test slurry through the filter } \\
\text { element could not provide sufficient power to achieve } \\
\text { the highest AV and TMP. For all } 8 \text {-ft scale-up tests, } \\
\text { including those at low and high UDS concentrations } \\
\text { for the simulant sludge solids and blended simulant } \\
\text { slurries, AV/TMP conditions of } 17 / 40 \text { and } 13 / 60 \\
\text { (where TMP is in psid and AV is in } \mathrm{ft} / \mathrm{s} \text { ) could not be } \\
\text { achieved under the current pump configuration. For } \\
\text { the affected tests, the highest AV achievable at the } \\
\text { target TMP was employed }(13.4-14.2 \mathrm{ft} / \mathrm{s} \text { at } 40 \text { psid } \\
\text { and } 11.8-12.6 \mathrm{ft} / \mathrm{s} \text { at } 60 \text { psid). }\end{array}$ \\
\hline 2) & $\begin{array}{l}\text { During execution of temperature tests associated with } \\
\text { test objective } 4 \text { (Section } 6.2 .2 \text { of TP-RPP-WTP-509), } \\
\text { the target axial velocity of } 13 \mathrm{ft} / \mathrm{s} \text { could not be } \\
\text { achieved at a transmembrane of } 40 \text { psid after caustic- } \\
\text { leaching and washing of the blended simulant slurry. }\end{array}$ & $\begin{array}{l}\text { Filtration targeted an AV of } 13 \mathrm{ft} / \mathrm{s} \text { and a TMP of } 40 \\
\text { psid. During temperature tests associated with the } \\
\text { leached blended simulant slurry (test objective } 4 \text { ), the } \\
\text { pump could not deliver sufficient power to drive the } \\
\text { slurry through the } 8 \text {-ft filter element at the targeted } \\
\text { AV and TMP combination. The highest AV } \\
\text { achievable at an operating TMP of } 40 \text { psid was } \\
\text { employed. For temperature testing of the post-leach } \\
\text { slurry, the pump was only able to provide power } \\
\text { sufficient to achieve AV of } 10 \text { to } 11 \mathrm{ft} / \mathrm{s} \text { at a TMP of } \\
40 \text { psid. Section } 7 \text { of this report provides additional } \\
\text { details. }\end{array}$ \\
\hline
\end{tabular}




\subsection{Introduction}

The scale-up performance of sintered stainless steel crossflow filter elements planned for use at the Pretreatment Engineering Platform (PEP) and at the Waste Treatment and Immobilization Plant (WTP) were characterized in partial fulfillment (see Table S.1) of the requirements of Test Plan TP-RPP-WTP-509. ${ }^{\text {(a) }}$ This test report details the results of experimental activities related only to filter scale-up characterization. These tests were performed under the Simulant Testing Program supporting Phase 1 of the demonstration of the pretreatment leaching processes at PEP. Pacific Northwest National Laboratory (PNNL) conducted the tests discussed herein for Bechtel National, Inc. (BNI) to address the data needs of Test Specification 24590-WTP-TSP-RT-07-004. ${ }^{\text {(b) }}$ Scale-up characterization tests employ high-level waste (HLW) simulants developed under the Test Plan TP-RPP-WTP-469. ${ }^{\left({ }^{c}\right)}$

The experimental activities outlined in TP-RPP-WTP-509 (WTP Doc. No. 24590-101-TSA-W0000004-72-00019 Rev 00A) examined specific processes from two broad areas of simulant behavior: 1) leaching performance of the boehmite simulant as a function of suspending phase chemistry and 2) filtration performance of the blended simulant with respect to filter scale-up and fouling. This test report contains only results of the filtration performance with respect to scale-up. Test results for boehmite leaching as a function of suspending phase concentration may be found in Test Report WTP-RPT-184, ${ }^{(\mathrm{d})}$ whereas test results for filter fouling characterization may be found in Test Report WTP-RPT-183. ${ }^{(e)}$

The primary goal of scale-up testing was to examine how filter length influenced permeate flux rates. To accomplish this, the existing cells unit filter system, which employs a 2-ft-long, 0.5 -in. (inner) diameter sintered stainless steel filter element, was redesigned to accommodate an 8-ft sintered stainless steel filter element of the same diameter. Testing was then performed to evaluate the filtration performance of waste simulant slurries. Scale-up testing consisted of two separate series of filtration tests: 1) scale-up axial velocity/transmembrane pressure (AV/TMP) matrix tests and 2) scale-up temperature tests. The AV/TMP matrix tests examined filtration performance of two different waste simulant slurries in the 8 - $\mathrm{ft}$ cells unit filter system. Waste simulant slurry formulation for the 8-ft scaleup test was selected to match simulant slurries for which filtration performance had been characterized on the 2-ft cells unit filter system. For the scale-up temperature tests, the filtration performance at three test temperatures (i.e., $25^{\circ} \mathrm{C}, 35^{\circ} \mathrm{C}$, and $45^{\circ} \mathrm{C}$ ) was determined to evaluate if filter flux versus temperature correlations developed for and applied to 2 - $\mathrm{ft}$ filter performance also correlated temperature performance for 8-ft filters.

(a) RC Daniel, and RW Shimskey. 2007. Test Plan for Simulant Testing in Support of Phase I Demonstration of the Ultrafiltration and Leaching Processes in the Integrated Test Facility. 24590-101-TSA-W000-0004-7200019 Rev 00A (TP-RPP-WTP-509, Rev. 0). Pacific Northwest National Laboratory, Richland, Washington.

(b) PS Sundar. 2007. Simulant Testing in Support of Phase I Demonstration of the Ultrafiltration and Leaching Processes in the Integrated Test Facility. 24590-WTP-TSP-RT-07-004, Rev. 0, Bechtel National, Inc., Richland, Washington.

(c) RL Russell, and HD Smith. 2007. Test Plan for the Development and Demonstration of Leaching and Ultrafiltration Simulants. 24590-101-TSA-W000-0004-182-00001 Rev 00A (TP-RPP-WTP-469, Rev. 0), Pacific Northwest National Laboratory, Richland, Washington.

(d) RL Russell, RA Peterson, HD Smith, DE Rinehart, PM Aker, and EC Buck. 2008. Development and Characterization of Boehmite Component Simulant. WTP-RPT-184, Pacific Northwest National Laboratory, Richland, Washington.

(e) RL Russell, HD Smith, JM Billing, RA Peterson, and DE Rinehart. 2008. Development and Demonstration of Ultrafiltration Simulants. WTP-RPT-183, Pacific Northwest National Laboratory, Richland, Washington. 
Ultimately, the filter scale-up testing results reported herein will allow assessment of the impact of filter length on filter performance. To date, bench-scale filtration studies for waste simulants and actual waste have primarily employed 2-ft filter elements. Data derived from these bench-scale studies help form the design basis for WTP. However, both PEP and WTP filtration process will employ 8- and 10-ft filter element bundles, and as such, there is an existing need to evaluate the influence length has on filtration performance. The tests and test results described in this report help address this need. 
WTP-RPT-168, Rev 0

\subsection{Quality Requirements}

PNNL's Quality Assurance Program is based on requirements defined in U.S. Department of Energy (DOE) Order 414.1C, Quality Assurance, and Title 10 of the Code of Federal Regulations (CFR) Part 830, "Energy/Nuclear Safety Management," Subpart A-Quality Assurance Requirements (a.k.a. the Quality Rule). PNNL has chosen to implement the requirements of DOE Order 414.1C and 10 CFR 830, Subpart A by integrating them into the Laboratory's management systems and daily operating processes. The procedures necessary to implement the requirements are documented through PNNL's StandardsBased Management System (SBMS).

PNNL implements the RPP-WTP quality requirements by performing work in accordance with the River Protection Project-Waste Treatment Plant Support Program (RPP-WTP) Quality Assurance Plan (RPP-WTP-QA-001, QAP). Work will be performed to the quality requirements of NQA-1-1989 Part I, "Basic and Supplementary Requirements," NQA-2a-1990 Part 2.7, and DOE/RW-0333P, Rev 13, Quality Assurance Requirements and Description (QARD). These quality requirements are implemented through the River Protection Project-Waste Treatment Plant Support Program (RPP-WTP) Quality Assurance Manual (RPP-WTP-QA-003, QAM). The analytical requirements are implemented through RPP-WTP's Statement of Work (RPP-WTP-QA-005) with the Radiochemical Processing Laboratory (RPL) Analytical Service Operations (ASO).

A matrix that cross-references the NQA-1, NQA-2a and QARD requirements with the procedures for RPP-WTP work is given in TP-RPP-WTP-509. ${ }^{\text {(a) }}$ It includes justification for those requirements not implemented.

Experiments that were not method-specific were performed in accordance with RPP-WTP's procedures QA-RPP-WTP-1101, "Scientific Investigations," and QA-RPP-WTP-1201, "Calibration and Control of Measuring and Testing Equipment." Properly calibrated measuring and test equipment (M\&TE) was used to acquire sufficient data to produce quality results.

RPP-WTP addresses internal verification and validation activities by conducting an independent technical review of the final data report in accordance with RPP-WTP's procedure QA-RPP-WTP-604. This review verifies that the reported results are traceable, that inferences and conclusions are soundly based, and the reported work satisfies the Test Plan objectives. This review procedure is part of PNNL's RPP-WTP Quality Assurance Manual (QAM).

(a) RC Daniel, and RW Shimskey. 2007. Test Plan for Simulant Testing in Support of Phase I Demonstration of the Ultrafiltration and Leaching Processes in the Integrated Test Facility. 24590-101-TSA-W000-0004-7200019 Rev 00A (TP-RPP-WTP-509, Rev. 0). Pacific Northwest National Laboratory, Richland, Washington. 



\subsection{Test Background}

Approximately 60,000 metric tons of HLW sludge are currently contained in 177 underground storage tanks at the Hanford Nuclear Reservation in Richland, Washington. It is the intention of DOE to vitrify this sludge into a final glass waste form through the Waste Treatment and Immobilization Plant (WTP), located at Hanford 200 East Area. Before waste vitrification, a series of waste pre-treatment activities are conducted to reduce the volume of highly radioactive material sent to the geological repository.

Pre-treatment activities will first involve separating HLW from the low-activity waste (LAW) liquid stream by cross-flow filtration in the Pretreatment Facility (PTF). After separation, the concentrated HLW will undergo caustic and oxidative leaching processes to dissolve and wash out materials that would otherwise limit HLW loading in the immobilized waste glass. Specific materials targeted by the leaching processes include aluminum, chromium, phosphates, and sulfates. The concentrated HLW solids are sequentially caustic leached, washed, and oxidative leached, if required, and then washed once more during pretreatment. Caustic leaching dissolves the aluminum in the HLW solids, whereas oxidative leaching oxidizes the chromium using a sodium permanganate $\left(\mathrm{NaMnO}_{4}\right)$ solution and dissolves it in a mild caustic solution. The HLW solids are concentrated after each leach and undergo a wash operation using cross-flow filtration.

In October 2005, a team of experts from industry, national laboratories, and universities, referred to as the External Flowsheet Review Team (EFRT), was assembled by BNI to conduct a thorough and critical review of the process flowsheet for the design of WTP. In March 2006, the EFRT released a comprehensive assessment of the WTP process flowsheet that identified 17 major issues. ${ }^{(a)}$ The following EFRT issues are considered relevant to experimental results discussed in this test report.

- Issue M1: Piping that transports slurries will plug unless it is properly designed to minimize this risk. This design approach has not been followed consistently, which will lead to frequent shutdowns due to line plugging.

- Issue M2: Large, dense particles will accelerate erosive wear in mixing vessels. The effects of such particles on vessel life must be re-evaluated.

- Issue M3: Issues were identified related to mixing-system designs that will result in insufficient mixing and/or extended mixing times. These issues include a design basis that discounts the effects of large particles and of rapidly settling Newtonian slurries. There is also insufficient testing of the selected designs.

- Issue M4: The WTP has not demonstrated that its design is sufficiently flexible to reliably process all of the Hanford tank farm wastes at design throughputs.

- Issue M6: Many of the process operating limits have not been defined. Further testing is required to define process limits for WTP unit operations. Without this more complete understanding of each process, it will be difficult or impossible to define a practical operating range for each unit operation.

(a) CCN 132846. 2006. Comprehensive Review of the Hanford Waste Treatment Plant Flowsheet and Throughput - Assessment Conducted by an Independent Team of External Experts. Chartered by the Hanford Waste Treatment and Immobilization Plant Project at the Direction of the US Department of Energy, Office of Environmental Management, Washington DC. 
- Issue M12: Neither the caustic leaching nor the oxidative leaching process has been demonstrated at greater than bench-scale size. The small-scale experiments are capable of defining the leaching chemistry. However, they are limited in their capability to predict the effectiveness of these processes without a scale-up demonstration.

- Issue M13: For wastes requiring leaching, a combination of inadequate filter flux and area will likely limit throughput to the HLW or LAW vitrification facilities.

This test report and the results discussed herein provide a portion of the information needed to address Issue M12 (also referred to as "Undemonstrated Leaching Processes") of the EFRT report. Specifically, the work described in this report address laboratory-scale testing needs to support process development at the PEP and satisfy a portion of the testing called for in Task 4 of BNI's M12 Issue Response Plan (IRP).

\subsection{Test Objectives and Scope of Work}

In April 2007, BNI submitted the test specification 24590-WTP-TSP-RT-07-004 ${ }^{(\mathrm{a})}$ to PNNL. This test specification outlined studies aimed at determining the impact of specific ions (and suspending phase chemistry) on the leaching rate of boehmite and gibbsite and the effects of filter length on filtration performance of waste simulants. Five specific test objectives were originally listed; these were:

1. Determine the effect of initial aluminate ion concentration on the rate of boehmite leaching in caustic solutions and in the presence of soluble anions in a waste. The anions to be considered are those that are typically present in the Hanford Tank Farm wastes and include carbonate, free-hydroxide, nitrate, nitrite, oxalate, phosphate and sulfate.

2. Determine the sensitivity of the rate of dissolution of boehmite to soluble anions, through a limited number of laboratory tests. The anions to be considered are those that are typically present in the Hanford Tank Farm wastes in significant amounts. This includes carbonate, free-hydroxide, nitrate, nitrite, oxalate, phosphate and sulfate.

3. Determine the effect of scaling the length of the ultrafilter element from $2 \mathrm{ft}$ to $8 \mathrm{ft}$ on the filtrate flux over the expected operating range of the ultrafilter, using the ultrafiltration simulant.

4. Determine, in the cells unit filter system with an 8-ft-long filter element, the effect of temperature on the filtration of a waste simulant over the range of temperature conditions for the leaching processes.

5. Evaluate, in the cells unit filter system with a 2-ft-long filter element, the effect of the fraction of fine particles in the ultrafiltration simulant on fouling of the filter element. The fine particle fraction is defined as the fraction of particles less than the lower 10 percentile particle size based on a number distribution (or particles $<\mathrm{dp} 10$ for a number distribution) for the ultrafiltration simulant.

(a) PS Sundar. 2007. Simulant Testing in Support of Phase I Demonstration of the Ultrafiltration and Leaching Processes in the Integrated Test Facility. 24590-WTP-TSP-RT-07-004, Rev. 0, Bechtel National, Inc., Richland, Washington. 
To fulfill the requirements of this test specification, PNNL authored and executed test plan TP-RPP-WTP-509. ${ }^{\text {(a) }}$ This test plan details multiple experiments to address the objectives outlined above. Initial test results indicated minimal anion influence on the leaching rate of boehmite, and as such, PNNL was released from test objective 2. At a later date, three additional test objectives were added to the test plan. These were:

1. Perform various simulant aging tests to understand the changes that may occur to the simulant in storage and to ensure the adequacy of the simulant for use in the PEP.

2. Perform Cr-simulant leaching tests to establish that the Cr-simulant from the larger batch exhibits similar or better leaching behavior than the initial trial batch during caustic and oxidative leaching operations.

3. Perform leaching tests to determine the mass losses and aluminum and chromium dissolution rates during caustic leaching under varying temperature processing conditions without aeration in both UFP-1A/B and UFP-2A/B vessels as well as to measure the effect of aeration on chromium leaching in UFP-2A/B.

This report provides a summary for a portion of the test results derived from experimental activities associated with TP-RPP-WTP-509. In particular, it provides results and discussion for those tests addressing test objectives 3 and 4, both of which relate to filter scale-up and temperature performance.

\subsection{Test Approach}

To address these test objectives, an existing cells unit filter system, which employed a 2-ft-long, 0.5-in. (inner) diameter sintered stainless steel filter element, was redesigned to accommodate an 8-ft sintered stainless steel filter element of the same diameter. Testing was then performed to evaluate the filtration performance of waste simulant slurries.

Scale-up testing consisted of two separate series of filtration tests: 1) scale-up AV/TMP matrix tests and 2) scale-up temperature tests. In both sets of tests, the simulant slurry was filtered with a bench-scale cells unit filter system (see Section 4 for equipment information and principle of operation). Simulant slurries used for filtration testing were derived from simulant development efforts under test plan TPRPP-WTP-469 $9^{(\mathrm{b})}$ and included a blended simulant waste slurry and a simulant sludge solids slurry (see Section 5 for materials information).

\subsubsection{Scale-Up AV/TMP Matrix Tests}

The AV/TMP matrix tests were aimed at addressing the original test objective \#3 and examined filtration performance of two different waste simulant slurries in the 8 - $\mathrm{ft}$ cells unit filter system. Waste simulant slurry formulation for the 8-ft scale-up test was selected to match simulant slurries whose filtration performance had been characterized on the 2 -ft cells unit filter system. Scale-up matrix tests

(a) RC Daniel, and RW Shimskey. 2007. Test Plan for Simulant Testing in Support of Phase I Demonstration of the Ultrafiltration and Leaching Processes in the Integrated Test Facility. 24590-101-TSA-W000-0004-7200019 Rev 00A (TP-RPP-WTP-509, Rev. 0). Pacific Northwest National Laboratory, Richland, Washington.

(b) RL Russell, and HD Smith. 2007. Test Plan for the Development and Demonstration of Leaching and Ultrafiltration Simulants. 24590-101-TSA-W000-0004-182-00001 Rev 00A (TP-RPP-WTP-469, Rev. 0), Pacific Northwest National Laboratory, Richland, Washington. 
were done for both blended simulant and simulant sludge solids slurries. Approximately $9 \mathrm{~L}^{(\mathrm{a})}$ of the test slurry at a concentration at or near 5-wt\% undissolved solids (UDS) were added to the cells unit filter system. Recycle-mode filter fluxes were measured for the dilute slurry at select AV and TMP set points. The slurry was then dewatered to the maximum achievable UDS based on cells unit filter system minimum volume requirements and/or slurry physical properties. After dewatering, the filter flux of the concentrated slurry was re-measured at the same AV and TMP set-points examined during the dilute filtration trials.

\subsubsection{Scale-Up Temperature Tests}

Scale-up temperature tests were intended to satisfy test objective 3 (Table S.1). Here, the filtration performance of a blended simulant slurry at three test temperatures (i.e., $25^{\circ} \mathrm{C}, 35^{\circ} \mathrm{C}$, and $45^{\circ} \mathrm{C}$ ) was determined to evaluate if filter flux versus temperature correlations developed using the 2-ft filters held for the 8-ft filters. For the tests, approximately $20 \mathrm{~L}^{(\mathrm{b})}$ of a blended simulant slurry at a concentration at or near 5-wt $\%$ UDS were added to the cells unit filter system. Recycle-mode filter fluxes were measured for this dilute slurry at AV and TMP set points of $13 \mathrm{ft} / \mathrm{s}$ and $40 \mathrm{psid}$, respectively, at $25^{\circ} \mathrm{C}, 35^{\circ} \mathrm{C}$, and $45^{\circ} \mathrm{C}$. The UDS concentration of the slurry was then increased by partially dewatering the waste slurry. After the dewatering operation, the steady-state recycle-mode filter flux was again determined at $25^{\circ} \mathrm{C}, 35^{\circ} \mathrm{C}$, and $45^{\circ} \mathrm{C}$. These dewatering operations and flux measurements continued until at least five different slurry concentration temperature tests had been run.

(a) It should be noted that the 2-foot characterization studies also used $9 \mathrm{~L}$ of test slurry. An important parameter for filtration is the ratio of slurry volume to filter surface area. In any scale-up study, it is optimal to maintain this ratio. The current 8-foot scale studies were planned around the original maximum slurry reservoir capacity of $10 \mathrm{~L}$, and as such, did not scale slurry volume to maintain the slurry volume-to-filter area ratio.

(b) In the 8-foot scale temperature tests, a slurry volume of $9 \mathrm{~L}$ was originally planned. This volume was revised to $20 \mathrm{~L}$ to take advantage of a modification of the slurry reservoir to allow up to $25 \mathrm{~L}$ of slurry to be tested. This revision to the slurry volume was also driven by the need to achieve a range of test concentrations both before and after caustic-leaching of the slurry. It should be noted that even at $20 \mathrm{~L}$, the slurry volume fell short of the $36 \mathrm{~L}$ target needed to maintain similarity of the ratio of slurry volume to filter surface area between 2-foot and 8 -foot scales. 
WTP-RPT-168, Rev 0

\subsection{Experimental Methods and Analyses}

This section describes the experimental equipment used to perform the filtration and leaching tests for scale-up AV/TMP matrix and temperature tests. The descriptions in this section provide an overview of the general methods used in cross-flow filtration. Specific operation and analysis methods for the AV/TMP matrix tests and the temperature tests are described in detail in later sections of this report.

\subsection{Filtration/Leaching Apparatus}

The testing apparatus was a bench top system mounted on a skid that allowed up to $25 \mathrm{~L}$ of a simulant waste solution to be circulated through a tubular filter that can measure filter feed flow rates, filtrate flow rates, system pressures, and temperatures simultaneously. The testing apparatus used a heat exchanger on the main flow loop to cool the feed solution during filtration operations and had a heater on the main holding tank to perform leaching at elevated temperatures.

\subsubsection{Cells Unit Filter}

The WTP-PTF plans to use crossflow filtration to separate the LAW liquid streams from the HLW slurry streams through the process. The filter elements, called cell unit filters, are porous sintered metal tubes. The filter feed flows through the inside of the filter element axially while the feed permeate passes through the tube walls radially. Filtration occurs when the pressure differential between the inside and outside walls of the filter element (the TMP) is high enough to drive the slurry permeate through the tubular walls. The axial flow across the filter walls minimizes solid buildup and allows filtration to occur continuously with minimal downtime for back-pulsing to remove the solids buildup.

The filters purchased for this testing were supplied from the Mott Corporation (Farmington, CT) using the same specifications for the filters being purchased for the WTP-PTF. The filters were 316 stainless steel symmetric elements from Mott Corporation with an effective filtration rating of $0.1 \mu \mathrm{m}$. To date, 2-ft-long and 8-ft-long filter elements have been employed. The dimensions of the 2-ft-long filter element are shown in Figure 4.1. The 8-ft-long filter elements consist of four 2-ft porous filter elements welded together. As such, they have the same radial dimensions and filtration ratings as the 2-ft elements and have a total filtration length of 96-in.

The filter element was received already installed in a shell-and-tube configuration with an outer tube surrounding the filter element to capture the filtrate while the inlet and the outlet of the filter (which extend past the shell and provide access to the inside diameter of the filter) were welded to steel tubing of a matching outer/inner diameter. The shell side had two $3 / 8$-inch stainless steel tubes exiting from the filter assembly, one in the center to collect filtrate from the filter, and the other near the inlet of the filter to function as a drain. Pressure ports ( $1 / 4$-inch stainless steel tubing) were installed on the inlet and outlet connections to the assembly to measure the pressure inside the filter. O-ring face seal (Swagelok VCO ${ }^{\circledR}$ ) fittings purchased from the Swagelok Company (Solon, $\mathrm{OH}$ ) were also placed on the inlet and outlet filter feed tube connections for easy installation to the filtration/leaching skid. Figure 4.2 and Figure 4.3 show the cell unit filter assembly. 

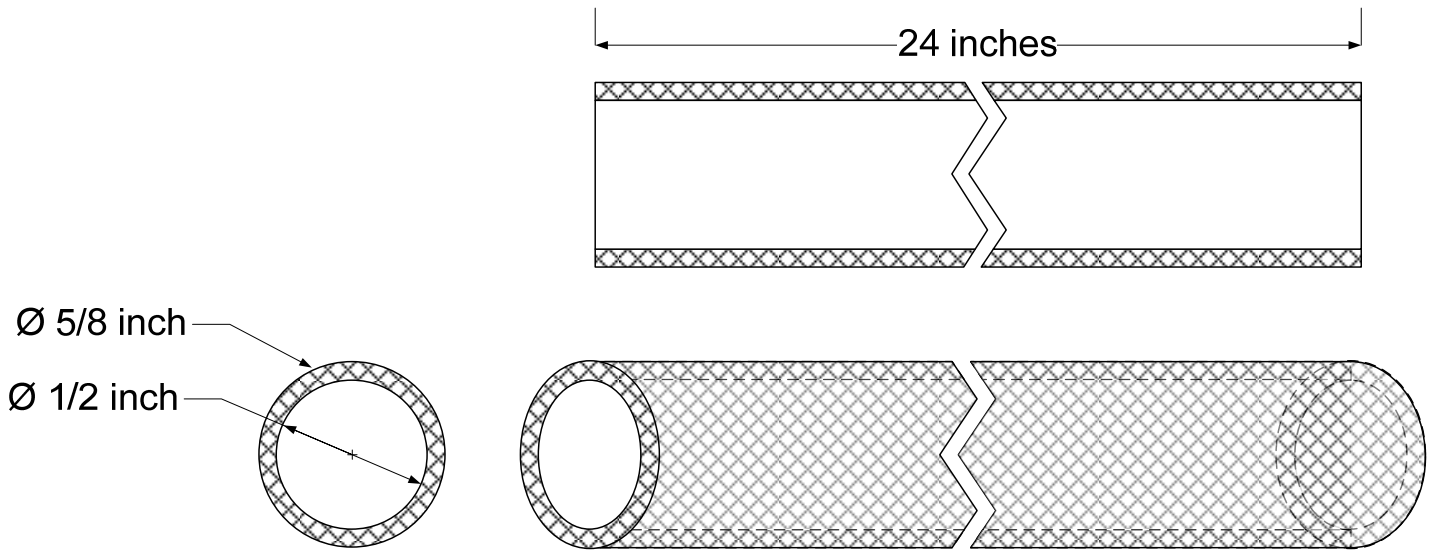

Figure 4.1. Cell Unit Filter Element

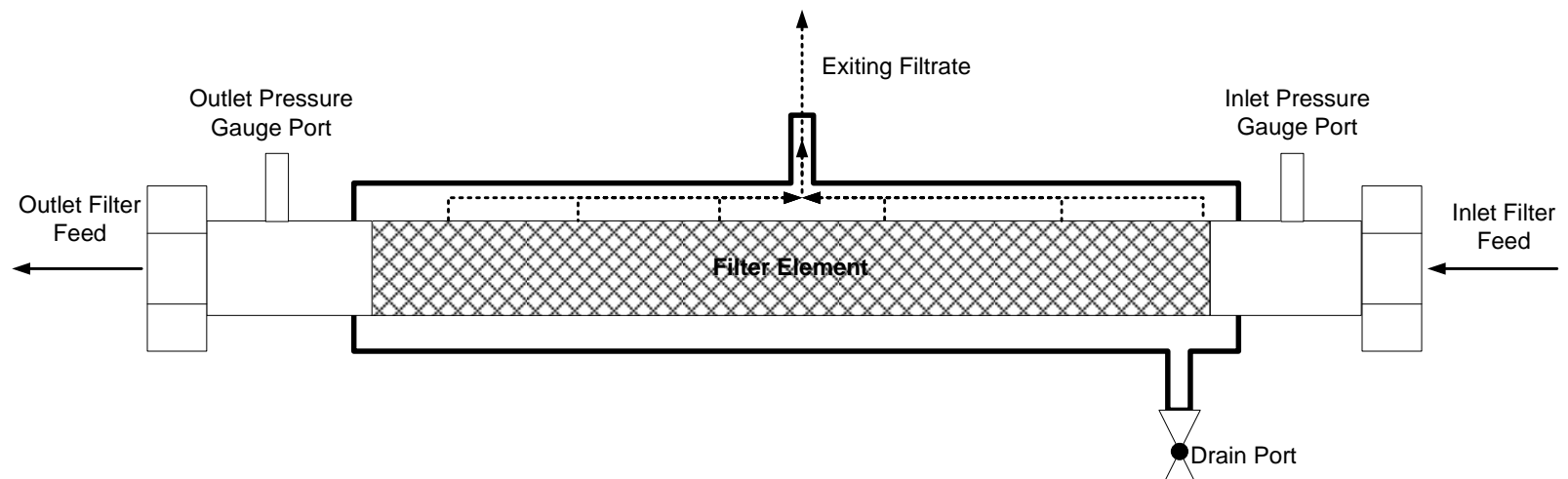

Figure 4.2. Cell Unit Filter Assembly Sketch (not to scale)

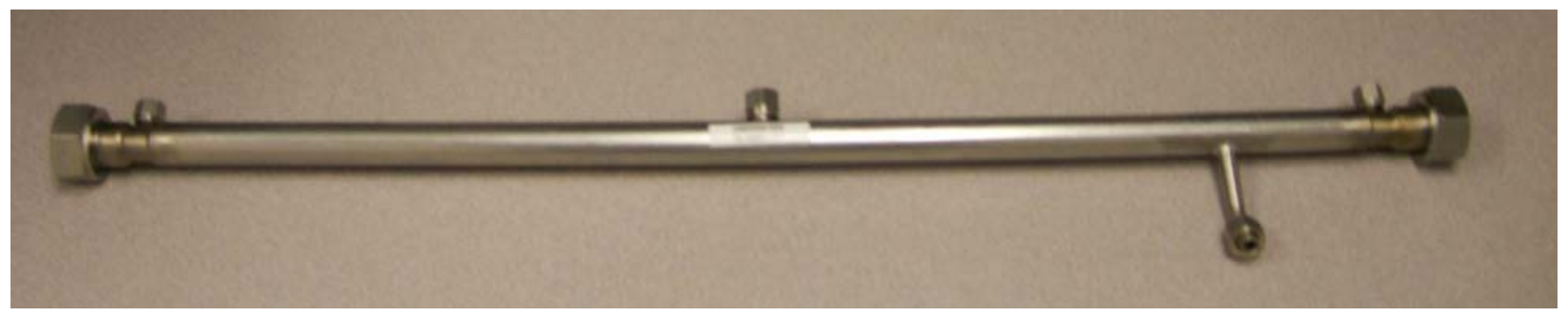

Figure 4.3. The Cell Unit Filter Assembly

\subsubsection{Crossflow Ultrafiltration Testing System}

The filter described in the section above was installed in a bench top testing apparatus that circulated the test filtration simulants through the inside of the filter and diverted the filter permeate to a collection bottle or recycled it back into the slurry reservoir. Figure 4.4 shows a piping diagram of the crossflow ultrafiltration (CUF) testing system. Figure 4.5 is a photograph of the assembled testing apparatus employing a 2-ft filter element. The 8-ft filter element setup uses the same component layout. The 3-HP electric motor and positive displacement pump that drives the filtration slurry simulant are shown to the left in this view. 
WTP-RPT-168, Rev 0

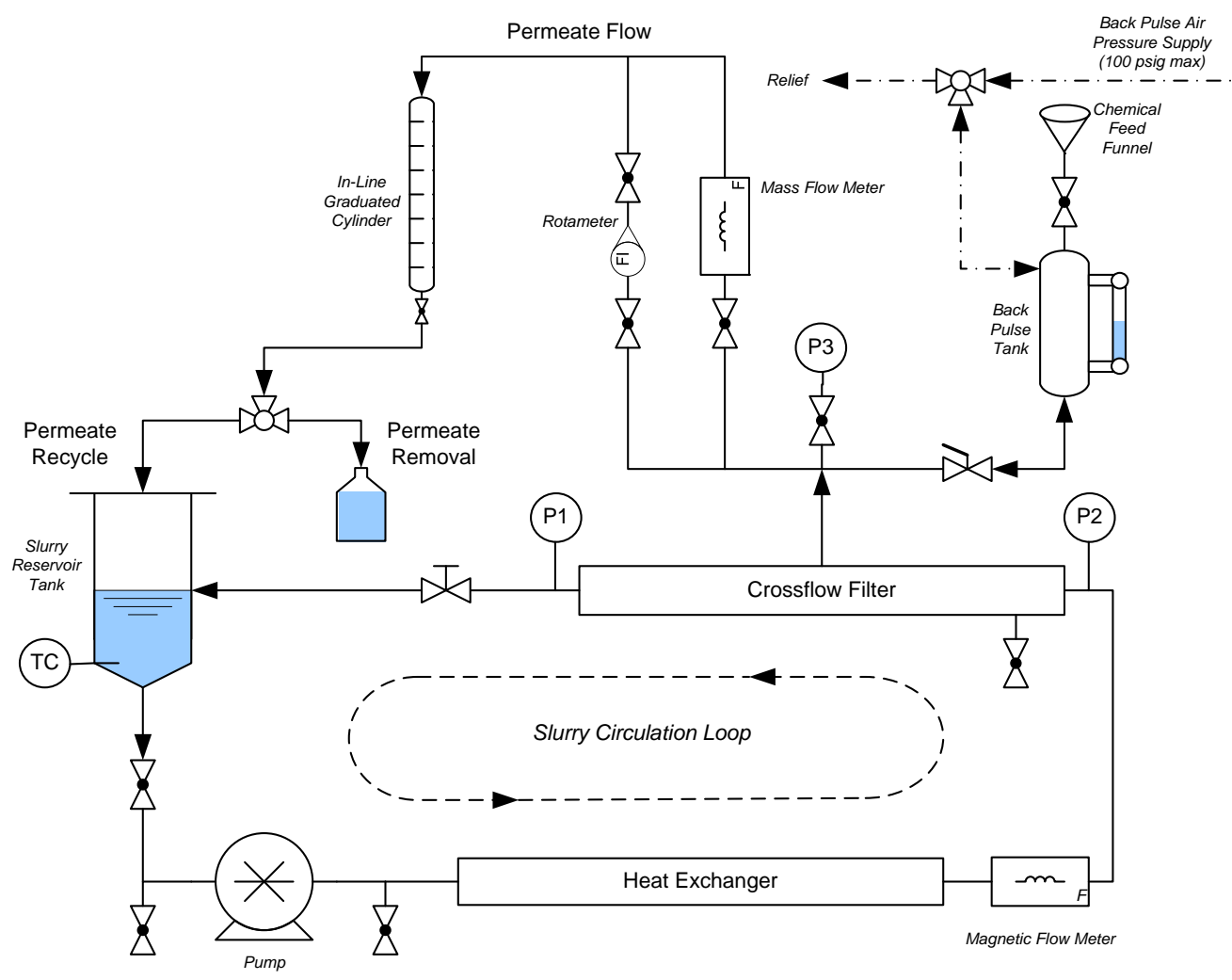

Figure 4.4. CUF Piping Diagram

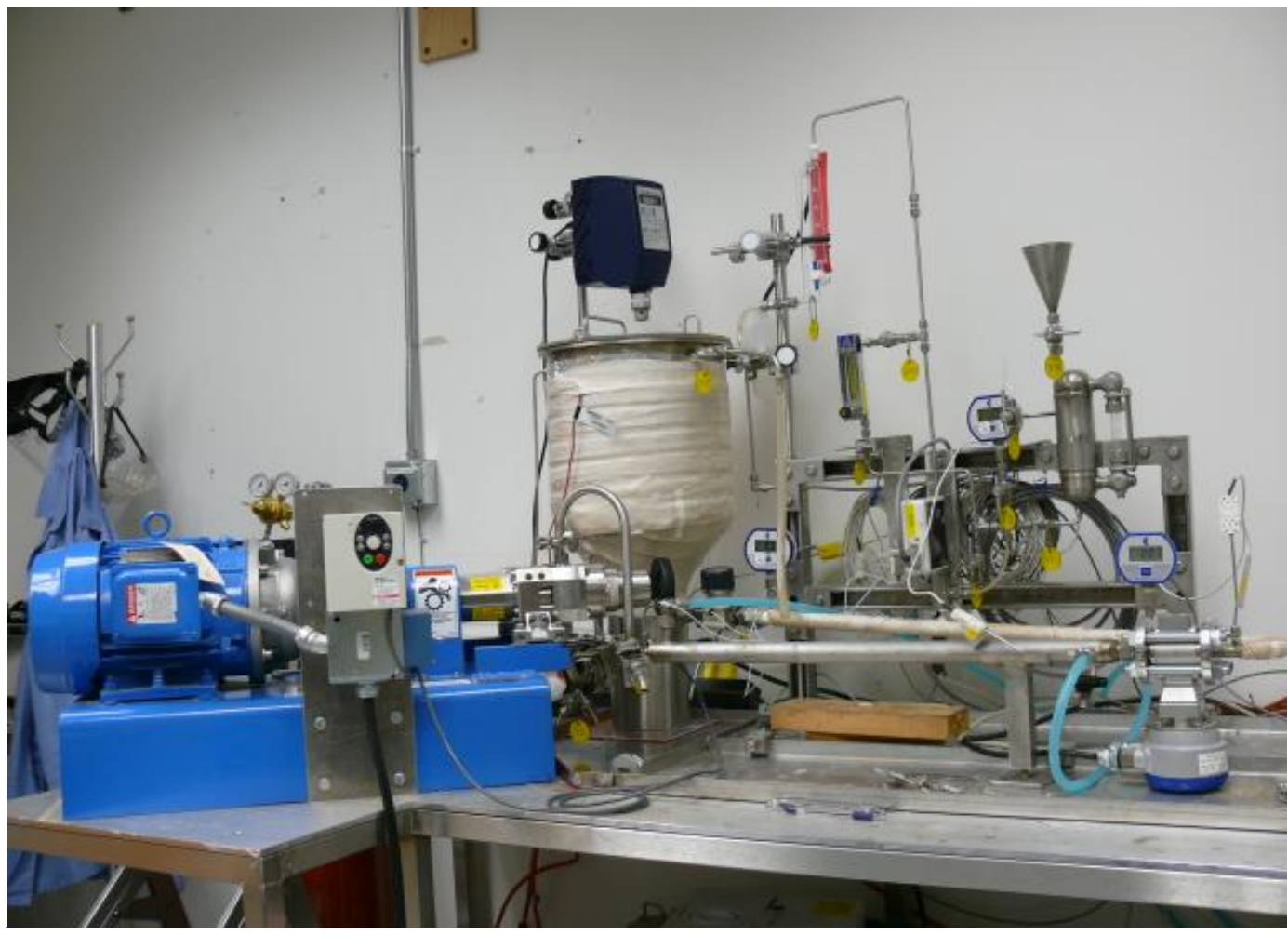

Figure 4.5. The CUF Apparatus 
The CUF has four main parts:

- Slurry reservoir tank

- Slurry recirculation loop

- Permeate flow loop

- Permeate back pulse chamber.

The slurry reservoir tank was a cylindrical 304-L stainless steel tank. Two tanks could be used with the testing apparatus depending on the test to be performed, one of $10-\mathrm{L}$ capacity and the other of $25-\mathrm{L}$ capacity. The larger reservoir, as shown in Figure 4.5, permitted scaled leaching tests to be performed. The smaller reservoir allowed smaller volumes of simulant to be used. For all tests discussed herein (i.e., the scale-up and temperature tests described in Sections 6 and 7 of this report), the large 25-L tank was employed.

Agitation in the tank was provided from an overhead mixer using a 2-in.-diameter, 3-blade marine propeller. To allow the system to be easily drained, the bottom of the vessel was sloped at a $15^{\circ}$ angle. Baffles were also installed on the tank wall to enhance mixing and slurry homogeneity. Heat tape was installed around the walls of the tank for leaching at elevated temperatures. The heat tape was connected to a temperature controller that adjusted the electrical load to the heat tape based on a thermocouple input. A dual Type-K thermocouple was installed inside the reservoir tank (extending just below the overhead mixing impeller) to measure the temperature of the slurry inside the reservoir. One of the thermocouple elements was connected to the heat tape's temperature controller and the other was connected to a data collection system.

The slurry recirculation loop directed slurry flow from the slurry reservoir through the filter and back into the slurry reservoir for filtration operations. The bottom of the slurry reservoir was connected to the suction side of the slurry recirculation pump - a progressive cavity pump. The discharge of the pump flowed through a single-pass shell and tube heat exchanger used to remove excess heat from the system from mechanical energy input from the mixer and pump and heat generated from frictional flow.

An exterior chiller circulated a water/anti-freeze mixture through the exterior shell of the heat exchanger to remove heat away from the circulating slurry on the tube side of the heat exchanger. The chiller controlled the chilling fluid temperature by monitoring the temperature of the slurry exiting the heat exchanger via a resistance temperature detector (RTD) installed in the discharge line.

The slurry then flowed through a magnetic flow sensor that monitored the volumetric flow of the slurry inside the slurry recirculation loop. The sensor's output was displayed on an external panel meter that generated an analog output signal monitored by a data collection system. The data from this device were used to calculate the AV inside the filter element.

The flowing slurry then entered the filter. Digital pressure gauges were installed on the inlet and outlet port of the filter, which displayed the pressure at both locations in a pounds-per-inch-squared gauge (psig). The gauges also transmitted analog output signals monitored by the data collection system. The data from these devices were used to calculate the average pressure inside the filter and the axial pressure drop across the element. 
A manual pinch valve was located at the filter's discharge. The valve was used to adjust the pressure inside the filter to drive permeate flow through the filter membrane wall. It was also connected to the slurry reservoir tank and was closed completely when the tank was isolated for leaching.

The permeate flow loop started at the center of the filter assembly where a poly-line connected the filter to a manifold of $3 / 8$-inch stainless steel piping that directed the filter permeate through a series of measurement devices. A digital pressure gauge was installed at this point to measure the pressure on the permeate side of the filter in psig. Like the other two digital gauges, this instrument transmitted an analog output signal to a data collection system. The TMP across the filter was then calculated by subtracting the pressure on the permeate side of the filter from the average pressure of the slurry inside the filter. TMP is reported in pounds-per-inch-squared differential pressure (psid).

Flow from the filter was either diverted through a mass flow meter calibrated up to $1.2 \mathrm{~L} / \mathrm{min}$ or to a user-calibrated rotameter that can measure flow up to $5.0 \mathrm{~L} / \mathrm{min}$. The mass flow meter also measured the density of the permeate flow and transmitted two analog output signals to the data collection system for the volumetric flow rate and the density. An in-line glass cylinder was installed on the discharge of both meters to take manual measurements of the permeate flow rate. Measurements were taken by closing a valve at the bottom of the cylinder and allowing permeate to fill the glass cylinder. Liquid volume in the glass cylinder was measured by volume markings on the outside. The permeate flow rate was calculated from observed changes in permeate volume in the cylinder over a measured time interval.

Permeate exited through a three-way valve connected to the slurry reservoir tank. This valve directed permeate either back to the slurry reservoir tank to be mixed with the slurry or to a sampling hose used to collect permeate into sample containers.

The permeate back pulse chamber was located to the right of the permeate flow loop and connected to the filter at the same location of the permeate pressure gauge. The chamber was an approximately $1000-\mathrm{mL}$ steel vessel with a sight-glass to track the permeate volume inside the chamber. The vessel had three entry ports:

- $\mathrm{A}^{3} / 8$-in. line with a two-way valve on the bottom connecting the vessel to the permeate side of the filter

- $\mathrm{A}^{3} / 8$-in. line with a two-way valve connecting the top of the vessel to a funnel

- A $1 / 4$-in. line with a three-way valve connecting the top of the vessel to a compressed air line and vent line connected to the top of the slurry reservoir tank.

The bottom line was used to direct permeate flow between the chamber to the filter. The funnel on the top of the chamber was used to introduce cleaning and rinse solutions directly to the vessel. The compressed gas line was used to pressurize the fluid in the chamber with compressed gas and to vent the chamber to atmospheric pressure.

To back pulse the filter, the vessel was first vented to atmospheric pressure. Next, permeate was allowed to fill the chamber by opening the valve. Once the chamber was half full of permeate (as seen from the sight-glass), the valve was closed. The three-way valve was then positioned to allow compressed gas at $80 \mathrm{psig}$ to fill the chamber and pressurize the fluid. The three-way valve was then positioned to isolate the now pressurized chamber. The slurry pressure inside the filter was then dropped below 20 psig. The valve at the bottom of the tank was opened, allowing the pressurized permeate inside 
the chamber to flow backwards through the filter element. The valve was closed when the permeate level was below the visible portion of the sight glass. After the back pulse was completed, the three-way valve was positioned to vent the chamber back to atmospheric pressure.

\subsubsection{Instrumentation and Data Acquisition System}

Most of the sensors on the testing apparatus transmit analog data to an external data-acquisition collection system (DACS) from the National Instruments Corporation (Austin, TX). This system relayed the analog data to a LabView data collection program operating on a computer desktop system using Windows XPTM, Service Pack 2. The software program scales the analog data, simultaneously records the data electronically, and displays it on the computer monitor. The program was verified by Software Test Plan RPP-WTP-QA-010, ${ }^{(a)}$ and all reportable data are measured on calibrated instrumentation including the external DACS board. Figure 4.6 shows a diagram of the electronic sensors attached to the DACS, and Figure 4.7 displays the screen windows from the data collection program.

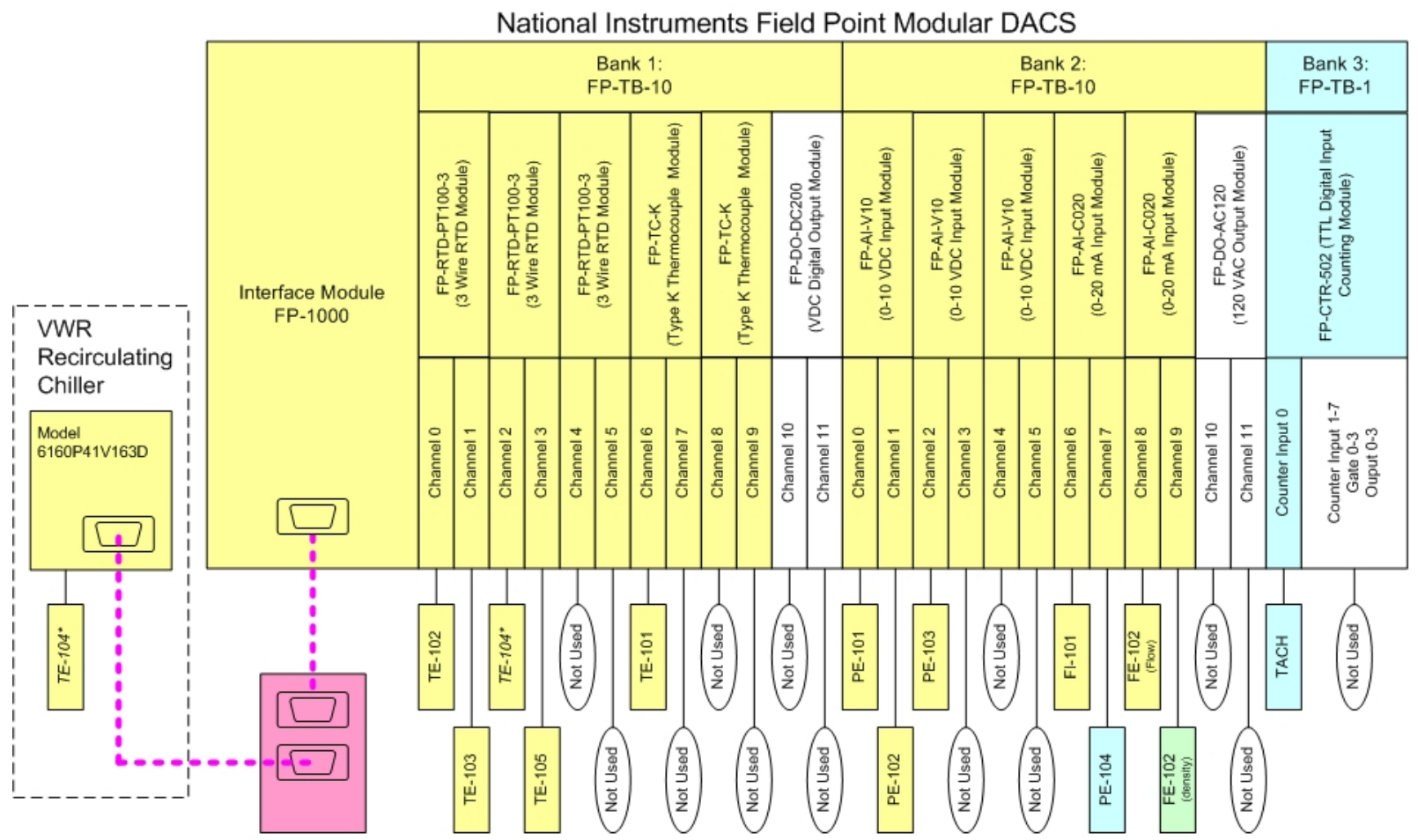

\begin{tabular}{|c|c|c|c|c|}
\hline$\square$ Windows XP PC & $\square$ M\&TE Data & Indication Only & * Note: & $\begin{array}{l}\text { TE-104 can only be wired to } \\
\text { either the chiller or the Field }\end{array}$ \\
\hline -- RS-232 Communication & User Calibration & Not Used & & Point system - not both. \\
\hline
\end{tabular}

Figure 4.6. Diagram of DACS System

(a) RS Shimskey. 2007. Software Test Plan: CUF Data Collection Program. RPP-WTP-QA-010, Rev. 0, Pacific Northwest National Laboratory, Richland, Washington. 




Figure 4.7. Digital Images of DACS Display Windows

\subsubsection{Operations of CUF and Sampling}

The CUF was developed to operate in several different modes to simulate filtration and leaching processes of the WTP Pretreatment system. Filtration operation occurred in a recycling or dewatering mode. During recycling operations, permeate was returned to the slurry reservoir tank. By returning permeate back into the slurry, the UDS concentration in the slurry was maintained at a steady state condition. The CUF was operated in this mode to understand how the effects of time, pressure, and AV impact filtration of slurry while maintaining the physical properties of the slurry. During dewatering operations, permeate from the filter was diverted to a collection vessel, operating the system at a constant TMP and axial flow rate, thus altering the UDS concentration of the slurry. The CUF was operated in this mode to understand how the slurry's rheological and filtration properties changed as its UDS concentration changed. Chemical leaching occurred in the slurry reservoir tank when isolated from the slurry circulation loop. Isolating the slurry reservoir tank for leaching operations required first draining the slurry and permeate inside the CUF filtration piping. Once the tank was isolated from the slurry circulation loop, the slurry and permeate were returned to the slurry reservoir tank along with the leaching agent. When the leaching operations occurred at elevated temperatures, heat tape surrounding the slurry reservoir was used to heat the vessel. 
Samples were collected throughout testing to measure the physical and chemical properties of the waste slurry or permeate. Slurry samples were collected from two separate locations on the system. When possible, slurry samples were collected using the drain valve on the pump discharge while the pump was running. For caustic-leaching operations, where the slurry had been isolated in the slurry reservoir (and the circulation loop was empty), slurry was sampled directly from the slurry reservoir with a plastic transfer pipette. Permeate samples were collected during dewatering operations directly from the dewatering sample hose.

\subsection{Measurement of Permeate Viscosity}

During scale-up temperature tests (discussed in Section 7), permeate samples were collected for the purpose of measuring permeate viscosity. Viscosity was measured using a Haake RS600 rheometer (Thermo Electron Corporation, Madison, WI). A Z41 concentric cylinder measuring system was employed for testing. Rheometer control and data acquisition are accomplished through remote computer connection using the RheoWin Pro Job Manager Software, Version 2.96.

Flow curve measurements (i.e., material stress response versus applied shear rate) at $25^{\circ} \mathrm{C}, 35^{\circ} \mathrm{C}$, and $45^{\circ} \mathrm{C}$ were performed for each permeate sample collected. Each flow curve was measured over an 11-min period. During the first $5 \mathrm{~min}$, the shear rate was gradually increased from zero up to a predefined maximum shear rate (typically between 200 and $1000 \mathrm{~s}^{-1}$ ). Next, the shear rate was held constant at the predefined maximum shear rate for $1 \mathrm{~min}$. For the final $5 \mathrm{~min}$, the shear rate was gradually reduced back to zero. During this time, the resisting torque and rotational rate were continuously monitored and recorded. 


\subsection{Test Materials}

Two baseline test slurries were employed in scale-up testing: a simulant sludge solids slurry and a blended simulant slurry. Slurry formulation and preparation match those of slurries tested previously under the simulant development test plan, TP-RPP-WTP-469. ${ }^{\text {(a) }}$ This allowed comparison of 8-ft filter performance data against existing 2 -ft data. The following sections provide an overview of simulant formulation and preparation. Composition and supplier information for the simulant sludge solids slurry is provided in Section 5.1. Composition and supplier information for the blended simulant slurry is provided in Section 5.2. This information is reproduced as a reference from the simulant development report WTP-RPT-183. ${ }^{\text {(b) }}$ Specifics regarding formulation choices and the waste properties that the simulant mimics may be found therein. In addition, report WTP-RPT-183 also provides details regarding simulant properties such as density, rheology, and particle size.

\subsection{Simulant Sludge Solids Slurry}

The simulant sludge solids slurry was employed for a single 2 -ft to 8 -ft filter element scaling test. Simulant sludge solids comprise a wide range of precipitated metal hydroxides and are also a starting component for the more complex blended simulant. Simulant sludge solids primarily represent a "filtration" component for leaching and filtration tests; specifically, they do not contain components removed during the chemical leaching processes (i.e., boehmite, gibbsite, chromium, and water soluble solids).

\subsubsection{Formulation}

Simulant sludge solids comprise primarily iron-oxyhydroxide solids and, as such, are also referred to as the iron-rich sludge. This iron-rich sludge contains a wide range of other metal hydroxide solids to simulate the full range of metal oxide phases that exist in actual Hanford tank waste. For the current testing, a simplified iron-rich sludge formulation was prepared by the Optima Chemical Corporation (Douglas, GA) based on a more complicated original formulation developed at PNNL. The simplified Optima formulation excludes some minor and toxic metal species. Table 5.1 lists the compositions for both the original PNNL formulation and the simplified formulation employed in the current studies.

\subsubsection{Preparation}

Preparation (as per PNNL's procedure) of the simulant sludge solids slurry for CUF scale-up testing involved three separate components: 1) a precipitated solids washing solution, 2) a supernate simulant, and 3) iron-rich sludge solids. The preparation procedure for Optima simulant is similar. The following sections provide recipes for these three components. It should be noted that preparation was strongly dependent on the order of addition. While this is not discussed in this report, details regarding order of addition for simulant preparation may be found in Appendix A of WTP-RPT-183. All simulant sludge

(a) RL Russell, and HD Smith. 2007. Test Plan for the Development and Demonstration of Leaching and Ultrafiltration Simulants. 24590-101-TSA-W000-0004-182-00001 Rev 00A (TP-RPP-WTP-469, Rev. 0), Pacific Northwest National Laboratory, Richland, Washington.

(b) RL Russell, HD Smith, JM Billing, RA Peterson, and DE Rinehart. 2008. Development and Demonstration of Ultrafiltration Simulants. WTP-RPT-183, Pacific Northwest National Laboratory, Richland, Washington. 
solid and supernate preparations associated with testing in the current report were performed by the Optima Chemical Corporation.

Table 5.1. Composition of the Original PNNL and Optima Formulations for the Iron-Rich Sludge Solids Component Used in Scale-up Testing

\begin{tabular}{ccc}
\hline Component & $\begin{array}{c}\text { PNNL } \\
\text { (mol fraction) }\end{array}$ & $\begin{array}{c}\text { Optima } \\
\text { (mol fraction) }\end{array}$ \\
\hline $\mathrm{Ba}(\mathrm{OH})_{2}$ & 0.0019 & --- \\
$\mathrm{Ca}(\mathrm{OH})_{2}$ & 0.0235 & 0.0237 \\
$\mathrm{Cd}(\mathrm{OH})_{2}$ & 0.0006 & --- \\
$\mathrm{Ce}(\mathrm{OH})_{3}$ & 0.0034 & 0.0035 \\
$\mathrm{Cu}(\mathrm{OH})_{2}$ & 0.0015 & --- \\
$\mathrm{Fe}(\mathrm{OH})_{3}$ & 0.7269 & 0.7324 \\
$\mathrm{La}(\mathrm{OH})_{3}$ & 0.0025 & 0.0026 \\
$\mathrm{~Pb}(\mathrm{OH})_{2}$ & 0.0090 & 0.0176 \\
$\mathrm{Mg}(\mathrm{OH})_{2}$ & 0.0153 & 0.0154 \\
$\mathrm{Nd}(\mathrm{OH})_{3}$ & 0.0069 & 0.0069 \\
$\mathrm{Ni}(\mathrm{OH})_{2}$ & 0.0226 & 0.0228 \\
$\mathrm{Pr}(\mathrm{OH})_{3}$ & 0.0017 & --- \\
$\mathrm{RuOOH}$ & 0.0013 & --- \\
$\mathrm{AgOH}$ & 0.0066 & --- \\
$\mathrm{Sr}(\mathrm{OH})_{2}$ & 0.0038 & 0.0038 \\
$\mathrm{Y}(\mathrm{OH})_{3}$ & 0.0008 & --- \\
$\mathrm{Zn}(\mathrm{OH})_{2}$ & 0.0013 & --- \\
$\mathrm{ZrO}(\mathrm{OH})_{2}$ & 0.0117 & 0.0118 \\
$\mathrm{Hg}(\mathrm{OH})_{2}$ & 0.0004 & --- \\
$\mathrm{MnO}{ }_{2}$ & 0.1584 & 0.1595 \\
\hline
\end{tabular}

Precipitated Solids Washing Solution

The simple washing solution was used for initial washing of the precipitated sludge solids that constitute the iron-rich sludge solids. The wash solution was a simplified version of the iron-rich solids supernate that contains the most abundant species in the supernate simulant but omits minor species. Table 5.2 lists the composition of the washing supernate. All components were added to and dissolved in deionized (DI) water. 
WTP-RPT-168, Rev 0

Table 5.2. Composition of the Precipitated Solids Washing Solution

\begin{tabular}{llc}
\hline \multicolumn{1}{c}{ Compound } & \multicolumn{1}{c}{ Formula } & Concentration $(\mathrm{g} / \mathrm{L})$ \\
\hline Sodium Carbonate & $\mathrm{Na}_{2} \mathrm{CO}_{3}$ & 102.3 \\
Sodium Hydroxide & $\mathrm{NaOH}$ & 15.38 \\
Sodium Nitrite & $\mathrm{NaNO}_{2}$ & 6.49 \\
Sodium Oxalate & $\mathrm{Na}_{2} \mathrm{C}_{2} \mathrm{O}_{4}$ & 5.30 \\
Sodium Phosphate & $\mathrm{Na}_{3} \mathrm{PO}_{4} \cdot 12 \mathrm{H}_{2} \mathrm{O}$ & 15.38 \\
Sodium Sulfate & $\mathrm{Na}_{2} \mathrm{SO}_{4}$ & 2.67 \\
\hline
\end{tabular}

\section{$\underline{\text { Supernate Simulant }}$}

Supernate simulant was used for the final washing of the iron-rich precipitated sludge solids and to dilute the iron-rich solids slurry to a target concentration following preparation. Table 5.3 lists the composition of the washing supernate. As before, all components were added to and dissolved in DI water.

Table 5.3. Composition of the Supernate Simulant

\begin{tabular}{llc}
\hline \multicolumn{1}{c}{ Compound } & \multicolumn{1}{c}{ Formula } & Concentration $(\mathrm{g} / \mathrm{L})$ \\
\hline Potassium Hydroxide & $\mathrm{KOH}$ & 0.2691 \\
Potassium Nitrate & $\mathrm{KNO}_{3}$ & 0.4325 \\
Sodium Acetate & $\mathrm{NaCH}_{3} \mathrm{COO} \cdot 3 \mathrm{H}_{2} \mathrm{O}$ & 1.034 \\
Sodium Carbonate & $\mathrm{Na}_{2} \mathrm{CO}_{3}$ & 102.3 \\
Sodium Chloride & $\mathrm{NaCl}$ & 0.2007 \\
Sodium Fluoride & $\mathrm{NaF}$ & 0.1345 \\
Sodium Formate & $\mathrm{NaHCOO}$ & 0.2062 \\
Sodium Hydroxide & $\mathrm{NaOH}$ & 15.380 \\
Sodium Metasilicate & $\mathrm{Na}_{2} \mathrm{SiO}_{3} \cdot 9 \mathrm{H}_{2} \mathrm{O}$ & 0.5455 \\
Sodium Nitrate & $\mathrm{NaNO}_{2}$ & 6.494 \\
Sodium Oxalate & $\mathrm{Na}_{2} \mathrm{C}_{2} \mathrm{O}_{4}$ & 5.303 \\
Sodium Phosphate & $\mathrm{Na}_{3} \mathrm{PO}_{4} \cdot 12 \mathrm{H}_{2} \mathrm{O}$ & 15.380 \\
Sodium Sulfate & $\mathrm{Na}_{2} \mathrm{SO}_{4}$ & 2.671 \\
Sodium Tungstate & $\mathrm{Na}_{2} \mathrm{WO}_{4} \cdot 2 \mathrm{H}_{2} \mathrm{O}$ & 0.1577 \\
\hline
\end{tabular}

$\underline{\text { Iron-Rich Sludge Solids (or Simulant Sludge Solids) }}$

The iron-rich sludge solids were derived from the dissolution of metal nitrates and subsequent reprecipitation as metal hydroxides through neutralization. The general steps for forming the iron-rich sludge solids were to:

1. dissolve metal nitrates

2. neutralize these nitrates to form the metal hydroxides 
3. add trim chemicals (fluoride, phosphate, oxalate, and carbonate)

4. wash the solids with the precipitated solids washing solution (described in preceding sections)

5. perform the final wash of the solids with the supernate simulant

6. dilute to the target UDS concentration with the supernate simulant.

Preparation of metal hydroxides (i.e., steps 1 and 2) involved mixing of the primarily metal nitrate components listed in Table 5.4 in sufficient DI water $(\sim 300 \mathrm{~g})$ to allow complete dissolution. As discussed in Appendix A of WTP-RPT-183, the mass of metal nitrates listed in Table 5.4 targets a final precipitated solids mass of $\sim 300 \mathrm{~g}$ after neutralization and washing. Once prepared, the initial metal nitrate solution was neutralized with $8 \mathrm{M} \mathrm{NaOH}$ until the $\mathrm{pH}$ reached 10-11. This step typically required $\sim 190 \mathrm{~g}$ of $8 \mathrm{M} \mathrm{NaOH}$ based on the mass of nitrates given in Table 5.4. The result of neutralization was a precipitated metal hydroxide solids (or precipitated sludge solids). After neutralization, the trim chemicals listed in Table 5.5 were added. Once the trim components were added, the precipitated sludge solids were washed with the precipitated solids wash solution to reduce the nitrate ion concentration to less than $500 \mathrm{mg}$ per kg of prepared simulant sludge solids slurry. A final wash of the simulant sludge solids with simulant supernate was performed to "finalize" the slurry. Before testing, the "finalized" simulant sludge solids slurry was diluted with supernate simulant to a target undissolved solid concentration of $\sim 5-\mathrm{wt} \%$.

Table 5.4. Composition of the Starting Metal Nitrate Solution for Metal Hydroxide Precipitation

\begin{tabular}{|c|c|c|}
\hline Compound & Formula & Target Mass (g) \\
\hline Barium Nitrate* & $\mathrm{Ba}\left(\mathrm{NO}_{3}\right)_{2}$ & 0.213 \\
\hline Cadmium Nitrate* & $\mathrm{Cd}\left(\mathrm{NO}_{3}\right)$ & 0.06 \\
\hline Calcium Nitrate & $\mathrm{Ca}\left(\mathrm{NO}_{3}\right)_{2} \cdot 4 \mathrm{H}_{2} \mathrm{O}$ & 2.425 \\
\hline Cerium Nitrate & $\mathrm{Ce}\left(\mathrm{NO}_{3}\right)_{3} \cdot 6 \mathrm{H}_{2} \mathrm{O}$ & 0.65 \\
\hline Copper Nitrate* & $\mathrm{Cu}\left(\mathrm{NO}_{3}\right)_{2} \cdot 3 \mathrm{H}_{2} \mathrm{O}$ & 0.157 \\
\hline Ferric Nitrate & $\mathrm{Fe}\left(\mathrm{NO}_{3}\right)_{3} \cdot 9 \mathrm{H}_{2} \mathrm{O}$ & 128.1 \\
\hline Lanthanum Nitrate & $\mathrm{La}\left(\mathrm{NO}_{3}\right) 3 \cdot 6 \mathrm{H}_{2} \mathrm{O}$ & 0.482 \\
\hline Lead Nitrate & $\mathrm{Pb}\left(\mathrm{NO}_{3}\right)_{2}$ & 1.295 \\
\hline Magnesium Nitrate & $\mathrm{Mg}\left(\mathrm{NO}_{3}\right)_{2} \cdot 6 \mathrm{H}_{2} \mathrm{O}$ & 1.72 \\
\hline Manganous Nitrate Solution & $\mathrm{Mn}\left(\mathrm{NO}_{3}\right)_{2}, 50-\mathrm{wt} \%$ solution & 14.85 \\
\hline Mercuric Nitrate* & $\mathrm{Hg}\left(\mathrm{NO}_{3}\right)_{2}$ & 0.052 \\
\hline Neodymium Nitrate & $\mathrm{Nd}\left(\mathrm{NO}_{3}\right) 3 \cdot 6 \mathrm{H}_{2} \mathrm{O}$ & 1.32 \\
\hline Nickel Nitrate & $\mathrm{Ni}\left(\mathrm{NO}_{3}\right)_{2} \cdot 6 \mathrm{H}_{2} \mathrm{O}$ & 2.87 \\
\hline Potassium Permanganate & $\mathrm{KMnO}_{4}$ & 4.37 \\
\hline Praseodymium Nitrate* & $\operatorname{Pr}\left(\mathrm{NO}_{3}\right)_{3} \cdot \mathrm{xH}_{2} \mathrm{O} \times \mathbf{x} \sim 6$ & 0.33 \\
\hline Ruthenium Trichloride* & $\mathrm{RuCl}_{3}$ & 0.11 \\
\hline Silver Nitrate* & $\mathrm{AgNO}_{3}$ & 0.486 \\
\hline Strontium Nitrate & $\mathrm{Sr}\left(\mathrm{NO}_{3}\right)_{2}$ & 0.347 \\
\hline Yttrium Nitrate* & $\mathrm{Y}\left(\mathrm{NO}_{3}\right)_{3} \cdot 6 \mathrm{H}_{2} \mathrm{O}$ & 0.14 \\
\hline Zinc Nitrate* & $\mathrm{Zn}\left(\mathrm{NO}_{3}\right)_{2} \cdot 6 \mathrm{H}_{2} \mathrm{O}$ & 0.169 \\
\hline Zirconyl Nitrate & $\mathrm{ZrO}\left(\mathrm{NO}_{3}\right)_{2} \cdot \mathrm{xH}_{2} \mathrm{O} \mathrm{x} \sim 6$ & 1.73 \\
\hline
\end{tabular}


WTP-RPT-168, Rev 0

Table 5.5. Trim Chemicals Added to Precipitated Metal Hydroxide Solution

\begin{tabular}{llc}
\hline \multicolumn{1}{c}{ Compound } & \multicolumn{1}{c}{ Formula } & Concentration $(\mathrm{g} / \mathrm{L})$ \\
\hline Calcium Fluoride & $\mathrm{CaF}_{2}$ & 0.205 \\
Sodium Carbonate & $\mathrm{Na}_{2} \mathrm{CO}_{3}$ & 9.5 \\
Sodium Oxalate & $\mathrm{NaC}_{2} \mathrm{O}_{4}$ & 6.7 \\
Sodium Phosphate & $\mathrm{Na}_{3} \mathrm{PO}_{4} \cdot 12 \mathrm{H}_{2} \mathrm{O}$ & 5.05 \\
\hline
\end{tabular}

\subsection{Blended Simulant Slurry}

A blended simulant slurry was employed for the 2-ft to 8-ft filter element scaling test and temperature tests. The blended simulant slurry is a waste simulant that contains a blend of solids that includes 1) the iron-rich sludge solids used for the simulant sludge solids slurry and 2) simulant solids targeted by leaching operations including boehmite, gibbsite, oxalate, and chromium.

As discussed in WTP-RPT-183, a number of blended simulant slurry formations were created under the simulant development subtasks associated with the PEP. The blended simulant slurry used for testing in this report is based on the blended simulant slurry formulation employed CUF Blended Matrix Test 3 (CBM3) in WTP-RPT-183, Although some blended simulant formulations include chrome oxyhydroxide solids $(\mathrm{CrOOH})$ for tests where oxidative leaching was performed, CBM3 did not include this component in its formulation. The blended simulant slurry used for the tests described herein was prepared by adding the following components to approximately $25 \mathrm{~kg}$ of supernate simulant:

1. $\sim 460 \mathrm{~g}$ of gibbsite solids

2. $\sim 460 \mathrm{~g}$ of boehmite solids

3. $\sim 130 \mathrm{~g}$ of sodium oxalate solids

4. $\sim 2150 \mathrm{~g}$ of "finalized" simulant sludge solids slurry

5. $\sim 380 \mathrm{~g}$ of $5 \mathrm{M} \mathrm{NaOH}$ solution.

Both the simulant sludge solids and supernate simulant used were prepared by the Optima Chemical Corporation (Douglas, GA). Gibbsite solids were supplied by Almatis (Frankfurt, Germany). Boehmite solids were supplied by Nabaltec AG (Schwandorf, Germany). Sodium oxalate solids were obtained from Noah Technologies Corporation (San Antonio, Texas, USA). Finally, the $5 \mathrm{M} \mathrm{NaOH}$ solution was prepared onsite by diluting $19 \mathrm{M} \mathrm{NaOH}$ concentrated caustic solution, purchased from Ricca Chemical Company (Pequannock, New Jersey, USA), with DI water. 



\subsection{Filter Scale-Up Tests}

The AV/TMP matrix tests were conducted to determine the effect of filter length on CUF filtration performance using the approach outlined in Sections 6.2.1 and 6.2.2 of Test Plan TP-RPP-WTP-509. (a) The primary objective of this work was to assess the impact of using a longer filter element on filtration performance. Previous bench-scale filtration tests have employed 2-ft filter elements of 0.5 inch inner diameter, whereas actual waste treatment operations will employ longer ( 8 - $\mathrm{ft}$ and $10-\mathrm{ft}$ ) elements of the same diameter. The need for bench-scale tests using longer (8-ft) filters is driven by potential differences in the degree of cake formation in 2-ft and 8-ft filters. Specifically, 8-ft filter elements provide greater length over which solid slurry particles can migrate to the filter wall and form a solids cake. Cake formation, combined with transport of that filter cake axially along the filter element, may yield a buildup of solids in the 8-ft element greater than that possible in the 2-ft element. Based on this argument, there was a concern that increased cake build-up would decrease the filter flux in longer filter elements.

Two simulant trials were performed using 1) a simulant sludge solids slurry and 2) a blended simulant slurry. The compositions of both simulant slurries are described in Section 5 of this report and are based on formulations developed under the simulant development test plan, TP-RPP-WTP-469. ${ }^{\text {(b) }}$ Both 8-ft scaling tests attempted to replicate tests performed as part of the simulant development task with the 2-ft filter element. To determine scaling effects, both the AV/TMP test matrix filter flux results and the dewatering curves for the 2 -ft and 8 -ft filters will be compared. Differences will be discussed and analyzed in terms of their implications for filter scaling.

\subsection{Scale-Up Test Description}

The filtration testing of the simulant trial slurries were conducted using a bench-scale CUF described in Section 4 of this report. Two simulant systems were employed for AV/TMP scale-up testing: 1) a simulant sludge solids slurry and 2) a blended simulant slurry. Details regarding slurry preparation are given in Section 5 of this report. After preparation, both slurries were diluted to an initial UDS concentration of approximately $5 \mathrm{wt} \%$.

The general test sequence used in the two stimulant trials was as follows:

1. Approximately $9 \mathrm{~L}$ of an $\sim 5 \mathrm{wt} \%$ UDS slurry was placed in the CUF slurry reservoir tank. After slurry load-in, the filter was backpulsed five times. Next, the filter was conditioned in an attempt to minimize flux transience from depth fouling. To do this, the slurry was filtered in continuous filtration recycle mode at a TMP of 40 psid and an AV of $13 \mathrm{ft} / \mathrm{s}$ for 4 hours.

2. The low-solids filtration test matrix was conducted using condition guidelines shown in Table 6.1. Each condition was tested in continuous filtration recycle mode at a temperature of $25 \pm 5^{\circ} \mathrm{C}$. Before each test, the pump and back pressure setting were adjusted to meet the target AV/TMP set-points. After conditions were set, the filter was backpulsed twice. The filtration system was allowed to run

(a) RC Daniel, and RW Shimskey. 2007. Test Plan for Simulant Testing in Support of Phase I Demonstration of the Ultrafiltration and Leaching Processes in the Integrated Test Facility. 24590-101-TSA-W000-0004-7200019 Rev 00A (TP-RPP-WTP-509, Rev. 0). Pacific Northwest National Laboratory, Richland, Washington.

(b) RL Russell, and HD Smith. 2007. Test Plan for the Development and Demonstration of Leaching and Ultrafiltration Simulants. 24590-101-TSA-W000-0004-182-00001 Rev 00A (TP-RPP-WTP-469, Rev. 0), Pacific Northwest National Laboratory, Richland, Washington. 
for the duration listed in Table 6.1 with minor adjustments to pump speed and backpressure to maintain AV/TMP set-points. During the entire test period, filtration data were collected by the DACS (see Section 4), with the start and stop times associated with each AV/TMP set point so that the data could be parsed and analyzed appropriately at the end of the test.

3. At the end of the low-solids filtration matrix test, the filter was backpulsed five times. Next, the CUF was run in the recycle mode at a TMP of $40 \mathrm{psid}$ and AV at $13 \mathrm{ft} / \mathrm{sec}$ (keeping the UDS concentration constant at $\sim 5 \mathrm{wt} \%$ ) for 2 hours. This step was done to stabilize the filter flux immediately before the dewatering operation.

4. After the 2-hour run-in period, the slurry was then dewatered at a TMP of $40 \mathrm{psid}$ and AV at $13 \mathrm{ft} / \mathrm{sec}$ to the maximum USD achievable (target 17 to $20 \mathrm{wt} \%$ ) for the stimulant being tested. This was based on the results from the simulant development test plan, TP-RPP-WTP-469. The filter was not backpulsed before dewatering.

5. At the end of dewatering, the filter was back-pulsed five times. Next, a high-solids filtration test matrix was conducted using the condition guidelines shown in Table 6.1. The text matrix was executed as described in Step 2.

6. At the end of each simulant test, the CUF was drained and cleaned before continuing with the next simulant slurry.

Table 6.1. Filtration Test Matrix Conditions

\begin{tabular}{cccc}
\hline Test number & $\begin{array}{c}\text { Duration } \\
\text { [hours] }\end{array}$ & $\begin{array}{c}\text { Target } \mathrm{AV}^{(\mathrm{a})} \\
{[\mathrm{ft} / \mathrm{s}]}\end{array}$ & $\begin{array}{c}\text { Target TMP } \\
{[\mathrm{psid}]}\end{array}$ \\
\hline 1 & 1 & 13 & 40 \\
2 & 1 & 9 & 40 \\
3 & 1 & 17 & 40 \\
4 & 1 & 13 & 20 \\
5 & 1 & 13 & 60 \\
6 & 1 & 13 & 40 \\
\hline
\end{tabular}

(a) Actual conditions may vary based upon slurry volume and rheology. All conditions may not be obtainable. Note that these conditions were selected to mirror those used in testing planned as part of simulant development (TP-RPP-WTP-469).

It should be noted that the 2-foot characterization studies also used $9 \mathrm{~L}$ of test slurry. An important parameter for filtration is the ratio of slurry volume to filter surface area. In any scale-up study, it is optimal to maintain this ratio. The current 8 -foot scale studies were planned around the original maximum slurry reservoir capacity of $10 \mathrm{~L}$, and as such, did not scale the slurry volume to maintain the slurry volume-to-filter area ratio. The consequence of this is a lower fines loading per surface area of filter in the 8-foot scale tests relative to that on the 2-foot scale tests. Specifically, the 8-foot tests have a fines loading $25 \%$ of that in the 2 -foot tests. Since fines are typically responsible for filter fouling, fouling effects are expected to have a smaller impact on the 8-foot scale test relative to the 2-foot scale test.

The filtration conditions listed in Table 6.1 provided a matrix of set points over which the influence of AV and TMP could be evaluated. Addition of the 8-ft filter element to the system increased the power required to circulate the slurry through the system. Because of this, the pump did not provide sufficient 
power to achieve some of the AV/TMP combinations listed in Table 6.1. In particular, test conditions 3 and 5 could not be met for either simulant sludge solids or blended simulant tests. For the affected tests, the highest AV achievable at the target TMP was employed. Table 6.2 provides a complete list of the tested conditions achieved during the 8 -ft scale tests.

Table 6.2. List of AV/TMP Achieved During 8-ft Scale-Up Matrix Tests

\begin{tabular}{cccccc}
\hline \multirow{2}{*}{ Slurry } & \multirow{2}{*}{$\begin{array}{c}\text { Test } \\
\text { Condition }\end{array}$} & \multicolumn{2}{c}{ Low-Solids Matrix Test } & \multicolumn{2}{c}{ High-Solids Matrix Test } \\
\cline { 3 - 6 } & 1 & 13.0 & 40.0 & 13.0 & 40.5 \\
\hline \multirow{2}{*}{ Simulant Sludge Solids } & 2 & 9.0 & 41.6 & 9.0 & 40.5 \\
& $3^{(\mathrm{a})}$ & 13.5 & 39.8 & 14.2 & 39.6 \\
& 4 & 13.1 & 20.0 & 12.9 & 20.1 \\
& $5^{(\mathrm{a})}$ & 11.8 & 60.0 & 12.6 & 59.9 \\
& 6 & 13.0 & 40.2 & 13.0 & 39.8 \\
Blended Simulant & 1 & 13.0 & 40.0 & 13.1 & 40.3 \\
& 2 & 9.0 & 40.8 & 9.0 & 40.6 \\
& $3^{(\mathrm{a})}$ & 13.5 & 40.3 & 13.4 & 39.6 \\
& 4 & 13.0 & 19.9 & 13.0 & 20.5 \\
& $5^{(\mathrm{a})}$ & 12.0 & 59.8 & 11.9 & 59.4 \\
& 6 & 13.0 & 40.1 & 13.0 & 39.8 \\
\hline
\end{tabular}

(a) Indicates condition where target AV could not be met.

The simulant sludge solids 8 - $\mathrm{ft}$ scale test employed $12.9 \mathrm{~kg}$ of simulant slurry at an as-prepared target concentration of $5 \mathrm{wt} \%$. After initial sampling, the slurry circulating mass was approximately $11.6 \mathrm{~kg}$. Dewatering of the slurry removed $9.6 \mathrm{~kg}$ of supernate. Table 6.3 shows the evolution of UDS concentration of the simulant sludge solids slurry throughout the 8-ft scale test process. After dewatering, the pump could not provide adequate power to circulate the slurry through the filtration loop because of slurry thickness and limited slurry volume. To facilitate continued testing, the slurry was diluted with approximately $1.1 \mathrm{~kg}$ of collected permeate. This decreased slurry thickness and provided sufficient test volume to continue the test. Careful accounting of slurry and permeate mass additions and removals allowed tracking of the circulating mass of solids and permeate in the filtration loop. This in turn allowed calculation of slurry UDS throughout all filtration processes. The calculations shown for the simulant sludge solids slurry are based on an as-prepared concentration of $5 \mathrm{wt} \%$. A similar mass balance approach was taken for both 8-ft blended simulant scale-up tests and 2-ft reference tests. Differences in calculated and measured UDS concentrations (including those shown in Table 6.3 and others in this report) result from a number of potential sources, including but not limited to

1. phase segregation of solids through settling, which results in poor representative sampling of solids for UDS measurements

2. indefinite volume hold-up of permeate in the permeate collection and metering system

3. experimental error. 
It should be noted that carry-through of typical wt $\%$ differences $\left( \pm 1 \mathrm{wt} \%{ }^{(\mathrm{a})}\right)$ in initial UDS measurements through the mass balance can yield significant differences $( \pm 5 \mathrm{wt} \%$ or greater) between calculated and measured dewatered UDS. Because of solid sampling issues, it is difficult to ascertain which UDS value best approximates the actual test concentrations. For consistency, all discussion of results in this report utilizes the calculated UDS concentrations.

Table 6.3. Solids Concentrations Tested During Simulant Sludge Solids 8-ft Scale Tests

\begin{tabular}{ccc}
\hline Test Step & $\begin{array}{c}\text { Calculated UDS } \\
\text { Concentration (wt\%) }\end{array}$ & $\begin{array}{c}\text { Measured UDS } \\
\text { Concentration (wt\%) }\end{array}$ \\
\hline Initial Slurry & 5.0 & not measured \\
Low-Solids Matrix Test & 5.4 & 4.5 \\
Initial Dewater Attempted & 31.2 & 19.4 \\
High-Solid Matrix Test & 20.2 & 11.8 \\
\hline
\end{tabular}

The blended simulant 8 - $\mathrm{ft}$ scale test employed $12.8 \mathrm{~kg}$ of simulant slurry at an as-prepared concentration of $5 \mathrm{wt} \%$. After initial sampling, the circulating slurry mass was approximately $11.4 \mathrm{~kg}$. Dewatering of the slurry removed $9.5 \mathrm{~kg}$ of permeate. Toward the end of the dewatering operation, the slurry volume became too low for the pump to circulate the slurry without cavitation. Because of pump noise, cavitation was only noticed after it began to yield significant variation in the slurry AV and permeate flow rate. Since the initially concentrated slurry volume and flow properties were insufficient to attain stable AV/TMP conditions, approximately $1.8 \mathrm{~kg}$ of permeate was returned to the slurry reservoir to dilute the blended simulant down to a pumpable concentration. Table 6.4 shows the evolution of UDS concentration for the blended simulant slurry throughout the 8 - $\mathrm{ft}$ scale test process. The calculations shown are based on an as-prepared concentration of $5 \mathrm{wt} \%$.

Table 6.4. Solids Concentrations Tested During Blended Simulant 8-ft Scale Tests

\begin{tabular}{ccc}
\hline Test Step & $\begin{array}{c}\text { Calculated UDS } \\
\text { Concentration }(\mathrm{wt} \%)\end{array}$ & $\begin{array}{c}\text { Measured UDS } \\
\text { Concentration (wt } \%)\end{array}$ \\
\hline Initial Slurry & 5.0 & not measured \\
Low-Solids Matrix Test & 5.4 & 6.2 \\
Initial Dewater Attempt & 32.6 & 22.0 \\
High-Solid Matrix Test & 15.9 & 15.5 \\
\hline
\end{tabular}

No 2-ft scale tests were performed under the current scope of work. Instead, 2-ft scale results of AV/TMP matrix tests carried under Simulant Development, TP-RPP-WTP-469, were employed to facilitate scale-up comparisons against the 8 -ft test data. The reference 2-ft scale test employed for the comparisons herein are described in detail in Section 4 of WTP-RPT- $183^{(\text {b) }}$ and include tests P3 and P4 for the simulant sludge solids and blended simulant slurries, respectively, in this report. The conditions tested in the 2-ft scale experiments match those listed in Table 6.1. Unlike the 8-ft scale tests, the CUF

(a) Note that the typical variation in a 5 -wt $\%$ UDS measurement is $\pm 1-w t \%$ (or $20 \%$ relative percent variation).

(b) RL Russell, HD Smith, JM Billing, RA Peterson, and DE Rinehart. 2008. Development and Demonstration of Ultrafiltration Simulants. WTP-RPT-183, Pacific Northwest National Laboratory, Richland, Washington. 
slurry pump provided sufficient power to achieve all AV/TMP set points. Table 6.5 lists the calculated and measured UDS concentrations for the low-solids and high-solids matrix tests in P3 and P4. Calculations assume a $5 \mathrm{wt} \%$ initial slurry UDS concentration.

Table 6.5. UDS concentrations Examined by the Reference 2-ft Scale Tests

\begin{tabular}{clcc}
\hline & Test Step & $\begin{array}{c}\text { Calculated UDS } \\
\text { Concentration } \\
\text { Test }\end{array}$ & $\begin{array}{c}\text { Measured UDS } \\
\text { Concentration } \\
(\mathrm{wt} \%)\end{array}$ \\
\hline P3 - Simulant Sludge Solids Slurry & Low-Solids Matrix Test & 5.2 & 4.1 \\
& High-Solid Matrix Test & 27.9 & not measured \\
P4 - Blended Simulant Slurry & Low-Solids Matrix Test & 5.1 & 5.2 \\
& High-Solid Matrix Test & 30.4 & not measured \\
\hline
\end{tabular}

Table 6.6 compares the UDS concentrations achieved in the 2-ft and 8-ft filter tests. The listed concentrations are based on calculated values of UDS concentration. Concentrations tested for the lowsolids matrix generally match well. In contrast, there are large disparities between the 2-ft and 8-ft UDS concentrations tested for the high-solids matrix tests. These differences result from the need to dilute the slurry in the 8-ft filter tests to overcome slurry pumping issues.

Table 6.6. Comparison of Calculated Concentrations Achieved in 2-ft and 8-ft Tests

\begin{tabular}{clcc}
\hline & AV/TMP Test & $\begin{array}{c}\text { 2-ft UDS } \\
\text { Concentration } \\
(\mathrm{wt} \%)\end{array}$ & $\begin{array}{c}\text { 8-ft UDS } \\
\text { Concentration } \\
(\mathrm{wt} \%)\end{array}$ \\
\hline Slurry & Low-Solids Matrix Test & 5.2 & 5.4 \\
Simulant Sludge Solids & High-Solid Matrix Test & 27.9 & 20.2 \\
& Low-Solids Matrix Test & 5.1 & 5.4 \\
& High-Solid Matrix Test & 30.4 & 15.9 \\
\hline
\end{tabular}

\subsection{Analysis of AV/TMP Scale-Up Test Filtration Data}

Test data derived for both simulant sludge solids and blended simulant slurries were collected and interpreted by the CUF DACS. The DACS provides measurement summary files that include the operational parameters listed in Table 6.7 at a given date and time. 
WTP-RPT-168, Rev 0

Table 6.7. Filtration test Measurement Parameters Provided by the CUF DACS

\begin{tabular}{ll}
\hline \multicolumn{1}{c}{ Parameter } & \multicolumn{1}{c}{ Units } \\
\hline Slurry Reservoir Temperature & ${ }^{\circ} \mathrm{C}$ \\
Permeate Pressure & $\mathrm{psig}$ \\
Filter Inlet Pressure & $\mathrm{psig}$ \\
Filter Outlet Pressure & $\mathrm{psig}$ \\
Filter TMP & $\mathrm{psid}$ \\
Volumetric Slurry Flow & $\mathrm{GPM}$ \\
Filter AV & $\mathrm{ft} / \mathrm{s}$ \\
Permeate Flow & $\mathrm{mL} / \mathrm{min}$ \\
Permeate Density & $\mathrm{g} / \mathrm{mL}$ \\
\hline GPM = gallons per minute & \\
\hline
\end{tabular}

For cross-flow filtration, filter flux is defined as:

$$
J=\frac{Q_{\text {permeate }}}{A_{\text {filter }}}
$$

where $J$ is the filter flux (GPM/ $\left.\mathrm{ft}^{2}\right), Q_{\text {permeate }}$ is the volumetric permeate flow (GPM), and $A_{\text {filter }}$ is the filtration surface area $\left(\mathrm{ft}^{2}\right)$. The filter area is assumed as the inside area of the filter element, which is defined as:

$$
A_{\text {filter }}=\pi D_{i, \text { filter }} L_{\text {filter }}
$$

where $D_{i, \text { filter }}$ is the filter element inside diameter, and $L_{\text {filter }}$ is the filter element length.

The permeate volumetric flow rate and/or filter flux is corrected for deviations in slurry temperature from the target test temperature (typically $25^{\circ} \mathrm{C}$ ). In WTP-RPT- $043,{ }^{(a)}$ the correction correlation for both permeate flow rate and flux at a given temperature $\mathrm{T}$ (in $\mathrm{K}$ ) is defined as:

$$
\begin{aligned}
Q_{25{ }^{\circ} \mathrm{C}} & =Q_{T} \exp \left[\beta\left(\frac{1}{T}-\frac{1}{298}\right)\right] \\
J_{25^{\circ} \mathrm{C}} & =J_{T} \exp \left[\beta\left(\frac{1}{T}-\frac{1}{298}\right)\right]
\end{aligned}
$$

(a) JGH Geeting, RT Hallen, LK Jagoda, AP Poloski, RD Scheele, DR Weier. 2003. Filtration, Washing, and Caustic Leaching of Hanford Tank AZ-101 Sludge. WTP-RPT-043, Rev. 1, Pacific Northwest National Laboratory, Richland, Washington. 
Here, $\beta$ is a positive constant and, as defined in WTP-RPT-043, is $2500 \mathrm{~K} . Q_{T}$ and $J_{T}$ are the uncorrected measured permeate flow rate and flux at a temperature $\mathrm{T}$, respectively. Finally $Q_{25^{\circ} \mathrm{C}}$ and $J_{25^{\circ} \mathrm{C}}$ are the temperature corrected flow rate and flux to $25^{\circ} \mathrm{C}$ (or $298 \mathrm{~K}$ ).

The pressure drop across the filter is commonly called transmembrane pressure (TMP). It is calculated in these tests to be:

$$
T M P=\Delta P_{m}=\frac{\left(P_{\text {inlet }}+P_{\text {outlet }}\right)}{2}-P_{\text {permeate }}
$$

where $P_{\text {inlet }}$ is the pressure at the filter inlet, $P_{\text {outlet }}$ is the pressure at the filter outlet, and $P_{\text {permeate }}$ is the pressure at the permeate side of the filter.

The AV inside the filter is calculated by dividing the volumetric slurry flow of the filter by the cross section area of the inside diameter of the filter:

$$
A V=\frac{Q_{\text {slurry }}}{S_{a}}=\frac{Q_{\text {slurry }}}{\frac{\pi}{4} D_{i, \text { filter }}^{2}}
$$

where $S_{a}$ is the cross sectional area of the axial flow and $Q_{\text {slurry }}$ is the volumetric slurry flow rate in the axial direction.

Overall filter behavior is modeled by the Darcy equation, which describes filter flux as:

$$
J=\frac{\Delta P_{m}}{\mu R_{m}}
$$

where $\Delta P_{m}$ is the pressure drop across filter membrane, $\mu$ is the viscosity of the permeate, and $R_{m}$ is the overall resistance of the filter membrane.

The overall filter resistance term is a sum of the resistance of the actual filter, the resistance of the filter cake that forms on the surface of the filter, and the resistance due to fouling of the filter. For dilute slurries and when turbulent flow conditions exist, the filter resistance is usually constant and the TMP and permeate viscosity are the controlling operational parameters. At higher solids concentrations, the slurry's flow properties change, and the filter cake resistance becomes more significant. When this occurs, the filter cake resistance becomes strongly dependent on system operational properties like AV and slurry concentration. Under these circumstances, treatment of filtration data against the Darcy equation is complicated by the need to account for the dependence of filter cake resistance on AV and slurry concentration. Eventually, the slurry can only be dewatered to a maximum UDS concentration limit at a given TMP. This limit is known as the gel concentration. As the simulant slurry's solid concentration approaches the gel concentration, the filter flux can be described as

$$
J=k \cdot \log \left[\frac{C_{s}}{C_{g}}\right]
$$


where $C_{s}$ is the slurry UDS concentration, $C_{g}$ is the slurry gel concentration at a given TMP, and $k$ is a constant for a given TMP and AV (note that $\mathrm{k}$ is a negative value).

Each one of the CUF operational parameters (i.e., slurry flow and pressure measurements) is recorded at 1 -min intervals and represents the average of 24 point measurements made every $2.5 \mathrm{sec}$. Application of equations 6.1 to 6.5 allows calculation of TMP, AV, and temperature-corrected flow rate and flux at each 1-min interval. As indicated in Table 6.1, each test condition AV/TMP was held for approximately 1-hour. As such, analysis yielded approximately 60 sets of AV, TMP, and $J_{25^{\circ} \mathrm{C}}$ data points at each test condition for all tests. To facilitate comparison of flux data between low- and high-solids concentrations for 2-ft and 8-ft filters, only the "final" or "ending" AV, TMP, and $J_{25^{\circ} \mathrm{C}}$ associated with each condition was considered. These "final" conditions were determined by averaging the last six AV, TMP, and $J_{25^{\circ} \mathrm{C}}$ measured at each condition.

The dewatering behavior of the test slurries is also considered on $2-\mathrm{ft}$ and $8-\mathrm{ft}$ filters. For these comparisons, the corrected filter flux (i.e., flux reduced to $25^{\circ} \mathrm{C}-\mathrm{J}_{25^{\circ} \mathrm{C}}$ as per Equation 6.3) is plotted as a function of UDS concentration. The UDS concentration is determined through careful accounting of the slurry and permeate masses added to or removed from the filter circulation loop. As such, UDS concentration reported in the dewatering curve plots are "calculated." The initial and final slurry concentrations reported for dewatering correspond to the calculated UDS values listed in Table 6.3, Table 6.4, and Table 6.5.

\subsection{Scale-Up Test Results}

The following sections discuss the results of filter scale-up testing. First, results for the simulant sludge solids slurry AV/TMP testing are presented. Next, the results of the blended simulant slurry AV/TMP tests are introduced and discussed. Finally, a summary of observations and conclusions for both tests is given.

\subsubsection{Simulant Sludge Solids Scale-Up Test Results}

Results of the simulant sludge solids scale-up testing are shown in Table 6.8 and Table 6.9 and Figure 6.1 to Figure 6.5. In addition to the results of the 8-ft filter element testing, the results of 2-ft filter element testing (from WTP-RPT-183) are included for comparison. 
WTP-RPT-168, Rev 0

Table 6.8. Tabular Results for the Low-Solids Test Matrix Simulant Sludge Solids Slurry Scaling Test

\begin{tabular}{ccccccccccc}
\hline $\begin{array}{c}\text { Test } \\
\begin{array}{c}\text { Condition } \\
\text { Number }\end{array}\end{array}$ & \multicolumn{2}{c}{ Targets } & \multicolumn{3}{c}{ 2-ft Test (5.2 wt\% UDS) } & \multicolumn{3}{c}{ 8-ft Test (5.4 wt\% UDS) } \\
\hline & $\begin{array}{c}\mathrm{AV} \\
{[\mathrm{ft} / \mathrm{s}]}\end{array}$ & $\begin{array}{c}\text { TMP } \\
{[\mathrm{psid}]}\end{array}$ & $\begin{array}{c}\mathrm{AV} \\
{[\mathrm{ft} / \mathrm{s}]}\end{array}$ & $\begin{array}{c}\text { TMP } \\
{[\mathrm{psid}]}\end{array}$ & $\begin{array}{c}\text { Flux } \\
{\left[\mathrm{GPM} / \mathrm{ft}^{2}\right]}\end{array}$ & $\begin{array}{c}\mathrm{APD}^{(\mathrm{a})} \\
{[\mathrm{psid} / \mathrm{ft}]}\end{array}$ & $\begin{array}{c}\mathrm{AV} \\
{[\mathrm{ft} / \mathrm{s}]}\end{array}$ & $\begin{array}{c}\text { TMP } \\
{[\mathrm{psid}]}\end{array}$ & $\begin{array}{c}\text { Flux } \\
{\left[\mathrm{GPM} / \mathrm{ft}^{2}\right]}\end{array}$ & $\begin{array}{c}\text { APD } \\
{[\mathrm{psid} / \mathrm{ft}]}\end{array}$ \\
\hline 1 & 13 & 40 & 13.0 & 40.5 & 0.061 & 0.7 & 13.0 & 40.0 & 0.054 & 1.0 \\
2 & 9 & 40 & 9.0 & 40.2 & 0.035 & 0.2 & 9.0 & 41.6 & 0.035 & 0.7 \\
3 & 17 & 40 & 17.0 & 40.8 & 0.072 & 1.3 & $13.5^{(\mathrm{b})}$ & $39.8^{(\mathrm{b})}$ & $0.056^{(\mathrm{b})}$ & 1.0 \\
4 & 13 & 20 & 13.0 & 20.3 & 0.046 & 0.8 & 13.1 & 20.0 & 0.043 & 1.0 \\
5 & 13 & 60 & 13.0 & 59.4 & 0.048 & 0.8 & $11.8^{(\mathrm{b})}$ & $60.0^{(\mathrm{b})}$ & $0.046^{(\mathrm{b})}$ & 1.0 \\
6 & 13 & 40 & 13.0 & 40.2 & 0.043 & 1.0 & 13.0 & 40.2 & 0.053 & 1.1 \\
\hline
\end{tabular}

(a) $\mathrm{APD}=$ axial pressure drop per length of filter element across the filter element (accurate to $\sim 0.5 \mathrm{psid} / \mathrm{ft}$ for the 2 -ft elements and $\sim 0.2$ psid for the 8 -ft element).

(b) Indicates tests where the target AV could not be achieved (also highlighted).

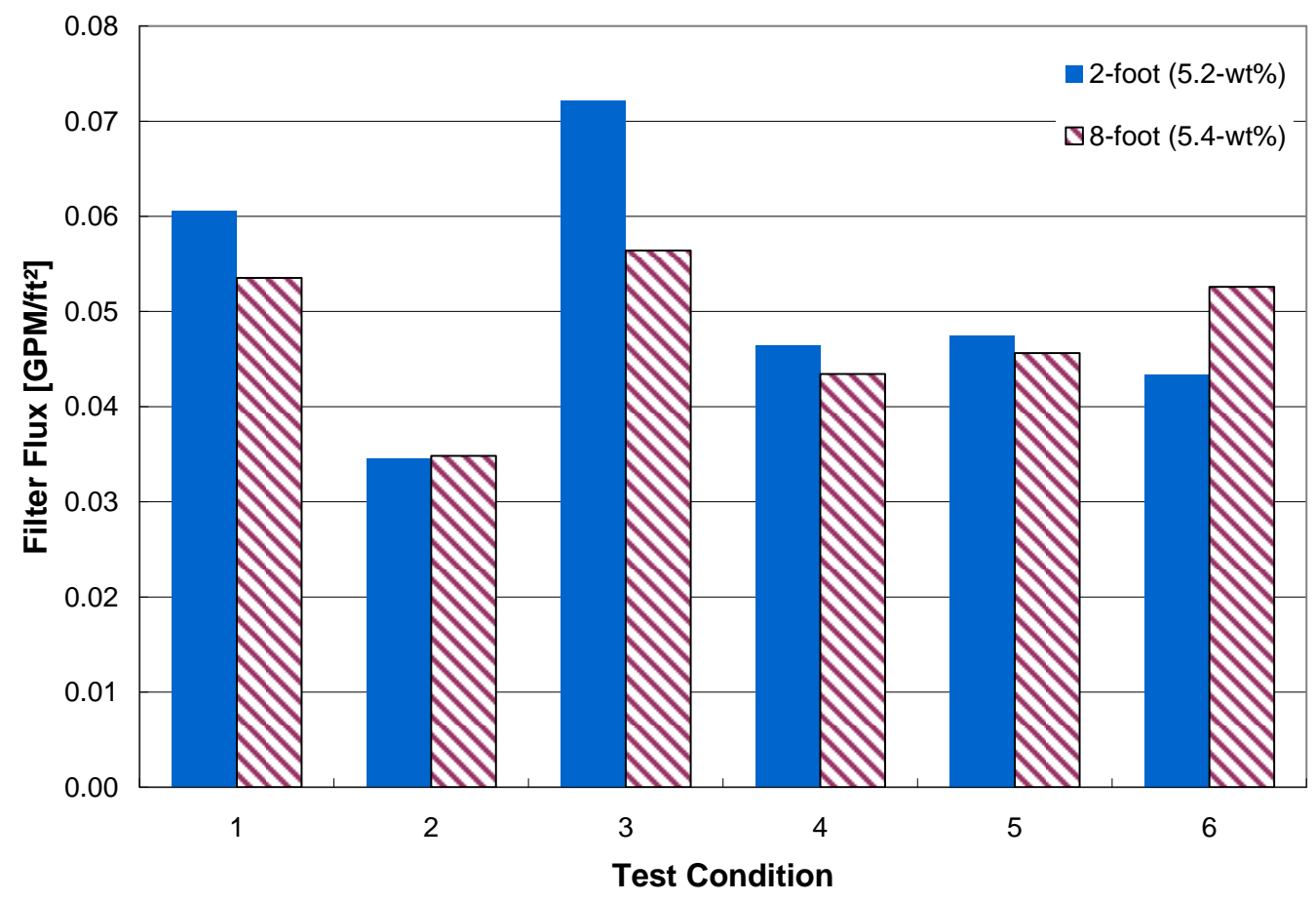

Figure 6.1. Graphical Results for the Low-Solids Text Matrix Simulant Sludge Solids Slurry Scaling Test 
WTP-RPT-168, Rev 0

\subsubsection{Low-Solids Matrix Test Results}

The final permeate fluxes for the low-solids (5.4 wt \% UDS) matrix filtration test run with the simulant sludge solids slurry are shown in Table 6.8 and Figure 6.1 for each test condition. For most test conditions, the measured flux results for the 8-ft filter test compare well with those for the 2 -ft filter (generally within 10\%). Significantly higher deviations did occur at test conditions 3 and 6 . These test conditions correspond to AV/TMP targets of 17/40 and 13/40, respectively. Condition 17/40 exceeded the pump capacity during testing of the 8-ft filter, resulting in axial velocities of only $13.5 \mathrm{ft} / \mathrm{s}$ instead of the target $17 \mathrm{ft} / \mathrm{s}$. Because of the lower AV achieved in the 8-ft test (run at the lower $13.5 \mathrm{ft} / \mathrm{s}$ ) a lower flux is expected relative to that measured in the 2-ft filter test (run at $17 \mathrm{ft} / \mathrm{s}$ ) and meaningful comparison of filter flux data between the 8 - $\mathrm{ft}$ and 2 -ft filters at condition 3 is not possible.

As indicated in preceding paragraphs, the target AV for conditions 3 and 5 could not be achieved during the 8-ft filter testing. Target AVs could not be achieved for these two conditions during the 8- $\mathrm{ft}$ filter testing because the pressure drop across the filter exceeded the pumping capacity (because of a pressure relief valve (PRV) - see Section 8.0). The highest achievable AV at $40 \mathrm{psid}$ was $13.5 \mathrm{ft} / \mathrm{s}$. At 60 psid, the greatest achievable AV was $11.8 \mathrm{ft} / \mathrm{s}$. The difference between the target and highest achievable AV was much greater (on a percentage basis) for test condition 3 than for test condition 5 . The achievable AV was $21 \%$ below the target for test condition 3 and $9 \%$ below for condition 5 . The reduced $\mathrm{AV}$ in the 8-ft filter during test condition 3 resulted in a reduction in flux (compared to the 2-ft filter) of $22 \%$. For test condition 5, the smaller reduced AV did not result in a reduced flux for the 8 -ft filter relative to the 2 -ft filter.

For test condition 6, the AV/TMP target of $13 / 40$ was achieved in both tests. As a result, the cause of the inconsistency between the fluxes measured for the 2-ft and 8-ft filter elements is not immediately clear. The most probable cause is a difference in fouling between the 2-ft and 8- $\mathrm{ft}$ filters. Specifically, a transient decrease in the 2-ft filter performance was observed during testing: the initial 13/40 condition showed a flux of $0.061 \mathrm{GPM} / \mathrm{ft}^{2}$ whereas the final $13 / 40$ condition showed a lower flux of $0.043 \mathrm{GPM} / \mathrm{ft}^{2}$. This decrease is suspected to have resulted from 1) differences in the initial state of filter cleanliness (resulting in higher initial flux for the 2-ft scale test) and 2) filter fouling in the 2-ft scale that was not observed in the 8 - $\mathrm{ft}$ test. In comparison, the initial $40 / 13$ filter flux on the 8 - $\mathrm{ft}$ system, $0.054 \mathrm{GPM} / \mathrm{ft}^{2}$, compares well to the final $13 / 40$ filter flux of $0.053 \mathrm{GPM} / \mathrm{ft}^{2}$. The absence of flux decrease (because of fouling) in the 8 - $\mathrm{ft}$ test between the starting and ending test conditions suggests that the $\sim 9 \mathrm{~L}$ volume of slurry does not contain sufficient fines to result in significant fouling of the 8-ft filter. It also highlights the importance of slurry volume-to-filter surface area in filter flux testing.

Figure 6.2 shows the dependence of permeate flux on AV and TMP for both the 2-ft and 8-ft filter tests for the simulant sludge solids slurry with a low-solids concentration. For both filter lengths, permeate flux illustrates a linear correlation with AV, whereas TMP appears to have little correlation with flux. This indicates that for the simulant sludge solids slurry with a low solids concentration, cake formation and thickness dynamics control filtration. As such, the current tests are a meaningful candidate to examine filter-length scaling effects. As stated in the introduction to Section 6.0, 8-ft filter elements provide greater length over which solid slurry particles can migrate to the filter wall and form a solids cake. Of concern is cake formation, which, combined with transport of that filter cake axially along the filter element, may yield a build-up of solids in the 8-ft element greater than that possible in the 2-ft element. This increased cake build-up would be expected to decrease the filter flux in longer filter elements. With regard to the results in Figure 6.2, the filtration performance of the simulant sludge solids 
slurry with a low-solids concentration appears to scale directly with length such that no change in the AV/TMP behavior is observed between 2-foot and 8-foot scales.
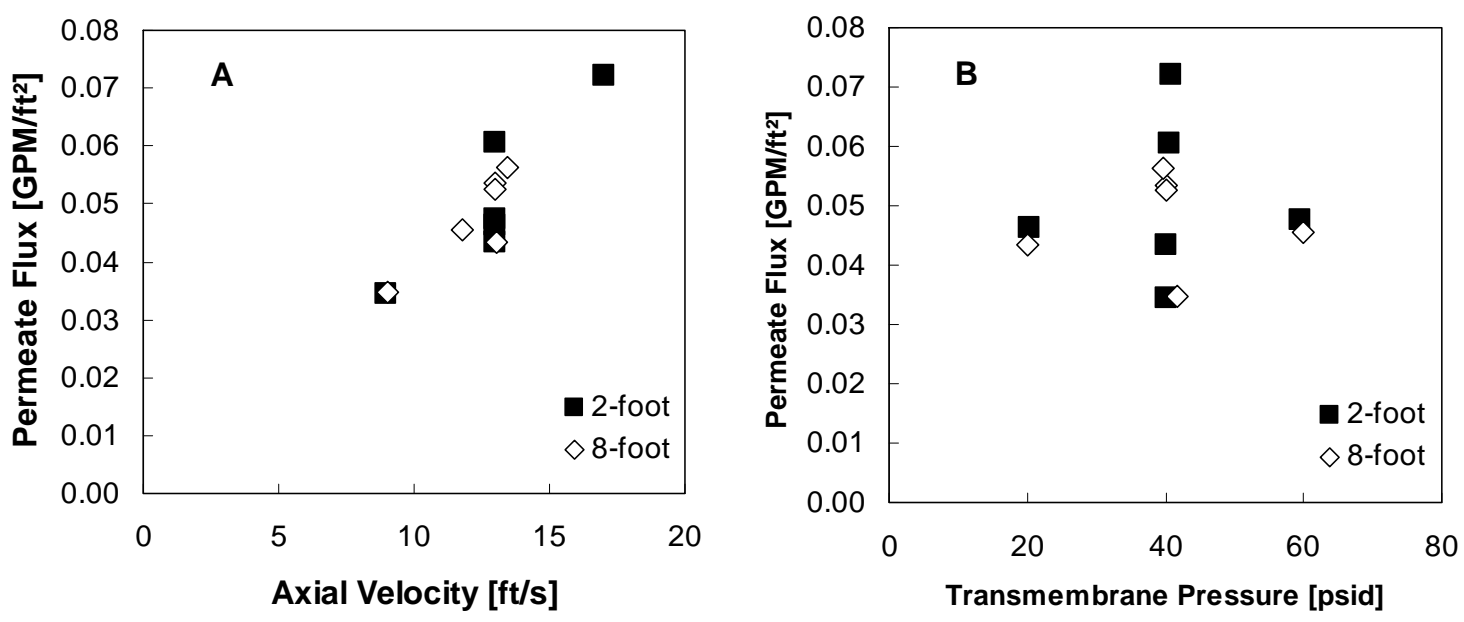

Figure 6.2. Filtration Results for the Low-Solids Matrix Simulant Sludge Solids Scaling Test Showing the Flux Dependence on A) AV and B) TMP

\subsubsection{Simulant Sludge Solids Slurry Dewatering}

The dewatering performance of the simulant sludge solids slurry on the 2-ft and 8-ft filters is shown in Figure 6.3. The graph shows two dewatering regimes. The change in flux with UDS concentration is minor over both 2 - $\mathrm{ft}$ and 8 -ft scale tests between $5-\mathrm{wt} \%$ and $9-\mathrm{wt} \%$ UDS. Typically, the flux behavior in this region would be associated primarily with the resistance of the filter alone, and cake effects would be assumed minimal. However, this contradicts the observation of strong AV impacts in Figure 6.2. Based on both Figure 6.2 and Figure 6.3, the filtration regime between 5-wt $\%$ to 9 -wt $\%$ UDS is best characterized as cake controlled with a minor sensitivity to slurry solids concentrations. At UDS concentrations above $9-\mathrm{wt} \%$, the flux decreases sharply with increasing solids concentration. The flux appears to behave as that for a system where the solids concentration is approaching the gel concentration (see Equation 6.7). For this second regime, the filter cake and those process parameters that impact the cake thickness are still expected to control the flux behavior.

As discussed in the preceding paragraphs, the initial (low-solids concentration) dewatering flux on the 2 -ft filter is lower relative to the 8 -ft and is likely a result of 1) errors in the estimates of the initial slurry UDS concentration and/or 2) reduced fouling on the 8- $\mathrm{ft}$ scale because of the lower ratio of slurry fines to filter area.

To assess the impact of error in the estimation of starting slurry concentration on the dewatering curve, two additional data sets were added to Figure 6.3. The two data sets include adjustments assuming an error in the initial slurry solids concentration of $\pm 1 \mathrm{wt} \%$. The results of these adjustments are shown as the lines on Figure 6.3 and correspond to a $4 \mathrm{wt} \%$ UDS and $6 \mathrm{wt} \%$ UDS starting (initial) slurry. By assuming that the initial slurry solids concentration was $4 \mathrm{wt} \%$, the fit between the 8 - $\mathrm{ft}$ filter element and the 2 - $\mathrm{ft}$ filter element is nearly coincident in the linear region of the dewatering curve. Based on a comparison of measured UDS to assumed UDS in Table 6.3, Table 6.4, and Table 6.5, a $\pm 1 \mathrm{wt} \%$ 
deviation in slurry UDS concentration is believable. As such, if potential errors in the estimates of the initial slurry solids concentration are considered, the dewatering performance of 2 -ft and 8 - $\mathrm{ft}$ filter elements appear comparable.

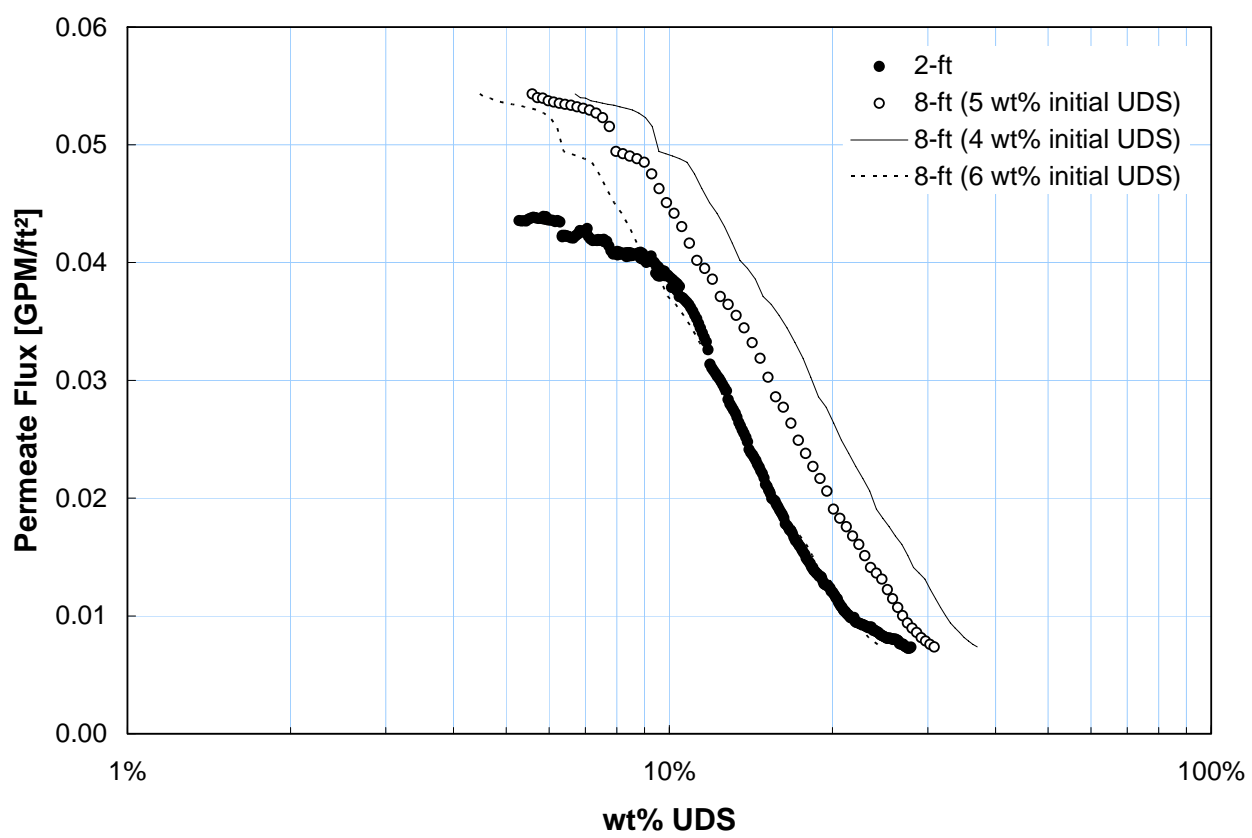

Figure 6.3. Dewatering Curve for Simulant Sludge Solids Slurry on 2-ft and 8-ft CUF Filter Elements Based on an Assumed $5 \mathrm{wt} \%$ Initial Slurry UDS Concentration. Dashed lines show the impact of $\mathrm{a} \pm 1 \mathrm{wt} \%$ difference in initial slurry concentration on the calculated dewatering curve for the 8 -ft filter.

The impact of difference in the ratio of slurry volume to filter surface area between 2-ft and 8-ft scale tests must also be considered, as this difference can impact the dewatering behavior. As discussed in WTP-RPT-183, fines loading changes the nature of the dewatering curve. Section 4 of WTP-RPT-183 describes a study comparing aged slurry dewatering to fresh slurry dewatering. The fraction of fines in the aged slurry is reduced relative to that of the fresh slurry as a result of Ostwald Ripening. As shown by Figure 4.13 in WTP-RPT-183, the aged slurry shows a higher initial filter flux and a "larger" dewatering slope (i.e., a more negative k via Eq. 6.7). In this same aging study, comparison of the dewatering curves found the same gel concentration.

For the current data, the 8-ft dewatering curve should show trends similar to those observed in the aged simulant because of its lower fines-to-filter surface area relative to the 2 - $\mathrm{ft}$ scale test. As expected, the flux of the 8-ft filter is higher than that of the 2-ft filter throughout the dewatering operation. On the other hand, the slopes of the dewatering curve (permeate flux versus the solids concentration in wt\%) on the 2-ft and 8-ft filter elements are comparable: $-0.090 \mathrm{GPM} / \mathrm{ft}^{2}$ for the 2 - $\mathrm{ft}$ versus $-0.083 \mathrm{GPM} / \mathrm{ft}^{2}$ for the 8 -ft test. As a result, the dewatering curves do not converge to the same gel concentration (as the curves did in the aging test reported in WTP-RPT-183). From linear regression analysis of the dewatering curves against Equation 6.7, the limiting gel concentrations for 2 -ft and 8 - $\mathrm{ft}$ data are $26.6 \mathrm{wt} \%$ and $34.8 \mathrm{wt} \%$, respectively. Because the dewatering curves for the 2 - $\mathrm{ft}$ and 8 - $\mathrm{ft}$ test scale do not agree with all of the expected trends derived from the aging study in WTP-RPT-183, there is uncertainty as to how 
comparable the 2-ft and 8-ft test scales are with respect to each other. While a tentative conclusion indicating the absence of scaling effects can be made on the error analysis of the initial slurry UDS, an additional study of $2-\mathrm{ft}$ to $8-\mathrm{ft}$ scaling is required to eliminate uncertainty with respect to the impact of fewer fines in the 8 -ft scaling test.

\subsubsection{High Solids Matrix Test Results}

Table 6.9 and Figure 6.4 show the ending permeate flux for the high-solids matrix filtration test run with a simulant sludge solids slurry. Because of the increased pressure drop across the 8-ft filter element, the pump did not have enough power to effectively circulate the dewatered slurry at a solids concentration comparable to that tested in the 2-ft filter test. To overcome this problem, a portion of the previously removed permeate was used to dilute the dewatered slurry to a pumpable solids concentration. As a result of dilution of the 8 - $\mathrm{ft}$ test slurry, the solids concentrations for 2 -ft and 8 - $\mathrm{ft}$ filtration tests are not comparable. The results in Table 6.9 and Figure 6.4 indicate that the $20.2 \mathrm{wt} \%$ slurry used for 8 -ft testing yielded higher permeate fluxes than the $27.9 \mathrm{wt} \%$ slurry used in 2-ft testing. The lower filter flux observed in all 2 -ft test conditions relative to the 8-ft results is expected given 1) the higher UDS concentration of the 2-ft and 2) the significant flux decrease that occurs for test concentration beyond $10 \mathrm{wt} \%$ (see Figure 6.3).

Even after dilution of the 8-ft test slurry, the pumping capacity during the 8-ft tests was still exceeded at conditions 3 and 5 during the high-solids matrix. The highest achievable velocities for conditions 3 and 5 were $14.2 \mathrm{ft} / \mathrm{s}$ and $12.6 \mathrm{ft} / \mathrm{s}$, respectively. For test condition 3, the actual AV used in the test was $16 \%$ below the target 17 . For test condition 5, the AV achieved was $3 \%$ below the target of $13 \mathrm{ft} / \mathrm{s}$.

Table 6.9. Tabular Results for the High-Solids Text Matrix Simulant Sludge Solids Slurry Scaling Test.

\begin{tabular}{|c|c|c|c|c|c|c|c|c|c|c|}
\hline \multirow{2}{*}{$\begin{array}{c}\text { Test } \\
\text { Condition } \\
\text { Number }\end{array}$} & \multicolumn{2}{|c|}{ Targets } & \multicolumn{4}{|c|}{ 2-ft Test (27.9 wt\% UDS) } & \multicolumn{4}{|c|}{8 -ft Test (20.2 wt\% UDS) } \\
\hline & $\begin{array}{c}\mathrm{AV} \\
{[\mathrm{ft} / \mathrm{s}]}\end{array}$ & $\begin{array}{l}\text { TMP } \\
\text { [psid] }\end{array}$ & $\begin{array}{l}\mathrm{AV} \\
{[\mathrm{ft} / \mathrm{s}]}\end{array}$ & $\begin{array}{c}\text { TMP } \\
\text { [psid] }\end{array}$ & $\begin{array}{c}\text { Flux } \\
{\left[\mathrm{GPM} / \mathrm{ft}^{2}\right]}\end{array}$ & $\begin{array}{c}\mathrm{APD}^{(\mathrm{a})} \\
{[\mathrm{psid} / \mathrm{ft}]}\end{array}$ & $\begin{array}{l}\mathrm{AV} \\
{[\mathrm{ft} / \mathrm{s}]}\end{array}$ & $\begin{array}{c}\text { TMP } \\
\text { [psid] }\end{array}$ & $\begin{array}{c}\text { Flux } \\
{\left[\mathrm{GPM} / \mathrm{ft}^{2}\right]}\end{array}$ & $\begin{array}{c}\text { APD } \\
{[\mathrm{psid} / \mathrm{ft}]}\end{array}$ \\
\hline 1 & 13 & 40 & 12.9 & 39.7 & 0.009 & 2.7 & 13.0 & 40.5 & 0.018 & 1.6 \\
\hline 2 & 9 & 40 & 9.1 & 39.8 & 0.008 & 2.5 & 9.0 & 40.5 & 0.012 & 1.1 \\
\hline 3 & 17 & 40 & 16.8 & 40.1 & 0.016 & 3.4 & $14.2^{(\mathrm{b})}$ & $39.6^{(\mathrm{b})}$ & $0.022^{(b)}$ & 1.7 \\
\hline 4 & 13 & 20 & 13.0 & 20.5 & 0.010 & 2.1 & 12.9 & 20.1 & 0.018 & 1.2 \\
\hline 5 & 13 & 60 & 13.0 & 59.4 & 0.013 & 2.4 & $12.6^{(\mathrm{b})}$ & $59.9^{(\mathrm{b})}$ & $0.021^{(b)}$ & 1.6 \\
\hline 6 & 13 & 40 & 13.0 & 40.1 & 0.012 & 2.2 & 13.0 & 39.8 & 0.020 & 1.5 \\
\hline
\end{tabular}

(a) $\mathrm{APD}=$ axial pressure drop per length of filter element across the filter element (accurate to $\sim 0.5 \mathrm{psid} / \mathrm{ft}$ for the 2 -ft elements and $\sim 0.2$ psid for the 8 -ft element).

(b) Indicates tests where the target AV could not be achieved (also highlighted). 


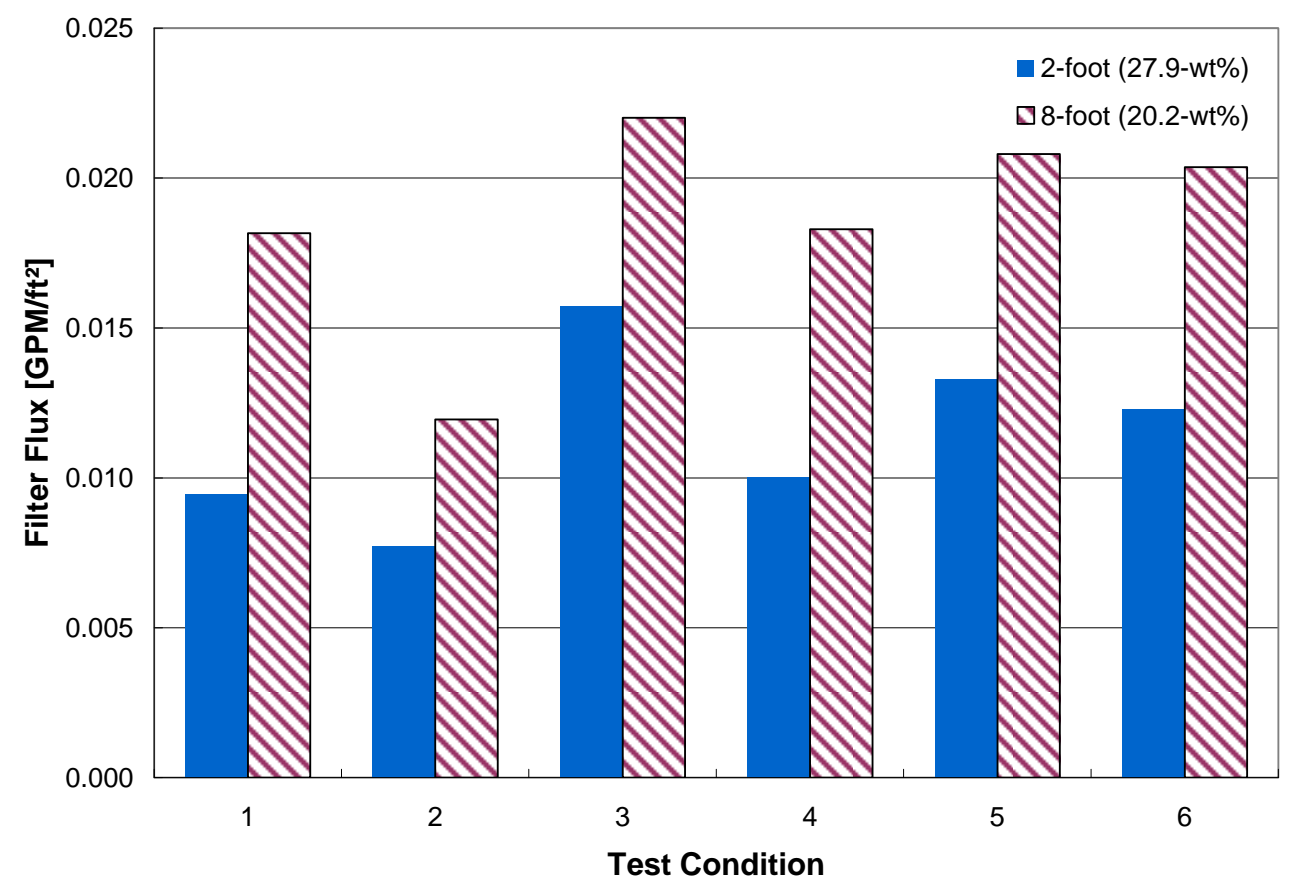

Figure 6.4. Graphical Results for the High-Solids Text Matrix Simulant Sludge Solids Slurry Scaling Test

Figure 6.5 shows the AV and TMP dependence for the high-solids matrix test. As was the case for the low-solids run, permeate flux illustrates a near-linear correlation with AV for both filter lengths. That is, an increase in AV from 9 to $13 \mathrm{ft} / \mathrm{s}$ appears to increase flux by $\sim 0.007 \mathrm{GPM} / \mathrm{ft}^{2}$ for both $2-\mathrm{ft}$ and 8 - $\mathrm{ft}$ filters during the high-solids matrix tests. This behavior is consistent with cake-controlled filtration. In contrast to the low-solids matrix test, increases in TMP during the high solids matrix test appear to improve filter performance over the entire TMP testing range of 20 to $60 \mathrm{psid}$. This is evidenced by increases in the filter flux at 60 psid relative to that at 20 psid. At the 2 -ft scale for high-solids, the increase in flux with TMP is $\sim 30 \%$, while at the 8 -ft scale for high-solids, the increase in flux with TMP is $\sim 15 \%$. The reduced increase in flux between 20 psid and 60 psid at the 8 -ft scale is indicative of the inability to reach target AV at 60 psid. For comparison, the low solids matrix only showed increases of $2 \%$ and $5 \%$ in filter flux when the TMP was increased from 20 psid to 60 psid.

The increased influence of TMP at higher UDS concentrations is difficult to rationalize. Prominent TMP effects are typically expected in membrane-controlled filtration where cake formation is minimal. As such, TMP effects are usually observed for dilute (low-solids concentrations) slurries. At higher solids concentration, cake formation is expected to overwhelm TMP effects. In contrast to these expectations, the behavior of the simulant sludge solids indicates little or no TMP at low solids and increased TMP impacts at high solids. This suggests that the simple model for AV and TMP influences described in this paragraph does not capture the full range of cake-formation dynamics observed for the current simulant (either on 2-ft or 8-ft scales). For the current test data, it can be speculated that increased cake thickness and resistance at high solids increase the importance (and effect) of TMP.

With respect to overall filter behavior, although the magnitude of flux between 2 -ft and 8-ft filter tests is different because the test employed different solids concentrations, both data sets show similar trends. Because the AV/TMP trends are similar, it can be tentatively concluded that the filter length has minimal 
impact on the AV/TMP functionality. It should be noted that this conclusion needs to be further verified by eliminating the difficulties of the current test, including the difference in 2 -ft and 8 -ft scale fines loading, limited pump capacity for 8-ft tests, and differences in achievable UDS concentrations.
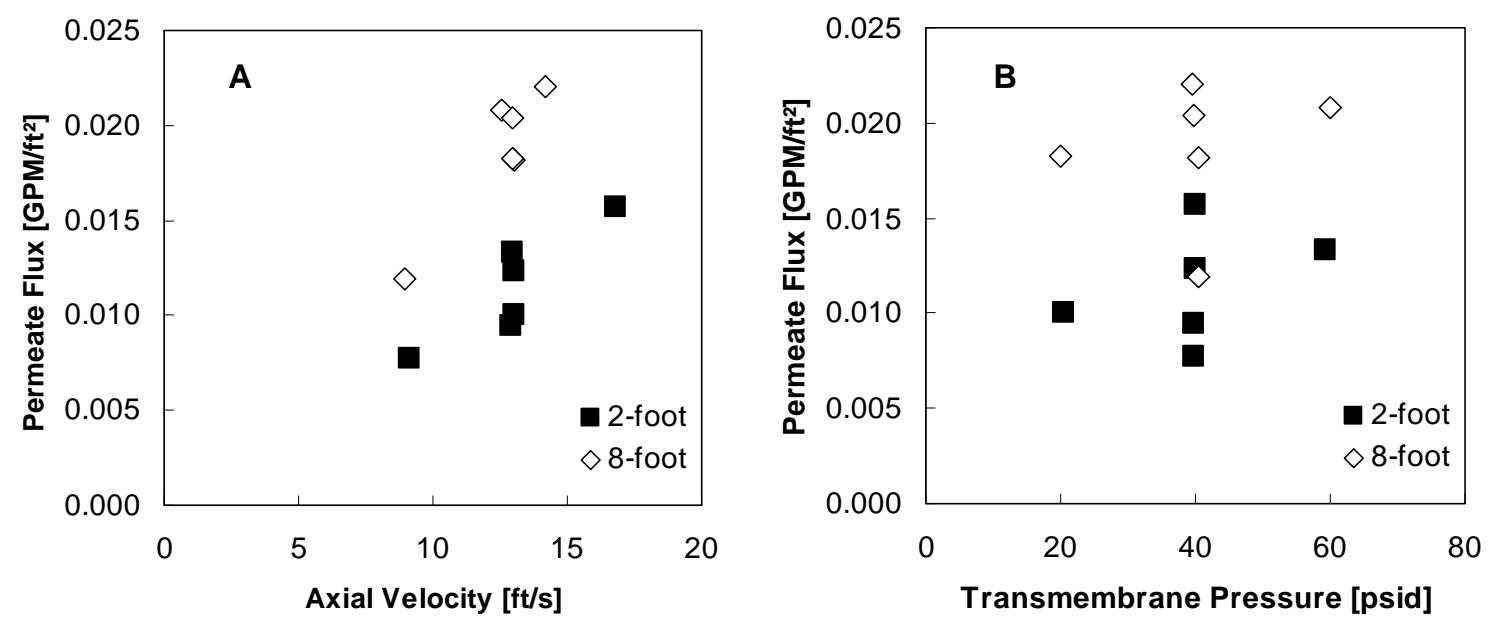

Figure 6.5. Filtration Results for the High-Solids Matrix Simulant Sludge Solids Scaling Test Showing the Flux Dependence on A) AV and B) TMP

In summary, results of the scaling tests conducted with a simulant sludge solids slurry indicate that the 2-ft and 8-ft filters exhibit comparable performance. Initial permeate flow rates appear to scale directly with filter length. Filtration mechanisms for both the 2-ft and 8-ft filter elements appear to be similar as the flux shows comparable AV and TMP dependences. One noticeable difference between the 2 - $\mathrm{ft}$ and 8-ft tests is the absence of transient filter flux decrease in the 8-ft test. Such a decrease is indicative of filter fouling and was observed in the 2-ft filter test. This suggests that fouling mechanisms may differ in the 2-ft and 8-ft tests; however, the 8-ft test used the same volume of slurry as the 2-ft test. Because the surface area-to-volume was not the same between the two tests, it is possible that the fines that cause the long-term decrease in filter flux in the 2-ft filter were simply not there to completely foul the 8-ft filter.

\subsubsection{Blended Simulant Scale-Up Test Results}

Results of the blended simulant slurry scale-up tests are shown in Table 6.10 and Table 6.11 and Figure 6.6 to Figure 6.10. In addition to the results of the 8 -ft filter element testing, results from the $2-\mathrm{ft}$ filter element testing are included for comparison.

\subsubsection{Low-Solids Matrix Test Results}

The final permeate fluxes for the low-solids matrix filtration test run with the blended simulant slurry are shown in Table 6.10 and Figure 6.6 for each test condition. During test condition 3 and 5, the capacity of the pump was exceeded during 8-ft scale testing, and the AV/TMP targets were not achieved. AVs of only 13.5 and 12.0 were achieved instead of the targets of 17 and 13 . These AVs are nearly the same as those measured in the 8-ft low-solids test matrix using the simulant sludge solids slurry. 
The 2-ft and 8-ft tests show slightly dissimilar permeate fluxes. Although the most significant differences occur for conditions 3 and 5 (where test conditions could not be reached in 8 -ft testing), conditions 1 and 2 show significant differences of $16 \%$ and $26 \%$, respectively. It appears that part of this difference results from differences in initial filter cleanliness and transient fouling of the 2-ft filter as the 2-ft and 8-ft fluxes for the final test cases, where target AV/TMP conditions were achieved, compare within $10 \%$. Fouling in the 2 - $\mathrm{ft}$ test manifests as a large (12\%) difference in flux for test conditions 1 and 6. In addition, the difference in 2-ft and 8-ft filter fluxes may also result, in part, from either 1) slight differences in as-prepared UDS concentrations of 2-ft and 8- $\mathrm{ft}$ test slurries and 2) differences in the initial state of filter cleanliness. Examination of the dewatering curves (see Section 6.3.2.2-Figure 6.8) indicates that the 8-ft filter flux is offset lower than the 2-ft data by a small but persistent $\sim 0.002 \mathrm{GPM} / \mathrm{ft}^{2}$ (or 3 to $4 \%$ of the total flux value). Such offsets are generally typical of differences in initial filter cleanliness. For the current test data set, the lower 8-ft filter flux observed during dewatering (Figure 6.8) is consistent with the lower flux observed in the 8-ft AV/TMP scale tests results (Table 6.10). Further, the initial fluxes for the freshly cleaned filter were measurably higher $\left(0.094 \mathrm{GPM} / \mathrm{ft}^{2}\right.$ for the first 10 minutes) for the 2 - $\mathrm{ft}$ filter element in comparison to the 8 - $\mathrm{ft}$ filter element $\left(0.084 \mathrm{GPM} / \mathrm{ft}^{2}\right.$ for the first 10 minutes). As such, it is likely that part of the difference between $2-\mathrm{ft}$ and 8 -ft scale fluxes shown in Table 6.10 and Figure 6.6 results from differences in filter cleanliness at the start of the test.

Table 6.10. Tabular Results for the Low-Solids Text Matrix Blended Simulant Slurry Scaling Test

\begin{tabular}{ccccccccccc}
\hline $\begin{array}{c}\text { Test } \\
\begin{array}{c}\text { Condition } \\
\text { Number }\end{array}\end{array}$ & \multicolumn{2}{c}{ Targets } & \multicolumn{3}{c}{ 2-ft Test (5.1 wt\% UDS) } & \multicolumn{3}{c}{ 8-ft Test (5.4 wt\% UDS) } \\
\hline & $\begin{array}{c}\text { AV } \\
{[\mathrm{ft} / \mathrm{s}]}\end{array}$ & $\begin{array}{c}\text { TMP } \\
{[\mathrm{psid}]}\end{array}$ & $\begin{array}{c}\text { AV } \\
{[\mathrm{ft} / \mathrm{s}]}\end{array}$ & $\begin{array}{c}\text { TMP } \\
{[\mathrm{psid}]}\end{array}$ & $\begin{array}{c}\text { Flux } \\
{\left[\mathrm{GPM} / \mathrm{ft}^{2}\right]}\end{array}$ & $\begin{array}{c}\mathrm{APD}^{(\mathrm{a})} \\
{[\mathrm{psid} / \mathrm{ft}]}\end{array}$ & $\begin{array}{c}\text { AV } \\
{[\mathrm{ft} / \mathrm{s}]}\end{array}$ & $\begin{array}{c}\text { TMP } \\
{[\mathrm{psid}]}\end{array}$ & $\begin{array}{c}\text { Flux } \\
{\left[\mathrm{GPM} / \mathrm{ft}^{2}\right]}\end{array}$ & $\begin{array}{c}\text { APD } \\
{[\mathrm{psid} / \mathrm{ft}]}\end{array}$ \\
\hline 1 & 13 & 40 & 13.0 & 40.3 & 0.072 & 0.7 & 13.0 & 40.0 & 0.060 & 1.1 \\
2 & 9 & 40 & 9.0 & 40.4 & 0.054 & 0.2 & 9.0 & 40.8 & 0.040 & 0.7 \\
3 & 17 & 40 & 16.9 & 40.3 & 0.082 & 1.5 & $13.5^{(\mathrm{b})}$ & $40.3^{(\mathrm{b})}$ & $0.062^{(\mathrm{b})}$ & 1.1 \\
4 & 13 & 20 & 13.0 & 20.3 & 0.049 & 0.8 & 13.0 & 19.9 & 0.044 & 1.0 \\
5 & 13 & 60 & 13.0 & 60.9 & 0.072 & 0.8 & $12.0^{(\mathrm{b})}$ & $59.8^{(\mathrm{b})}$ & $0.051^{(\mathrm{b})}$ & 0.9 \\
6 & 13 & 40 & 13.0 & 40.2 & 0.064 & 0.6 & 13.0 & 40.1 & 0.057 & 1.0 \\
\hline
\end{tabular}

(a) $\mathrm{APD}=$ axial pressure drop per length of filter element across the filter element (accurate to $\sim 0.5 \mathrm{psid} / \mathrm{ft}$ for the 2 -ft elements and $\sim 0.2$ psid for the 8 -ft element).

(b) Indicates tests where the target AV could not be achieved (also highlighted). 
WTP-RPT-168, Rev 0

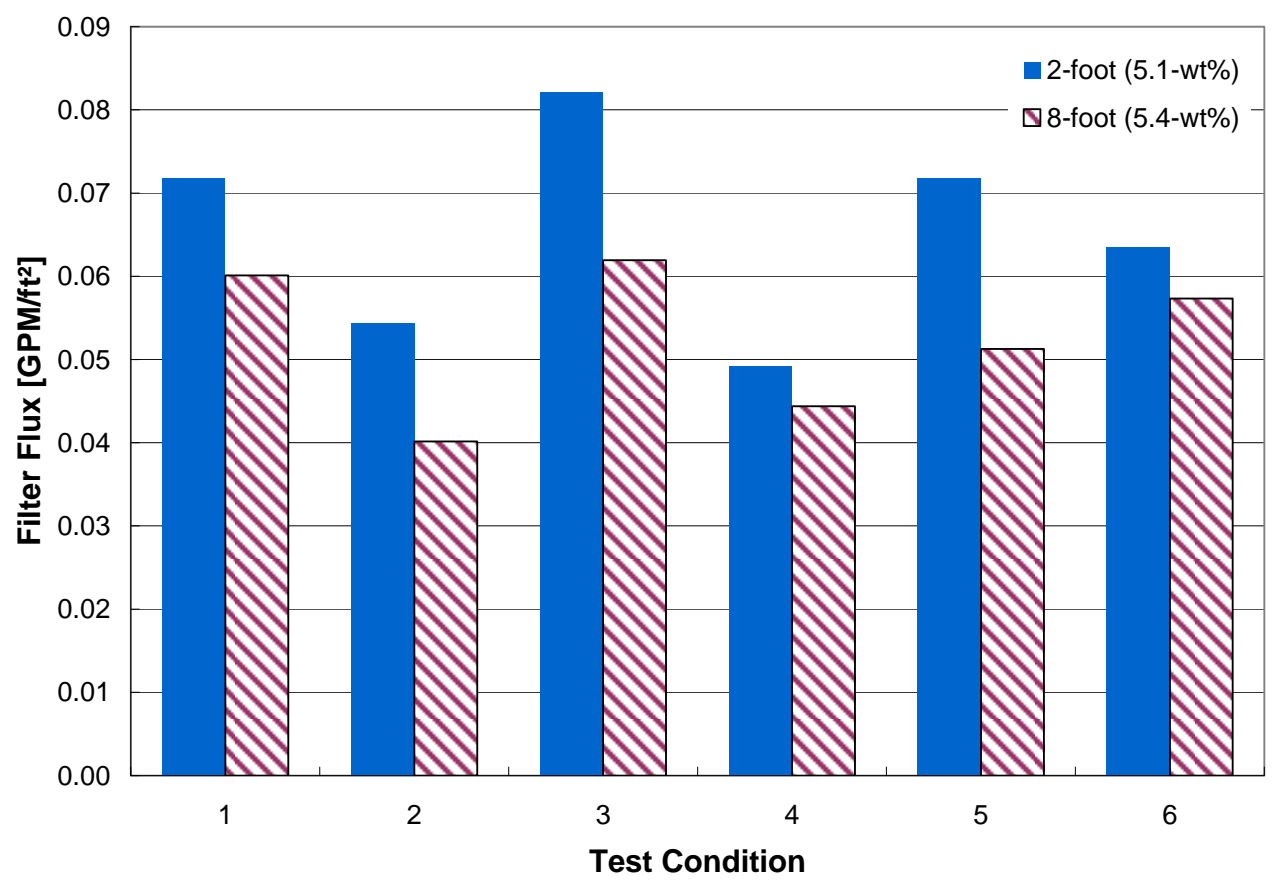

Figure 6.6. Graphical Results for the Low-Solids Text Matrix Blended Simulant Slurry Scaling Test

Figure 6.7 shows the dependence of permeate flux on AV and TMP for the 2- and 8-ft filter tests for the blended simulant slurry with a low-solids concentration. The results indicate mixed AV and TMP control, suggesting that cake-formation dynamics and thickness-control filtration are involved and that either membrane or cake resistance can be overcome by increasing TMP. Because part of the filter-flux behavior appears to be cake-resistance controlled, the current test should allow assessment of length scaling effects based on arguments presented in the introduction to Section 6.0.

Although Figure 6.6 indicates differences in the magnitude of flux between the 2-ft and 8-ft scale tests, the AV/TMP relationships show similar trends. With regard to AV, the trends of the permeate flux with AV are similar for 2-ft and 8-ft data, and at both scales, the $13 \mathrm{ft} / \mathrm{s}$ data show significant variation $\left(\sim 0.02 \mathrm{GPM} / \mathrm{ft}^{2}\right)$ as a result of changes in TMP. Likewise, both 2 - $\mathrm{ft}$ and 8 -ft permeate flux versus TMP plot data indicate a slight increase in filter performance with increasing TMP. The magnitude of increase between the 20 and 60 psid TMP conditions in the 8-ft data is less substantial than observed in the 2-foot data over this same TMP range. This difference in flux versus TMP scaling is likely a result of reduced $\mathrm{AV}$ in the 8-foot scale test (see condition 5 in Table 6.10) rather than a filter-length scaling effect. Specifically, TMP control in the 8-ft scaling test is diminished because of insufficient pumping power, and direct comparison of 2-ft and 8-ft filter flux at 60 psid is not possible. With regard to the 40 psid data, both 2-ft and 8-ft scale flux measurements show significant scatter in response to changes in AV. Overall, the AV/TMP dependence of filter flux at the 2-ft and 8-ft scales appears similar. 

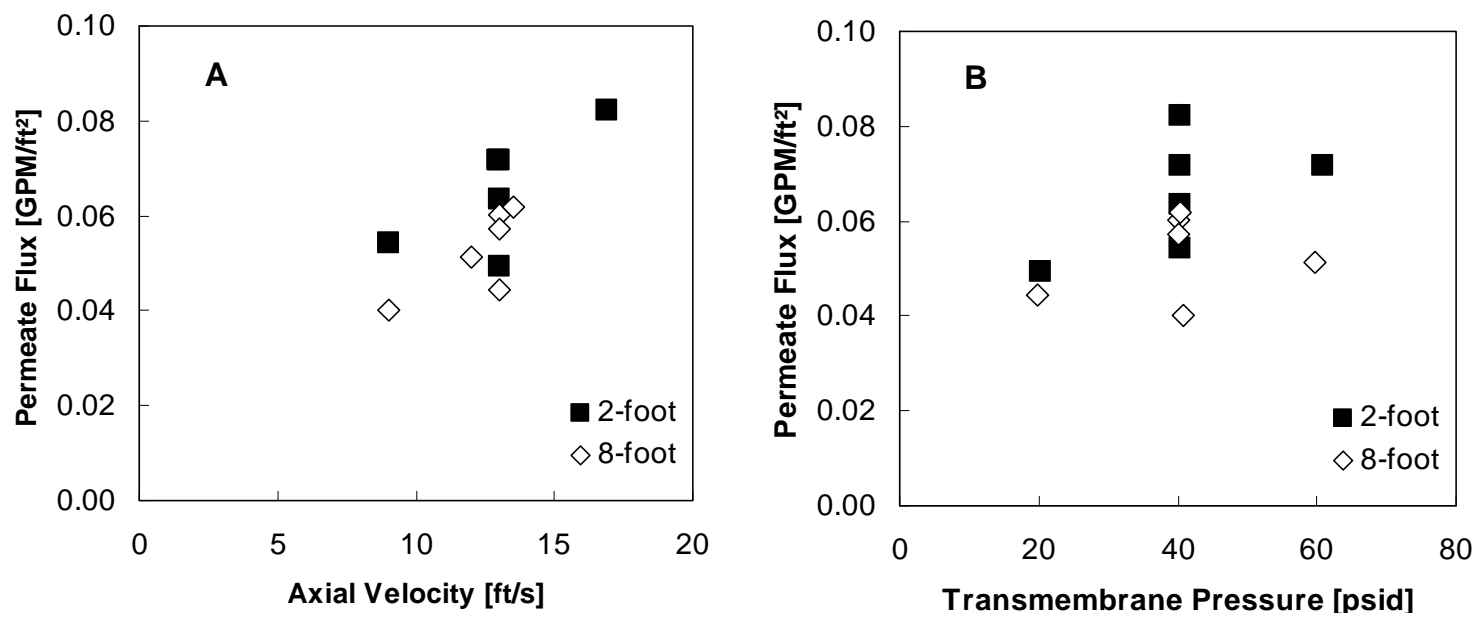

Figure 6.7. Filtration Results for the low-Solids Matrix Blended Simulant Scaling Test Showing The Flux Dependence on A) AV and B) TMP

\subsubsection{Blended Simulant Slurry Dewatering}

The dewatering performance of the blended simulant slurry on the 2-ft and 8-ft filters is shown in Figure 6.8. At UDS concentrations lower than $10 \mathrm{wt} \%$ [or 1.0 for $\log _{10}(\mathrm{wt} \%$ UDS $)$ ], both $2-\mathrm{ft}$ and $8-\mathrm{ft}$ dewatering curves show a similar, relatively flat dewatering profile. Over $10 \mathrm{wt} \%$ to $15 \mathrm{wt} \%$ UDS, the data appear to suggest that the curves will diverge at higher UDS. Specifically, the 2-ft filter fluxes continue a relatively steady flux decline whereas the 8 - $\mathrm{ft}$ filter decline appears to accelerate near $\log (\mathrm{wt} \% \mathrm{UDS})=1.1$. Filter flux data for the 8 - $\mathrm{ft}$ scale test beyond $10 \mathrm{wt} \%$ are not available because of pump cavitation. As a result, continued decline of the 8 - $\mathrm{ft}$ data cannot be confirmed.

It can be speculated that the divergence over $10 \mathrm{wt} \%$ to $15 \mathrm{wt} \%$ UDS could indicate filter scaling effects at high slurry solids concentration; however, CUF operational difficulties during the 8-ft test prevent meaningful analysis of the data. Specifically, the 8-ft dewatering operations yielded significant pump cavitation as dewatering approached completion. Because of pump noise, cavitation was only noticed when the axial flow velocity of the slurry began to decline rapidly (showing a $50 \%$ decrease over 10 -min), and the filter flux began to oscillate significantly (showing $\pm 50 \%$ flux variations between each 1-min measurement interval). It is highly possible that the flux decline for the 8-ft filter data in Figure 6.8 indicates the beginning of pump cavitation rather than a scaling effect.

The relative insensitivity of the 2-ft scale data with respect to UDS concentration would typically be interpreted as a filter-resistance control mechanism for filtration (rather than a cake of solids on the filter surface). However, the AV/TMP trends observed in Figure 6.6 contradict this assertion. As such, the dewatering behavior indicates that although filtration is cake controlled, the UDS solids concentration does not strongly impact filter flux (as least to the extent observed in Figure 6.3. This latter observation has an important implication for comparison of flux at high solids concentrations at 2-ft and 8-ft scales: large changes in slurry concentration yield small changes in filter flux. Consequently, comparison of filter flux at two disparate slurry concentrations on either 2-ft and 8-ft filters can yield the same filter flux with regard to flux measurement repeatability. Comparison of $2-\mathrm{ft}$ and $8-\mathrm{ft}$ data is complicated by the flux offset between the 2 -ft and 8 - $\mathrm{ft}$ scale data. The 2 - $\mathrm{ft}$ data are approximately $0.002 \mathrm{GPM} / \mathrm{ft}^{2}$ higher than the 8 -ft scaling test data over $5 \mathrm{wt} \%$ to $10 \mathrm{wt} \%$. This flux offset (or difference) is typical when comparing data on two different filters and results from differences in the filter cleanliness. 
As indicated above, there was an up to $10 \%$ difference between the initial filter fluxes. Unfortunately, this type of difference in filter cleanliness and its respective "clean" flux yields differences in flux comparable to the change in filter flux as a result of UDS concentration changes alone. Also note that there may be some divergence in the performance with increasing solids between the $2-\mathrm{ft}$ and 8 -ft filter elements. This might be attributable to degradation of the slurry particles; however, this conclusion cannot be drawn definitively.

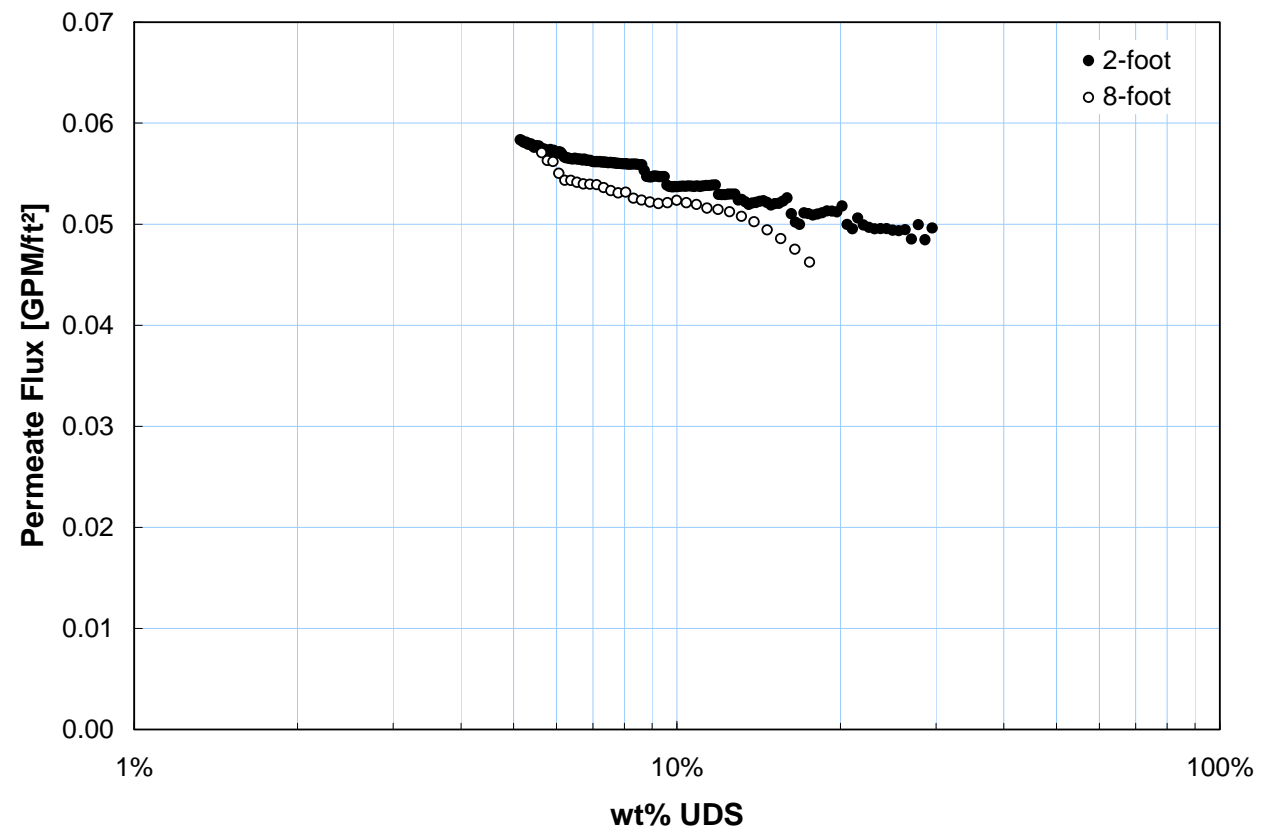

Figure 6.8. Dewatering Curve for a Blended Simulant Slurry on 2-ft and 8-ft CUF Filter Elements

As stated in the preceding paragraph, the data in Figure 6.3 indicate a filter resistance controlled filtration mechanism at both 2- and 8-ft scales. Based on the absence of transition points or a rapid flux decline, it appears that cake controlled filtration was not achieved over the range of concentrations tested. Because the tests do not achieve cake controlled filter flux regime, length scaling issues that derive from axial transport and build-up of filter cake should not impact this data. Because of this, it is recommended that the 2-ft filter fluxes for the blended simulant slurries be used without scaling to estimate performance with 8 -ft filter elements.

\subsubsection{High Solids Matrix Test Results}

The final permeate fluxes for the high-solids matrix filtration test run with the blended simulant slurry are shown in Table 6.11 and Figure 6.9 for each test condition. During test condition 3 and 5, the capacity of the pump was exceeded during testing, and the AV/TMP targets were not achieved. AVs of only 13.4 and $11.9 \mathrm{ft} / \mathrm{s}$ were achieved instead of the targets of 17 and $13 \mathrm{ft} / \mathrm{s}$. These AVs are similar to those measured in the 8-ft high-solids test matrix using the blended simulant slurry.

Despite the difference in test concentrations, the 2-ft and 8-ft slurries show similar filter flux at many test conditions. As discussed in the Section 6.3.2.2, similarity between the 2-ft and 8-ft flux results from the insensitivity of the filter flux to solids concentrations. Comparable UDS concentrations for the 2-ft 
and 8-ft scale tests could not be achieved because of operating volume limitations in the 8-ft filter CUF. Specifically, the extra slurry volume required to fill the 8 - $\mathrm{ft}$ circulation loop $(\sim 500 \mathrm{~mL})$ significantly limits the upper range of test concentrations that can be achieved on this test scale. Direct comparison is further hindered by flux offset between the two data sets that result from different states of filter cleanliness (see Section 6.3.2.2). All together, these limitations prevent meaningful comparison of the high-solids data for 2 -ft and 8 -ft scale tests.

Table 6.11. Tabular Results for the High-Solids Text Matrix Blended Simulant Slurry Scaling Test

\begin{tabular}{|c|c|c|c|c|c|c|c|c|c|c|}
\hline \multirow{2}{*}{$\begin{array}{c}\text { Test } \\
\text { Condition } \\
\text { Number }\end{array}$} & \multicolumn{2}{|c|}{ Targets } & \multicolumn{4}{|c|}{ 2-ft Test (30.4 wt\% UDS) } & \multicolumn{4}{|c|}{8 -ft Test (15.9 wt\% UDS) } \\
\hline & $\begin{array}{c}\mathrm{AV} \\
{[\mathrm{ft} / \mathrm{s}]}\end{array}$ & $\begin{array}{l}\text { TMP } \\
\text { [psid] }\end{array}$ & $\begin{array}{c}\mathrm{AV} \\
{[\mathrm{ft} / \mathrm{s}]}\end{array}$ & $\begin{array}{l}\begin{array}{l}\text { TMP } \\
\text { [psid] }\end{array} \\
\end{array}$ & $\begin{array}{c}\text { Flux } \\
{\left[\mathrm{GPM} / \mathrm{ft}^{2}\right]}\end{array}$ & $\begin{array}{c}\mathrm{APD}^{(\mathrm{a})} \\
{[\mathrm{psid} / \mathrm{ft}]}\end{array}$ & $\begin{array}{c}\mathrm{AV} \\
{[\mathrm{ft} / \mathrm{s}]}\end{array}$ & $\begin{array}{c}\text { TMP } \\
{[\mathrm{psid}]}\end{array}$ & $\begin{array}{c}\text { Flux } \\
{\left[\mathrm{GPM} / \mathrm{ft}^{2}\right]}\end{array}$ & $\begin{array}{c}\text { APD } \\
{[\mathrm{psid} / \mathrm{ft}]}\end{array}$ \\
\hline 1 & 13 & 40 & 13.0 & 40.2 & 0.036 & 1.1 & 13.1 & 40.3 & 0.036 & 1.3 \\
\hline 2 & 9 & 40 & 9.0 & 40.2 & 0.029 & 0.7 & 9.0 & 40.6 & 0.024 & 0.7 \\
\hline 3 & 17 & 40 & 17.0 & 40.3 & 0.034 & 1.9 & $13.4^{(\mathrm{b})}$ & $39.6^{(\mathrm{b})}$ & $0.036^{(b)}$ & 1.3 \\
\hline 4 & 13 & 20 & 13.0 & 20.2 & 0.028 & 1.0 & 13.0 & 20.5 & 0.031 & 1.2 \\
\hline 5 & 13 & 60 & 13.0 & 59.8 & 0.042 & 0.7 & $11.9^{(\mathrm{b})}$ & $59.4^{(\mathrm{b})}$ & $0.032^{(b)}$ & 1.1 \\
\hline 6 & 13 & 40 & 13.0 & 40.1 & 0.039 & 1.0 & 13.0 & 39.8 & 0.035 & 1.3 \\
\hline
\end{tabular}

(a) $\mathrm{APD}=$ axial pressure drop per length of filter element across the filter element (accurate to $\sim 0.5 \mathrm{psid} / \mathrm{ft}$ for the 2 -ft elements and $\sim 0.2 \mathrm{psid}$ for the 8 -ft element).

(b) Indicates tests where the target AV could not be achieved (also highlighted).

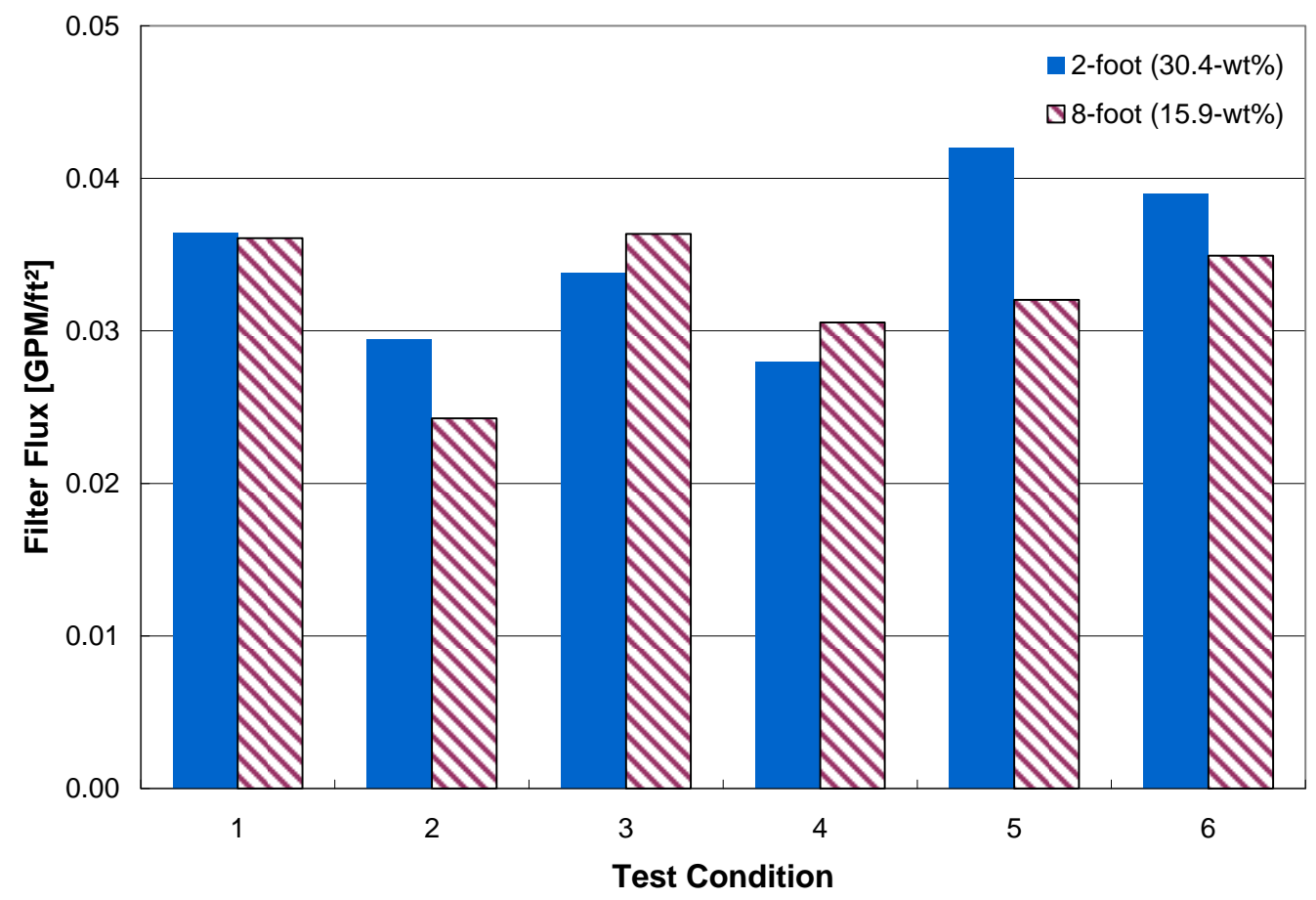

Figure 6.9. Graphical Results for the High-Solids Test Matrix Blended Simulant Slurry Scaling Test 
Figure 6.10 shows the dependence of permeate flux on AV and TMP for the 8-ft filter tests for the high-solids concentration blended simulant slurry. The results are generally similar to those observed for the low-solids matrix; however, the results suggest changes in the controlling mechanism for the 2-ft scaling test at $30.4 \mathrm{wt} \%$. Although mixed AV / TMP control is observed for the 2-ft element, TMP effects appear dominant. For the 2-ft scale high-solids (30.4 wt\%) test, an increase in AV from 9 to $17 \mathrm{ft} / \mathrm{s}$ yields only a $\sim 0.005 \mathrm{GPM} / \mathrm{ft}^{2}$ flux increase (i.e., $\sim 0.029$ to $0.034 \mathrm{GPM} / \mathrm{ft}^{2}$ or $\sim 15 \%$ increase). In contrast, similar increase in AV for the low-solids $(5.1 \mathrm{wt} \%)$ test yielded a more substantial $\sim 0.028 \mathrm{GPM} / \mathrm{ft}^{2}$ increase (i.e., $\sim 0.054$ to $\sim 0.082 \mathrm{GPM} / \mathrm{ft}^{2}$ or $\sim 50 \%$ increase). As such, AV effects appear to be reduced at high-solids in the 2 -ft scale test. TMP effects at high-solids concentration in the 2 -ft scale test are similar to those observed at low-solids concentrations. At both concentrations, increase of the TMP from 20 to 60 psid yields an approximate 50\% increase in flux.
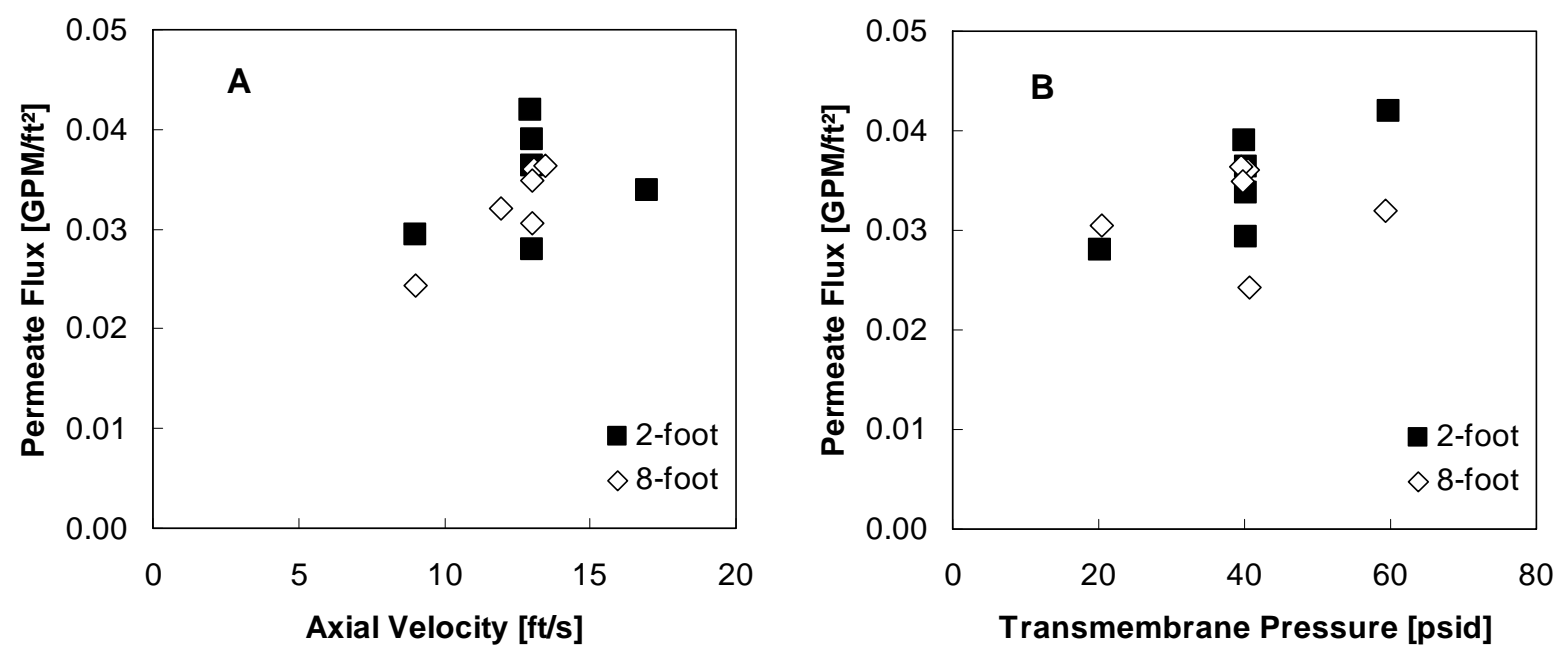

Figure 6.10. Filtration Results for the High-Solids Matrix Blended simulant Scaling Test Showing the Flux Dependence on A) AV and B) TMP

The 8-ft scale AV/TMP relationships appear to be unchanged relative to that observed at low solids concentrations. Mixed AV and TMP control for the filter flux can be assumed. Unlike for the 2-ft data, a significant reduction in the AV dependence of filtration is not observed. However, changes in the 8-ft filtration behavior may not be observable over the range of AV tested, which was limited by the inability of the pump to provide the power required to reach $17 \mathrm{ft} / \mathrm{s}$ at $40 \mathrm{psid}$ and $13 \mathrm{ft} / \mathrm{s}$ at $60 \mathrm{psid}$. In addition, differences in the 2-ft and 8-ft high-solids scaling tests (30.4 wt\% and $15.9 \mathrm{wt} \%$ UDS, respectively) may also contribute to differences in the observed controlling mechanisms for filtration. Because of these factors, conclusions regarding filter scaling effects at high-solids concentrations for the blended simulant slurry cannot be made with confidence from the limited number of tests reported here.

\subsection{Summary and Conclusions of Scale-Up Tests}

Results of the scaling tests conducted with a simulant sludge solids slurry indicate that the 2 -ft and 8-ft filters exhibit comparable performance. Initial permeate flux rates do not appear to be significantly affected by filter length. Filtration mechanisms for both the 2-ft and 8-ft filter elements appear to be 
similar, as the flux shows comparable AV and TMP dependences. One noticeable difference between 2-ft and 8 - $\mathrm{ft}$ tests is the absence of transient filter flux decrease in the 8-ft test. Such a decrease is indicative of filter fouling and was observed in the 2 -ft filter test. This suggests that fouling mechanisms may differ in the 2-ft and 8-ft tests; however, the 8-ft test used the same volume of slurry as used in the 2-ft test. Because of this, it is possible that the fines that cause the long-term decrease in filter flux in the 2-ft filter were simply depleted before fully fouling the 8 -ft filter. The suspected cause of depletion in the 8 - $\mathrm{ft}$ scale test is a lower slurry solids-to-filter surface area ratio (as $9 \mathrm{~L}$ of slurry were used in both 2-ft and 8-ft scale tests).

Analysis of filter scaling effects for a blended simulant slurry were complicated by the inability to achieve all AV and transmembrane conditions (due to limited pump capacity) and by an insensitivity of the filtrate flux (relative to that shown by the simulant sludge solids slurry) for the blended simulant slurry with respect to UDS concentration (as shown by Figure 6.8 when compared to Figure 6.3). Comparison of the 2 -ft and 8 - $\mathrm{ft}$ scale blended simulant filter fluxes at low-solids concentration suggests $10 \%$ to $25 \%$ decreases, as filter length is increased from 2 to $8 \mathrm{ft}$. The significance of this decrease is questionable given likely differences in filter cleanliness and slight difference in starting solids concentration. The behavior of low-solids filter flux with regard to changes in AV and TMP appear similar for the 2- and 8-ft scales, and as such, it can be tentatively concluded that scaling effects for dilute blended simulants are minor.

Meaningful evaluation of scaling effects for a blended simulant slurry at high-solids concentration was complicated by disparate test concentrations between 2- and 8-ft scale tests. Specifically, the test concentration achieved in the $2-\mathrm{ft}$ scale $(30.4 \mathrm{wt} \%$ ) could not be achieved in the 8 - $\mathrm{ft}$ scale tests without pump cavitation. The highest concentration for the 8 -ft scale test under which stable pump conditions could be achieved was $15.9 \mathrm{wt} \%$. Comparison of the 2 - $\mathrm{ft}$ high-solids $(30.4 \mathrm{wt} \%)$ data to the 8 - $\mathrm{ft}$ highsolids ( $15.9 \mathrm{wt} \%$ ) data finds similar filter flux at all test conditions. Similarity between the 2-ft and 8-ft high-solids flux, despite their disparate test concentrations, is indicative of the insensitivity of the blended simulant filter flux to solids concentrations rather than scaling effects. As with the low-solids blended simulant data, the behavior of high-solids blended simulant filter flux with regard to changes in AV and TMP is similar for the 2- and 8-ft scales.

For both simulant slurries tested herein, the dewatering profiles indicate that filter flux is independent of filter length for AV and TMP conditions typically employed in testing. The 2-ft and 8-ft scale dewatering curves for the simulant sludge solids slurry indicate a cake controlled filtration mechanism. Because scaling effects are believed to derive from axial transport and build-up of cake, then scaling effects would be evident in the comparison of the dewatering profiles for $2-\mathrm{ft}$ and 8 - $\mathrm{ft}$ simulant sludge solids scaling tests. The dewatering profiles for the simulant sludge solids slurry indicate that the filter flux for the 8-ft filter element is either equivalent or slightly higher than that for the 2-ft filter element. This suggests that axial transport is not a significant factor for the simulant sludge solids slurry. For this reason, it is recommended that the 2-ft filter fluxes for simulant sludge solids slurries be used without scaling to estimate performance with 8 - $\mathrm{ft}$ filter elements. Data for the blended simulant slurry indicate a filtration mechanism controlled primarily by the resistance of the filter cake.

For the blended simulant slurry, the dewatering profiles at both 2-ft and 8-ft scales suggest that the filter flux is relatively insensitive to changes in UDS concentrations (over 5 to $20 \mathrm{wt} \%$ ). Despite this difference, cake-controlled filtration at both 2-ft and 8-ft scales can be inferred from the observation of AV impacts on filter flux during the low and high solids matrix tests. As such, scaling effects during 
periods where the pump is providing the target dewatering conditions of $40 \mathrm{psid}$ and $13 \mathrm{ft} / \mathrm{s}$ should be observable as a difference in the dewatering flux behavior of the $2-\mathrm{ft}$ and $8-\mathrm{ft}$ scale tests. Discounting the small offset, both dewatering curves show similar behavior up to $\sim 12-\mathrm{wt} \%$ UDS. Divergence at higher solids concentrations is coincident with pump cavitation and cannot be attributed to a scaling effect with confidence. Thus, it is tentatively recommended that the 2- $\mathrm{ft}$ filter fluxes for the blended simulant slurries be used without scaling to estimate performance with 8 -ft filter elements. It should be noted that this conclusion needs to be further verified by eliminating the difficulties of the current test, including the difference in 2-ft and 8-ft scale fines loading, limited pump capacity for 8-ft tests, and differences in achievable UDS concentrations. Further testing of scaling effects is recommended to address these issues. 

WTP-RPT-168, Rev 0

\subsection{Temperature Tests}

This section describes the approach and results of CUF scale-up temperature testing. The goal of scale-up temperature tests was to determine the effect of temperature on the filtration of a waste simulant over the range of temperature conditions for the leaching processes. The temperature tests allow the evaluation of filter performance at select temperatures and, in turn, verification of temperature correction correlations developed for the 2-ft-long filter element on a scaled-up CUF system. To this end, filtration of blended simulant slurry was examined on a CUF system with an 8-ft-long filter element. Recyclemode filter fluxes at a single AV and TMP set point of $13 \mathrm{ft} / \mathrm{s}$ and $40 \mathrm{psid}$, respectively, were measured at $25^{\circ} \mathrm{C}, 35^{\circ} \mathrm{C}$, and $45^{\circ} \mathrm{C}$ for six distinct slurry concentrations. Tests employed both an "as-prepared" and a caustic leached and washed blended slurry to evaluate what impacts the leaching process has on the filter flux versus temperature correlation.

\subsection{Test Approach}

Test Plan TP-RPP-WTP-509 ${ }^{(a)}$ dictated the approach for the scale-up temperature tests. Testing employed the cross-flow filtration system described in Section 4 of this report. Approximately $20 \mathrm{~L}$ of a dilute ( $\sim 5 \mathrm{wt} \%)$ "as-prepared" blended simulant slurry was loaded into the CUF system. It should be noted that a slurry volume of $9 \mathrm{~L}$ was originally planned in the 8 -foot scale temperature tests. This volume was revised to $20 \mathrm{~L}$ to take advantage of a modification of the slurry reservoir to allow up to $25 \mathrm{~L}$ of slurry to be tested. This revision to the slurry volume was also driven by the need to achieve a range of test concentrations both before and after caustic-leaching of the slurry. It should be noted that even at $20 \mathrm{~L}$, the slurry volume fell short of the $36 \mathrm{~L}$ target needed to maintain similarity of the ratio of slurry volume-to-filter surface area between 2-foot and 8-foot scales.

After load-in was completed, the slurry was subjected to continuous recycle filtration (such that all permeate collected was recycled back into the slurry reservoir) for 4 hours at $25^{\circ} \mathrm{C}, 35^{\circ} \mathrm{C}$, and $45^{\circ} \mathrm{C}$. At the end of the $45^{\circ} \mathrm{C}$ measurement, the slurry was cooled back to $25^{\circ} \mathrm{C}$, and the 4-hour recycle filtration test was repeated. All filtration steps employed a target AV of $13 \mathrm{ft} / \mathrm{s}$ and a TMP of $40 \mathrm{psid}$. During filtration, the CUF operational parameters such as TMP, AV, permeate flow rate, and slurry temperature were continuously monitored using the CUF data acquisition system.

The temperature series outlined in the preceding paragraph was performed for both an initial (i.e., "as-prepared") and a caustic leached and washed blended simulant slurry. Temperature tests were run initially on the as-prepared blended simulant slurry. Once this first set of tests was complete, the slurry was caustic leached at $100^{\circ} \mathrm{C}$ for 12 hours in concentrated sodium hydroxide solution $(\sim 6.3 \mathrm{M}-$ see following sections for details). After leaching, the slurry was washed and subsequently diluted to 5-wt $\%$ UDS, and the temperature test series was repeated. Comparison of pre- and post-leach data allows evaluation of the effects of chemical processing and slurry chemistry on the temperature correlations.

Both initial and leached/washed slurries were tested at six separate UDS concentrations. Solids concentrations were controlled by dewatering the slurry after each temperature series. Dewatering

(a) RC Daniel, and RW Shimskey. 2007. Test Plan for Simulant Testing in Support of Phase I Demonstration of the Ultrafiltration and Leaching Processes in the Integrated Test Facility. 24590-101-TSA-W000-0004-7200019 Rev 00A (TP-RPP-WTP-509, Rev. 0). Pacific Northwest National Laboratory, Richland, Washington. 
operations typically targeted removal of approximately one-third of the slurry supernate volume until the minimum operating slurry volume of the CUF was reached or six different concentrations had been tested. Comparison of temperature correlations at different solids concentrations allows evaluation of concentration effects.

\subsubsection{Preleach Temperature Tests in Detail}

The preleach temperature tests immediately followed the blended simulant scale-up testing (i.e., the tests described in Section 6.0 of this report). Approximately $3.5 \mathrm{~kg}$ (or $2.6^{(\mathrm{a})}$ ) of a $16 \mathrm{wt} \%$ UDS blended simulant slurry remained in the slurry reservoir after blended simulant AV/TMP scale-up tests. This slurry was diluted by returning $7.7 \mathrm{~kg}$ (or $6.3 \mathrm{~L}$ ) of blended simulant permeate collected during dewatering operations associated with the AV/TMP tests. This diluted slurry was then supplemented by an addition $15.6 \mathrm{~kg}$ (or $12.4 \mathrm{~L}$ ) of $5 \mathrm{wt} \%$ untested blended simulant slurry to bring the total preleach slurry mass for temperature testing to $26.7 \mathrm{~kg}(21.3 \mathrm{~L}$ at approximately $5 \mathrm{wt} \% \mathrm{UDS})$.

After the slurry loading steps, the $\sim 5 \mathrm{wt} \%$ initial slurry was circulated through the filtration loop for 5 to 10 min to allow mixing of the blended simulant solids. The CUF permeate-side (i.e., the part of the CUF including the backpulse chamber and permeate flow metering systems) had not been flushed out at the end of the blended simulant AV/TMP scaling test. As such, the permeate side was already filled with blended simulant permeate before testing, and the initial filtering of the simulant should not have resulted in a slight dewatering of the slurry typically required to fill the backpulse chamber and permeate flow lines.

Next, a series of temperature tests was performed on the slurry. Specifically, the slurry was subjected to the following operations on the CUF system with the 8-ft filter element installed.

1. Continuous recycle filtration (such that all permeate collected was recycled back into the slurry reservoir) for 4 hours at $25^{\circ} \mathrm{C}$

2. Heat-up to $35^{\circ} \mathrm{C}$

3. Continuous recycle filtration (such that all permeate collected was recycled back into the slurry reservoir) for 4 hours at $35^{\circ} \mathrm{C}$

4. Heat-up to $45^{\circ} \mathrm{C}$

5. Continuous recycle filtration (such that all permeate collected was recycled back into the slurry reservoir) for 4 hours at $45^{\circ} \mathrm{C}$

6. Cool-down to $25^{\circ} \mathrm{C}$

7. Continuous recycle filtration (such that all permeate collected was recycled back into the slurry reservoir) for 4 hours at $25^{\circ} \mathrm{C}$.

Immediately before each 4-hour period of continuous recycle filtration, the filter was backpulsed twice to disrupt the filter cake and to remove weakly entrained particles from the filter. Comparison of the filter flux as a function of temperature allows evaluation of temperature effects. Filtration targeted an $\mathrm{AV}$ of $13 \mathrm{ft} / \mathrm{s}$ and a TMP of $40 \mathrm{psid}$. In some cases, the pump could not deliver sufficient power to drive the slurry through the 8-ft filter element at the targeted AV and TMP combination. In such cases, the highest axial velocity achievable at an operating TMP of 40 psid was employed.

(a) All slurry/permeate volumes reported in this section correspond to $25^{\circ} \mathrm{C}$ unless otherwise stated. 
Heating of the slurry to the various temperature set points was accomplished by balancing the heat input produced by pumping the slurry against the heat removed by the chiller attached to the CUF system. Direct heating of the slurry through the heat exchanger could not be accomplished because the connected re-circulating chiller was not equipped with a heater. For all test cases, the pump generated sufficient heat-through friction and viscous dissipation to reach slurry temperatures well above the maximum test temperature of $45^{\circ} \mathrm{C}$. To heat the slurry, the chiller was briefly turned off until the temperature of the slurry had reached its target. Once the slurry was at temperature, the chiller was turned on and set at an appropriate temperature set point to maintain the slurry reservoir at the target temperature. Typically, a 5 to $10^{\circ} \mathrm{C}$ temperature differential between the target test temperature (i.e., $25^{\circ} \mathrm{C}, 35^{\circ} \mathrm{C}$, or $45^{\circ} \mathrm{C}$ ) and the chiller set point was required to maintain temperature stability. During testing, the temperature of the slurry reservoir was frequently checked and, if necessary, the temperature set point of the chiller was adjusted to maintain the test temperature.

The temperature series (i.e., steps 1 through 7 above) was performed at six unique UDS concentrations of the blended simulant slurry. The first concentration tested was that of the dilute slurry initially loaded into the CUF. Subsequent concentrations were achieved by dewatering the blended simulant slurry. Dewatering operations targeted removal of approximately one-third of the slurry supernate volume in the slurry reservoir. UDS concentration was tracked through accounting of the mass of slurry added to or removed from the slurry reservoir and the mass of permeate was collected.

To corroborate the results of the mass balance, two $\sim 150$-g slurry aliquots were sampled before and after the completion of all temperature tests to allow direct measurement of slurry UDS at the start and end of the preleach temperature tests. The initial sample was designated TempTest-BS-IN-SL, whereas the final sample was designated TempTest-BS-FIN-SL. A sample of the collected permeate was also aliquoted to assist in determining the UDS fraction in the two slurry samples and for measuring permeate viscosity as a function of temperature. The sampled permeate was designated TempTest-Permeate. Table 7.1 provides a summary of samples taken during the preleach temperature test.

Table 7.1. Summary of Samples Collected in Association with Preleach Temperature Testing

\begin{tabular}{cl}
\hline Sample Designation & \multicolumn{1}{c}{ Description } \\
\hline TempTest-Permeate & $\begin{array}{l}\text { This sample corresponds to a preleach blended simulant permeate. It was sampled to } \\
\text { determine the concentration of dissolved solids in the blended simulant before leaching }\end{array}$ \\
TempTest-BS-IN-SL & $\begin{array}{l}\text { This sample corresponds to the dilute blended simulant slurry sampled before preleach } \\
\text { temperature tests. It was used to determine the total and UDS concentrations in the } \\
\text { dilute initial slurry. }\end{array}$ \\
TempTest-BS-FIN-SL & $\begin{array}{l}\text { This sample corresponds to the concentrated blended simulant slurry sampled after } \\
\text { preleach temperature tests. It was used to determine the total and UDS concentrations in } \\
\text { the concentrated initial slurry and to determine the viscosity of the blended simulant } \\
\text { slurry permeate as a function of temperature. }\end{array}$ \\
\hline
\end{tabular}

Table 7.2 shows the slurry mass balance and the UDS concentration at each of the six test conditions for preleaching temperature testing. The concentrations tested range from 5.0 to $28.3 \mathrm{wt} \%$ UDS based on calculations derived from the mass balance. Based on the measured UDS of the samples taken before and after preleach temperature testing, the range is slightly lower and spans 3.5 to $24.9 \mathrm{wt} \%$. The difference in measured and calculated UDS concentration is likely a result of a combination of errors from sampling 
and simulant make up. Significant deviation between end point concentrations reported results from propagation of errors through the mass balance. For consistency, the calculated UDS are used throughout this report. Table 7.3 shows the achievable test conditions for preleach temperature testing. In all cases, the pump provided sufficient power to obtain an axial velocity of $13 \mathrm{ft} / \mathrm{s}$ at a TMP of $40 \mathrm{psid}$. Table 7.4 shows the axial pressure drop across the 8 -ft filter element expressed as pressure drop per unit of filter length.

Table 7.2. Simple Mass Balance for the Preleach Temperature Tests

\begin{tabular}{cccccc}
\hline Concentration & $\begin{array}{c}\text { Slurry } \\
\text { Mass }^{(\mathrm{a})} \\
(\mathrm{kg})\end{array}$ & $\begin{array}{c}\text { Slurry } \\
\text { Volume }^{(\mathrm{a})} \\
(\mathrm{L})\end{array}$ & $\begin{array}{c}\text { Supernate } \\
\text { Volume }^{(\mathrm{a})} \\
(\mathrm{L})\end{array}$ & $\begin{array}{c}\text { Calculated } \\
\text { UDS } \\
(\mathrm{wt} \%)\end{array}$ & $\begin{array}{c}\text { Measured } \\
\text { UDS } \\
\left(\mathrm{wt}^{2} \%\right)\end{array}$ \\
\hline 1 & 26.4 & 21.1 & 20.6 & 5.0 & 3.5 \\
2 & 18.0 & 14.2 & 13.7 & 7.3 & not measured \\
3 & 12.5 & 9.6 & 9.1 & 10.5 & not measured \\
4 & 8.7 & 6.6 & 6.1 & 14.9 & not measured \\
5 & 6.2 & 4.5 & 4.0 & 20.9 & not measured \\
6 & 4.5 & 3.2 & 2.7 & 28.3 & 24.9 \\
\hline
\end{tabular}

(a) Note: the mass and volumes provided are based on the circulating mass and volume and do not include the approximately $850 \mathrm{~mL}$ of permeate held up on the CUF permeate collection and metering system. Volume is reported at $25^{\circ} \mathrm{C}$.

Table 7.3. Achievable Conditions for Preleach Temperature Testing

\begin{tabular}{ccccccccc}
\hline & \multicolumn{7}{c}{ Achievable Conditions at Temperature } \\
\cline { 2 - 8 } Concentration & \multicolumn{2}{c}{$25^{\circ} \mathrm{C}$} & \multicolumn{2}{c}{$35^{\circ} \mathrm{C}$} & \multicolumn{2}{c}{$45^{\circ} \mathrm{C}$} & \multicolumn{2}{c}{$25^{\circ} \mathrm{C}$ (repeat) } \\
\cline { 2 - 8 } & $\mathrm{AV}$ & $\mathrm{TMP}$ & $\mathrm{AV}$ & $\mathrm{TMP}$ & $\mathrm{AV}$ & $\mathrm{TMP}$ & $\mathrm{AV}$ & $\mathrm{TMP}$ \\
\hline 1 & 12.9 & 39.9 & 12.9 & 39.7 & 13.0 & 39.4 & 13.0 & 40.3 \\
2 & 13.0 & 41.3 & 12.9 & 39.2 & 12.9 & 40.1 & 13.0 & 40.2 \\
3 & 13.0 & 39.4 & 12.9 & 39.8 & 13.0 & 39.8 & 13.0 & 40.2 \\
4 & 13.0 & 40.1 & 13.0 & 40.4 & 13.0 & 40.2 & 13.0 & 40.6 \\
5 & 13.0 & 40.1 & 13.0 & 40.5 & 13.0 & 39.8 & 12.9 & 40.1 \\
6 & 12.9 & 40.3 & 13.0 & 39.5 & 12.8 & 39.5 & 13.0 & 39.8 \\
\hline Note: Axial velocity (AV) is in ft/s. Transmembrane pressure (TMP) is in psid.
\end{tabular}


WTP-RPT-168, Rev 0

Table 7.4. Axial Pressure Drop for Preleach Temperature Testing

\begin{tabular}{ccccc}
\hline \multirow{2}{*}{ Concentration } & \multicolumn{4}{c}{ APD [psid/ft] at Temperature } \\
\cline { 2 - 5 } & $25^{\circ} \mathrm{C}$ & $35^{\circ} \mathrm{C}$ & $45^{\circ} \mathrm{C}$ & $25^{\circ} \mathrm{C}$ (repeat) \\
\hline 1 & 1.0 & 0.9 & 0.9 & 1.1 \\
2 & 1.2 & 0.9 & 0.9 & 1.1 \\
3 & 1.1 & 1.1 & 1.0 & 1.1 \\
4 & 1.2 & 1.2 & 1.0 & 1.3 \\
5 & 1.3 & 1.2 & 1.1 & 1.3 \\
6 & 1.4 & 1.3 & 1.2 & 1.4 \\
\hline
\end{tabular}

Note: $\mathrm{APD}=\mathrm{Axial}$ pressure drop per length of filter element across the filter element (accurate to $\sim 0.2 \mathrm{psid} / \mathrm{ft}$ for the 8 -ft element).

\subsubsection{Caustic Leaching in Detail}

At the end of preleach temperature testing, approximately $4.5 \mathrm{~kg}$ (or $3.1 \mathrm{~L}$ ) of concentrated slurry (at $28.4 \mathrm{wt} \%$ UDS) remained in the CUF slurry reservoir. To prepare the system for caustic leaching, the follow operations were performed:

1. Both circulation loop and permeate-collection systems were drained

2. The entire volume of blended simulant slurry and permeate side hold-up volume $(\sim 850 \mathrm{~mL})$ was loaded into an isolated slurry reservoir (i.e., closed to the circulation loop and permeate side)

3. The slurry was diluted with $\sim 950 \mathrm{~g}$ (or $780 \mathrm{~mL}$ ) of permeate.

These operations provided a leach slurry mass of $6.5 \mathrm{~kg}(4.8 \mathrm{~L})$ at UDS concentration of $19.6 \mathrm{wt} \%$. To this leach slurry, caustic leaching reagents were added. This included $8.1 \mathrm{~kg}$ of $19 \mathrm{M}$ sodium hydroxide solution and $7.5 \mathrm{~kg}$ of condensate (i.e., water to simulate steam heating at PEP). The addition of leaching reagents brought the total slurry mass and UDS concentrations to $21.9 \mathrm{~kg}(17.5 \mathrm{~L})$ and $5.6 \mathrm{wt} \%$, respectively, and the concentration of sodium hydroxide in solution to $\sim 6.3 \mathrm{M}$. The addition of leaching reagents caused a rise in slurry temperature $\left(\sim 10\right.$ to $\left.20^{\circ} \mathrm{C}\right)$. No attempt was made to correct this temperature rise because of a lack of cooling capability at the slurry reservoir, and the next operation immediately following reagent addition was to heat the slurry to $100^{\circ} \mathrm{C}$ to facilitate leaching.

The mass of leaching reagents added to the slurry was based on previous leach tests performed during CUF Blended Matrix Test 3 (CBM3 - see Section 5.0 details on CBM3 formulation). For CBM3, the target masses of leaching reagents were $\sim 1.62 \mathrm{~kg} 19 \mathrm{M} \mathrm{NaOH}$ solution per liter of slurry and $\sim 1.49 \mathrm{~kg}$ condensate per liter of slurry. BNI concurrence on leaching conditions was obtained through hold-point 3 communication dictated by test plan TP-RPP-WTP-509, Rev 0 (see Appendix C for details). An initial slurry mass balance estimated the expected volume of blended simulant slurry for temperature test leach operations at $5 \mathrm{~L}$. The masses of leaching reagents employed for temperature testing, $8.1 \mathrm{~kg}$ of $19 \mathrm{M}$ $\mathrm{NaOH}$ solution, and $7.5 \mathrm{~kg}$ of condensate were based on this initial volume estimate. Post-leach mass balance calculations determined the actual volume of slurry in the tank at the time of leaching reagent addition to be $4.6 \mathrm{~L}$, which was less than initially expected. Because of the difference between the 
expected and actual slurry volumes, the slurry was leached with more caustic and condensate than used in CBM3.

To caustic leach the blended simulant slurry, the following operations were performed:

1. The slurry was heated to $100^{\circ} \mathrm{C}$ at a heating rate of $0.238^{\circ} \mathrm{C} / \mathrm{min}$

2. The slurry was held at $100^{\circ} \mathrm{C}$ for 12 hours

3. The slurry was cooled to $25^{\circ} \mathrm{C}$ over 12 hours using a $4.6^{\circ} \mathrm{C} / \mathrm{hr}$ cooling rate.

During this leach operation, the slurry was continuously agitated with an overhead mixer. Estimates of the post-leach slurry composition indicated a slurry mass of $21.9 \mathrm{~kg}(16.8 \mathrm{~L})$ and a slurry UDS concentration of $2.8 \mathrm{wt} \%$.

After caustic leaching, the leached slurry was washed with a dilute $(0.01 \mathrm{M})$ sodium hydroxide solution. To prepare the leached slurry for washing, it was first allowed to circulate through the CUF system. Next, the slurry was dewatered to a slurry mass of $4.6 \mathrm{~kg}$ (or $3.4 \mathrm{~L}$ ) and a UDS concentration of $13.2 \mathrm{wt} \%$. The dewatered slurry was then washed incrementally 24 times with $0.01 \mathrm{M}$ sodium hydroxide solution. Each wash consisted of 1) an addition of $\sim 700 \mathrm{~mL}$ of dilute caustic to the slurry reservoir, 2) a brief period of circulation of $\sim 5$ min to allow mixing, and 3) dewatering $\sim 700 \mathrm{~mL}$ of slurry permeate to remove the wash volume. This washing scheme yielded a total wash volume of $16.8 \mathrm{~L}$, which was equivalent to approximately five post-leach blended simulant slurry volumes. At the end of washing, the estimated slurry concentration was $18.1-w t \%$ UDS. The increase in UDS that occurred during washing was a result of a lowering of the supernate density.

To help corroborate the mass balance, slurry samples were taken immediately before leaching reagent addition and immediately after post-leach slurry cool down. The preleach sample was designated TempTest-Pre-Leach-SL, and the post-leach sample was designated TempTest-Post-Leach-SL. In addition, a 200-mL sample of the post-leach permeate was taken immediately before post-leach slurry washing. This sample, designated TempTest-Post-Leach-FIL, was held for observation for a period of 7 days after sampling to determine if any precipitation of solids occurred over long times after leaching. Table 7.5 provides a summary of samples taken during the caustic leaching operations associated with temperature testing.

Table 7.5. Summary of Samples Collected in Association with Temperature Test Leaching Operations

\begin{tabular}{|c|c|}
\hline Sample Designation & Description \\
\hline TempTest-Post-Leach-FIL & $\begin{array}{l}\text { This sample corresponded to a post-leach filtrate. It was used to evaluate long- } \\
\text { term post-leach solids precipitation. It was also used to determine the mass } \\
\text { fraction of dissolved solids in the leached permeate. }\end{array}$ \\
\hline TempTest-Pre-Leach-SL & $\begin{array}{l}\text { This sample corresponded to the preleach blended simulant slurry immediately } \\
\text { before the addition of leaching reagents. It was sampled to determine the } \\
\text { concentration of total and UDS in the blended simulant immediately before } \\
\text { leaching. }\end{array}$ \\
\hline TempTest-Post-Leach-SL & $\begin{array}{l}\text { This sample corresponded to the post-leach blended simulant slurry immediately } \\
\text { after post-leach slurry cool-down. It was sampled to determine the concentration } \\
\text { of total and UDS in the blended simulant immediately after leaching. }\end{array}$ \\
\hline
\end{tabular}

Table 7.6 shows the slurry mass balance and the UDS concentration at selected steps in the temperature test leaching operations. The calculated preleach concentration is somewhat higher than the 
measured value. This difference may be a result of poor slurry sampling because the aliquot of material tested had to be obtained from the slurry reservoir (rather than from the typical location on the slurry sampling loop) using a cut plastic transfer pipette. In contrast, the post-leach calculated and measured UDS compare well.

Table 7.6. Simple Mass Balance for the Temperature Test Leaching Operations

\begin{tabular}{cccccc}
\hline & $\begin{array}{c}\text { Slurry } \\
\text { Mass } \\
(\mathrm{kg})\end{array}$ & $\begin{array}{c}\text { Slurry } \\
\text { Volume } \\
(\mathrm{L})\end{array}$ & $\begin{array}{c}\text { Supernate } \\
\text { Volume } \\
(\mathrm{L})\end{array}$ & $\begin{array}{c}\text { Calculated } \\
\text { UDS } \\
(\mathrm{wt} \%)\end{array}$ & $\begin{array}{c}\text { Measured } \\
\text { UDS } \\
(\mathrm{wt} \%)\end{array}$ \\
\hline Consolidated Slurry $^{(\mathrm{a})}$ & 6.5 & 4.8 & 4.3 & 19.6 & 14.1 \\
Leach Mixture $^{(\mathrm{b})}$ & 21.9 & 17.5 & 17.0 & 5.6 & not measured \\
Leached Slurry $^{(\mathrm{c})}$ & 21.9 & 16.8 & 16.5 & 2.8 & 2.6 \\
Dewatered Slurry $_{\text {Washed Slurry }}$ & 4.6 & 3.4 & 3.1 & 13.2 & not measured \\
W & 3.4 & 3.0 & 2.8 & 18.1 & not measured \\
\hline
\end{tabular}

(a) Before leaching reagent addition.

(b) After leaching reagent addition.

(c) After caustic leaching, but before washing.

Note: All slurry mass/volumes are total mass (rather than circulating mass).

Caustic leaching and subsequent washing causes a significant change in the dissolved solids content of the slurry supernate phase. Table 7.7 shows the dissolved solids concentration as a function of processing, which were determined by moisture content analysis of permeates collected before, during, and after the leaching and washing processes.

Table 7.7. Measured Dissolved Solids of Slurry Supernates at Various Steps in the Caustic Leaching and Washing Processes.

\begin{tabular}{cc}
\hline Supernate & Measured Dissolved Solids Concentration $(\mathrm{wt} \%)^{(\mathrm{a})}$ \\
\hline Initial (Preleach) & 26.9 \\
After Leaching & 27.3 \\
After Washing & 0.4 \\
\hline
\end{tabular}

(a) Based on the mass of dissolved solids per mass of supernate.

\subsubsection{Post-Leach Temperature Tests in Detail}

To prepare the leached blended simulant slurry for post-leach temperature testing, the concentrated $18.1 \mathrm{wt} \%$ washed slurry was diluted with $9.4 \mathrm{~kg}$ of $0.01 \mathrm{M}$ sodium hydroxide solution to a target UDS concentration of $5 \mathrm{wt} \%$. After dilution, the leached slurry had a circulating mass of $12.8 \mathrm{~kg}$ (or $12.4 \mathrm{~L}$ ) and a calculated UDS concentration of $4.8 \mathrm{wt} \%$.

Once diluted, the post-leach temperature test was performed on the leached blended simulant slurry (as described in Section 7.1.1). As before, the slurry was subjected to four separate 4-hour periods of continuous recycle filtration at $25^{\circ} \mathrm{C}$ (initial), $35^{\circ} \mathrm{C}, 45^{\circ} \mathrm{C}$, and $25^{\circ} \mathrm{C}$ (final). At the start of each 4-hour period, the filter was backpulsed twice to disrupt the filter cake and to remove weakly entrained particles from the filter. Heating was accomplished by balancing the heat input from the mechanical action of the pump against the heat removed by the recirculating chiller. 
The temperature series tests were repeated for six different slurry UDS concentrations. The first five concentrations were achieved by successive dewatering of the slurry, with a removal target of approximately one-third of the slurry supernate volume. The slurry volume achieved at the fifth test concentration was near the minimum operating volume of the CUF filtration system. Attempts to dewater to the sixth and final test concentration were hindered by pump cavitation. Because of this, the highest test concentration was abandoned. Instead, a portion of the permeate collected during dewatering operations to reach the fifth concentration was returned to the slurry reservoir. This yielded a sixth test concentration that fell between the fourth and fifth test concentrations. As before, the leached blended simulant slurry UDS concentration was tracked by recording the mass of slurry added to or removed from the slurry reservoir and the mass of permeate collected.

Two $\sim 150$-g slurry aliquots were sampled before and after the completion of all post-leach temperature tests to allow direct measurement of slurry UDS at the start and end of the preleach temperature tests. The dilute post-leach sample was designated TempTest-BS-CL-DIL-SL and the concentrated post-leach sample was designated TempTest-BS-CL-CONC-SL. In addition, a sample of the collected permeate was aliquoted and designated TempTest-Leached, Washed-Solids-Permeate. The sampled permeate was used to assist in determination of post-leach slurry UDS concentrations and to measure the viscosity of the post-leach blended simulant permeate as a function of temperature. Table 7.8 provides a summary of samples taken during the post-leach temperature test.

Table 7.8. Summary of Samples Collected in Association with Post-Leach Temperature Testing

\begin{tabular}{ll}
\hline \multicolumn{1}{c}{ Sample Designation } & \multicolumn{1}{c}{ Description } \\
\hline $\begin{array}{l}\text { TempTest-Leached, Washed- } \\
\text { Solids-Permeate }\end{array}$ & $\begin{array}{l}\text { This sample corresponded to a leached and washed blended simulant } \\
\text { permeate. It was sampled to determine the concentration of dissolved solids } \\
\text { in the blended simulant after leaching and washing. }\end{array}$ \\
TempTest-BS-CL-DIL-SL & $\begin{array}{l}\text { This sample corresponded to the dilute blended simulant slurry sampled } \\
\text { before post-leach temperature tests. It was used to determine the total and } \\
\text { IDS concentrations in the dilute leached slurry. } \\
\text { TempTest-BS-CL-CONC-SL }\end{array}$ \\
$\begin{array}{l}\text { This sample corresponded to the concentrated blended simulant slurry } \\
\text { sampled after post-leach temperature tests. It was used to determine the total } \\
\text { and UDS concentrations in the concentrated leached slurry and to determine } \\
\text { the leached and washed slurry permeate viscosity as a function of } \\
\text { temperature. }\end{array}$ \\
\hline
\end{tabular}

Table 7.9 shows the slurry mass balance and the UDS concentration at each of the six test conditions for post-leaching temperature testing. The concentrations tested range from 4.8 to $21.7 \mathrm{wt} \%$ UDS based on calculations derived from the mass balance. Based on the measured UDS of the samples taken before and after preleach temperature testing, the range is slightly lower and is $3.6 \mathrm{wt} \%$ at concentration 1 and $12.3 \mathrm{wt} \%$ at concentration 6 (which corresponds to calculated UDS concentration of $17.8 \mathrm{wt} \%$ ).

Table 7.10 shows the achievable test conditions for post-leach temperature testing. In all cases, the pump was only able to provide power sufficient to achieve AVs of 10 to $11 \mathrm{ft} / \mathrm{s}$ at a TMP of $40 \mathrm{psid}$. The inability to achieve target AV can be attributed to the lower viscosity (see Section 7.3.1) of the suspending phase, which prevented the pump from developing the pressure required to move the fluid at $13 \mathrm{ft} / \mathrm{s}$. Table 7.11 shows the axial pressure drop across the 8-ft filter element expressed as pressure drop per unit of filter length. The axial pressure drop was substantially lower for all conditions in the postleach tests compared to the preleach tests (Table 7.4). 
Table 7.9. Simple Mass Balance for the Post-Leach Temperature Tests

\begin{tabular}{cccccc}
\hline Concentration & $\begin{array}{c}\text { Slurry } \\
\text { Mass }^{(\mathrm{a})} \\
(\mathrm{kg})\end{array}$ & $\begin{array}{c}\text { Slurry } \\
\text { Volume }^{(\mathrm{a})} \\
(\mathrm{L})\end{array}$ & $\begin{array}{c}\text { Supernate }_{\text {Volume }^{(\mathrm{a})}} \\
(\mathrm{L})\end{array}$ & $\begin{array}{c}\text { Calculated } \\
\text { UDS } \\
(\mathrm{wt} \%)\end{array}$ & $\begin{array}{c}\text { Measured } \\
\text { UDS } \\
(\mathrm{wt} \%)\end{array}$ \\
\hline 1 & 12.6 & 12.2 & 12.0 & 4.8 & 3.6 \\
2 & 8.4 & 8.1 & 7.8 & 7.1 & not measured \\
3 & 5.8 & 5.4 & 5.2 & 10.3 & not measured \\
4 & 3.9 & 3.6 & 3.3 & 15.1 & not measured \\
5 & 2.7 & 2.4 & 2.1 & 21.7 & not measured \\
6 & 3.3 & 3.0 & 2.7 & 17.8 & 12.3 \\
\hline
\end{tabular}

(a) Note: the mass and volumes provided are based on the circulating mass and volume and do not include the approximately $850 \mathrm{~mL}$ of permeate held up on the CUF permeate collection and metering system. Volume is reported at $25^{\circ} \mathrm{C}$.

Table 7.10. Achievable Conditions for Post-Leach Temperature Testing

\begin{tabular}{|c|c|c|c|c|c|c|c|c|}
\hline \multirow{3}{*}{ Concentration } & \multicolumn{8}{|c|}{ Achievable Conditions at Temperature } \\
\hline & \multicolumn{2}{|c|}{$25^{\circ} \mathrm{C}$} & \multicolumn{2}{|c|}{$35^{\circ} \mathrm{C}$} & \multicolumn{2}{|c|}{$45^{\circ} \mathrm{C}$} & \multicolumn{2}{|c|}{$25^{\circ} \mathrm{C}$ (repeat) } \\
\hline & $\mathrm{AV}$ & TMP & $\mathrm{AV}$ & TMP & $\mathrm{AV}$ & TMP & $\mathrm{AV}$ & TMP \\
\hline 1 & 10.4 & 39.7 & 10.3 & 40.7 & 10.3 & 41.0 & 10.4 & 40.5 \\
\hline 2 & 10.5 & 41.1 & 10.4 & 41.1 & 10.4 & 40.3 & 10.5 & 40.7 \\
\hline 3 & 10.7 & 40.7 & 10.6 & 40.3 & 10.5 & 40.7 & 10.6 & 41.2 \\
\hline 4 & 10.9 & 40.7 & 10.8 & 40.4 & 10.7 & 40.5 & 10.9 & 40.8 \\
\hline 5 & 11.4 & 40.1 & 11.2 & 39.9 & 11.0 & 40.4 & 11.2 & 40.5 \\
\hline 6 & 11.1 & 39.8 & 10.9 & 40.5 & 10.7 & 40.6 & 10.9 & 40.7 \\
\hline
\end{tabular}

Note: Axial velocity (AV) is in ft/s. Transmembrane pressure (TMP) is in psid.

Table 7.11. Axial Pressure Drop for Post-Leach Temperature Testing

\begin{tabular}{ccccc}
\hline \multirow{2}{*}{ Concentration } & \multicolumn{4}{c}{ APD [psid/ft] at Temperature } \\
\cline { 2 - 5 } & $25^{\circ} \mathrm{C}$ & $35^{\circ} \mathrm{C}$ & $45^{\circ} \mathrm{C}$ & $25^{\circ} \mathrm{C}$ (repeat) \\
\hline 1 & 0.5 & 0.4 & 0.5 & 0.5 \\
2 & 0.6 & 0.6 & 0.5 & 0.5 \\
3 & 0.5 & 0.5 & 0.5 & 0.7 \\
4 & 0.6 & 0.6 & 0.5 & 0.7 \\
5 & 0.9 & 0.8 & 0.8 & 0.8 \\
6 & 0.7 & 0.7 & 0.6 & 0.7 \\
\hline
\end{tabular}

Note: $\mathrm{APD}=\mathrm{Axial}$ pressure drop per length of filter element across the filter element (accurate to $\sim 0.2 \mathrm{psid} / \mathrm{ft}$ for the 8 -ft element) 


\subsection{Analysis of Temperature Test Flux Data}

Test data derived from both pre- and post-leach temperature tests are collected and interpreted by the CUF DACS. The DACS provides measurement summary files that include the operational parameters listed in Table 7.12 at a given date and time.

Table 7.12. Filtration Test Measurement Parameters Provided by the CUF DACS

\begin{tabular}{ll}
\hline \multicolumn{1}{c}{ Parameter } & \multicolumn{1}{c}{ Units } \\
\hline Slurry Reservoir Temperature & ${ }^{\circ} \mathrm{C}$ \\
Permeate Pressure & psig \\
Filter Inlet Pressure & psig \\
Filter Outlet Pressure & psig \\
Transmembrane Pressure & psid \\
Volumetric Slurry Flow & $\mathrm{GPM}$ \\
Filter Axial Velocity & $\mathrm{ft} / \mathrm{s}$ \\
Permeate Flow & $\mathrm{mL} / \mathrm{min}$ \\
Permeate Density & $\mathrm{g} / \mathrm{mL}$ \\
\hline GPM $=$ gallons per minute & \\
\hline
\end{tabular}

Each of the CUF operational parameters (i.e., slurry flow and pressure measurements) was recorded at 1-min intervals and represents the average of 24 point measurements made every $2.5 \mathrm{sec}$.

The DACS system calculates both filter AV and TMP. Calculation of AV is accomplished by dividing the volumetric slurry flow $\left(Q_{\text {slurry }}\right)$ of the filter by the cross-sectional area $\left(S_{a}\right)$ of the inner diameter of the filter $\left(D_{i, \text { filter }}\right)$ :

$$
A V=\frac{Q_{\text {slurry }}}{S_{a}}=\frac{Q_{\text {slurry }}}{\frac{\pi}{4} D_{i, \text { filter }}^{2}}
$$

Determination of TMP is accomplished by subtracting the permeate pressure $\left(\mathrm{P}_{\text {permeate }}\right)$ from the average of the filter inlet and outlet pressures ( $P_{\text {inlet }}$ and $P_{\text {outlet }}$ respectively).

$$
T M P=\frac{\left(P_{\text {inlet }}+P_{\text {outlet }}\right)}{2}-P_{\text {permeate }}
$$

Although filter flux $(\mathrm{J})$ is not provided by the DACS, it may be calculated by dividing the volumetric flow rate of permeate out of the filter $\left(Q_{\text {permeate }}\right)$ by the filter area $\left(A_{\text {filter }}\right)$. Thus, the filter flux may be defined as

$$
J=\frac{Q_{\text {permeate }}}{A_{\text {filter }}}
$$


where $J$ is typically reported in units of $\mathrm{GPM} / \mathrm{ft}^{2}$. Filter area is typically based on the inner diameter of the filter. As such, $\mathrm{A}_{\text {filter }}$ is defined as:

$$
A_{\text {filter }}=\pi D_{i_{\text {filter }}} L_{\text {filter }}
$$

where $D_{i, f i l t e r}$ is the filter element inside diameter and $L_{\text {filter }}$ is the filter element length. For the 8-ft filter element, the inner diameter and length are 0.5 in. and $8 \mathrm{ft}$, respectively.

The permeate volumetric flow rate is typically corrected for temperature deviations from $25^{\circ} \mathrm{C}$. As defined by WTP-RPT-043, ${ }^{(a)}$ the corrected permeate flow rate and flux at a given temperature $T$ are defined as:

$$
\begin{aligned}
& Q_{25{ }^{\circ} \mathrm{C}}=Q_{T} \exp \left[2500\left(\frac{1}{T}-\frac{1}{298}\right)\right] \\
& J_{25^{\circ} \mathrm{C}}=J_{T} \exp \left[2500\left(\frac{1}{T}-\frac{1}{298}\right)\right]
\end{aligned}
$$

Here, $T$ is absolute temperature $(\mathrm{K})$ and $Q_{T}$ and $J_{T}$ are the uncorrected flow rate and flux, respectively, at the temperature $T$. For the current testing, the slurry temperature $T$ is taken as that of the slurry reservoir. Because the current tests are aimed at evaluating the temperature dependency of flux, this correlation will not be applied to the temperature test permeate flow/flux data. Instead, it will be used as a point of comparison for the temperature correlations developed herein.

Equation 7.5 is based upon an exponential temperature relationship for flux. This relationship correlates the permeate flux $\left(\mathrm{J}_{\mathrm{T}}\right)$ at a temperature T using two arbitrary constants, $\alpha$ and $\beta$, such that:

$$
J_{T}=\alpha \exp \left(-\frac{\beta}{T}\right)
$$

Here, $\alpha$ is positive such that flux is always positive and $\beta$ is positive such that flux always increases with increasing temperature. Equation 7.5 may be derived from this relationship by defining a reference flux condition and dividing that reference flux by equation 7.5 to eliminate $\alpha$. If the reference flux condition is defined at $25^{\circ} \mathrm{C}(298 \mathrm{~K})$, then:

$$
J_{25^{\circ} \mathrm{C}}=J_{T} \exp \left[\beta\left(\frac{1}{T}-\frac{1}{298}\right)\right]
$$

From this relationship, it can be seen that WTP-RPT-043 defines $\beta$ as $2500 \mathrm{~K}$.

(a) JGH Geeting, RT Hallen, LK Jagoda, AP Poloski, RD Scheele, DR Weier. 2003. Filtration, Washing, and Caustic Leaching of Hanford Tank AZ-101 Sludge. WTP-RPT-043, Rev. 1, Pacific Northwest National Laboratory, Richland, Washington. 
For the current testing, parameters $\alpha$ and $\beta$ will be evaluated by comparing and fitting uncorrected flux data at the three separate test temperatures to Equation 7.6. To ease analysis, Equation 7.6 is linearized by taking the natural log of both sides such that,

$$
\ln J_{T}=-\frac{\beta}{T}+\ln \alpha
$$

Equation 7.8 is of the form $y=m x+b$, where $m=-\beta, b=\ln \alpha$, and $x=1 / T$. As such, the temperature correlation constants $\alpha$ and $\beta$ can be easily assessed through linear regression analysis.

In terms of physical meaning, the constants $\alpha$ and $\beta$ are representative of the process. The constant $\alpha$ represents the limiting flux at large temperature (i.e., as $\mathrm{T} \rightarrow \infty$ ). Likewise, $\beta$ describes how quickly flux varies with temperature. Large values of $\beta$ indicate a rapidly increasing flux with temperature, whereas small values of $\beta$ indicate a filter flux that is relatively insensitive to changes in temperature. It should be noted that although $\alpha$ and $\beta$ are treated as constants in the preceding equations, their actual values depend strongly on filtration parameters such as TMP, AV, and slurry concentration. An important implication of this is that a particular set of $\alpha$ and $\beta$ is valid only for the operational conditions under which they were derived. In addition, both $\alpha$ and $\beta$ may be transient. This is particularly true of $\alpha$, which represents a filter flux and is subject to transient decrease as a result of filter fouling. As such, both operational parameters and time effects must be considered when evaluating Equation 7.5.

In addition to comparing the data against the expected temperature correction given by Equation 7.5, they will also be compared against temperature correlations developed for permeate viscosity. As stated in Section 7.1, the viscosity of permeate samples for the initial and leached/washed slurries was determined as a function temperature. Like permeate flux, permeate viscosity can be correlated to an exponential temperature relationship given by the equation,

$$
\mu=\mu_{o} \exp \left(\frac{\lambda}{T}\right)
$$

where $\mu_{\mathrm{o}}$ and $\lambda$ are arbitrary positive constants. The form of Equation 7.9 is such that increases in temperature yield decreases in permeate viscosity. In addition, Equation 7.9 may be linearized to allow application of linear regression analysis for determination $\mu_{0}$ and $\lambda$. The linearized form is:

$$
\ln \mu=\frac{\lambda}{T}+\ln \mu_{o}
$$

Unlike Equation 7.5, the parameters $\mu_{\mathrm{o}}$ and $\lambda$ in Equation 7.9 are constant. Specifically, neither depends on time or on the CUF operational parameters under which the permeates were collected. In general, $\mu_{\mathrm{o}}$ and $\lambda$ will be unique. However, these parameters do depend on the concentration of dissolved solids, and as such, permeates collected before and after the leaching processes should have different descriptive constants. 
The rationale behind comparing permeate flux to viscosity is the Darcy equation, which states that permeate flux is a function of the applied TMP, permeate viscosity $(\mu)$, and effective filter resistance $\left(\mathrm{R}_{\mathrm{m}}\right)$ :

$$
J=\frac{T M P}{\mu R_{m}}
$$

Substituting in Equation 7.9 yields,

$$
J=\left(\frac{T M P}{\mu_{o} R_{m}}\right) \exp \left(-\frac{\lambda}{T}\right)
$$

This equation is of the same form as Equation 7.6 and can be used to assess if change in permeate viscosity is the sole driver for changes in filter flux as a function of temperature. Specifically, if comparison of Equations 7.6 and 7.12 finds equivalent $\beta$ and $\lambda$, then it can be concluded that the change in permeate viscosity is the only cause for increases in flux. On the other hand, if comparison finds dissimilar $\beta$ and $\lambda$, then other causes for the change in flux with temperature must be considered (such as resistance of the filter solids cake).

\subsection{Results and Discussion}

This section presents and discusses results from the filtration temperature tests. First, a discussion of permeate viscosity and temperature trends is given in Section 7.3.1. This discussion provides a basis upon which to compare slurry temperature behavior. Following discussion of permeate viscosity, Section 7.3.2 presents a discussion of blended simulant filtration performance with respect to temperature and introduces the blended simulant slurry specific temperature correlations. Section 7.3.3 compares these correlations to the existing temperature correction equation currently used in permeate filtration analysis (see Section 4). Section 7.3.4 discusses the relative importance of permeate viscosity and filter/cake resistance in the filtration temperature correlations. Finally, Section 7.3.5 discusses the test results for observation of post-leach precipitation of solids from filtered simulant supernate samples.

\subsubsection{Temperature Dependence of Permeate Viscosity}

As described by the Darcy equation (i.e., Equation 7.11), permeate viscosity is an important parameter governing filter flux. Lower permeate viscosity should yield higher permeate filter flux assuming similar TMP, structuring of solids in the filter cake, and fouling of the filter by solids. Likewise, permeate viscosity depends on temperature as described by Equation 7.9. For the current tests, the increase in slurry temperature yields a corresponding decrease in the viscosity of the slurry permeate (i.e., the suspending phase), which in turn should yield a corresponding increase in filter flux. To determine if any or all of the changes in permeate flux with temperature is a result of permeate viscosity change, the viscosity of both initial and leached/washed blended simulant permeates was determined. 


\subsubsection{Initial (Preleach) Blended Simulant Permeate Viscosity}

Measurement of initial (preleach) blended simulant permeate viscosity employed sample TempTestPermeate (see Table 7.1). Table 7.13 shows the result of two separate viscosity determinations for the initial (preleach) blended simulant permeate sample. The measurement results indicate a permeate viscosity that ranges from $2.4-2.6 \mathrm{cP}$ at $25^{\circ} \mathrm{C}$, from $2.0-2.1 \mathrm{cP}$ at $35^{\circ} \mathrm{C}$, and from $1.6-1.7 \mathrm{cP}$ at $45^{\circ} \mathrm{C}$. As expected, permeate viscosity decreases with increasing temperature. Primary and duplicate measurements agree to within a $0.1 \mathrm{cP}$ margin of error, which is less than the $15 \%$ expected for measurements within this range (i.e., below $10 \mathrm{cP}$ ).

Figure 7.1 shows the viscosity data plotted in accordance with Equation 7.10. As expected, the natural logarithm of the permeate viscosity is linear with $1 / T$ (where $T$ is temperature in Kelvin). Linear regression analysis of the data in Figure 7.1 yields the constants, $\mu_{\mathrm{o}}$ and $\lambda$ associated with the measurement. Fitting constants are reported in Table 7.14 and indicate an average $\lambda$ of $1950 \mathrm{~K}$.

Table 7.13. Initial (Preleach) Blended Simulant Permeate Viscosity as a Function of Temperature

\begin{tabular}{ccc}
\hline Measurement & $\begin{array}{c}\text { Temperature } \\
\left({ }^{\circ} \mathrm{C}\right)\end{array}$ & $\begin{array}{c}\text { Viscosity }(\mu) \\
(\mathrm{cP})\end{array}$ \\
\hline Primary & $25(1$ of 2$)$ & 2.4 \\
& 35 & 2.0 \\
& 45 & 1.6 \\
Duplicate & $25(2$ of 2$)$ & 2.5 \\
& $25(1$ of 2$)$ & 2.5 \\
& 35 & 2.1 \\
& 45 & 1.7 \\
& $25(2$ of 2$)$ & 2.6 \\
\hline
\end{tabular}

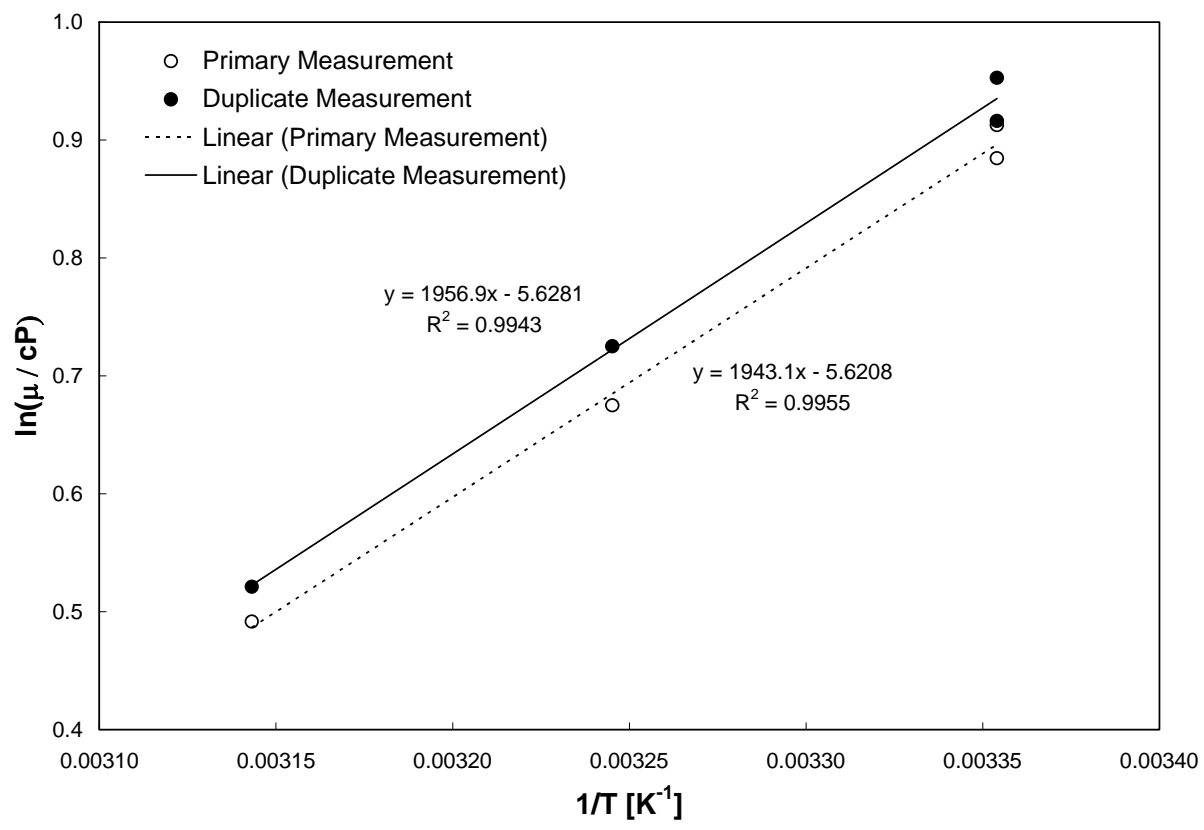

Figure 7.1. Plot of Initial Permeate Viscosity in Accordance with Temperature Relationship Given by Equation 7.10 
WTP-RPT-168, Rev 0

Table 7.14. Initial (preleach) Blended Simulant Permeate Viscosity as a Function of Temperature

\begin{tabular}{ccc}
\hline Measurement & $\begin{array}{c}\mu_{\mathrm{o}} \\
(\mathrm{cP})\end{array}$ & $\begin{array}{c}\lambda \\
(\mathrm{K})\end{array}$ \\
\hline Primary & $3.62 \times 10^{-3}$ & 1940 \\
Duplicate & $3.60 \times 10^{-3}$ & 1960 \\
Average & $3.61 \times 10^{-3}$ & 1950 \\
\hline
\end{tabular}

\subsubsection{Leached and Washed Blended Simulant Permeate Viscosity}

Measurement of the leached and washed blended simulant permeate viscosity employed sample TempTest-Leached, Washed-Solids-Permeate (see Table 7.8). Table 7.15 shows the result of the single viscosity determination for this leached and washed permeate sample. The measurement result indicates a permeate viscosity of $\sim 1.0 \mathrm{cP}$ at $25^{\circ} \mathrm{C}$, from $0.8 \mathrm{cP}$ at $35^{\circ} \mathrm{C}$, and $0.7 \mathrm{cP}$ at $45^{\circ} \mathrm{C}$. Like the initial permeate sample, viscosity decreases with increasing temperature. The initial and repeat measurements at $25^{\circ} \mathrm{C}$ compare well and suggest good reproducibility. Relative to the preleach permeate viscosity, the leached and washed permeate is lower. The difference in viscosity can be attributed to the reduced content of dissolved solids in the leached and washed permeate.

Table 7.15. Leached and Washed Blended Simulant Permeate Viscosity as a Function of Temperature

\begin{tabular}{cc}
\hline $\begin{array}{c}\text { Temperature } \\
\left({ }^{\circ} \mathrm{C}\right)\end{array}$ & $\begin{array}{c}\text { Viscosity }(\mu) \\
(\mathrm{cP})\end{array}$ \\
\hline $25(1$ of 2$)$ & 1.02 \\
35 & 0.81 \\
45 & 0.70 \\
$25(2$ of 2$)$ & 0.97 \\
\hline
\end{tabular}

Figure 7.2 shows the viscosity data plotted in accordance with Equation 7.10. As before, the natural logarithm of the permeate viscosity appears to be linear with $1 / \mathrm{T}$. Relative to the preleach data shown in Figure 7.1, the current data show more scatter. This increased scatter is a result of a higher noise-tosignal ratio and is typical for low-viscosity samples such as the leached and washed permeate. Linear regression analysis of the data in Figure 7.1 yields the constants, $\mu_{\mathrm{o}}$ and $\lambda$ associated with the measurement. Fitting constants are reported in Table 7.16 and indicate a reduced $\lambda$ of $1680 \mathrm{~K}$ relative to the preleach value.

Table 7.16. Leached and Washed Blended Simulant Permeate Viscosity as a Function of Temperature

\begin{tabular}{cc}
\hline $\begin{array}{c}\mu_{\mathrm{o}} \\
(\mathrm{cP})\end{array}$ & $\begin{array}{c}\lambda \\
(\mathrm{K})\end{array}$ \\
\hline $3.50 \times 10^{-3}$ & 1680 \\
\hline
\end{tabular}




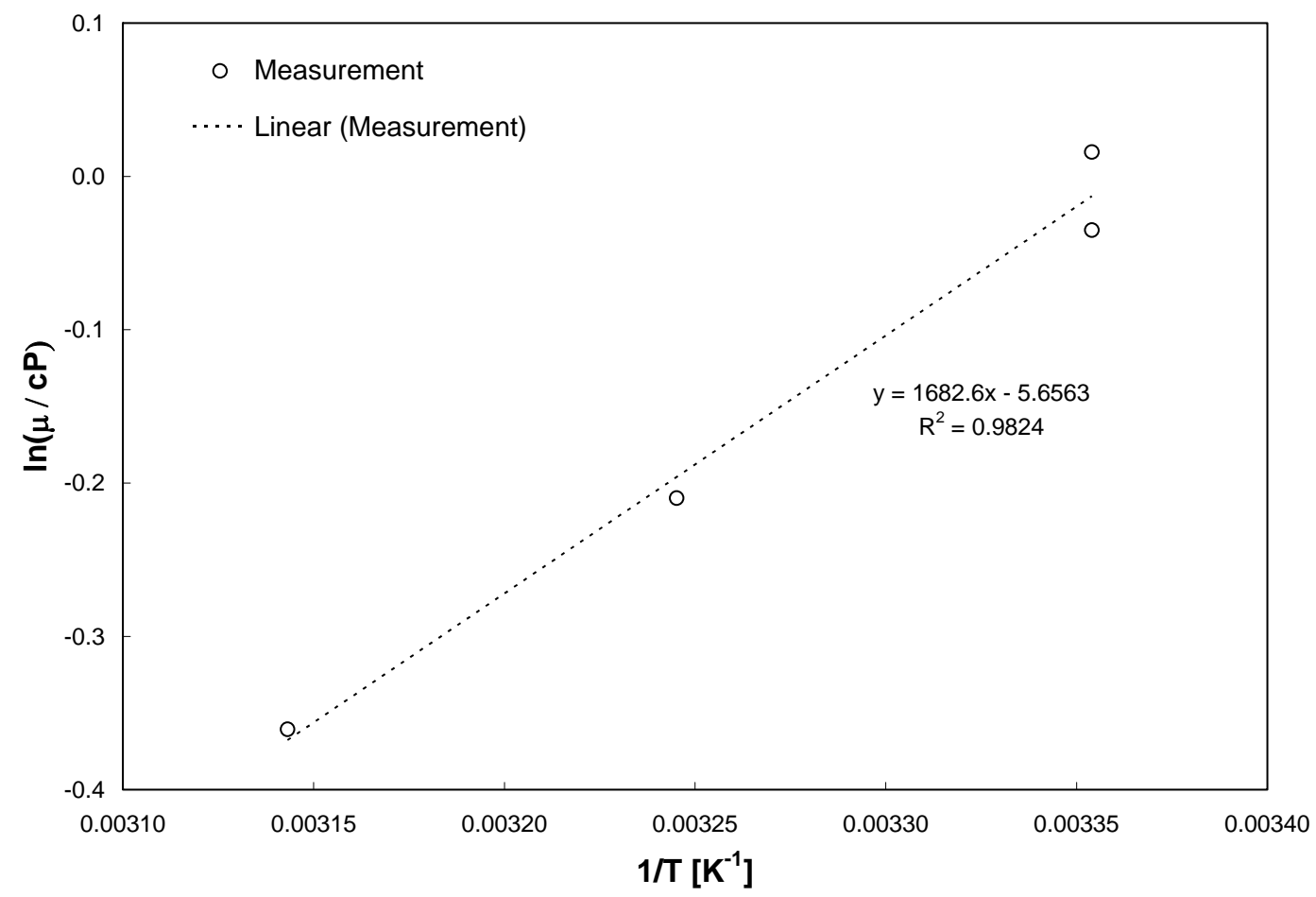

Figure 7.2. Plot of Leached and Washed Permeate Viscosity in Accordance with Temperature Relationship Given by Equation 7.10

\subsubsection{Temperature Dependence of Filter Flux}

As described in preceding sections, the filtration performance of a blended simulant slurry (both before and after caustic leaching and washing) was assessed at $25^{\circ} \mathrm{C}, 35^{\circ} \mathrm{C}$, and $45^{\circ} \mathrm{C}$ over periods of 4-hour continuous recycle filtration. The filter flux was continuously monitored during this period. The filter flux measurement for the preleach blended simulant slurry at 5.0 wt\% UDS is shown in Figure 7.3. At all temperatures, the flux data shown in Figure 7.3 decrease steadily over the 4-hour period of continuous recycle filtration. As expected, filter flux increases with increasing temperature. The range of flux variation at $25^{\circ} \mathrm{C}$ is 0.045 to $0.065 \mathrm{GPM} / \mathrm{ft}^{2}$. In comparison, the flux ranges from 0.068 to $0.082 \mathrm{GPM} / \mathrm{ft}^{2}$ and from 0.092 to $0.108 \mathrm{GPM} / \mathrm{ft}^{2}$ at $35^{\circ} \mathrm{C}$ and $45^{\circ} \mathrm{C}$, respectively. Flux measurements at $25^{\circ} \mathrm{C}$ compare well, indicating that long-term, irreversible filter fouling is not affecting the data to a substantial or noticeable degree.

The filter flux behaviors at different slurry UDS concentrations and for the leached/washed blended simulant slurry are similar to those shown in Figure 7.3. For brevity, they will not be introduced or discussed here. However, Appendix A of this report provides plots of filter flux as a function of time and temperature for all concentrations tested and for both pre- and post-leach slurries. 


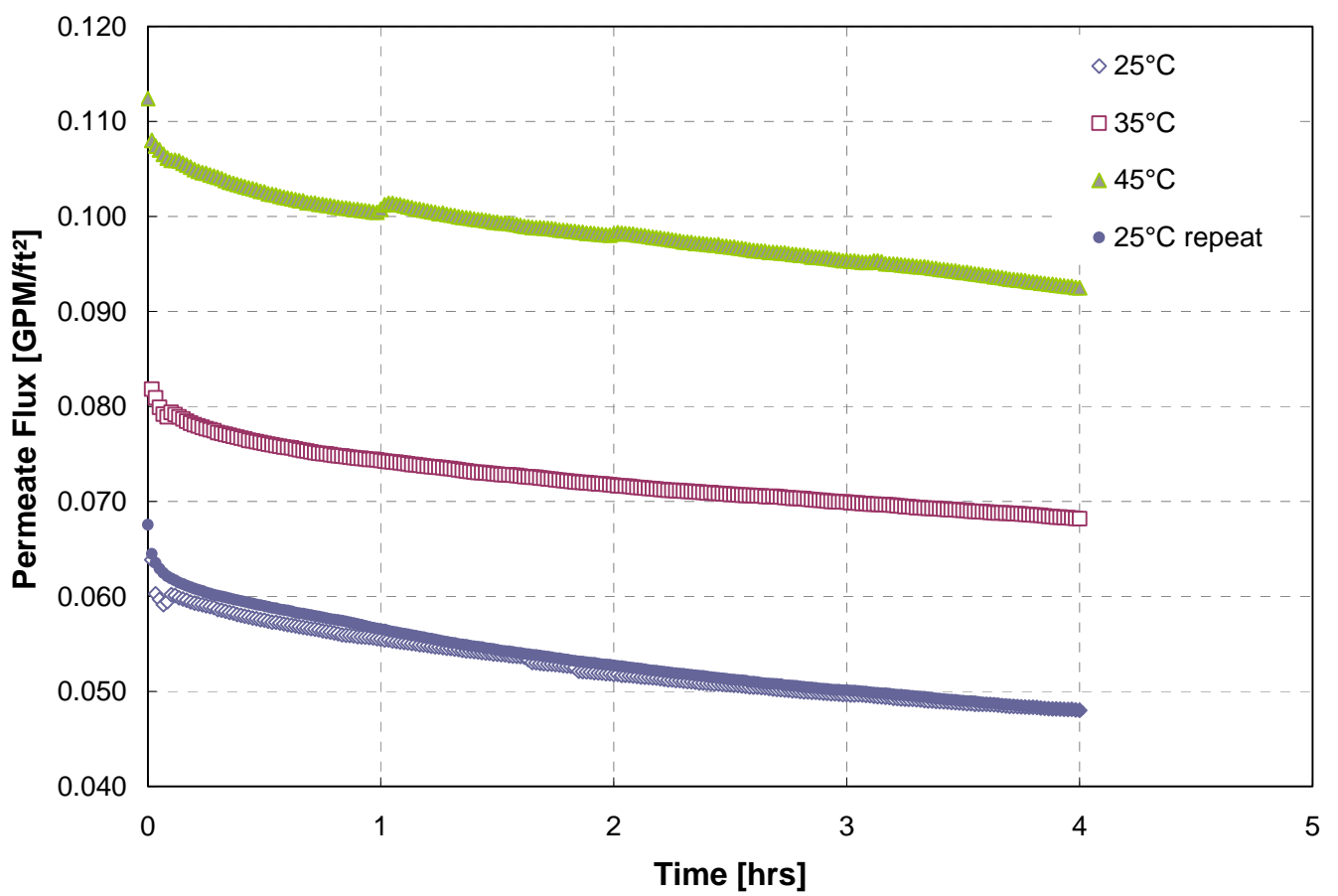

Figure 7.3. Filter Flux Data Collected During the Initial (Preleach) Blended Simulant Temperature Tests. Plot shows the filter flux as a function of time for a $5.0 \mathrm{wt} \%$ (concentration 1) blended simulant slurry at $25^{\circ} \mathrm{C}, 35^{\circ} \mathrm{C}$, and $45^{\circ} \mathrm{C}$. Initial and repeat measurements at $25^{\circ} \mathrm{C}$ overlap and are difficult to differentiate.

To analyze the temperature trends that exist in the filter flux data, the filter flux is plotted in accordance with Equation 7.8. To limit the amount of data for analysis, flux is considered only at halfhour intervals. In addition, flux data are only considered after 1-hour of continuous filtration in an attempt to prevent inclusion of flux instabilities that typically affect the first hour of operation following filter backpulses. Next, linear regression analysis is applied to the data to determine 1) if Equation 7.8 adequately captures the temperature trends and 2) the best-fit values of $\alpha$ and $\beta$. Figure 7.4 shows the result of this analysis for the preleach blended simulant slurry at $5.0 \mathrm{wt} \%$ UDS (i.e., the data shown in Figure 7.3). It should be noted that only data at 1-hour intervals are shown here to avoid plot clutter. 


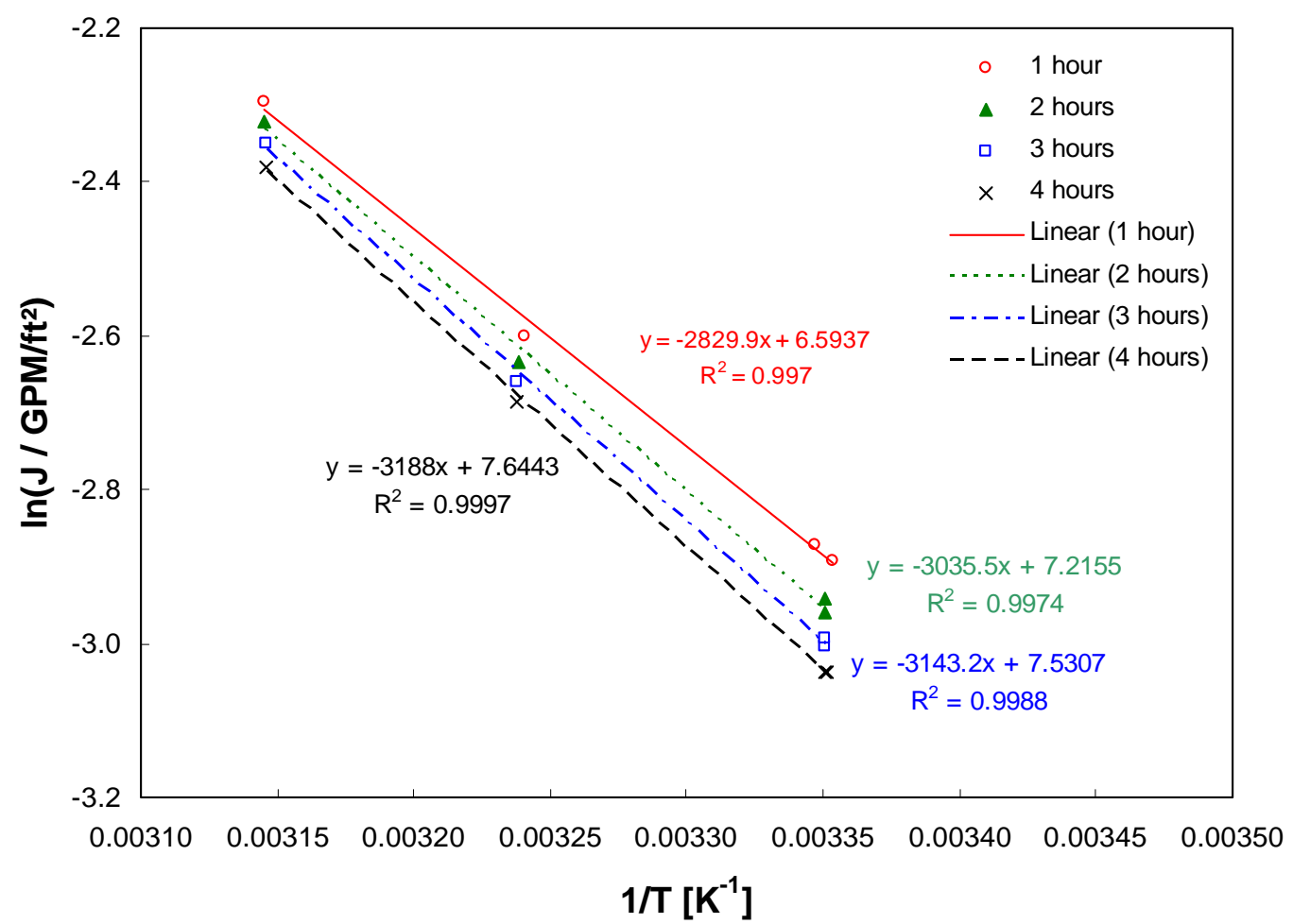

Figure 7.4. Filter Flux Data Plotted in Accordance with Equation 7.8. Data correspond to a preleach blended simulant slurry at $5.0 \mathrm{wt} \%$ UDS.

For the four times shown in Figure 7.4, the flux-versus-temperature data are relatively linear when plotted in accordance Equation 7.8. Linear fits of this data provide slopes of $-2830 \mathrm{~K},-3040 \mathrm{~K},-3140 \mathrm{~K}$, and $-3190 \mathrm{~K}$ at 1, 2, 3, and 4 hours, respectively. Likewise, regression analysis provides intercept values of $6.6,7.2,7.5$, and 7.6 at 1,2,3, and 4 hours, respectively. Values of $\alpha$ and $\beta$ can be determined from the fit slope and intercept using the equations:

$$
\begin{gathered}
\beta=-S_{\text {fit }} \\
\alpha=\exp \left(I_{f i t}\right)
\end{gathered}
$$

where $S_{f i t}$ and $I_{f i t}$ are the slope and intercept of the data determined by linear regression analysis. For the current example, the $\alpha$ and $\beta$ corresponding to the 1-hour fit are $730 \mathrm{GPM} / \mathrm{ft}^{2}$ and $2830 \mathrm{~K}$, respectively. It should be noted that $\alpha$ corresponds to the limiting filter flux as $\mathrm{T} \rightarrow \infty$. This limiting flux is not meaningful in terms of the typical CUF operating temperatures. As such, $\alpha$ will be reported as the flux at $25^{\circ} \mathrm{C}, J_{0,298}$, which is defined as:

$$
J_{o, 298}=\alpha \exp \left(-\frac{\beta}{298 \mathrm{~K}}\right)
$$


This definition can also be incorporated into Equation 7.8 such that

$$
J=J_{o, 298} \exp \left[-\beta\left(\frac{1}{T}-\frac{1}{298 \mathrm{~K}}\right)\right]
$$

Table 7.17 shows the evolution of $J_{o, 298}$ and $\beta$ for the $5.0 \mathrm{wt} \%$ UDS preleach blended simulant slurry over a 4-hour period of continuous recycle filtration. The range of values and temperature trends is discussed in sections that follow. It should be noted that analysis of data corresponding to higher concentrations and to the leached and washed blended simulant slurry is similar to that shown in Figure 7.4. Data are generally linear when plotted in accordance with Equation 7.8, which allows determination of both $J_{o, 298}$ and $\beta$ from the results of linear regression analysis. A summary of regression plots for all concentrations and test slurries is provided in Appendix B. The sections that follow are limited to reporting and discussion of regressed values $J_{o, 298}$ and $\beta$.

Table 7.17. Temperature Constants $J_{o, 298}$ and $\beta$ for the $5.0 \mathrm{wt} \%$ UDS Preleach Blended Simulant Slurry as a Function of Filtration Time

\begin{tabular}{ccc}
\hline $\begin{array}{c}\text { Time Into Run } \\
(\mathrm{hrs})\end{array}$ & $\begin{array}{c}\beta \\
(\mathrm{K})\end{array}$ & $\begin{array}{c}\mathrm{J}_{\mathrm{o}, 298} \\
\left(\mathrm{GPM} / \mathrm{ft}^{2}\right)\end{array}$ \\
\hline 1.0 & 2830 & 0.0549 \\
1.5 & 2930 & 0.0530 \\
2.0 & 3040 & 0.0513 \\
2.5 & 3100 & 0.0500 \\
3.0 & 3150 & 0.0490 \\
3.5 & 3180 & 0.0480 \\
4.0 & 3190 & 0.0472 \\
Average & 3060 & $\mathbf{0 . 0 5 0 5}$ \\
Standard Deviation & 130 & $\mathbf{0 . 0 0 2 8}$ \\
\hline
\end{tabular}

\subsubsection{Preleach Filter Flux Temperature Correlation Parameters}

Table 7.18 and Table 7.19 summarize the temperature correlation constants for the preleach blended simulant slurry at various UDS concentrations. Figure 7.5 and Figure 7.6 show the time evolution of the temperature correlation parameters $J_{o, 298}$ and $\beta$.

The regressed $J_{o, 298}$ appears to be strong functions of both time and slurry UDS concentration. In particular, $J_{0,298}$ both decreases with increasing time and increasing slurry UDS concentration. This is expected, as $J_{o, 298}$ represents a reference flux and, as such, will be subject to the same variables as a steady-temperature flux. Thus, the time dependence is indicative of filter fouling (both pore and cake) whereas the concentration dependence is indicative of increased filter cake thickness/resistance at higher solids concentrations. 
The regressed $\beta$ values also appear to be a function of both time and temperature; however, the variation of $\beta$ with respect to these variables is less coherent than that observed in $J_{0,298}$. The following general observations can be made with respect to the regressed $\beta$ values:

- $\beta$ ranges from $2600 \mathrm{~K}$ to $3400 \mathrm{~K}$

- At the lowest concentration (5.0 wt\% UDS), $\beta$ steadily increases with time

- At middle concentrations (7.3 wt $\%$ to $14.9 \mathrm{wt} \% \mathrm{UDS}), \beta$ is relatively constant with time

- At the highest concentrations (20.9 wt $\%$ and $28.3 \mathrm{wt} \%$ UDS), $\beta$ decreases with time.

Because of the contradictory time trends between the lowest and highest concentration slurries, it is difficult to assess the slurry concentration effects. However, based on three middle concentrations (from 7.3 to $14.9 \mathrm{wt} \%$ UDS), the $\beta$ temperature correlation results indicate a general increase in $\beta$ with increasing slurry concentration. In physical terms, this means that increased temperature for concentrated slurries yields a larger improvement in filter flux relative to that that occurs for dilute slurries. Typically, filter resistance at high slurry concentration is a result of the formation of a filter cake over the surface of the filter. As such, high $\beta$ at increased slurry concentration suggests that flux improvements result from changes in the cake structure or thickness with temperature. These changes reduce the resistance of the filter at higher temperatures.

Table 7.18. Temperature Constant $J_{o, 298}$ at select UDS Concentrations for the Preleach Blended Simulant Slurry.

\begin{tabular}{ccccccc}
\hline \multirow{2}{*}{$\begin{array}{c}\text { Time Into Run } \\
(\mathrm{hrs})\end{array}$} & \multicolumn{5}{c}{$J_{0,298}$ at Select UDS Concentrations $\left(\mathrm{GPM} / \mathrm{ft}^{2}\right)$} \\
\cline { 2 - 7 } & $5.0 \mathrm{wt} \%$ & $7.3 \mathrm{wt} \%$ & $10.5 \mathrm{wt} \%$ & $14.9 \mathrm{wt} \%$ & $20.9 \mathrm{wt} \%$ & $28.3 \mathrm{wt} \%$ \\
\hline 1.0 & 0.055 & 0.048 & 0.041 & 0.035 & 0.028 & 0.022 \\
1.5 & 0.053 & 0.047 & 0.040 & 0.034 & 0.027 & 0.022 \\
2.0 & 0.051 & 0.046 & 0.039 & 0.032 & 0.026 & 0.021 \\
2.5 & 0.050 & 0.045 & 0.038 & 0.032 & 0.025 & 0.020 \\
3.0 & 0.049 & 0.044 & 0.037 & 0.031 & 0.024 & 0.019 \\
3.5 & 0.048 & 0.043 & 0.036 & 0.030 & 0.023 & 0.019 \\
4.0 & 0.047 & 0.042 & 0.036 & 0.029 & 0.023 & 0.018 \\
Average & 0.050 & 0.045 & 0.038 & 0.032 & 0.025 & 0.020 \\
Standard Deviation & 0.003 & 0.002 & 0.002 & 0.002 & 0.002 & 0.001 \\
\hline
\end{tabular}

Table 7.19. Temperature Constant $\beta$ at Select UDS Concentrations for the Preleach Blended Simulant Slurry.

\begin{tabular}{ccccccc}
\hline Time Into Run & \multicolumn{5}{c}{$\beta$ at Select UDS Concentrations (K) } \\
\cline { 2 - 6 }$(\mathrm{hrs})$ & $5.0 \mathrm{wt} \%$ & $7.3 \mathrm{wt} \%$ & $10.5 \mathrm{wt} \%$ & $14.9 \mathrm{wt} \%$ & $20.9 \mathrm{wt} \%$ & $28.3 \mathrm{wt} \%$ \\
1.0 & 2830 & 2810 & 2980 & 3290 & 3280 & 3420 \\
1.5 & 2930 & 2810 & 2970 & 3270 & 3170 & 3170 \\
2.0 & 3040 & 2810 & 2990 & 3240 & 3110 & 3060 \\
2.5 & 3100 & 2850 & 3020 & 3210 & 3030 & 2960 \\
3.0 & 3140 & 2860 & 2960 & 3200 & 2970 & 2820 \\
3.5 & 3180 & 2870 & 2940 & 3130 & 2940 & 2730 \\
4.0 & 3190 & 2890 & 2970 & 3120 & 2850 & 2590 \\
Average & 3060 & 2840 & 2970 & 3210 & 3050 & 2970 \\
Standard Deviation & 130 & 30 & 20 & 70 & 150 & 280 \\
\hline
\end{tabular}


Based on the results listed in Table 7.18, Table 7.19, Figure 7.5, and Figure 7.6, the following overall temperature correction equation can be proposed for the preleach blended simulant slurry tested herein:

$$
J_{25^{\circ} \mathrm{C}}^{\mathrm{AR}}=J_{T} \exp \left[3000\left(\frac{1}{T}-\frac{1}{298}\right)\right]
$$

Here, $J_{25^{\circ} \mathrm{C}}^{A R}$ is the temperature corrected flux of a preleach (as-received) slurry. This correction equation uses a $\beta$ value of $3000 \pm 200 \mathrm{~K}$, which is derived by taking a global average and standard deviation of the $\beta$ values presented in Table 7.19. After Equation 7.5, the correction references a measured flux $J_{T}$ rather than using $\alpha$ or its derivatives (i.e., $J_{o, 298}$ ). The choice of a single global $\beta$ value is driven by the contradictory trends observed in individually regressed $\beta$ with concentration and time.

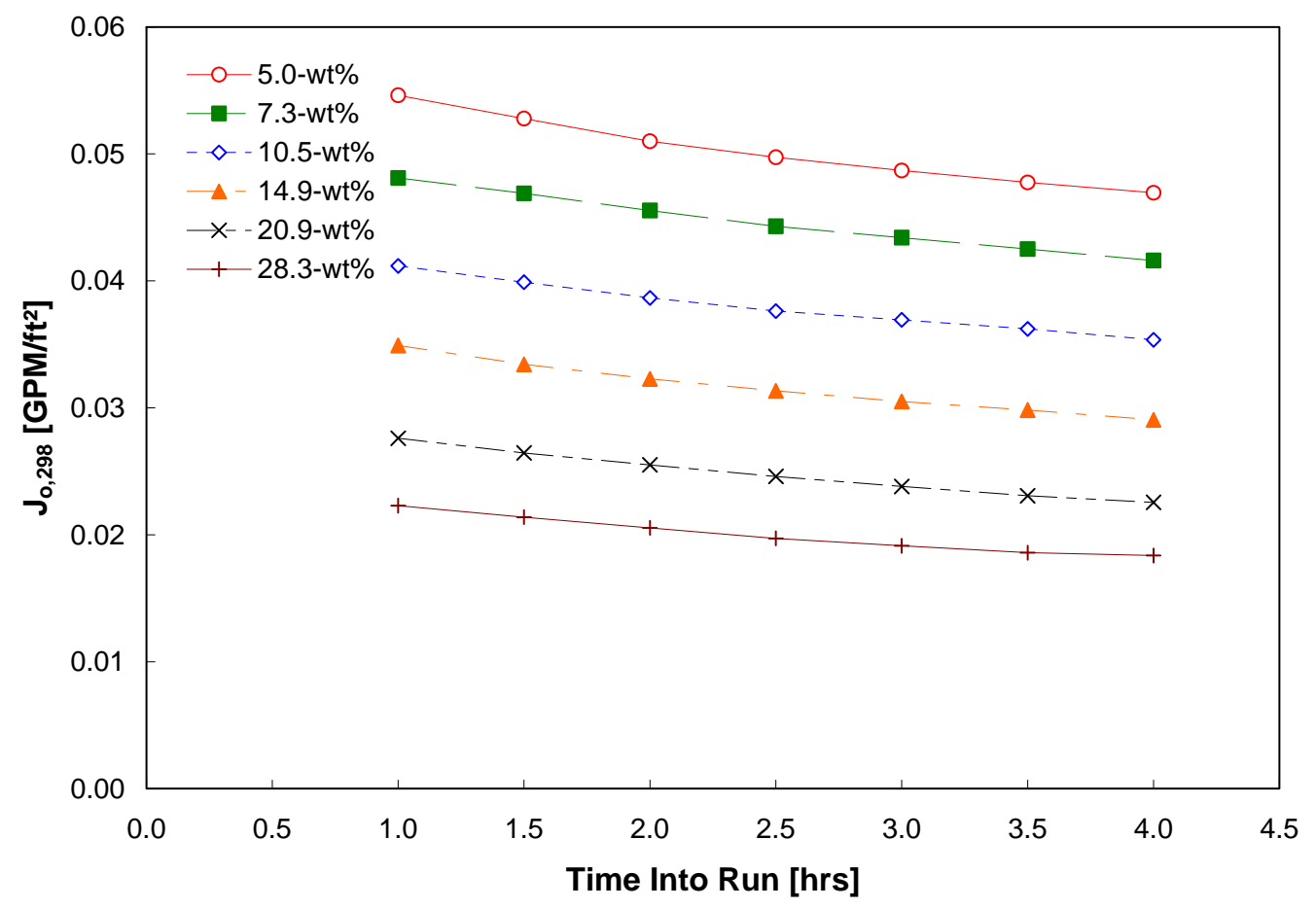

Figure 7.5. Time Evolution of the $\mathrm{J}_{0,298}$ Temperature Correlation Parameter During the Preleach Blended Simulant Slurry Temperature Tests 


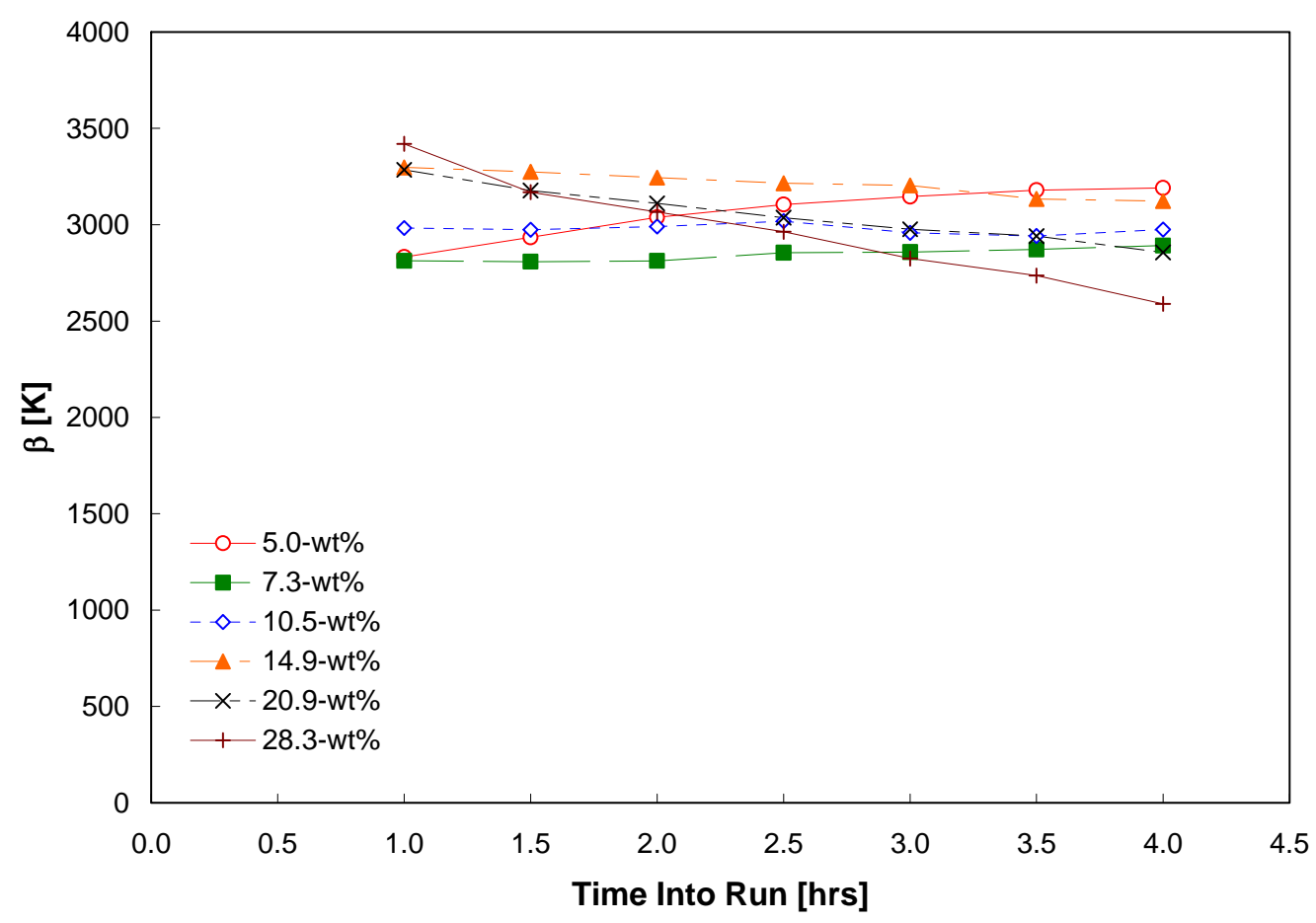

Figure 7.6. Time Evolution of the $\beta$ Temperature Correlation Parameter During the Preleach Blended Simulant Slurry Temperature Tests

\subsubsection{Leached and Washed Filter Flux Temperature Correlation Parameters}

Table 7.20 and Table 7.21 summarize the temperature correlation constants for the leached and washed blended simulant slurry at various UDS concentrations. Figure 7.7 and Figure 7.8 show the time evolution of the temperature correlation parameters $J_{o, 298}$ and $\beta$.

The regressed $J_{o, 298}$ for the leached and washed slurry are strong functions of both time and slurry UDS concentration. $J_{o, 298}$ decreases with increasing time and increasing slurry concentration. This behavior is expected, as $J_{o, 298}$ represents a reference flux and is subject to the same variables as a steadytemperature flux. As before, the time dependence is indicative of filter fouling (both pore and cake) whereas the concentration dependence is indicative of increased filter cake thickness/resistance at higher solids concentrations.

The regressed $\beta$ values for the leached and washed slurry appear to show only slurry concentration effects. Changes in $\beta$ with time appear minimal. The following general observations can be made with respect to the regressed $\beta$ values:

- $\beta$ ranges from 2000 to $2600 \mathrm{~K}$

- At the lowest concentrations (4.8 wt $\%$ and $7.1 \mathrm{wt} \% \mathrm{UDS}$ ), $\beta$ varies from $\sim 2000$ to $\sim 2100 \mathrm{~K}$

- At $10.3 \mathrm{wt} \%$ UDS, $\beta$ is $\sim 2300 \mathrm{~K}$.

- At the highest concentrations ( $15.1 \mathrm{wt} \%$ to $21.7 \mathrm{wt} \%$ ), $\beta$ generally varies from 2400 to $2500 \mathrm{~K}$ 
These trends suggest that $\beta$ increases with increasing slurry concentration. This $\beta$ behavior is consistent with that seen for the preleach blended simulant slurry. As before, it indicates that the flux increase for concentrated slurries as a result of increased temperature is greater than that observed for dilute slurries. For the leached and washed slurry, the improvement appears to happen over a limited concentration range of $4.8 \mathrm{wt} \%$ to $15 \mathrm{wt} \%$ UDS. Increases in slurry concentration beyond this point do not appear to affect $\beta$. As discussed in Section 7.3.2.1, increased $\beta$ at high slurry concentration suggests a change in the filter cake structure that reduces its resistance to filter flux.

Table 7.20. Temperature Constant $J_{o, 298}$ at select UDS Concentrations for the Leached and Washed Blended Simulant Slurry.

\begin{tabular}{ccccccc}
\hline \multirow{2}{*}{$\begin{array}{c}\text { Time Into Run } \\
\text { (hrs) }\end{array}$} & \multicolumn{7}{c}{$J_{o, 298}$ at Select UDS Concentrations $\left(\mathrm{GPM} / \mathrm{ft}^{2}\right)$} \\
\cline { 2 - 7 } 1.0 & $4.8 \mathrm{wt} \%$ & $7.1 \mathrm{wt} \%$ & $10.3 \mathrm{wt} \%$ & $15.1 \mathrm{wt} \%$ & $17.8 \mathrm{wt} \%$ & $21.7 \mathrm{wt} \%$ \\
1.5 & 0.099 & 0.095 & 0.088 & 0.073 & 0.064 & 0.050 \\
2.0 & 0.092 & 0.087 & 0.081 & 0.068 & 0.060 & 0.048 \\
2.5 & 0.087 & 0.081 & 0.076 & 0.064 & 0.056 & 0.046 \\
3.0 & 0.083 & 0.078 & 0.072 & 0.062 & 0.054 & 0.044 \\
3.5 & 0.079 & 0.073 & 0.069 & 0.059 & 0.051 & 0.043 \\
4.0 & 0.076 & 0.071 & 0.066 & 0.057 & 0.049 & 0.041 \\
Average & 0.073 & 0.068 & 0.064 & 0.056 & 0.048 & 0.040 \\
Standard Deviation & 0.084 & 0.079 & 0.074 & 0.063 & 0.055 & 0.044 \\
\hline
\end{tabular}

Table 7.21. Temperature Constant $\beta$ at Select UDS Concentrations for the Leached and Washed Blended Simulant Slurry.

\begin{tabular}{ccccccc}
\hline \multirow{2}{*}{$\begin{array}{c}\text { Time Into Run } \\
\text { (hrs) }\end{array}$} & \multicolumn{7}{c}{$\beta$ at Select UDS Concentrations $(\mathrm{K})$} \\
\cline { 2 - 7 } 1.0 & $4.8 \mathrm{wt} \%$ & $7.1 \mathrm{wt} \%$ & $10.3 \mathrm{wt} \%$ & $15.1 \mathrm{wt} \%$ & $17.8 \mathrm{wt} \%$ & $21.7 \mathrm{wt} \%$ \\
1.5 & 2070 & 2080 & 2290 & 2560 & 2480 & 2620 \\
2.0 & 2050 & 2110 & 2310 & 2450 & 2430 & 2480 \\
2.5 & 2010 & 2050 & 2320 & 2490 & 2440 & 2460 \\
3.0 & 2010 & 2070 & 2290 & 2470 & 2450 & 2450 \\
3.5 & 2050 & 2160 & 2310 & 2480 & 2450 & 2450 \\
4.0 & 2060 & 2140 & 2330 & 2390 & 2440 & 2430 \\
Average & 2030 & 2140 & 2320 & 2390 & 2440 & 2430 \\
Standard Deviation & 2040 & 2110 & 2310 & 2460 & 2450 & 2470 \\
\hline
\end{tabular}

In keeping with the approach developed for the preleach slurry temperature data, an overall temperature correction equation was developed for the leached and washed blended simulant slurry. Based on the results listed in Table 7.20, Table 7.21, Figure 7.7, and Figure 7.8, this temperature correlation is:

$$
J_{25^{\circ} \mathrm{C}}^{C L W}=J_{T} \exp \left[2300\left(\frac{1}{T}-\frac{1}{298}\right)\right]
$$


Here, $J_{25^{\circ} \mathrm{C}}^{C L W}$ is the temperature-corrected flux of a caustic leached and washed (CLW) slurry. This correction equation uses a $\beta$ value of $2300 \pm 200 \mathrm{~K}$, which is derived by taking a global average and standard deviation of the $\beta$ values presented in Table 7.21. Although a more rigorous approach that includes the concentration functionality of $\beta$ could be derived from the data in Table 7.21, this is excluded from the current approach for simplicity and for ease of comparison against the temperature correlation developed for the preleach slurry.

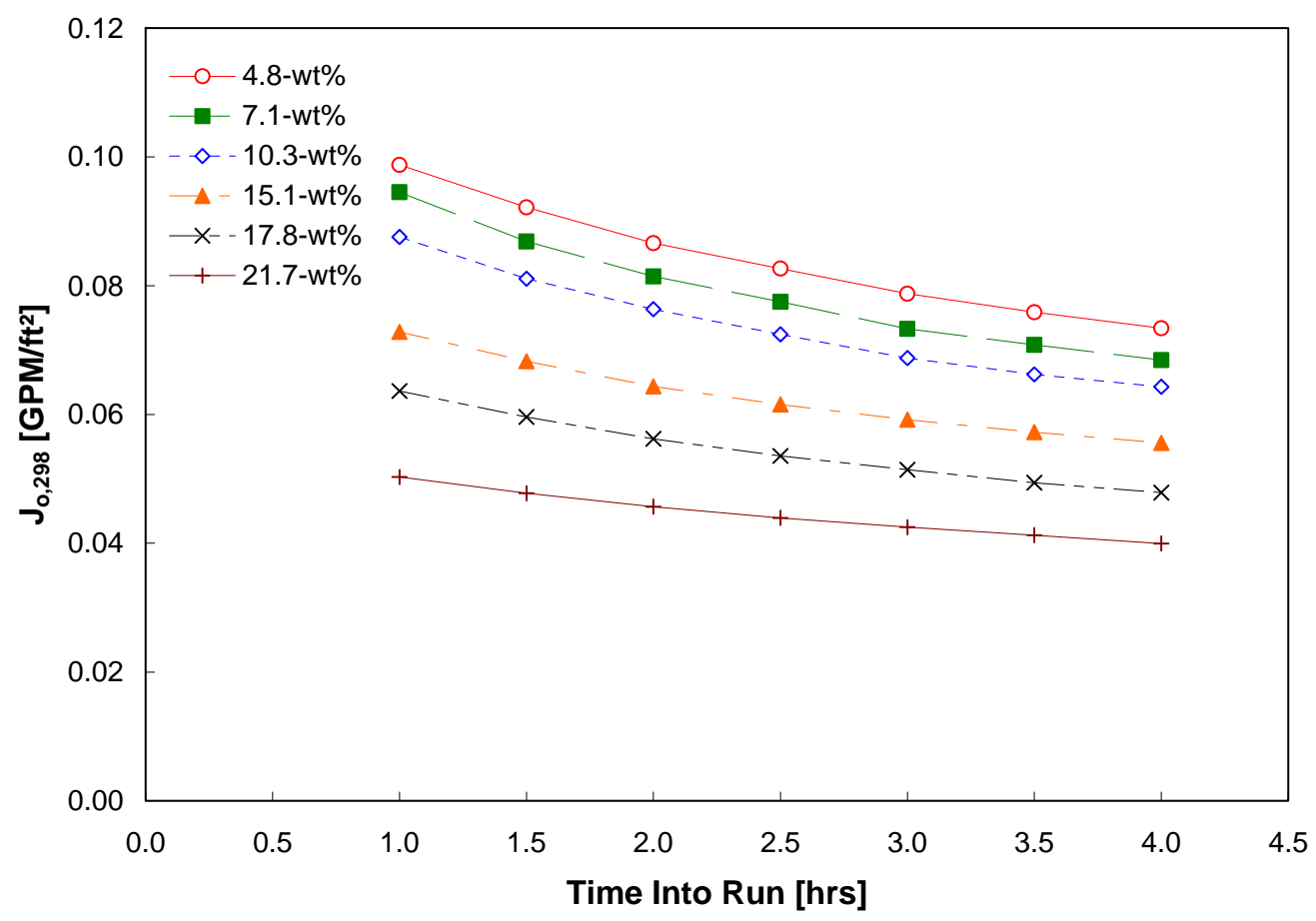

Figure 7.7. Time Evolution of the $J_{o, 298}$ Temperature Correlation Parameter During the Leached and Washed Blended Simulant Slurry Temperature Tests 


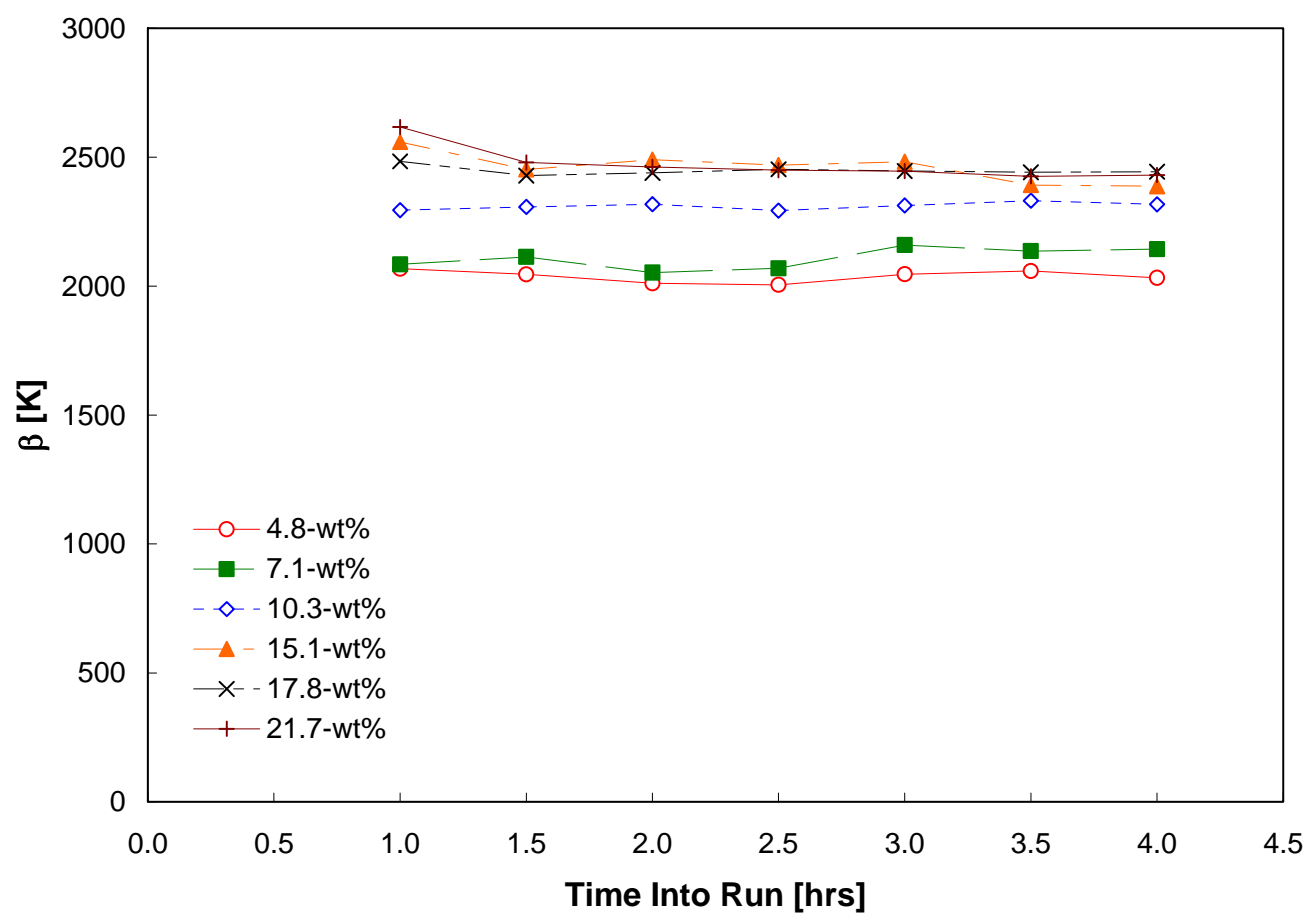

Figure 7.8. Time Evolution of the $\beta$ Temperature Correlation Parameter During the Leached and Washed Blended Simulant Slurry Temperature Tests

\subsubsection{Comparison of Temperature Correlations}

The existing temperature correlation used for temperature correction of flux data, as defined by WTP-RPT-043, is

$$
J_{25^{\circ} \mathrm{C}}=J_{T} \exp \left[2500\left(\frac{1}{T}-\frac{1}{298}\right)\right]
$$

Based on the results of the temperature test studies described herein, two separate temperature correction correlations for an "as-prepared" (i.e., preleach) blended simulant slurry and a caustic leached and washed blended simulant slurry were derived. For the preleach blended simulant slurry, the derived correction equation is:

$$
J_{25^{\circ} \mathrm{C}}^{\mathrm{AR}}=J_{T} \exp \left[3000\left(\frac{1}{T}-\frac{1}{298}\right)\right]
$$

The preleach slurry correction equation employs a $\beta$ value of $3000 \pm 200 \mathrm{~K}$. Likewise, the derived correction equation for the caustic leached and washed blended simulant slurry is:

$$
J_{25^{\circ} \mathrm{C}}^{C L W}=J_{T} \exp \left[2300\left(\frac{1}{T}-\frac{1}{298}\right)\right]
$$


This correction equation employs a $\beta$ value of $2300 \pm 200 \mathrm{~K}$.

These temperature correlations differ only in the value of $\beta$ used. The correction equation for the preleach simulant shows a significantly higher value of $3000 \pm 200 \mathrm{~K}$ relative to that of the existing correlation (i.e., $2500 \mathrm{~K}$ ). This difference may derive from a number of factors including flux transience, filter length, slurry concentration, and permeate physical and chemical properties. On the other hand, the $\beta$ value for the caustic leached and washed blended simulant $(2300 \pm 200 \mathrm{~K})$ agrees with the existing coefficient of $2500 \mathrm{~K}$ to within the range of variation observed in the measurement.

\subsubsection{The Effect of Permeate Viscosity and Its Implications}

Section 7.2 discusses the importance of permeate viscosity with respect to filter flux. By incorporating the temperature dependence of waste simulant slurry permeate viscosity in to the Darcy equation, the following relationship can be derived:

$$
J=\left(\frac{T M P}{\mu_{o} R_{m}}\right) \exp \left(-\frac{\lambda}{T}\right)
$$

This equation suggests that if a lowering in the permeate viscosity is the sole driver for increased filter flux, then the $\beta$ value that characterizes the change in flux with temperature should be equivalent to $\lambda$. Likewise, differences between $\beta$ and $\lambda$ can provide information on how temperature changes other controlling mechanisms for filter flux.

Table 7.22 compares regressed values of $\beta$ and $\lambda$ for both as-prepared and leached and washed blended simulant slurries. For both the as-prepared and the leached and washed blended simulant slurries, $\beta$ is significantly larger than $\lambda$. This indicates that changes in slurry temperature improve crossflow filtration flux beyond that provided by lowered permeate viscosity alone. Possible factors yielding this increase are 1) a change in the slurry filter cake structure or thickness or 2) a change in the filter medium (such as increased porosity via thermal expansion). Given that the $\beta$ values also appear to increase with increasing slurry concentration (although this trend is less conclusive for the preleach slurry-see Section 7.3.2), it is likely that the main factor yielding $\beta>\lambda$ is filter cake structure/thickness.

Table 7.22. Comparison of $\beta$ and $\lambda$ Values Regressed for Both As-prepared and Leached/Washed Blended Simulant Slurries

\begin{tabular}{ccc}
\hline Simulant Slurry & $\beta(\mathrm{K})$ & $\lambda(\mathrm{K})$ \\
\hline As-Prepared & $3000 \pm 200$ & 1950 \\
Caustic Leached and Washed & $2300 \pm 200$ & 1680 \\
\hline
\end{tabular}

In short, the observation that 1) $\beta$ is greater than $\lambda$ and that 2) $\beta$ increases with increased slurry concentration indicates that changes in the filter cake structure at higher temperatures yield an improvement in flux. Changes in filter cake structure and thickness can occur as a dynamic process during filtration, whereby existing cake is sheared away and replaced by new solids, or can occur during backpulsing, when the filter cake is fully disturbed and forced off the filter surface. An additional factor 
that may change cake structure is the change in compressive force exerted by permeate that passes through the filter cake with changing permeate viscosity. Lower permeate viscosity would tend to lower the compressive force applied to the filter cake, resulting in a less compact (lower resistance) cake at higher temperatures. Although the data generated from temperature testing do not allow assessment of which mechanism functions herein, data measured during fines fouling testing carried out under the simulant development test plan (TP-RPP-WTP-469 ${ }^{(\mathrm{a})}$ ) provide insight into the mechanism governing filter cake restructuring.

Figure 7.9 shows filter flux data corresponding to a $\sim 5 \mathrm{wt} \%$ blended simulant fines fouling test employing zirconium oxide $\left(\mathrm{ZrO}_{2}\right)$ fines. A detailed description of this experiment and the simulant make-up can be found in Section 5 of WTP-RPT-183 ${ }^{\mathrm{b}}$. The figure shows blended simulant temperature behavior over four distinct regions (as numbered in the graph). These are:

- $\underline{\text { Region } 1}$ (0 to $120 \mathrm{~min}$ ) shows filter flux at $25^{\circ} \mathrm{C}$ during continuous recycle filtration.

- $\underline{\text { Region } 2}$ (120 to $180 \mathrm{~min}$ ) shows the continuous recycle filter flux during heating of the slurry from $25^{\circ} \mathrm{C}$ to $45^{\circ} \mathrm{C}$. The filter was not backpulsed at any time before, during, or after this heat-up period.

- $\underline{\text { Region } 3}$ (180 to $290 \mathrm{~min}$ ) shows filter flux at $45^{\circ} \mathrm{C}$ during continuous recycle filtration. The filter was not backpulsed at any time before or during this operation. However, the filter was backpulsed at the end of this region.

- Region 4 (290 to $540 \mathrm{~min}$ ) shows the continuous recycle filter flux at $45^{\circ} \mathrm{C}$ with intermediate backpulsing (i.e., every $30 \mathrm{~min}$ ). The filter was backpulsed before this region.

The filter flux behavior shown in Figure 7.9 suggests that filter backpulsing, rather than dynamic restructuring during continuous recycle filtration, is the primary cause of cake restructuring. This is evidenced by the fact that

- Heating from $25^{\circ} \mathrm{C}$ to $45^{\circ} \mathrm{C}$ provides only an increase in filter flux of $\sim 0.02 \mathrm{GPM} / \mathrm{ft}^{2}$ (region 2),

- Steady flux at $45^{\circ} \mathrm{C}$ is achieved shortly after the temperature set point is reached (region 3), and

- The backpulse between regions 3 and 4 provides an additional $\sim 0.02 \mathrm{GPM} / \mathrm{ft}^{2}$ increase in filter flux over that provided by temperature increase alone.

Based on this information, it can be speculated that flux improvements in region 2 derive from lowering of permeate viscosity alone. In addition, the steady flux in region 3 suggests that axial shear is not sufficient to restructure the filter cake alone. Finally, the jump in permeate flux that occurs between regions 3 and 4 is likely a result of changes in the filter cake structure/thickness facilitated by backpulsing.

(a) RL Russell, and HD Smith. 2007. Test Plan for the Development and Demonstration of Leaching and Ultrafiltration Simulants. 24590-101-TSA-W000-0004-182-00001 Rev 00A (TP-RPP-WTP-469, Rev. 0), Pacific Northwest National Laboratory, Richland, Washington.

(b) RL Russell, HD Smith, JM Billing, RA Peterson, and DE Rinehart. 2008. Development and Demonstration of Ultrafiltration Simulants. WTP-RPT-183, Pacific Northwest National Laboratory, Richland, Washington. 
WTP-RPT-168, Rev 0

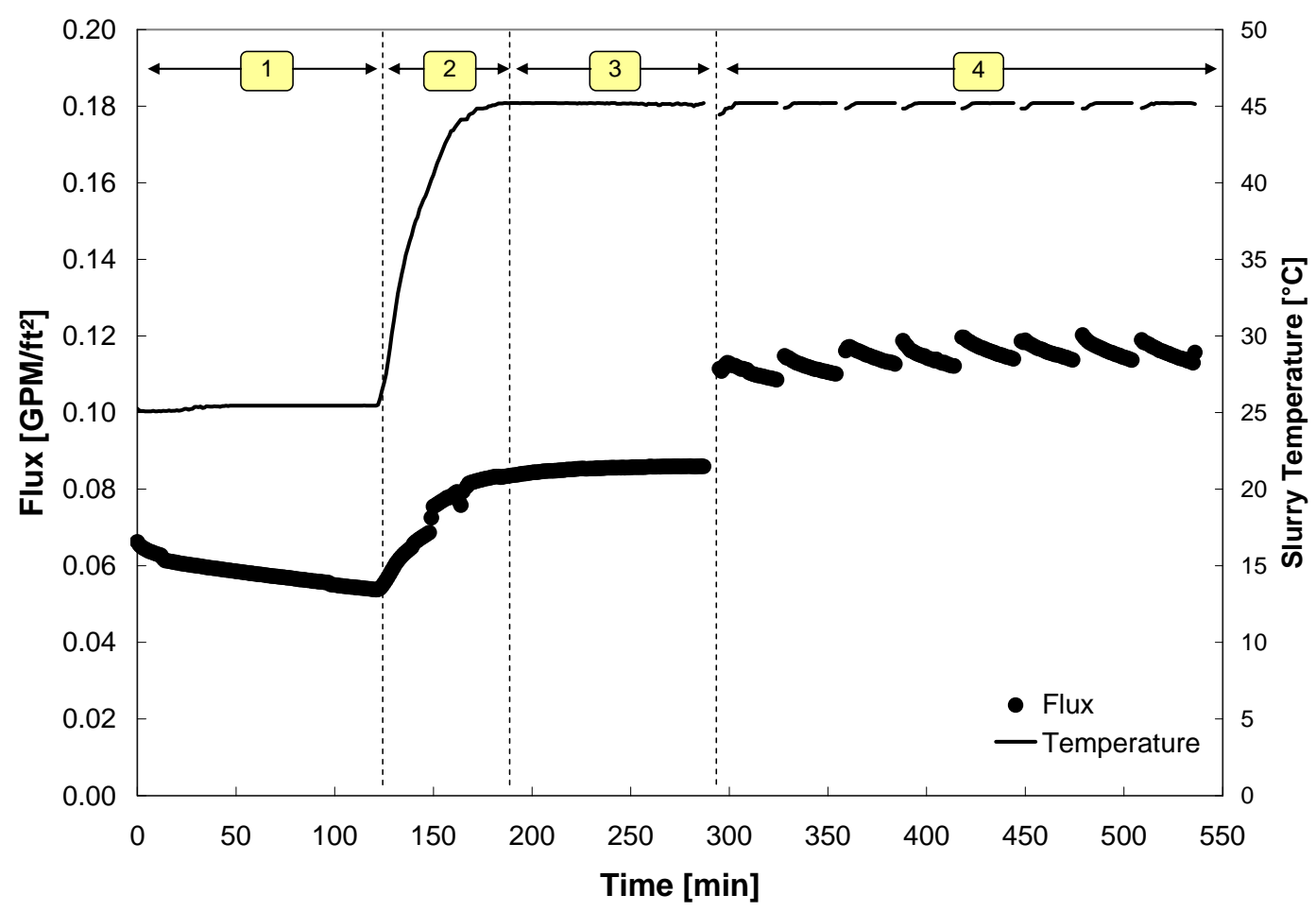

Figure 7.9. Time Evolution of Filter Flux for a Blended Simulant Slurry (with $\mathrm{ZrO}_{2}$ fines) During HeatUp and Backpulsing Tests. Data taken from WTP-RPT-183

To test the assertions made in the preceding paragraph, the flux data in Figure 7.9 are corrected for temperature (to $25^{\circ} \mathrm{C}$ ) using two separate approaches. In the first approach, the flux is corrected for permeate viscosity variation only such that

$$
J_{25^{\circ} \mathrm{C}}=J_{T} \exp \left[\lambda\left(\frac{1}{T}-\frac{1}{298 \mathrm{~K}}\right)\right]
$$

In the second approach, flux data are corrected for both permeate and cake variation such that,

$$
J_{25^{\circ} \mathrm{C}}=J_{T} \exp \left[\beta\left(\frac{1}{T}-\frac{1}{298 \mathrm{~K}}\right)\right]
$$

The data in Figure 7.9 correspond to the preleach blended simulant slurry with $\mathrm{ZrO}_{2}$ fines. Thus, correction employs $\lambda=1950 \mathrm{~K}$ and $\beta=3000 \mathrm{~K}$. The result of correction is shown in Figure 7.10 and indicates the following:

- In region 1, where temperature corrections are minor, both permeate viscosity and full permeate viscosity and cake variation corrections provide similar results

- In regions 2 and 3, the permeate viscosity correction appears to provide the most appropriate flux correction. The full permeate viscosity and cake variation correction appears to over-correct permeate flux, yielding a sharp drop in permeate flux in region 2 
- In region 4, the full permeate viscosity and cake variation correction appears to provide the most appropriate flux correction. The permeate viscosity correction does not account for the jump in flux that occurs upon the first backpulse at 290 minutes. In contrast, the transition from permeate corrected to fully corrected flux between regions 3 and 4 is nearly seamless.

It is interesting to note that the flux decay observed in region 1 does not carry over into region 3. Indeed, both corrected flux terms indicate a slight increase in flux in region 3 . This increase may suggest some dynamic restructuring of the filter cake during continuous recycle. However, the increase appears to continue well into the backpulsed region 4 , and as such, may result from a gradual release of deeply fouled material at the higher temperatures. This could suggest that increased filtration temperature may arrest or even reverse filter fouling.

Overall, the data and results shown in Figure 7.9 and Figure 7.10 indicate that both permeate viscosity and filter cake formation play important roles in how filter flux behaves with temperature. These results suggest that application of temperature corrections to flux data must consider physical processes accompanying that temperature change such as filter backpulsing. Specifically, temperature variations that occur during continuous filtration without any backpulse appear to be best corrected by considering variation of permeate viscosity alone (such that $\beta=\lambda$ ). On the other hand, changes in temperature accompanied by backpulsing and/or complete disruption of the filter cake need to be treated using the full temperature correlation (i.e., $\beta=3000 \pm 200 \mathrm{~K}$ for preleach materials or $\beta=2300 \pm 200 \mathrm{~K}$ for leached and washed material).

\subsubsection{Precipitation of Solids the Post-Leach Permeate}

Immediately following the cool-down period after caustic leaching, a sample of the leached permeate, TempTest-Post-Leach-FIL, was aliquoted and held for observation over a period of 7 days to determine if any precipitation of solids occurred over long times after leaching. No precipitation of solids from the leached permeate was observed at any time during the 7-day period of observation. This result suggests that if any precipitation of solids does occur after leaching, it reaches completion before the end of the cool-down period or occurs on much longer time scales than observed herein. 


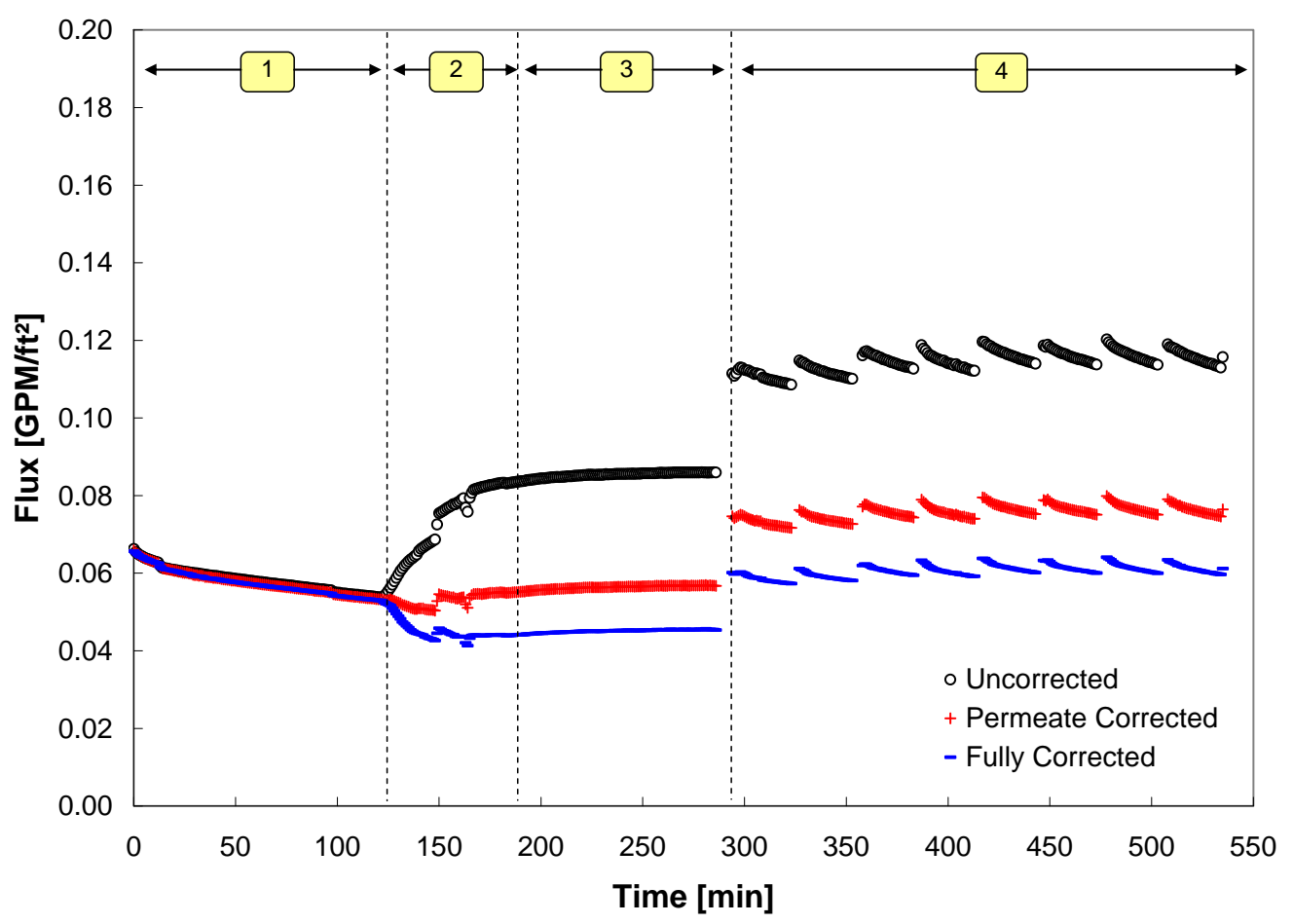

Figure 7.10. Time Evolution of Filter Flux for a Blended Simulant Slurry (with $\mathrm{ZrO}_{2}$ fines) During Heat-Up and Backpulsing Tests. Uncorrected data taken from WTP-RPT-183. The graph shows flux that is uncorrected (for temperature) and flux that is corrected for temperature based on permeate viscosity variation (permeate corrected) and permeate viscosity and cake resistance variations (fully corrected).

\subsection{Conclusions}

The filtration performance of blended simulant slurries was evaluated on a CUF system with an 8-ft filter element installed at $25^{\circ} \mathrm{C}, 35^{\circ} \mathrm{C}$, and $45^{\circ} \mathrm{C}$. From these tests, correlations allowing correction of flux for temperature were derived for both an as-prepared and a caustic leached and washed slurry. In both cases, the correction correlation is of the form:

$$
J_{25^{\circ} \mathrm{C}}=J_{T} \exp \left[\beta\left(\frac{1}{T}-\frac{1}{298}\right)\right]
$$

In this equation, $T$ is temperature in $\mathrm{K}, J_{T}$ is an uncorrected flux at temperature $T$, and $J_{25^{\circ} \mathrm{C}}$ is the corrected flux (to $25^{\circ} \mathrm{C}$ ). The correction correlation is based on an existing equation that is derived from 2-ft filtration work and has been used extensively for flux correction. It is:

$$
J_{25^{\circ} \mathrm{C}}=J_{T} \exp \left[2500\left(\frac{1}{T}-\frac{1}{298}\right)\right]
$$

Analysis of the filter flux at different temperatures indicate $\beta$ values of $3000 \pm 200 \mathrm{~K}$ and $2300 \pm 200 \mathrm{~K}$ for as-prepared (preleach) and caustic leached/washed slurries, respectively. 
These temperature correlations differ only in the value of $\beta$ used. The temperature-correction equations for the preleach simulant show a significantly higher value of $3000 \pm 200 \mathrm{~K}$ relative to that of the existing correlation (i.e., $2500 \mathrm{~K}$ ). This difference may derive from a number of factors including flux transience, filter length, slurry concentration, and permeate physical and chemical properties. On the other hand, the $\beta$ value for the caustic leached/washed blended simulant $(2300 \pm 200 \mathrm{~K})$ agrees with the existing coefficient of $2500 \mathrm{~K}$ to within the range of variation observed in the measurement.

The temperature tests also provided information on the mechanisms underlying the change in filter flux with temperature. Improvement in permeate flux at increased slurry temperature is typically attributed to reduced permeate viscosity. However, for both the as-prepared and caustic leached/washed simulant slurries, the measured increase in filter flux with increasing temperature during the 8 - $\mathrm{ft}$ scale tests was greater than expected from the lowering of permeate viscosity alone. In addition, the improvement in filter flux became greater at higher slurry concentrations. For all 8-ft scaling temperature tests, the increase in temperature was accompanied by filter backpulsing. As such, it appears that changes in filter flux are governed by a combination of changes in the permeate viscosity and in the overall filter resistance. Possible factors effecting filter resistance include 1) the slurry filter cake structure or thickness, 2) changes in the degree of depth fouling, or 3) changes in the filter medium properties such as porosity and pore size.

Given that slurry concentration appears to affect the degree of flux improvement with temperature, changes in the filter cake structure or thickness likely govern a significant part of the filtration performance at increased temperature. These changes can occur as a dynamic process during filtration, whereby existing cake is sheared away and replaced by new solids or they can occur during backpulsing, when the filter cake is fully disturbed and forced off the filter surface. Although the data generated from temperature testing do not allow assessment of which mechanism functions herein, data measured in previous tests suggest that these changes do not occur dynamically at higher temperatures and that they are primarily driven by filter backpulsing. The latter has important implications for how filtration data are corrected for temperature because it indicates that filter cake disruption must be considered when applying temperature correction formulas.

Analysis of filter fouling data reported in Section 5 of WTP-RPT-183 suggests that temperature variations that occur during continuous filtration without any backpulsing are best corrected by considering variation of permeate viscosity alone. As such, the temperature correction formula becomes:

$$
J_{25^{\circ} \mathrm{C}}=J_{T} \exp \left[\lambda\left(\frac{1}{T}-\frac{1}{298 \mathrm{~K}}\right)\right]
$$

where $\lambda$ describes how permeate viscosity changes with temperature and is $1950 \mathrm{~K}$ and $1680 \mathrm{~K}$ for preleach and leached/washed blended simulant slurries, respectively. On the other hand, changes in temperature accompanied by backpulsing and/or complete disruption of the filter cake need to be treated using the full temperature correlation (i.e., that with $\beta=3000 \pm 200 \mathrm{~K}$ for preleach materials or $\beta=2300 \pm 200 \mathrm{~K}$ for leached and washed material). 

WTP-RPT-168, Rev 0

\subsection{Lessons Learned}

The AV/TMP and temperature scaling tests described in Sections 6.0 and 7.0 of this report were subject to a number of difficulties that lessened the significance of the results and their applicability to the engineering design of WTP. The primary difficulties were:

- Inability to achieve target AV conditions as a result of limited pump capacity

- Difference in the transient and fouling behavior of the 2-ft and 8-ft filter scales

- Differences in measured and expected UDS concentrations.

These difficulties and potential lessons and solutions for future testing are discussed in more detail in the sections that follow.

\subsection{Inability to Achieve Target AV Conditions}

The target AV for several AV/TMP and temperature scale-up test conditions could not be achieved as a result of limited pump capacity. The pump capacity was reduced because a PRV was installed in response to revised PNNL pressure safety requirements. The PRV allows an increasing backflow of slurry through the pump at increased pump pressure to prevent pressure build-up in the circulation loop. Although the pump still had sufficient power to meet all target AV and TMPs with a 2-ft filter element, the pressure drop across the 8-ft filter element was sufficiently larger to exceed the maximum PRV pressure setting. Subsequent backflow of slurry through the pump prevented reaching the highest AV conditions for tests examining $40 \mathrm{psid} / 17 \mathrm{fps}$ and $60 \mathrm{psid} / 13 \mathrm{fps}$.

To correct this difficulty, future experiments need to consider 1) the impact of safety-related modifications on CUF throughput and 2) resizing the pump to provide additional capacity or redesigning the safety systems to lessen their impact.

\subsection{Differences in Fouling Behavior of the 2-ft and 8-ft Elements}

Differences in the fouling behavior between the 2-ft and 8-ft scale elements appear to have impacted the results of AV/TMP testing presented in Section 6.0 of this report. The 2-ft scale tests appear to show a decrease with time over the course of the test not observed in the 8 -ft scale tests. This is evidenced by a decrease in filter flux between the initial matrix test condition at $40 \mathrm{psid} / 13 \mathrm{fps}$ and the final matrix repeat of $40 \mathrm{psid} / 13 \mathrm{fps}$ for the 2-ft scale test that is not observed in the 8-ft scale test (see Table 6.8). It is speculated that this potential difference in fouling behavior is caused by the use of different slurry volume to filter surface are ratios in the two tests. Both 2-ft and 8-ft scale tests in Section 6.0 employ $9 \mathrm{~L}$ of slurry. The consequence of this is that there is four times the surface area available for the fines in the 8 -ft tests, which would tend to lessen the impact of fouling. For the current tests, the lower slurry volume-to-surface area ratio may result in the dissimilar fouling trends in the 2 -ft and 8 -ft scale tests.

To correct this difficulty, future 2-ft and 8-ft scale CUF experiments should employ a single (or similar) slurry volume-to-surface area ratio. This change would require either 1) a reduction in the slurry 
volume used in 2-ft scale tests or 2) a modification of the CUF slurry reservoir to accommodate up to 45 to $50 \mathrm{~L}$ of slurry during 8 - $\mathrm{ft}$ tests. Both modifications have their disadvantages. A reduction in the slurry volume used for 2-ft tests would limit the range of UDS concentrations achievable because there is a minimum volume of slurry $(\sim 1 \mathrm{~L})$ required to maintain circulation through the loop. On the other hand, resizing the slurry reservoir to accommodate up to 45 to $50 \mathrm{~L}$ for 8 -ft tests increases the difficulty of slurry handling operations (i.e., slurry load-in) and also presents scale-up issues with regard to mixing and suspension of slurry solids in the larger volume vessel.

\subsection{Differences in Measured and Expected UDS concentrations}

In both AV/TMP and temperature scaling tests, significant differences in the measured and calculated (based on slurry mass balances) UDS concentrations were observed. Examples of these differences may be seen in Table 6.3, Table 6.4, Table 6.6, Table 7.2, Table 7.6, and Figure 6.3. The exact cause of these discrepancies is unknown; however, the repeatability of UDS measurements on a single slurry sample is typically $5 \%$ relative percent error. This indicates that the likely source of error is slurry sampling. To reduce the discrepancy between expected and measured UDS in future CUF testing, the slurry sampling protocol must be examined and revised to allow for better representative sampling of slurry solids. 
WTP-RPT-168, Rev 0

\subsection{References}

CCN 132846. 2006. Comprehensive Review of the Hanford Waste Treatment Plant Flowsheet and Throughput - Assessment Conducted by an Independent Team of External Experts. Chartered by the Hanford Waste Treatment and Immobilization Plant Project at the Direction of the US Department of Energy, Office of Environmental Management, Washington DC.

Daniel RC and RW Shimskey. 2007. Test Plan for Simulant Testing in Support of Phase I Demonstration of the Ultrafiltration and Leaching Processes in the Integrated Test Facility. 24590-101TSA-W000-0004-72-00019 Rev 00A (TP-RPP-WTP-509, Rev. 0). Pacific Northwest National Laboratory, Richland, Washington.

Geeting JGH, RT Hallen, LK Jagoda, AP Poloski, RD Scheele, DR Weier. 2003. Filtration, Washing, and Caustic Leaching of Hanford Tank AZ-101 Sludge. WTP-RPT-043, Rev. 1, Pacific Northwest National Laboratory, Richland, Washington.

Russell RL and HD Smith. 2007. Test Plan for the Development and Demonstration of Leaching and Ultrafiltration Simulants. 24590-101-TSA-W000-0004-182-00001 Rev 00A (TP-RPP-WTP-469, Rev. 0), Pacific Northwest National Laboratory, Richland, Washington.

Russell RL, HD Smith, RA Peterson, and DE Rinehart. 2008. Development and Characterization of Gibbsite Component Simulant. WTP-RPT-176, Pacific Northwest National Laboratory, Richland, Washington.

Russell RL, HD Smith, JM Billing, RA Peterson, and DE Rinehart. 2008. Development and Demonstration of Ultrafiltration Simulants. WTP-RPT-183, Pacific Northwest National Laboratory, Richland, Washington.

Russell RL, RA Peterson, HD Smith, DE Rinehart, PM Aker, and EC Buck. 2008. Development and Characterization of Boehmite Component Simulant. WTP-RPT-184, Pacific Northwest National Laboratory, Richland, Washington.

Shimskey RS. 2007. Software Test Plan: CUF Data Collection Program. RPP-WTP-QA-010, Rev. 0, Pacific Northwest National Laboratory, Richland, Washington.

Sundar PS. 2007. Simulant Testing in Support of Phase I Demonstration of the Ultrafiltration and Leaching Processes in the Integrated Test Facility. 24590-WTP-TSP-RT-07-004, Rev. 0, Bechtel National, Inc., Richland, Washington. 



\section{Appendix A}

\section{Effect of Temperature on Permeate Flux versus Time on 8-Ft Ultrafilter Used for Scale-Up Testing}





\section{Appendix A}

\section{Effect of Temperature on Permeate Flux versus Time on 8-Ft Ultrafilter Used for Scale-Up Testing}

This section presents graphs of all flux versus time measurements for the 4-hour period of continuous recycle filtration associated with Scale-Up Temperature Testing. Section 7 provides a detailed discussion regarding execution of temperature testing and analysis of the resulting filtration data. 
WTP-RPT-168, Rev 0

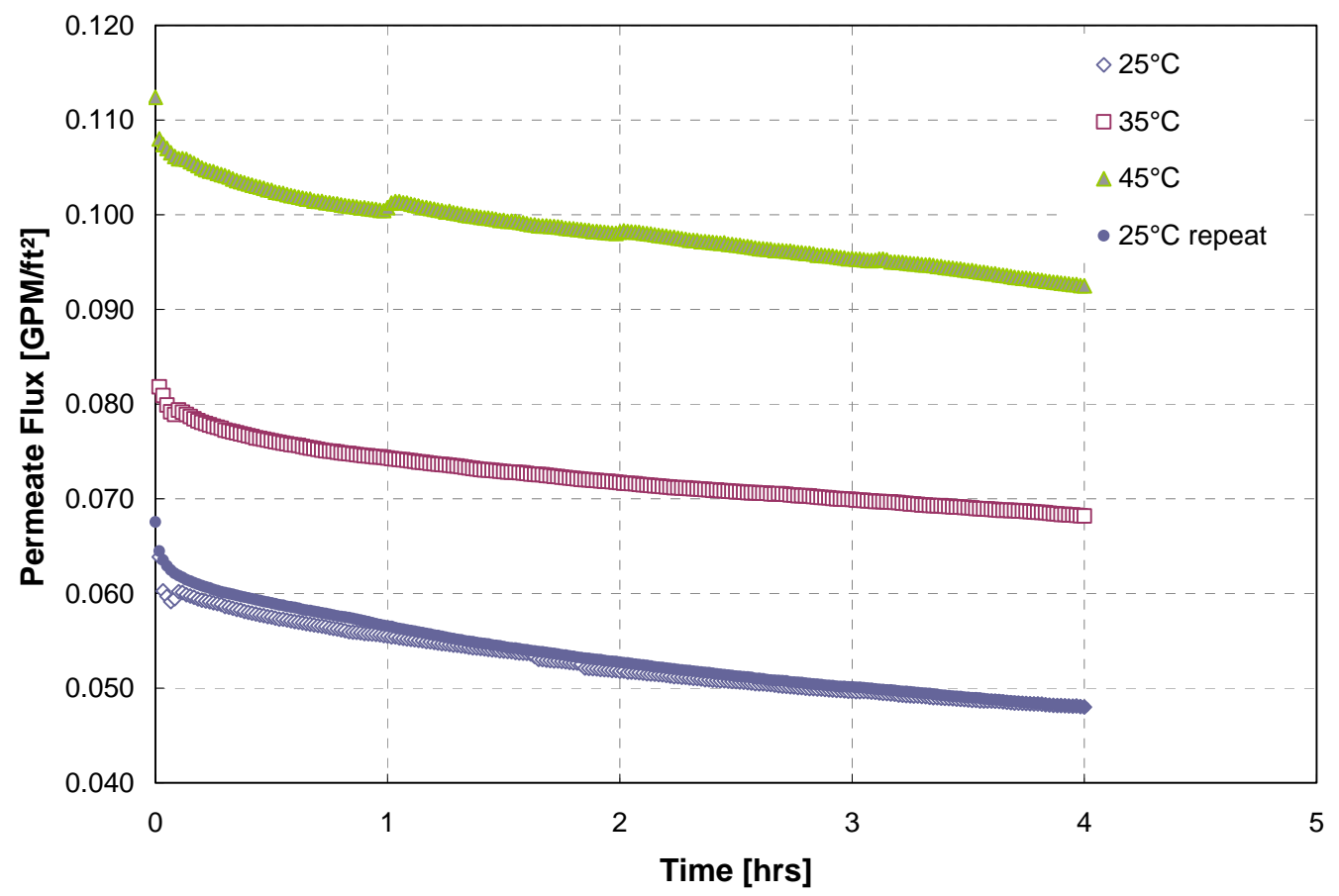

Figure A.1. Permeate Flux Versus Time at $25^{\circ} \mathrm{C}, 35^{\circ} \mathrm{C}, 45^{\circ} \mathrm{C}$, and $25^{\circ} \mathrm{C}$ (repeated) for a Preleach (asprepared) Slurry Containing $5.0 \mathrm{wt} \%$ UDS

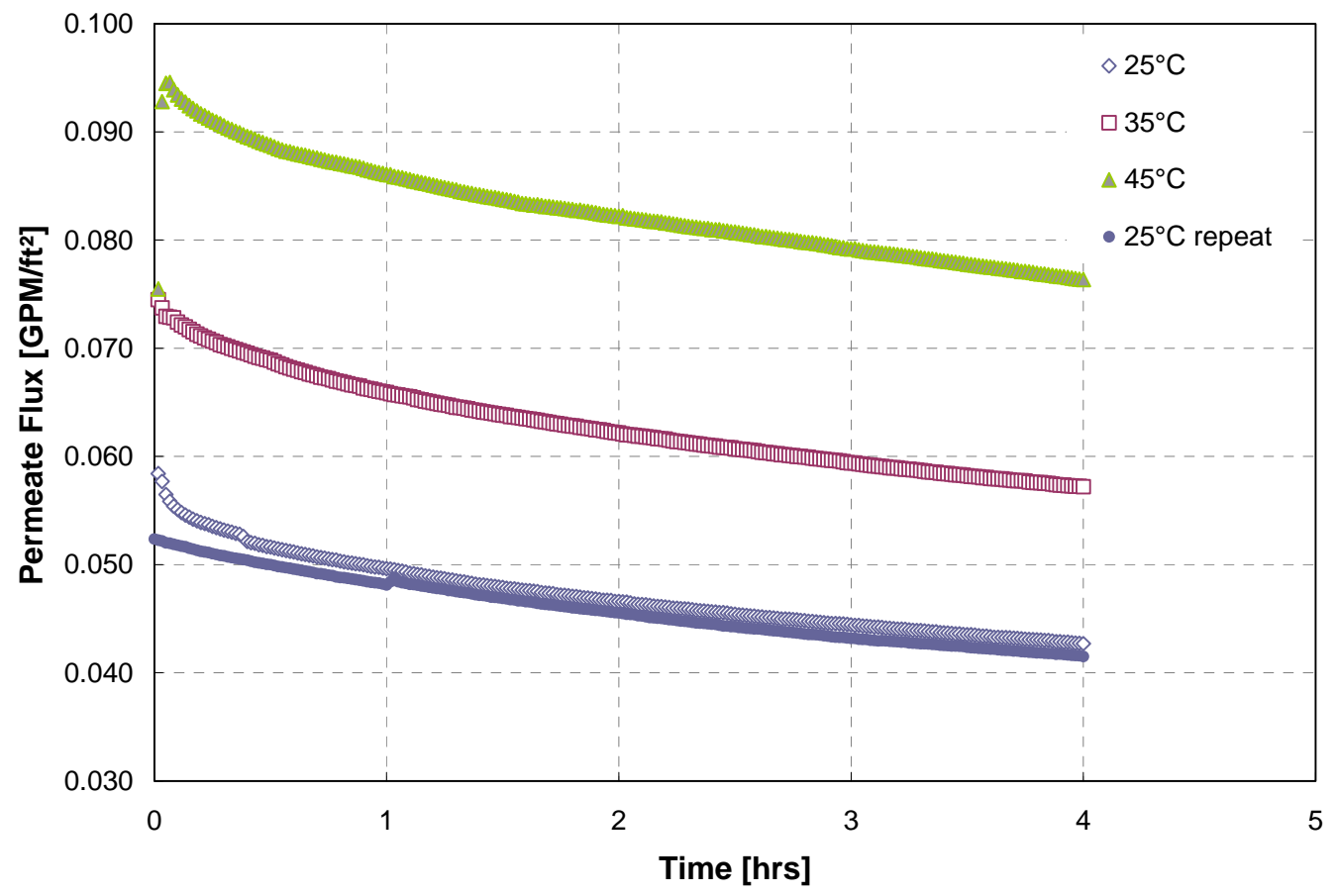

Figure A.2. Permeate Flux Versus Time at $25^{\circ} \mathrm{C}, 35^{\circ} \mathrm{C}, 45^{\circ} \mathrm{C}$, and $25^{\circ} \mathrm{C}$ (repeated) for a Preleach (as-prepared) Slurry Containing $7.3 \mathrm{wt} \%$ UDS 


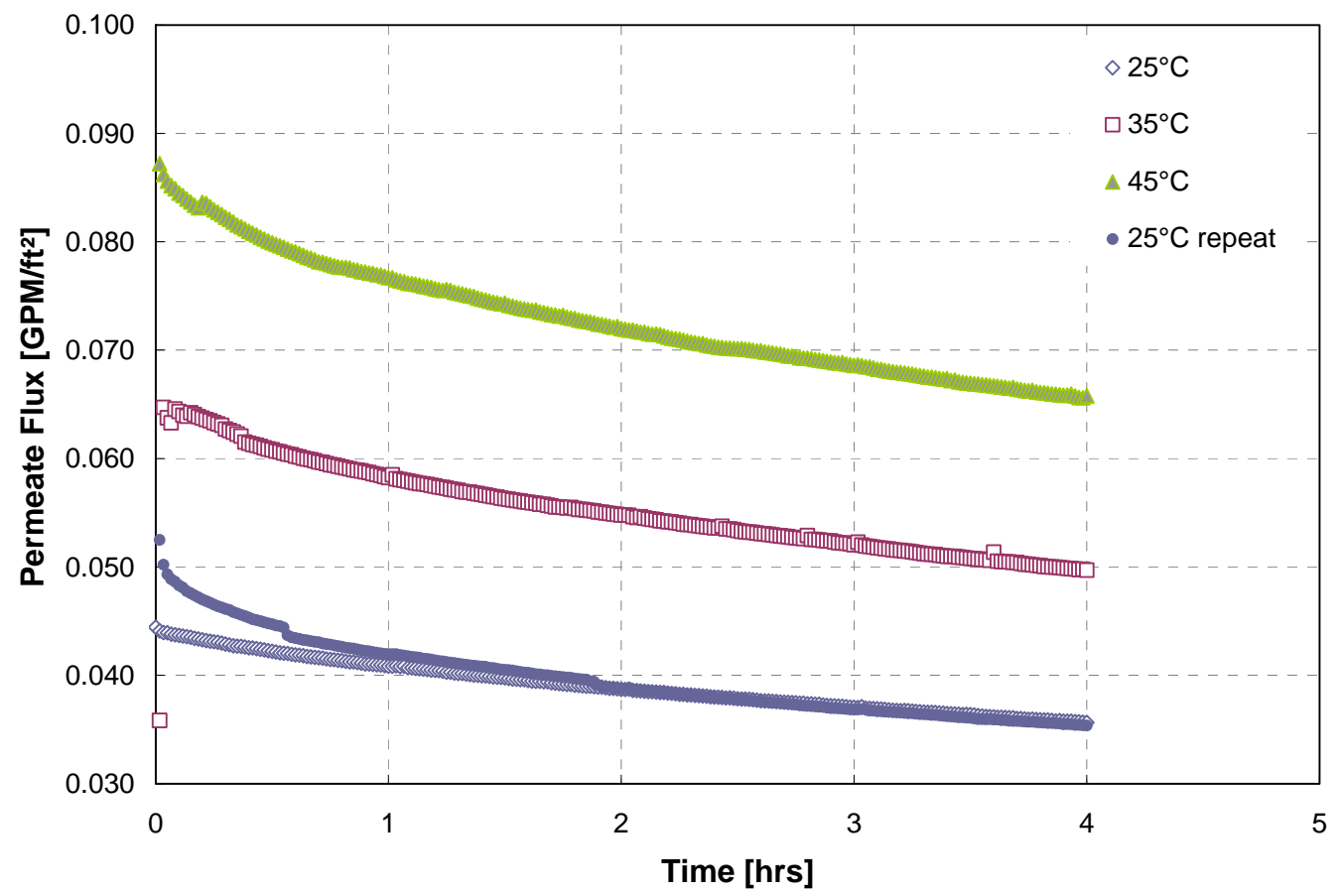

Figure A.3. Permeate Flux Versus Time at $25^{\circ} \mathrm{C}, 35^{\circ} \mathrm{C}, 45^{\circ} \mathrm{C}$, and $25^{\circ} \mathrm{C}$ (repeated) for a Preleach (as-prepared) Slurry Containing $10.5 \mathrm{wt} \%$ UDS

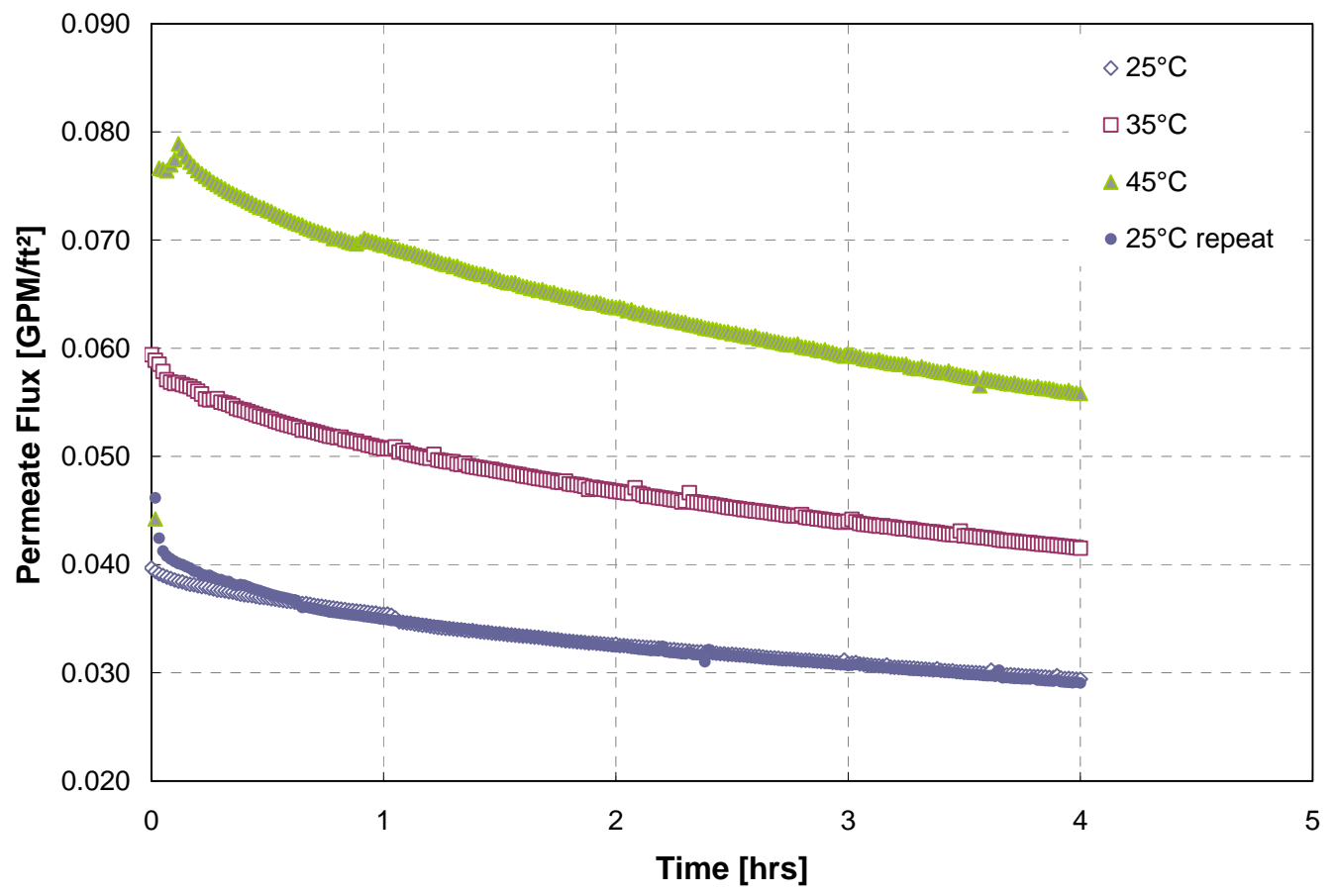

Figure A.4. Permeate Flux Versus Time at $25^{\circ} \mathrm{C}, 35^{\circ} \mathrm{C}, 45^{\circ} \mathrm{C}$, and $25^{\circ} \mathrm{C}$ (repeated) for a Preleach (as-prepared) Slurry Containing $14.9 \mathrm{wt} \%$ UDS 


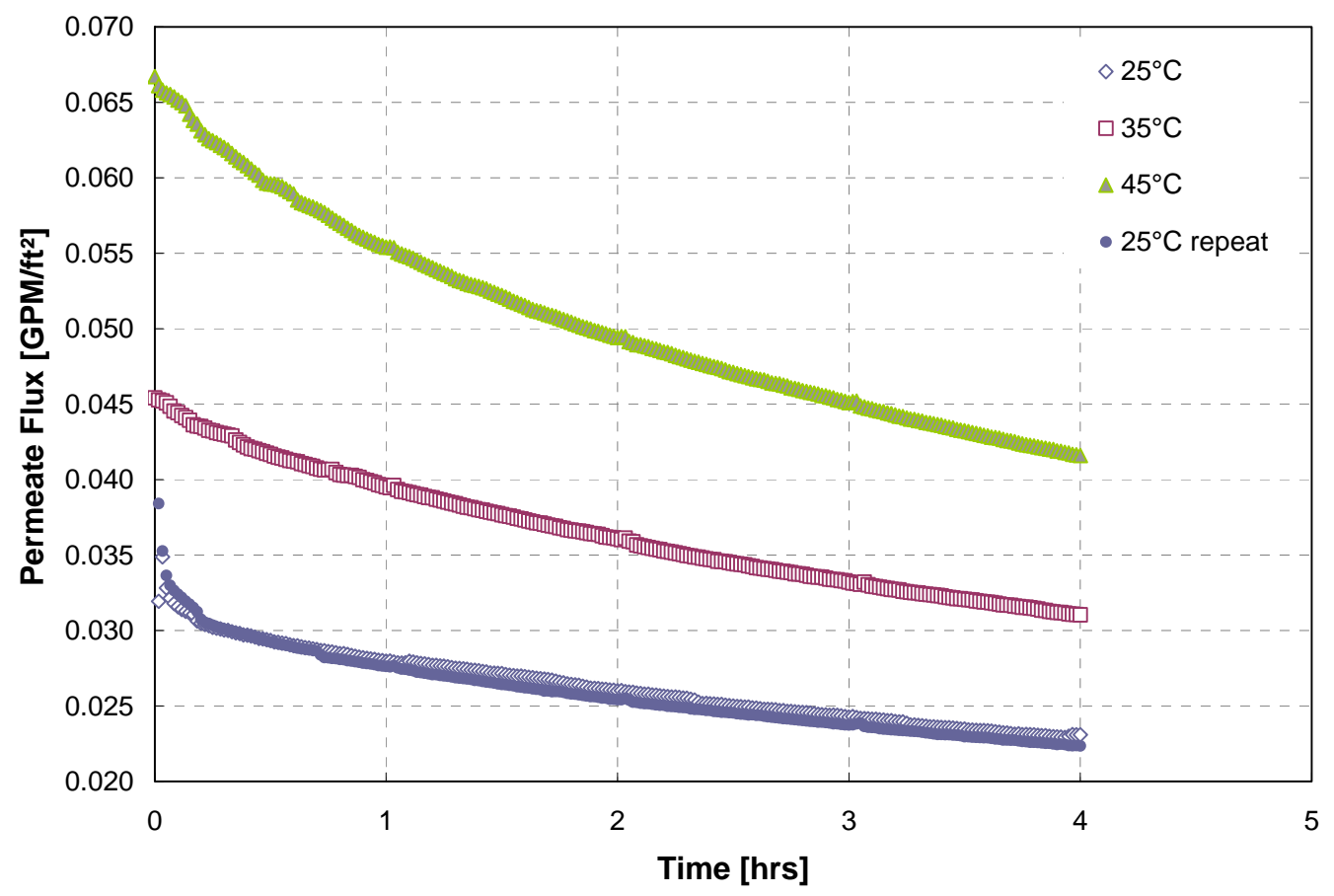

Figure A.5. Permeate Flux Versus Time at $25^{\circ} \mathrm{C}, 35^{\circ} \mathrm{C}, 45^{\circ} \mathrm{C}$, and $25^{\circ} \mathrm{C}$ (repeated) for a Preleach (as-prepared) Slurry Containing $20.9 \mathrm{wt} \%$ UDS

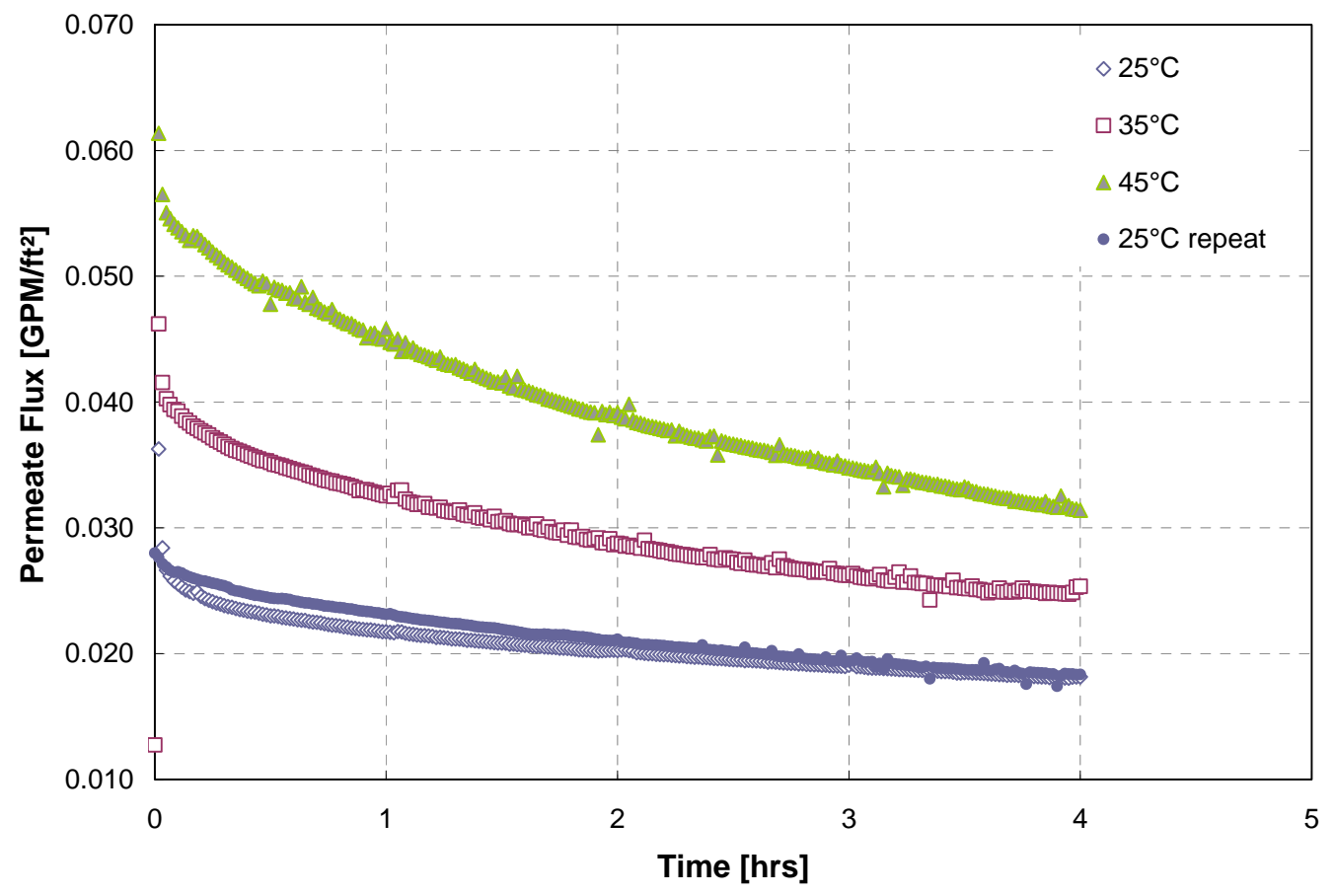

Figure A.6. Permeate Flux Versus Time at $25^{\circ} \mathrm{C}, 35^{\circ} \mathrm{C}, 45^{\circ} \mathrm{C}$, and $25^{\circ} \mathrm{C}$ (repeated) for a Preleach (as-prepared) Slurry Containing $28.3 \mathrm{wt} \%$ UDS 
WTP-RPT-168, Rev 0

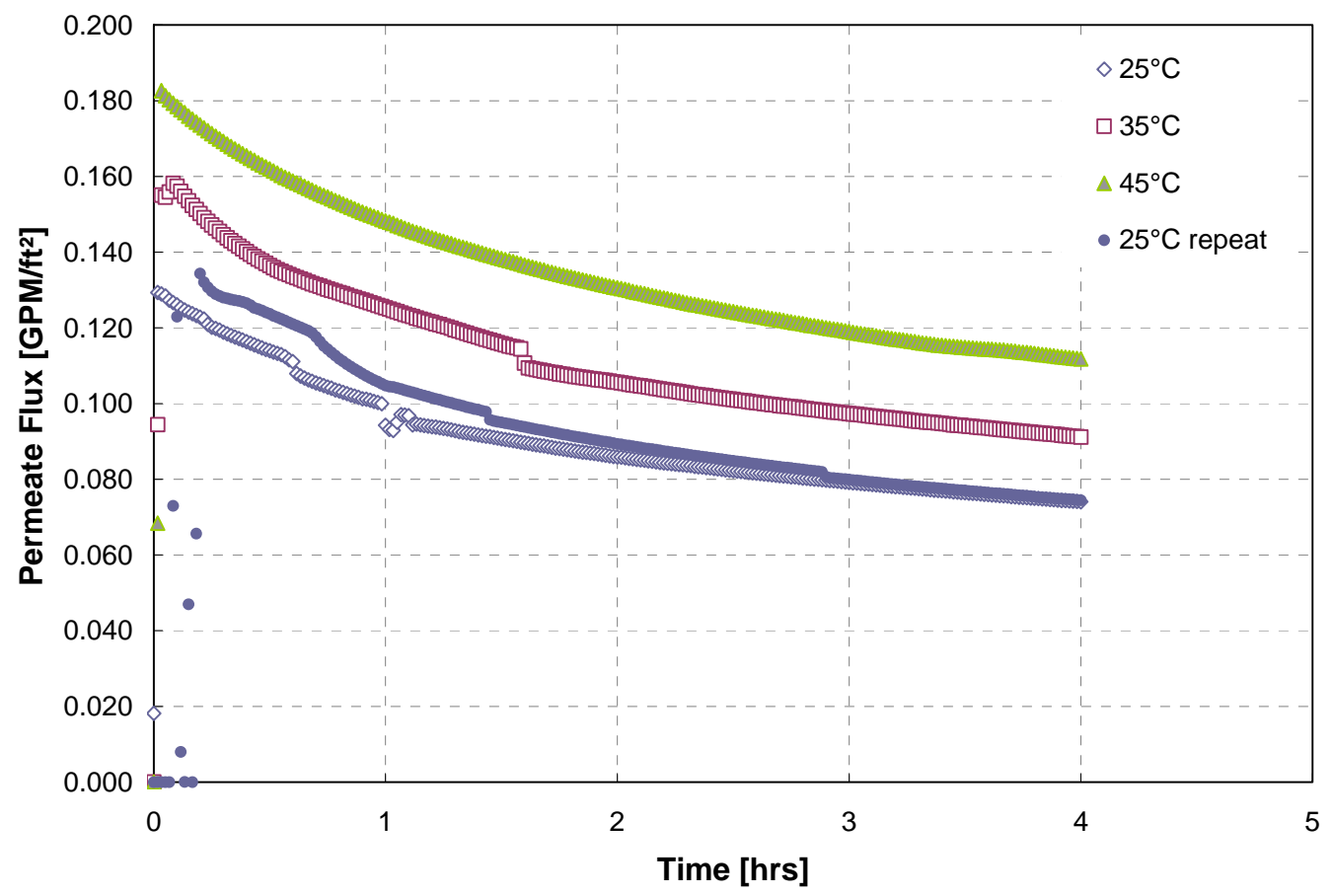

Figure A.7. Permeate Flux Versus Time at $25^{\circ} \mathrm{C}, 35^{\circ} \mathrm{C}, 45^{\circ} \mathrm{C}$, and $25^{\circ} \mathrm{C}$ (repeated) for a Caustic Leached and Washed Slurry Containing $4.8 \mathrm{wt} \%$ UDS

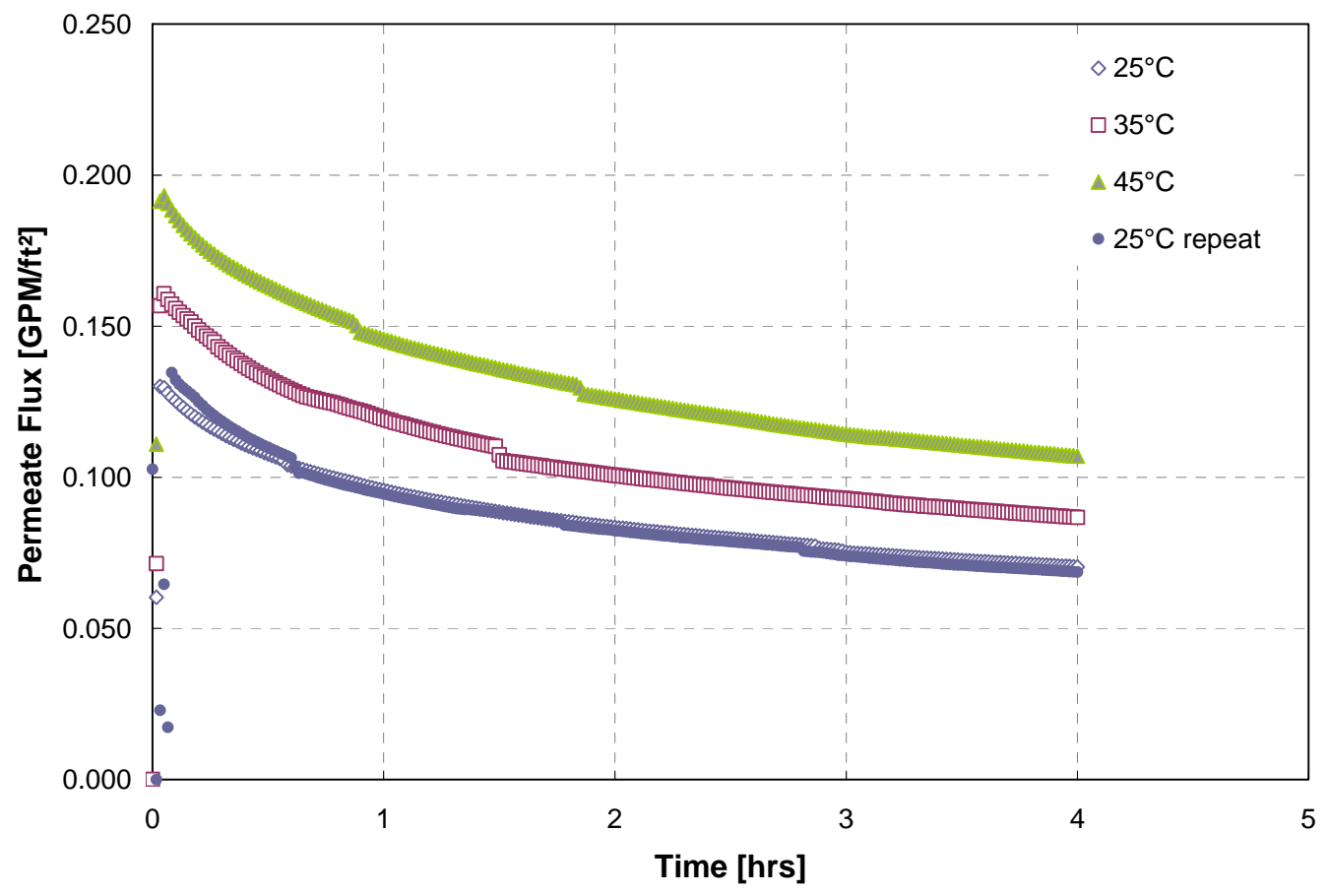

Figure A.8. Permeate Flux Versus Time at $25^{\circ} \mathrm{C}, 35^{\circ} \mathrm{C}, 45^{\circ} \mathrm{C}$, and $25^{\circ} \mathrm{C}$ (repeated) for a Caustic Leached and Washed Slurry Containing $7.1 \mathrm{wt} \%$ UDS 
WTP-RPT-168, Rev 0

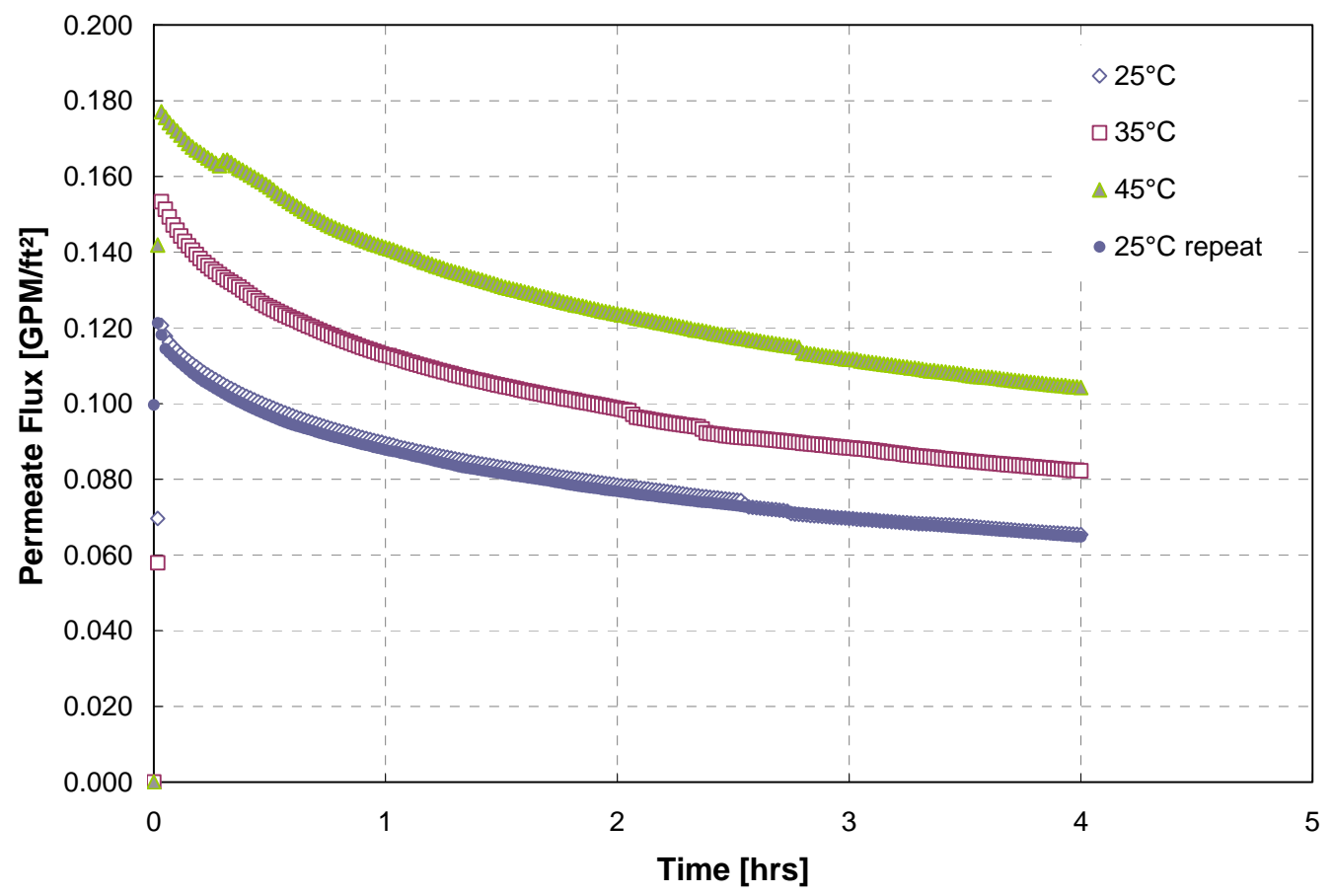

Figure A.9. Permeate Flux Versus Time at $25^{\circ} \mathrm{C}, 35^{\circ} \mathrm{C}, 45^{\circ} \mathrm{C}$, and $25^{\circ} \mathrm{C}$ (repeated) for a Caustic Leached and Washed Slurry Containing $10.3 \mathrm{wt} \%$ UDS

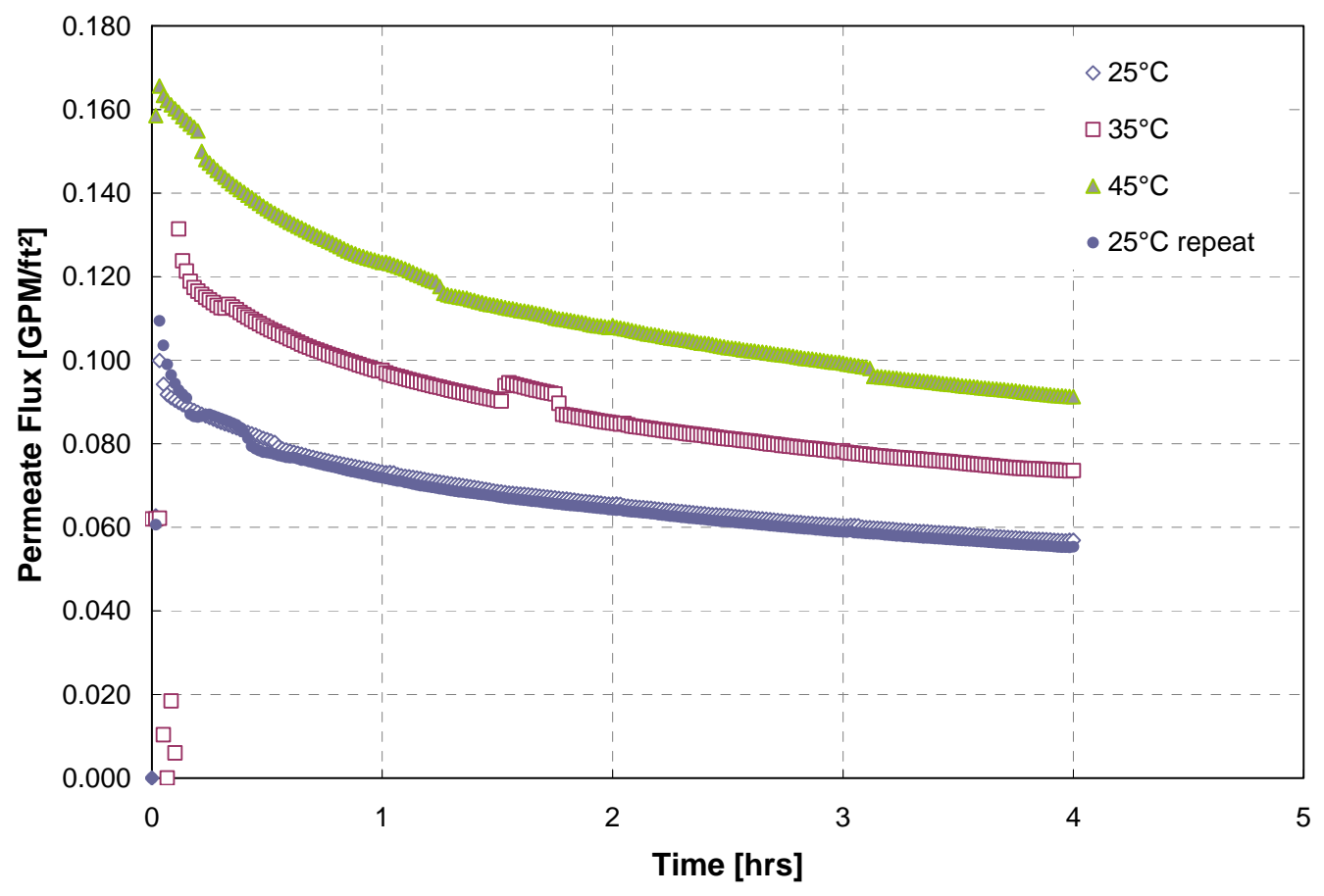

Figure A.10. Permeate Flux Versus Time at $25^{\circ} \mathrm{C}, 35^{\circ} \mathrm{C}, 45^{\circ} \mathrm{C}$, and $25^{\circ} \mathrm{C}$ (repeated) for a Caustic Leached and Washed Slurry Containing $15.1 \mathrm{wt} \%$ UDS 
WTP-RPT-168, Rev 0

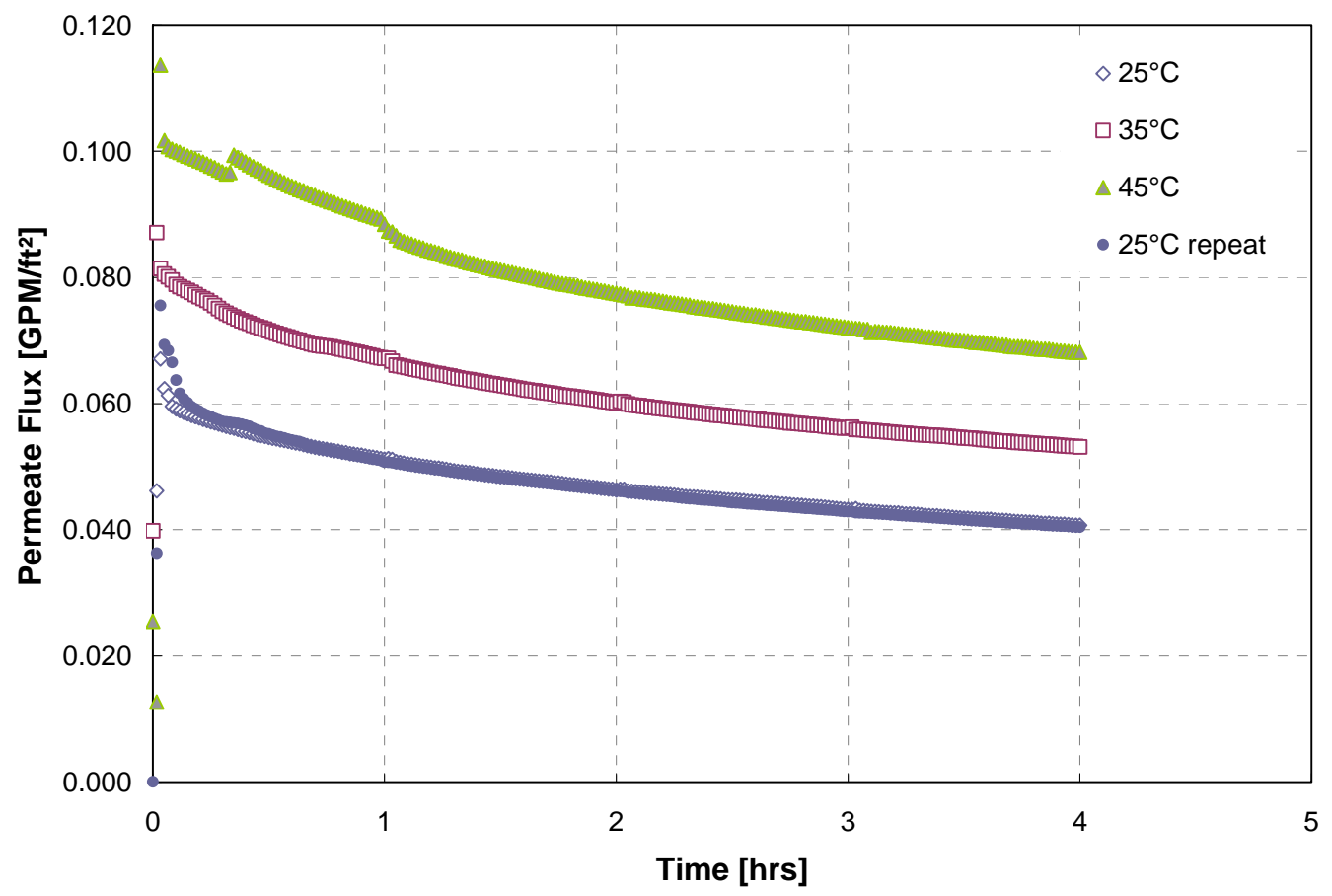

Figure A.11. Permeate Flux Versus Time at $25^{\circ} \mathrm{C}, 35^{\circ} \mathrm{C}, 45^{\circ} \mathrm{C}$, and $25^{\circ} \mathrm{C}$ (repeated) for a Caustic Leached and Washed Slurry Containing $17.8 \mathrm{wt} \%$ UDS

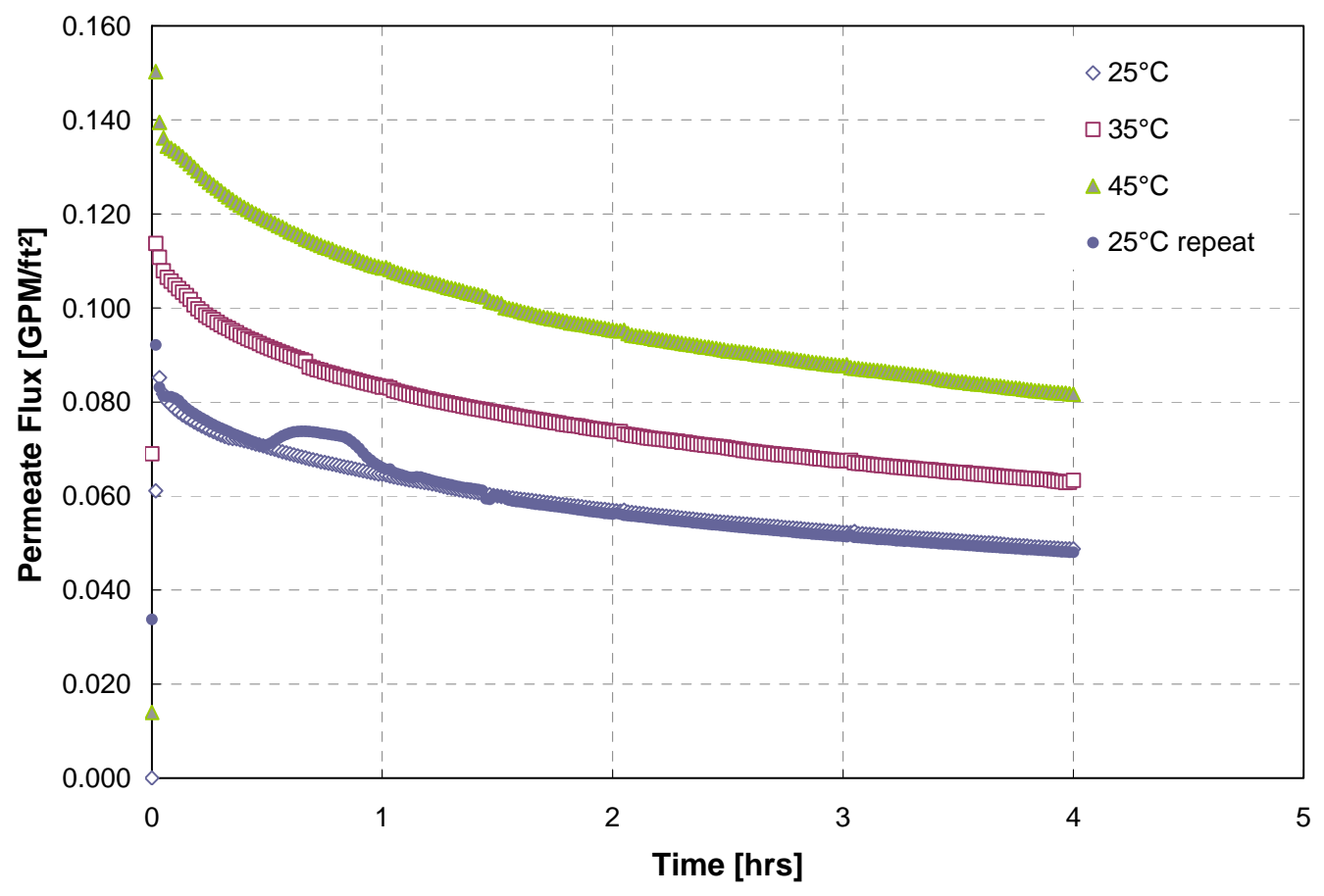

Figure A.12. Permeate Flux Versus Time at $25^{\circ} \mathrm{C}, 35^{\circ} \mathrm{C}, 45^{\circ} \mathrm{C}$, and $25^{\circ} \mathrm{C}$ (repeated) for a Caustic Leached and Washed Slurry Containing $21.7 \mathrm{wt} \%$ UDS 

Appendix B

Sample Analyses of Permeate Flux versus Temperature for 8-Ft Ultrafilter Used for Scale-Up Testing 



\section{Appendix B}

\section{Sample Analyses of Permeate Flux versus Temperature for 8-Ft Ultrafilter Used for Scale-Up Testing}

This section presents graphs of filter flux data associated with the temperature tests described in Section 7 of this report. The data have been linearized and plotted in accordance with Equation 7.8. Each graph shows the results of linear regression analysis at 1-hour intervals. Section 7.2 provides an explanation of the approach used. Section 7.3.2 provides discusses how the results presented in this section are interpreted.

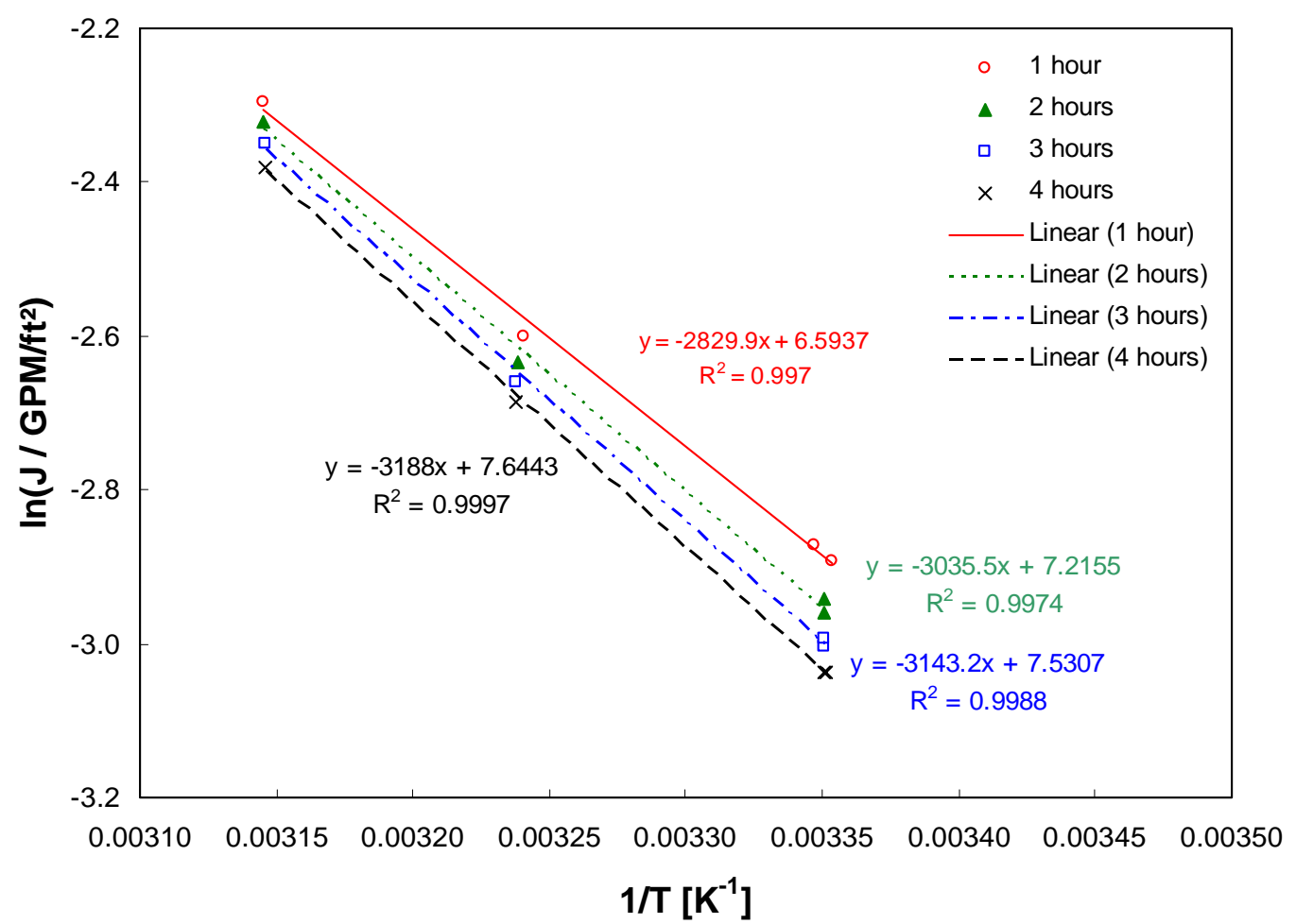

Figure B.1. Linearized Permeate Flux as a Function of Temperature for a Preleach (as-prepared) Blended Simulant Slurry at $5.0 \mathrm{wt} \%$ UDS 
WTP-RPT-168, Rev 0

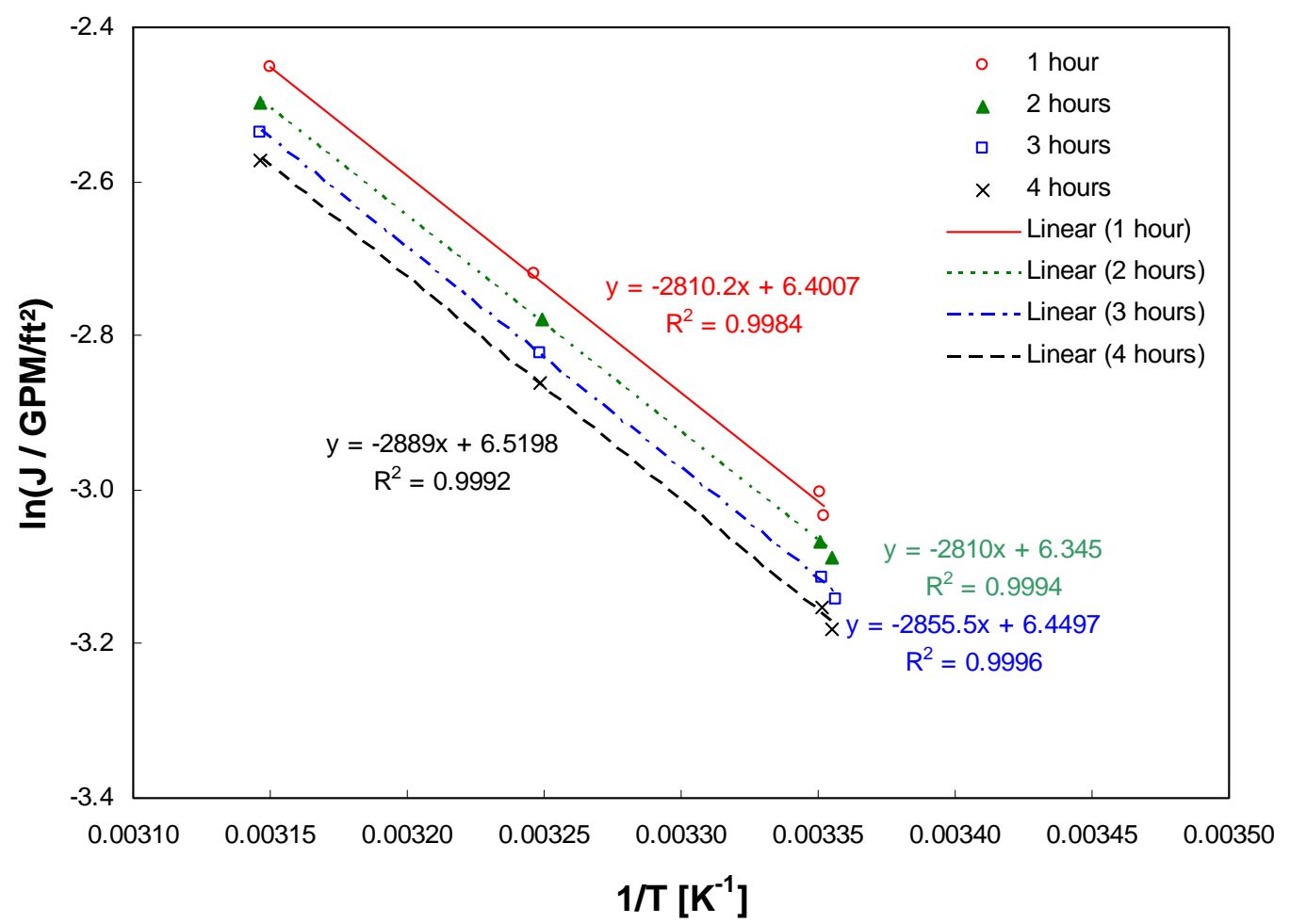

Figure B.2. Linearized Permeate Flux as a Function of Temperature for a Preleach (as-prepared) Blended Simulant Slurry at $7.3 \mathrm{wt} \%$ UDS 
WTP-RPT-168, Rev 0

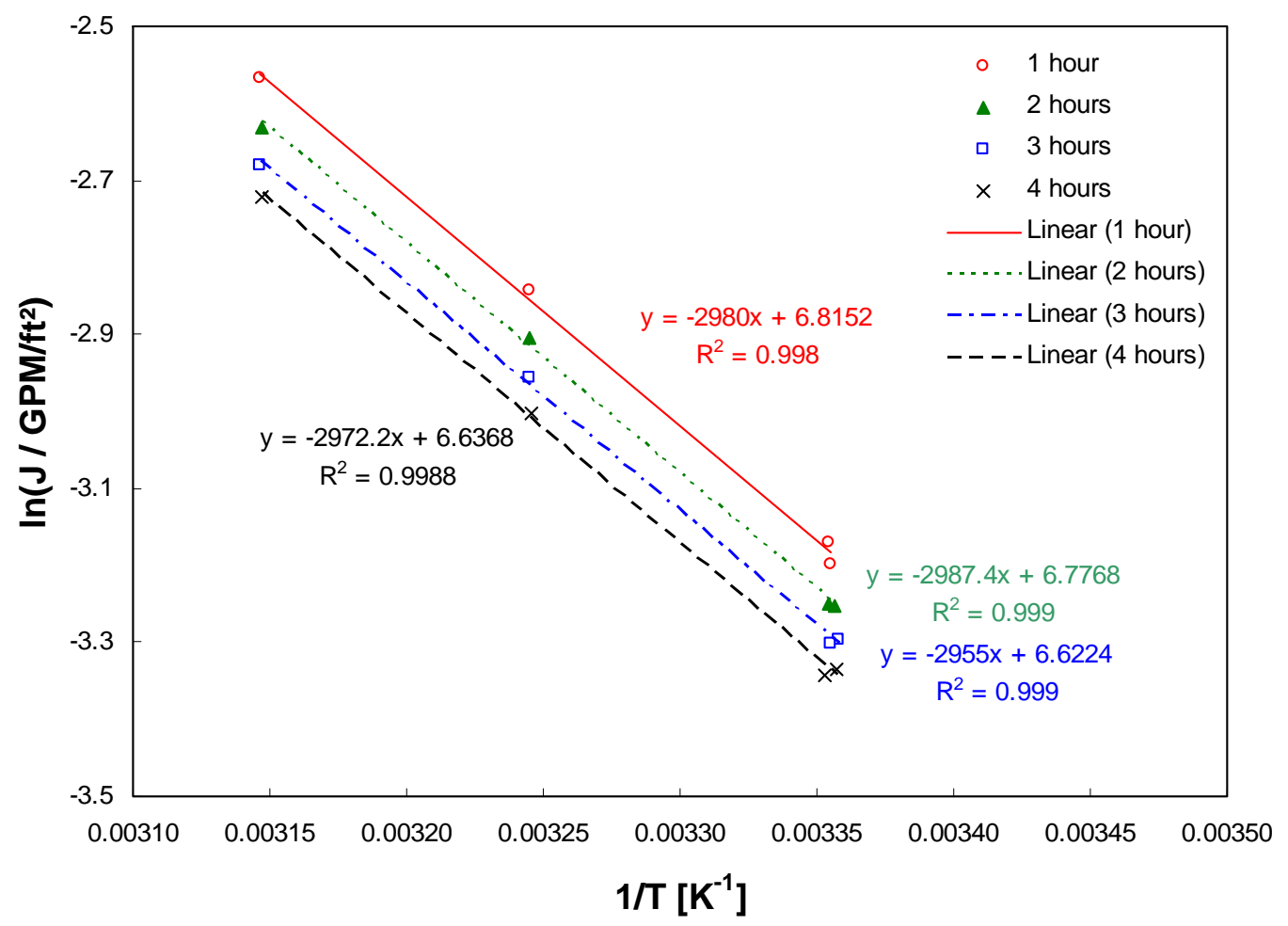

Figure B.3. Linearized Permeate Flux as a Function of Temperature for a Preleach (as-prepared) Blended Simulant Slurry at $10.5 \mathrm{wt} \%$ UDS 
WTP-RPT-168, Rev 0

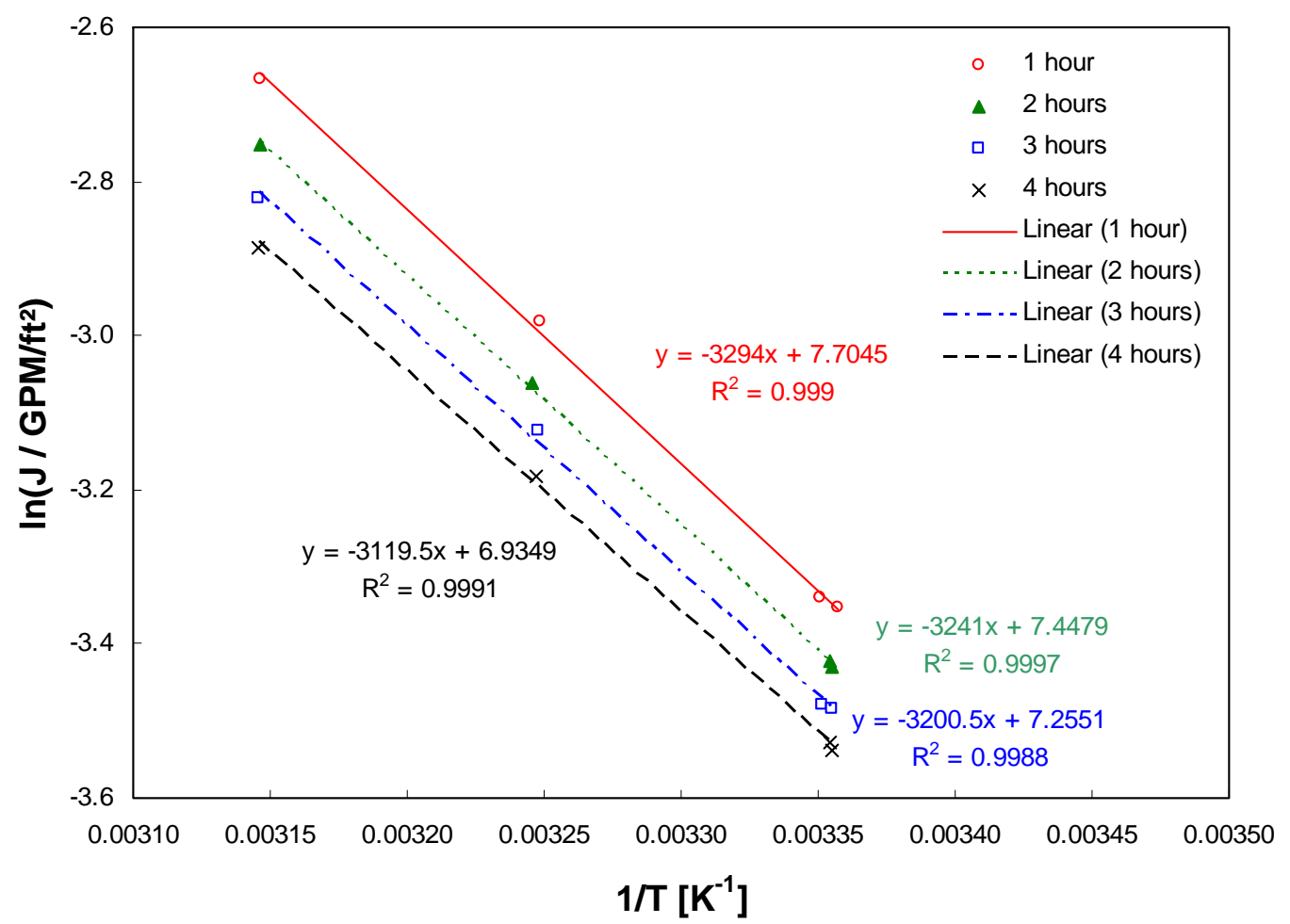

Figure B.4. Linearized Permeate Flux as a Function of Temperature for a Preleach (as-prepared) Blended Simulant Slurry at $14.9 \mathrm{wt} \%$ UDS 
WTP-RPT-168, Rev 0

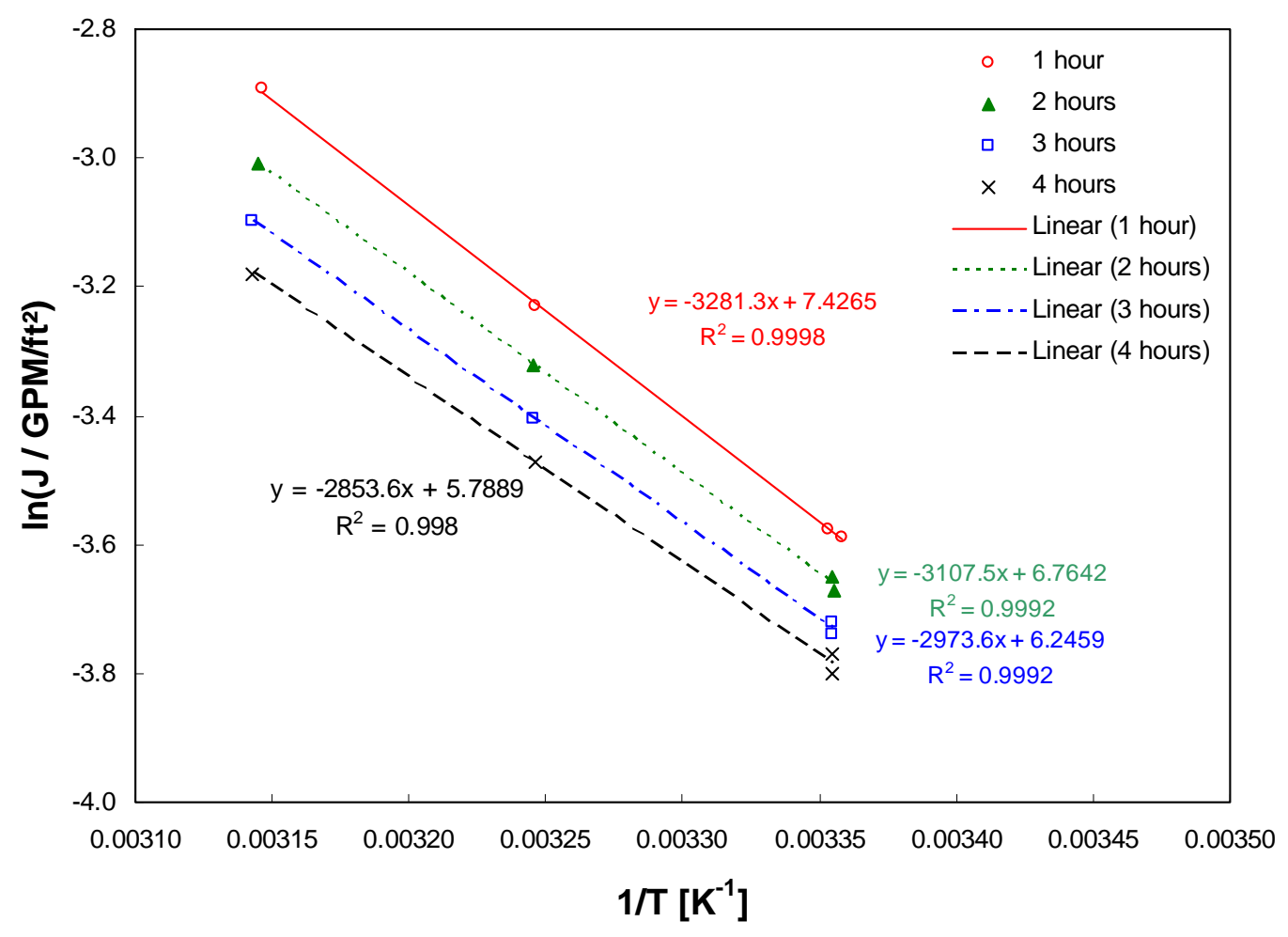

Figure B.5. Linearized Permeate Flux as a Function of Temperature for a Preleach (as-prepared) Blended Simulant Slurry at $20.9 \mathrm{wt} \%$ UDS 
WTP-RPT-168, Rev 0

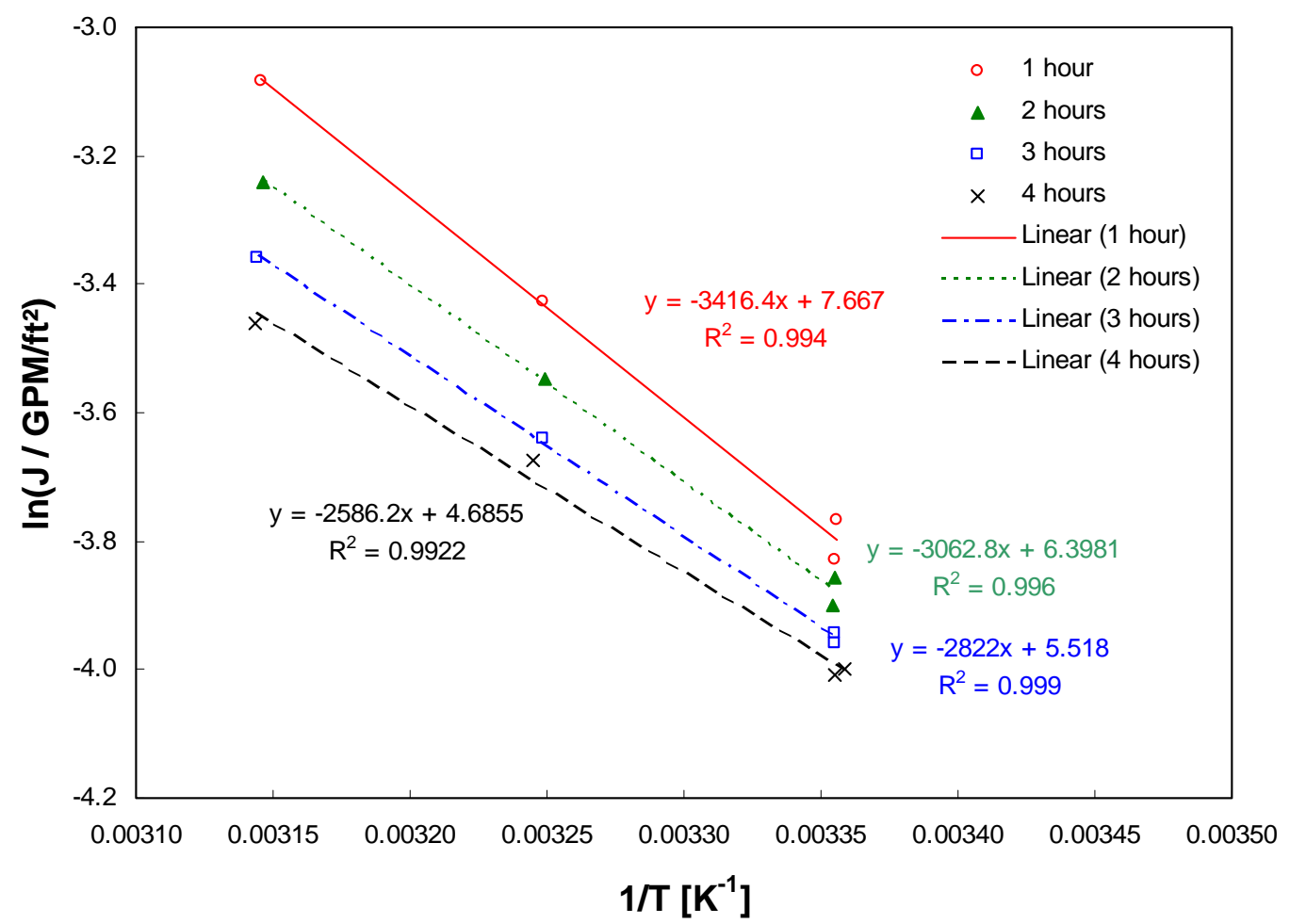

Figure B.6. Linearized Permeate Flux as a Function of Temperature for a Preleach (as-prepared) Blended Simulant Slurry at $28.3 \mathrm{wt} \%$ UDS 
WTP-RPT-168, Rev 0

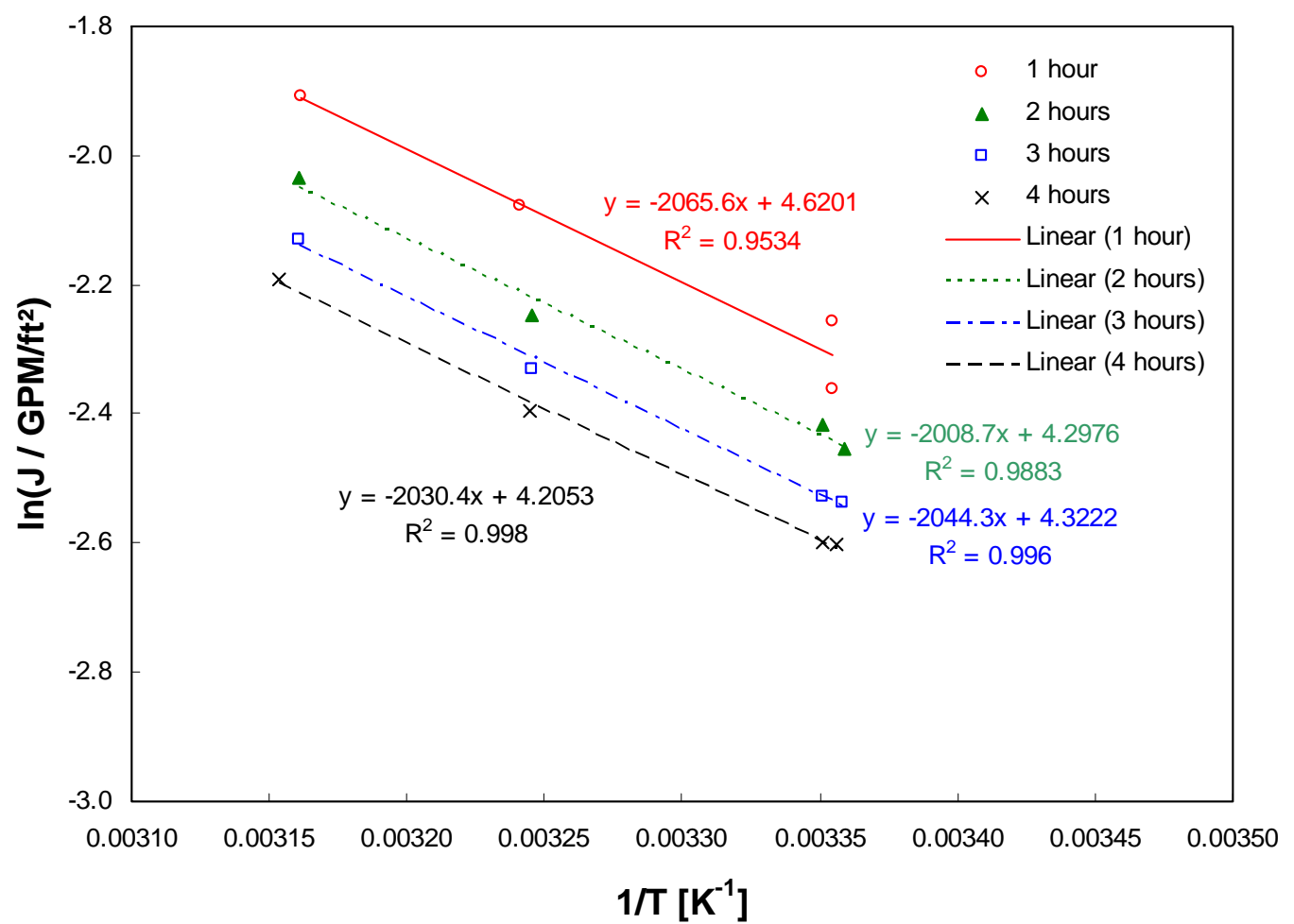

Figure B.7. Linearized Permeate Flux as a Function of Temperature for a Caustic Leached and Washed Blended Simulant Slurry at $4.8 \mathrm{wt} \%$ UDS 
WTP-RPT-168, Rev 0

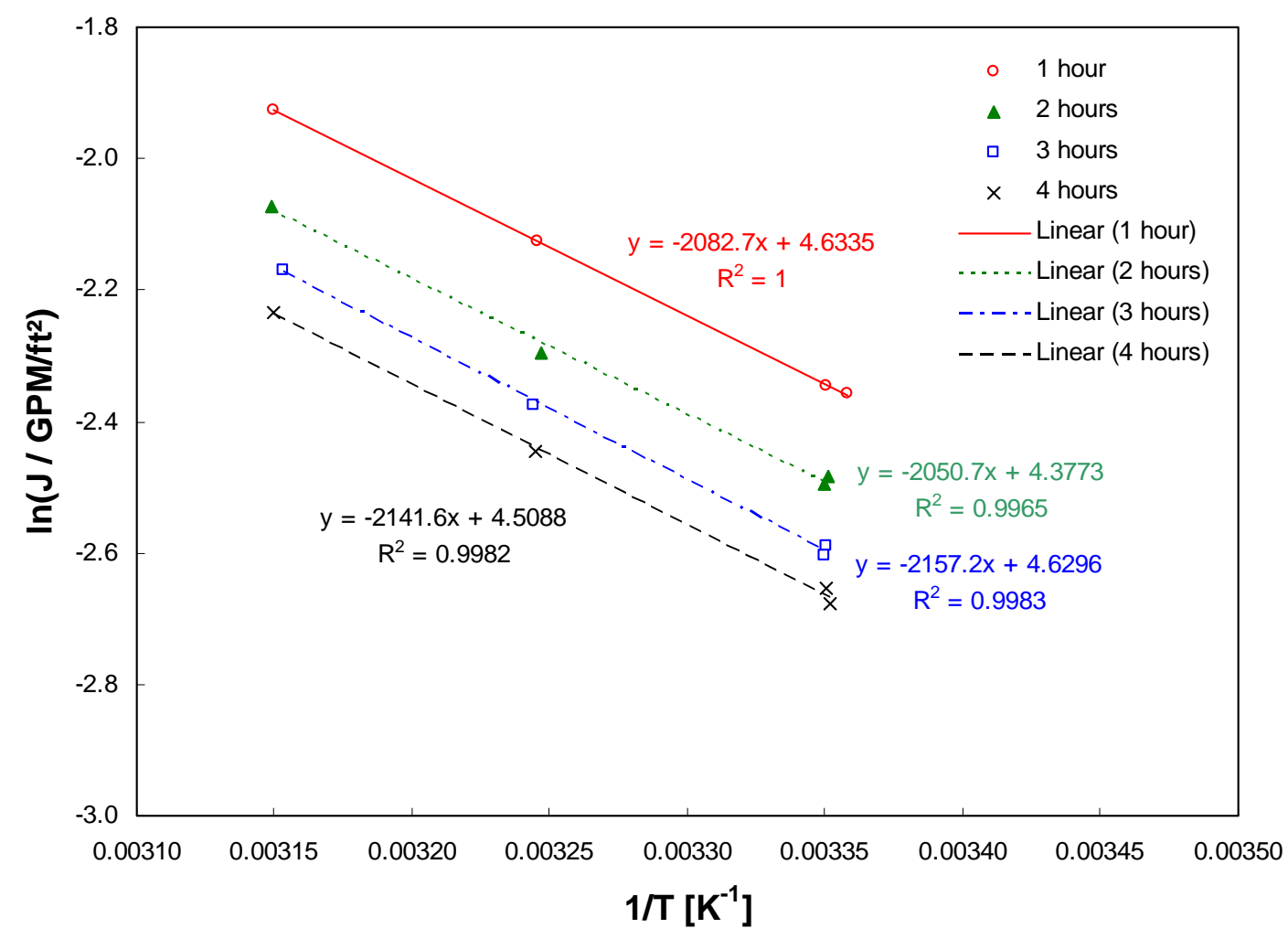

Figure B.8. Linearized Permeate Flux as a Function of Temperature for a Caustic Leached and Washed Blended Simulant Slurry at $7.1 \mathrm{wt} \%$ UDS 
WTP-RPT-168, Rev 0

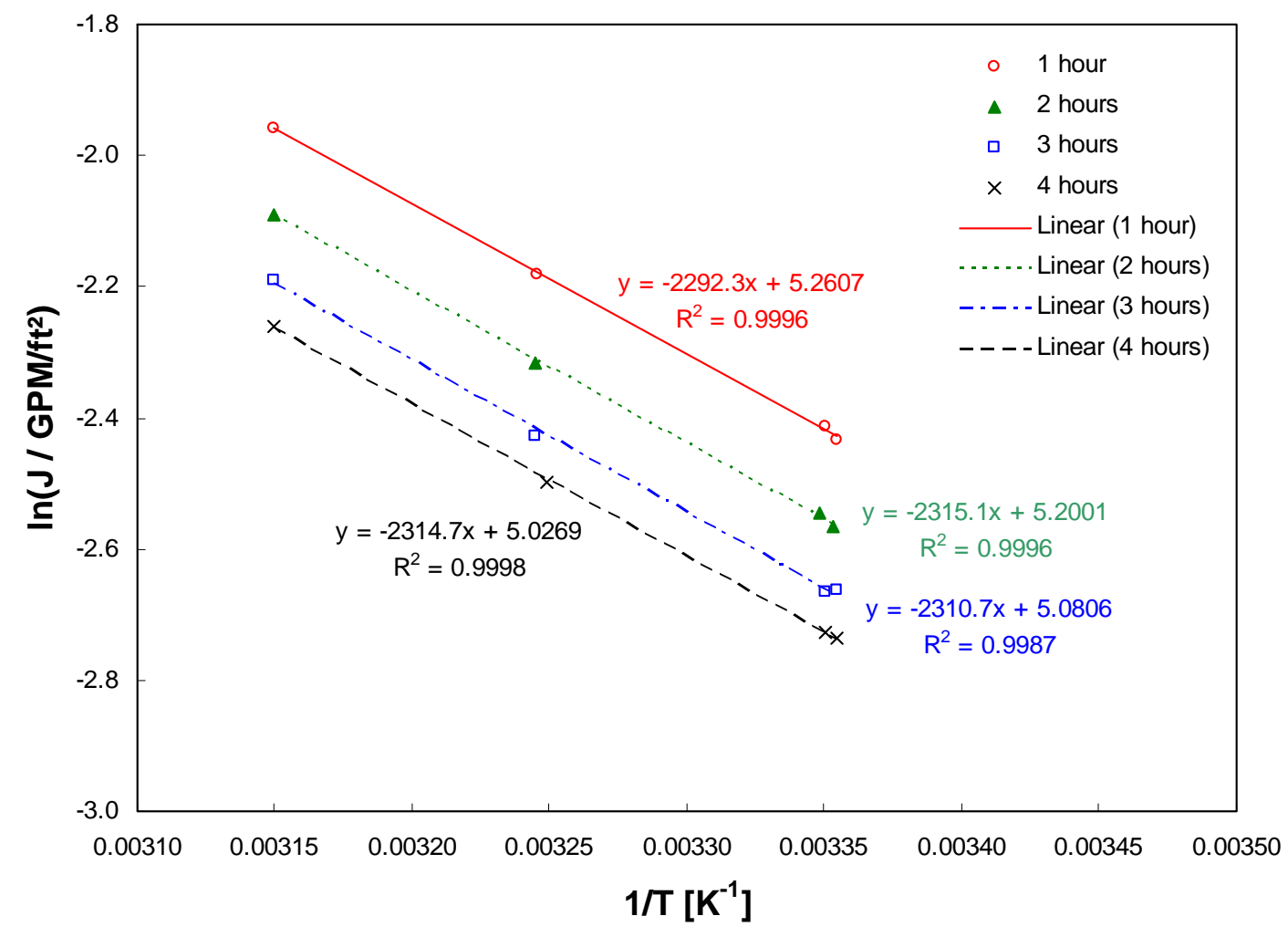

Figure B.9. Linearized Permeate Flux as a Function of Temperature for a Caustic Leached and Washed Blended Simulant Slurry at $10.3 \mathrm{wt} \%$ UDS 
WTP-RPT-168, Rev 0

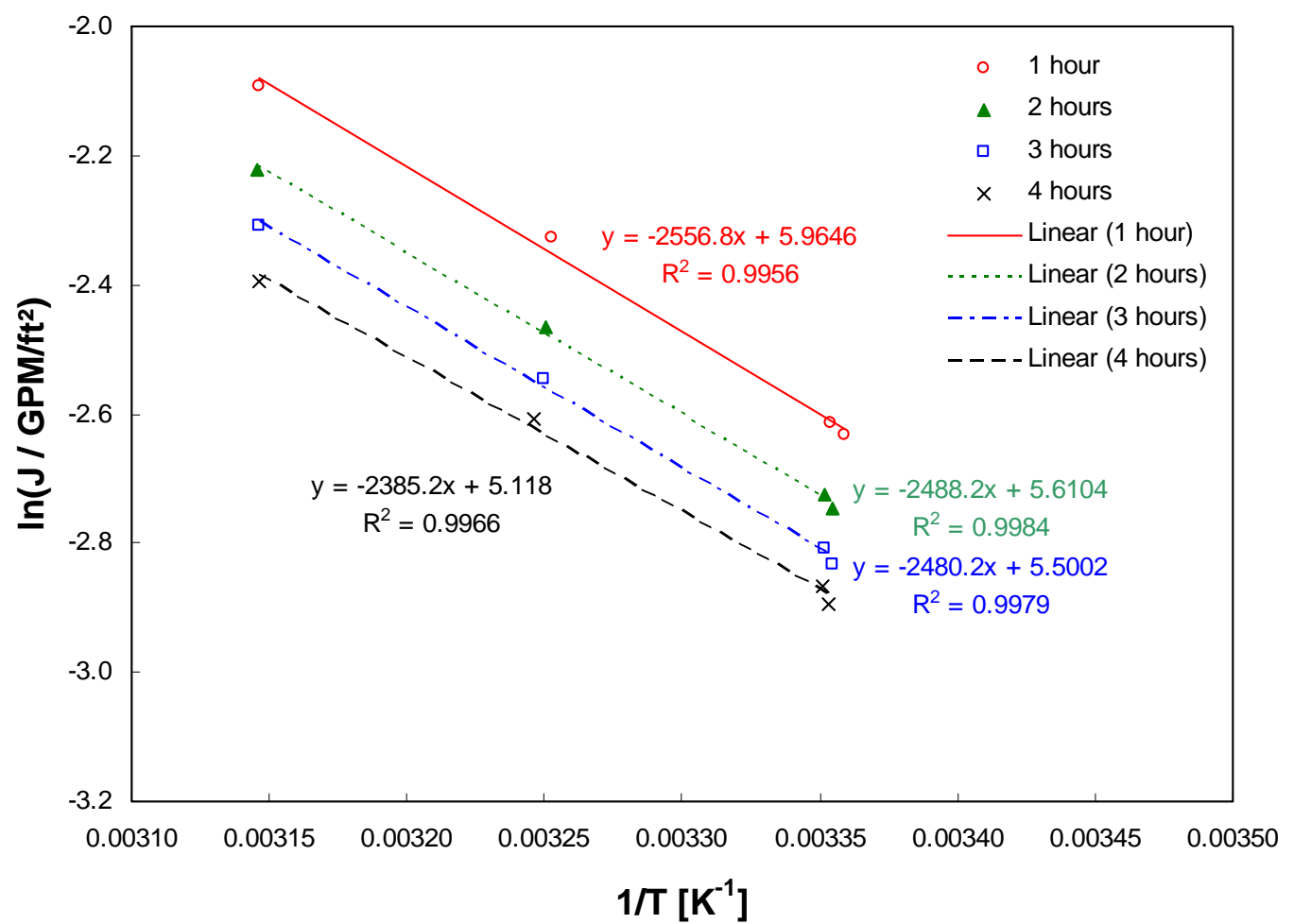

Figure B.10. Linearized Permeate Flux as a Function of Temperature for a Caustic Leached and Washed Blended Simulant Slurry at $15.1 \mathrm{wt} \%$ UDS 
WTP-RPT-168, Rev 0

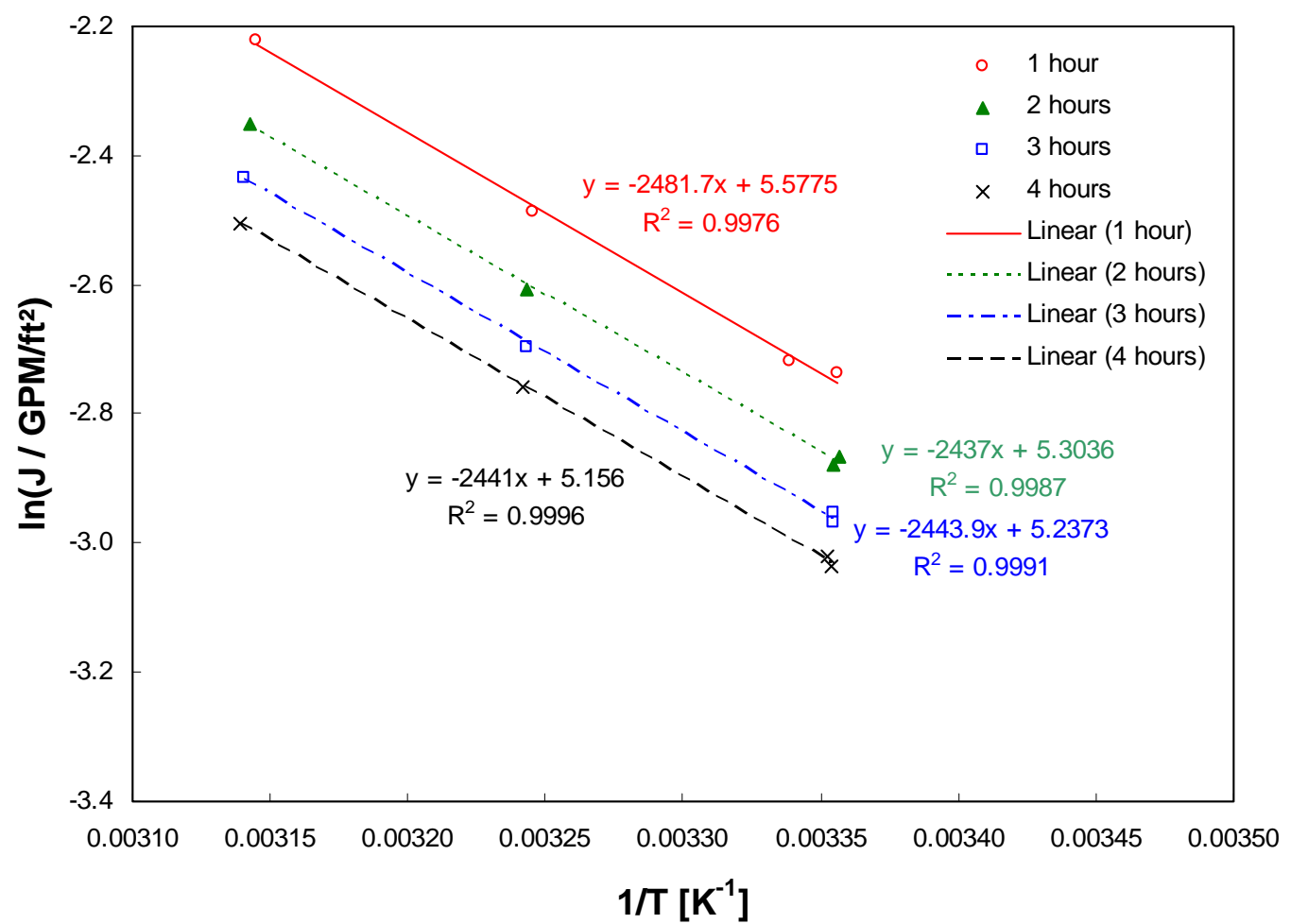

Figure B.11. Linearized Permeate Flux as a Function of Temperature for a Caustic Leached and Washed Blended Simulant Slurry at $17.8 \mathrm{wt} \%$ UDS 
WTP-RPT-168, Rev 0

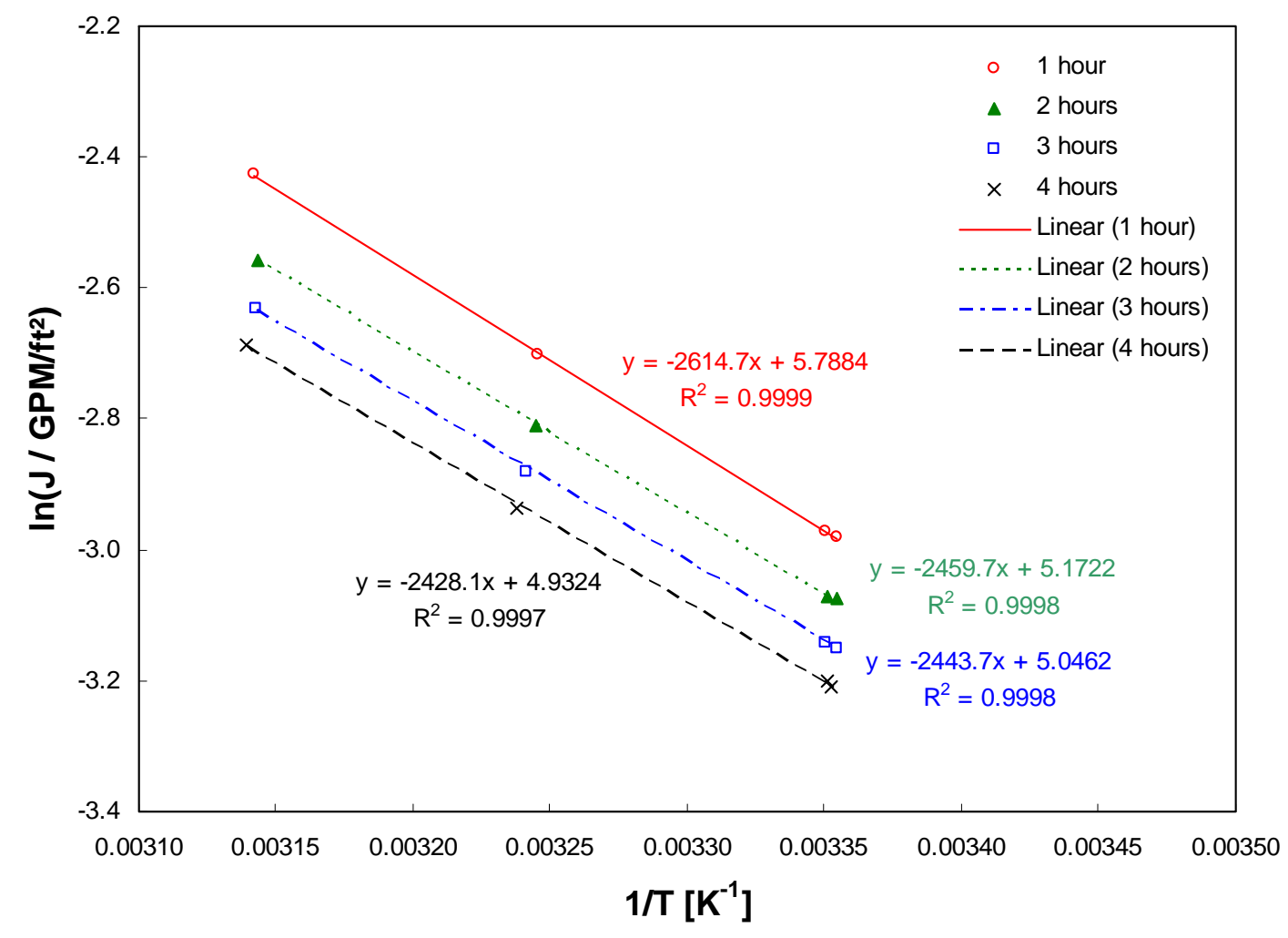

Figure B.12. Linearized Permeate Flux as a Function of Temperature for a Caustic Leached and Washed Blended Simulant Slurry at $21.7 \mathrm{wt} \%$ UDS 


\section{Appendix C}

\section{Temperature Test Caustic-Leaching Conditions and Justifications}





\section{Appendix C}

\section{Temperature Test Caustic-Leaching Conditions and Justifications}

This section presents the background information supplied to BNI in response to hold-point 3. This hold-point was placed in the test plan and required BNI and ORP approval on the conditions used to caustically leach the blended simulant slurry used in the temperature scaling tests described in Section 7 of this report. 
WTP-RPT-168, Rev 0

\section{PNNL Recommendation for Filtration Temperature Test Caustic Leaching Conditions $^{\left({ }^{2}\right)}$}

The purpose of this letter is to seek concurrence with the recommendation for the caustic leaching conditions to be used in the execution of tests in Section 6.2.2 of Test Plan TP-RPP-WTP-509 Rev. 0, Test Plan for Simulant Testing in Support of Phase I Demonstration of the Ultrafiltration and Leaching Processes in the Integrated Test Facility. Concurrence is being sought in accordance with Hold Point \#3 of the test plan, which states that

Prior to start of the caustic leach, a concurrence of the leaching conditions (e.g. caustic concentration, temperature, reaction time) to be used in this test will be obtained (in writing or electronically) from BNI (WTP Manager for Issue M12) and ORP. For this purpose, BNI will obtain the concurrence from ORP. The concurrence requirement has been identified as a holdpoint in Section 8 on reporting requirements. This request for concurrence will be sent to BNI at least one week before testing is scheduled to start to allow adequate time for review.

As per Hold Point \#3 guidance, this letter provides recommendations for the leach conditions (concentration, temperature, and reaction time) to be used during Section 6.2.2 testing. In the following section, a brief overview of Section 6.2.2 testing is given. After that, the recommended leach conditions and the rationale for their selection are outlined.

\section{Background Information}

The tests detailed in Section 6.2.2 of TP-RPP-WTP-509 evaluate the effect of temperature on the filtration of a waste simulant. Specifically, filtration of a blended simulant is performed using the FY07 version of PNNL's Cells Unit Filter (CUF) with an 8 -foot filter element at $25^{\circ} \mathrm{C}, 35^{\circ}$, and $45^{\circ} \mathrm{C}$. Starting with approximately $22 \mathrm{~L}$ of a $\sim 5-\mathrm{wt} \%$ blended simulant, the CUF temperature tests were conducted as follows:

1. The $5-w t \%$ blended simulant is loaded into a CUF filtration system with 8 -foot filter installed.

2. The CUF is operated at $25^{\circ} \mathrm{C}$ in filtration recycle-mode (where all permeate collected is returned to the CUF slurry reservoir) until a steady state permeate flux is achieved and recorded.

3. The temperature is increased to $35^{\circ} \mathrm{C}$ and allowed to again reach steady state.

4. The temperature is increased to $45^{\circ} \mathrm{C}$ and allowed to again reach steady state.

5. The temperature is decreased to $25^{\circ} \mathrm{C}$ and allowed to again reach steady state

6. The slurry is dewatered to concentrate the slurry to a new testing solids-concentration by removing $\sim 1 / 3$ of the supernatant volume. Steps 2 through 5 are repeated at this new concentration to facilitate measurement of the steady-state flux conditions at $25^{\circ} \mathrm{C}, 35^{\circ} \mathrm{C}$, and $45^{\circ} \mathrm{C}$.

7. Step 6 is repeated until six test concentrations have been evaluated. This protocol provides a standard basis for the varying dewater steps that are readily achievable experimentally.

At the conclusion of these tests, the test plan TP-RPP-WTP-509 calls for the slurry to be caustic leached, after which Steps 2 through 7 repeated again.

To date, tests carried out in accordance with Section 6.2.2 of TP-RPP-WTP-509 have examined the influence of temperature on filtration performance using an unleached blended simulant. Before the simulant can be leached and temperature testing continued, PNNL must obtain concurrence on the leaching conditions (concentration, temperature, and reaction time) from BNI.

(a) PNNL's recommendation for caustic-leaching conditions was drafted on and submitted to PS Sundar [pssundar@bechtel.com] on August 28, 2008 via email. 
WTP-RPT-168, Rev 0

\section{Recommendation for Hold Point \#3}

For the execution of the 8-foot filter element temperature tests outlined in Section 6.2.2 of Test Plan TP-RPP-WTP-509, Rev 0., PNNL recommends the following caustic leaching scheme:

1. Component Addition - starting with a approximately $5 \mathrm{~L}$ of a $20-\mathrm{wt} \%$ unleached blended simulant slurry, add approximately $8.1 \mathrm{~kg}$ of $19 \mathrm{M} \mathrm{NaOH}$ (caustic) and $7.5 \mathrm{~kg}$ of deionized (DI) water (to simulate steam condensate). Addition should be carried out at $25^{\circ} \mathrm{C}$.

2. Leach Mixture Heating - heat the leach mixture from $25^{\circ} \mathrm{C}$ to $100^{\circ} \mathrm{C}$ over 5.3 hours $\left(0.236^{\circ} \mathrm{C} / \mathrm{min}\right)$. An overhead mixer will be used to agitate the slurry during heating. Any decrease in slurry level as a result of evaporation shall be corrected by periodic addition of DI water.

3. Caustic Leaching - leach the mixture for 12 hours at $100^{\circ} \mathrm{C}\left(+5 /-10^{\circ} \mathrm{C}\right)$. Again, any decrease in slurry level as a result of evaporation shall be corrected by periodic addition of DI water.

4. Leached Mixture Cooling - cool the leached mixture from $100^{\circ} \mathrm{C}$ to $25^{\circ} \mathrm{C}$ over 12 hours $\left(4.6^{\circ} \mathrm{C} /\right.$ hour $)$. An overhead mixer will be used to agitate the slurry during heating. Again, any decrease in slurry level as a result of evaporation shall be corrected by periodic addition of DI water.

5. Post-Leach Hold - At the end of cool down period above, hold the slurry at $25^{\circ} \mathrm{C}$ for 12 hours. At the end of this 12 -hour hold period, obtain a $200 \mathrm{~mL}$ sample of filtrate. This sample will be stored at ambient temperature $\left(20-25^{\circ} \mathrm{C}\right)$ for 7 days for observation to determine if any precipitation of solids occurs over this length of time.

6. Post-Leach Washing - Dewater the slurry to approximately $17-\mathrm{wt} \%$ and perform $24700-\mathrm{mL}$ washes with $0.01 \mathrm{M}$ sodium hydroxide solution. Washing shall employ a CUF axial velocity and transmembrane pressure of $13 \mathrm{ft} / \mathrm{s}$ and $40 \mathrm{psid}$, respectively.

7. Leached Slurry Testing-continue with the temperature tests described in the "Background Information" section

This recommendation is designed to match previous leaching schemes for a $20-\mathrm{wt} \%$ blended simulant slurry. The rationale for this scheme is outlined in the following section.

\section{Rationale for Recommendation}

The leaching conditions and scheme presented in the previous section were chosen to match leaching conditions employed during CUF Run \#3 Blended Matrix tests (CBM3) under simulant development, as described in Test Plan TP-RPP-WTP-469, "Test Plan for the Development and Demonstration of Leaching and Ultrafiltration Simulants". The slurry employed in Section 6.2.2 of the current test plan (TP-RPP-WTP-509) is based on the blended simulant formulation used in CBM3. During CBM3, the leach conditions outlined in Table 1 were applied to approximately $5.3 \mathrm{~L}$ of a $20-\mathrm{wt} \%$ blended simulant CUF. 
WTP-RPT-168, Rev 0

Table 1. Conditions employed for leaching of Blended Simulant in CUF Run \#3 Blended Matrix Tests (CMB3). Tests use approximately $5.3 \mathrm{~L}$ of a $20-\mathrm{wt} \%$ slurry.

\begin{tabular}{||l|l||}
\hline Caustic (19M NaOH Solution) Mass Added: & $8.57 \mathrm{~kg}$, or \\
& $1.62 \mathrm{~kg}$ per L blended simulant \\
\hline Condensate (DI Water) Mass Added: & $7.92 \mathrm{~kg}$, or \\
& $1.49 \mathrm{~kg}$ per L blended simulant \\
\hline Starting Temperature: & $25^{\circ} \mathrm{C}$ \\
\hline Leaching Temperature: & $100^{\circ} \mathrm{C}$ \\
\hline Heating Time: & 5.3 hours \\
\hline Leach Time: & 12 hours \\
\hline Cool-down Time: & 12 hours \\
\hline Final Temperature: & $25^{\circ} \mathrm{C}$ \\
\hline Hold Period: & 12 hours \\
\hline
\end{tabular}

It should also be noted that the conditions listed in Table 1 were also applied to actual waste characterization efforts for waste Group 5 under Test Plan TP-RPP-WTP-467, "Characterization and Small Scale Testing of Hanford Wastes to Support the Development and Demonstration of Leaching and Ultrafiltration Pretreatment Processes".

Current mass estimates of the slurry anticipate approximately $5 \mathrm{~L}$ of $20-\mathrm{wt} \%$ blended simulant shall be available for the leaching operations for Section 6.2.2 testing of Test Plan TP-RPP-WTP-509. Because this volume is lower than the $5.3 \mathrm{~L}$ of $20-\mathrm{wt} \%$ blended simulant using in test CBM3, the mass addition of condensate and caustic for Section 6.2.2 testing must be lowered accordingly. Based on the mass additions required per liter of simulant listed in Table 1, the following caustic and condensate quantities shall be employed for leaching during Section 6.2.2 testing:

Mass Caustic Required $=(5 \mathrm{~L})(1.62 \mathrm{~kg} / \mathrm{L})=8.1 \mathrm{~kg}$

Mass Condensate Required $=(5 \mathrm{~L})(1.49 \mathrm{~kg} / \mathrm{L})=7.5 \mathrm{~kg}$

Because other conditions such as leach/heating/cooling times are not slurry volume dependent (from a point of process control), these variables were all selected to remain the same. As such, the leaching conditions selected for Section 6.2.2 testing are similar to those in Table 1. A summary of selected leaching conditions for Section 6.2.2 testing is provided in Table 2.

Table 2. Leaching conditions planned for Section 6.2.2 testing.

\begin{tabular}{||l|l||}
\hline $\begin{array}{l}\text { Caustic (19M NaOH Solution) Mass } \\
\text { Added: }\end{array}$ & $8.1 \mathrm{~kg}$ \\
\hline Condensate (DI Water) Mass Added: & $7.5 \mathrm{~kg}$ \\
\hline Starting Temperature: & $25^{\circ} \mathrm{C}$ \\
\hline Leaching Temperature: & $100^{\circ} \mathrm{C}$ \\
\hline Heating Time: & 5.3 hours \\
\hline Leach Time: & 12 hours \\
\hline Cool-down Time: & 12 hours \\
\hline Final Temperature: & $25^{\circ} \mathrm{C}$ \\
\hline Hold Period: & 12 hours \\
\hline
\end{tabular}




\section{BNI Concurrence on Hold-Point \#3}

The following is a copy of a series of emails indicating BNI concurrence for the leach-conditions outlined in PNNL's communication regarding hold-point \#3:

From: Barnes, Steven M

Sent: Thursday, September 04, 2008 10:00 AM

To: 'Peterson, Reid A'

Cc: Sundar, Parameshwaran S

Subject: RE: Concurrence for Section 6.2.2 Leaching Conditions

We concur with the test conditions described in the attachment provided below.

From: Sundar, Parameshwaran S

Sent: Thursday, September 04, 2008 9:58 AM

To: Barnes, Steven M

Subject: FW: Concurrence for Section 6.2.2 Leaching Conditions

Steve: FYI - Sundar

From: Peterson, Reid A [mailto:reid.peterson@pnl.gov]

Sent: Thursday, August 28, 2008 4:01 PM

To: Sundar, Parameshwaran S

Cc: Daniel, Richard C; Shimskey, Rick W; Billing, J ustin M

Subject: FW: Concurrence for Section 6.2.2 Leaching Conditions

Sundar,

Pursuant to Test Plan TP-RPP-WTP-509, we need your concurrence on the leaching conditions for the upcoming second temperature filtration trial. Please see the attached.

Thanks,

Reid

From: Daniel, Richard C

Sent: Thursday, August 28, 2008 11:42 AM

To: Peterson, Reid A

Cc: Shimskey, Rick W; Billing, Justin M

Subject: Concurrence for Section 6.2.2 Leaching Conditions

Reid,

Attached please find my concurrence letter for the leaching conditions planned for Section 6.2.2 testing

(Hold Point \#3 of TP-RPP-WTP-509). The conditions are based on those used by Renee Russell for CUF

Blended Matrix Test \#3 (CBM3). It should be noted that the blended simulant formulation we selected for Section 6.2.2 matches that used for CBM3. Please provide any comments or feedback you might have.

We would like to start leaching late next week (around Thursday) so we can minimize any down-time between the end of leaching and the start of leached-slurry temperature testing.

$<<$ TP-RPP-WTP-509 Concurence Hold 3 - Rev 0.doc >>

Thanks,

\section{Richard Daniel}

Radiochemical Engineering Team

Tel: 509-372-1389

richard.daniel@pnl.gov

www.pnl.gov 

PNNL-18117

WTP-RPT-168, Rev 0

\section{Distribution}

No. of

Copies

4 Bechtel National, Inc.

WTP R\&T Docs (2)

P. S. Sundar

S. Barnes
H4-02

H4-02

H4-02
No. of

Copies

13 Pacific Northwest National Laboratory JM Billing

ML Bonebrake

P7-25

RC Daniel (2)

$\mathrm{P} 7-25$

KJ Cantrell

$\mathrm{P} 7-22$

LK Jagoda

K6-81

DE Kurath

K6-24

ML Luna

K3-52

RA Peterson

K2-21

RL Russell

P7-22

RW Shimskey

K6-24

Information Release

P7-27

Project File

P8-55

K3-52 